\title{
Bernadette Poliwoda
}

\section{FE்KS - \\ Fabrik des exzentrischen Schauspielers}

\section{Vom Exzentrismus zur Poetik des Films in der frühen Sowjetkultur}

Verlag Otto Sagner München · Berlin - Washington D.C.

Digitalisiert im Rahmen der Kooperation mit dem DFG-Projekt „Digi20“

der Bayerischen Staatsbibliothek, München. OCR-Bearbeitung und Erstellung des eBooks durch den Verlag Otto Sagner:

http://verlag.kubon-sagner.de

() bei Verlag Otto Sagner. Eine Verwertung oder Weitergabe der Texte und Abbildungen, insbesondere durch Vervielfältigung, ist ohne vorherige schriftliche Genehmigung des Verlages unzulässig.

«Verlag Otto Sagner» ist ein Imprint der Kubon \& Sagner GmbH. 


\title{
SLAVISTISCHE BEITRÄGE
}

\author{
Begründet von \\ Alois Schmaus
}

Herausgegeben von

Peter Rehder

Beirat:

Tilman Berger - Walter Breu - Johanna Renate Döring-Smirnov

Wilfried Fiedler - Walter Koschmal · Miloß Sedmidubsky · Klaus Steinke

BAND 312

VERLAG OTTO SAgneR

MÜNCHEN 1994 


\section{Bernadette Poliwoda}

\section{FE்KS - \\ Fabrik des exzentrischen Schauspielers}

Vom Exzentrismus zur Poetik des Films

in der frühen Sowjetkultur

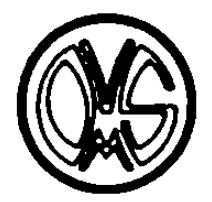

Verlag OtTo SAgNer

MÜNCHEN 1994 


\section{Vorwort}

Ursprünglich wollte ich mich mit der Gruppe FEKS (Fabrik des exzentrischen Schauspielers) nur im Rahmen ihrer Literaturverfilmung von Gogol's Erzählung "Sinel'/Der Mantel" von 1926 beschäftigen. Diese wollte ich mit einer Literaturverfilmung der gleichen Vorlage durch Aleksej Batalov von 1959 anhand ihrer thematischen und stilistischen Unterschiede vergleichen.

Es zeigte sich jedoch. daß es in den zwanziger Jahren kaum stilistische Kriterien für Literaturverfilmungen gab und die FEKS selbst in der einschlägigen westeuropäischen Literatur nur am Rande eruähnt wurde. Bei intensiveren Recherchen entstand zunehmend der Eindruck, daß die Féksy (wie sich die Mitglieder der Gruppe nannten) und ihre Arbeit zu Unrecht in Vergessenheit geraten waren.

So ergab sich fast von selbst eine Verschiebung der Aufgabenstellung hin zu einer Untersuchung des Wesens, der Leistungen und Grenzen und damit der Bedeutung der Gruppe in ihrem kulturhistorischen Kontext.

Der ans Ende der Arbeit geriickte Vergleich der Literaturverfilmungen von "Sinel'" dient jetzt als Verdeutlichung der wichtigsten Leistung der FEKS. ihrer Entwicklung einer Poetik des Films und deren Spezifität.

Die Anregung zu dieser Arbeit, sowie Unterstützung bei der Änderung des urspringlichen Planes erhielt ich von meiner Betreuerin Frau Prof. Dr. Maria Deppermann, der ich für ihre wertvolle Kritik danke, und dafür, daß sie trotz ihrer umfangreichen Verpflichtungen immer die Zeit fand, auf die Probleme einzugehen. die sich für mich im Verlauf dieser Arbeit ergaben.

Auch Prof. Dr. Georg Mayer möchte ich für anregende Gespräche und Hinweise danken.

Ebenso danke ich meinen Moskauer Freunden für ihre Hilfe, insbesondere Herrn Valerij Kičin und Herrn Karen Gevorkian, die mir den Zugang zu wichtigem Material sowie Treffen mit Freunden und Verwandten Leonid Traubergs ermöglichten.

Des weiteren gilt mein Dank den Mitarbeitern des Filmmuseums in München für ihre Hilfsbereitschaft und Unterstutzung.

Bedanken möchte ich mich aber auch bei meinen Freunden in Salzburg. insbesondere bei Frau Dr. Iris Melcher-Smejkal, Frau Iris Theuer und bei meinem Bruder Dr. Sebastian Poliwoda für ihre unermüdliche Korrekturarbeit. sowie bei meinen Eltem für ihre geistige Interstutzung in dieser Zeit. 
Ebenso habe ich Prof. Dr. Peter Rehder zu danken für Rat und Hilfe beim Erstellen des druckreifen Layouts. sowie den Herausgebern der Reihe "Slavistische Beiträge" und dem Verlag Otto Sagner in München.

Die vorliegende Arbeit ist 1993 als Dissertation am Institut für Slawistik der Philosophischen Fakultät der Universität Salzburg angenommen worden.

Salzburg im Mai 1994

Bernadette Poliwoda 


\section{Inhaltsverzeichnis}

Vorwort 5

Inhaltsverzeichnis $\quad 7$

0. Einleitung 10

$\begin{array}{ll}\text { 0.1. Methode } & 12\end{array}$

$\begin{array}{ll}\text { 0.2. Materiallage } & 13\end{array}$

Kapitel 1. Das russische Theater von 1900 bis za den zwanziger Jahren

1.1. Das Theater vor der Revolution von 1917

1.1.1. Das Moskauer Kunstlertheater und Vsevolod Mejerchol'ds Experimente an Konstantin Stanislavskijs 1. Studio

1.1.2. Mejerchol'ds Inszenierung von Bloks "Balagancik" am

$\begin{array}{ll}\text { Theater von Vera Komissarzevskaja und das stilisierte Theater } & 18\end{array}$

1.1.3. Theaterexperimente 22

1.2. Das Theater nach der Revolution von $1917 \quad 27$

1.2.1. Revolution des Theaters 29

1.2.2. Massentheater 30

1.2.3. Proletkul't 32

1.2.4. Selbsttätiges Theater $\quad 35$

1.2.5. Die traditionellen Theater nach der Revolution von $1917 \quad 36$

1.2.6. Evgenij Vachtangov 37

1.2.7. Sergej Radlov 37

1.2.8. Theateroktober 39

1.2.9. Das Theater zur Zeit der NEP $\$ 2$

1.2.10. Mejerchol'ds Biomechanik 4.3

1.2.11. Sergej Ejzenstejns Theaterarbeit am Moskauer Proletkul't 46

I.2.12. LEF 51

1.2.13. Mastfor 53 
Kapitel 2. Die Gruppe FEKS und der Begriff des "Exzentrismus"

2.1. Die Anfange 58

2.1.1. Die Gründung der FEKS $\mathbf{5 8}$

2.1.2. Der Werdegang von Grigorij Kozincev und Leonid Trauberg bis zur Grundung der FEKS

2.2 Exzentrismus 65

2.2.1. Der Begriff "Exzentrismus" 65

2.2.2. Das Manifest "Ekscentrizm" 69

$\begin{array}{ll}\text { 2.3. Futurismus } & 102\end{array}$

2.3.1. Futuristische Elemente im Exzentrismus 102

2.3.2. Amerikanismus 113

2.3.3. Exzentrismus und Charles Chaplin 116

$\begin{array}{ll}\text { 2.3.4. Die Figur des Clowns } & 120\end{array}$

2.4. Formalismus 122

2.4.1. Exzentrismus und Formalismus $\quad 122$

$\begin{array}{ll}\text { 2.4.2. Das Prinzip der Verfremdung (Ostranenie) } & 128\end{array}$

Kapitel 3. Die Theaterstücke und Filme der FEKS

3.1. Die Theaterstiucke 132

3.1.1. Die Heirat (Zenit ba) 1.32

3.1.2. Außenhandel auf dem Eiffelturm (Vnëstorg na Ejfelevoj basinje) 134

Exkurs: Der russische/ soujetische Film bis 1920

3.2. Die Filme 145

3.2.1. Die Abenteuer der Oktjabrina (Pochozdenija Oktjabriny) 145 und Miška gegen Judenic (Miśka protiv Judenica)

3.2.2. Das Teufelsrad (Certovo Koleso) 149

3.2.3. Der Mantel (ŚSinel') 1.54

3.2.4. Briderchen (Bratysha) 156

3.2.5. SWD(SVD) 1.59

3.2.6. Das Neue Babylon (Nor yj Vavilon) 168 
Kapitel 4. Sinei’ als Beispiel der Literaturverfilmung durch die FEKS

4.1. Voruberiegungen zur Literaturverfilmung und zum Drehbuch $\begin{array}{ll}\text { als literarischem Genre } & 178\end{array}$

4.2. Gogol' in der Verfilmung durch Kozincev und Trauberg 182

4.3. Vergleich der Verfilmungen von Sinel' durch Kozincev und Trauberg und durch Aleksej Batalov 200

$\begin{array}{lr}\text { Schlußbemerkungen } & 209\end{array}$

$\begin{array}{ll}\text { Literaturverzeichnis } & 213\end{array}$

$\begin{array}{lr}\text { Anhang } & 222\end{array}$ 


\section{Einleitung}

"Мне совершенно неважно, много ли людей знают о ФЭКСе, мне достаточно того, что узнали о нем."

"Es ist mir überhaupt nicht wichtig. ob viele Menschen die FEKS kennen. es genügt mir. daß sie von ihr hörten."

Diese bescheidene Aussage Leonid Zacharovic̀ Traubergs zeigt. wie gering selbst er als Mitbegründer der 1921 im damaligen Petrograd gegrundeten Theater- und Filmgruppe "Fabrik des exzentrischen Schauspielers" ("Fabrika Ekscentriceskogo Aktera", kurz: FEKS) ${ }^{2}$ deren Bekanntheitsgrad einschätzt.

Während die übrigen großen Regisseure des frühen sowjetischen Films. wie Ejzenśtejn. Pudovkin, Vertov, Kulesov u.a., auch im westlichen Ausland nach wie vor als Wegbereiter der Filmkunst bekannt sind, ist die FFKS nur denen ein Begriff, die sich intensiv mit dem sowjetischen Stummfilm beschäftigen.

lan Christie schreibt diesen Umstand einerseits der Tatsache zu, daß die Fèksy in Leningrad arbeiteten. die Leitung des Filmwesens jedoch in Moskau lag, und andererseits die ungewohnlichen Themen ihrer Filme nicht in den üblichen Rahmen des sowjetisch revolutionären Kinos paßten, das entweder Massenfilme oder sozial engagiene Themen forderte. ${ }^{3}$ Mit den FEKS-Filmen ließ sich im Ausland keine Werbung für das leben im neuen Sowjetstaat machen. deshalb wurden sie dort nicht gezeigt und blieben weitgehend unbekannt. Die Hauptgründe für die Vernachlässigung der Fèksy dürften jedoch ihr ausgeprägter Individualismus und die Tatsache gewesen sein, daß sie nicht als eindeutig "rote" Charaktere einzuordnen waren. Hinzu kam der Mangel an Respekt und Emsthaftigkeit gegenüber der neuen politischideologischen Ordnung.

Es zeigt sich jedoch. daß gerade in den letzten Jahren das Interesse an der FEKS wieder zugenommen hat. Ihre Filme werden auch im westlichen

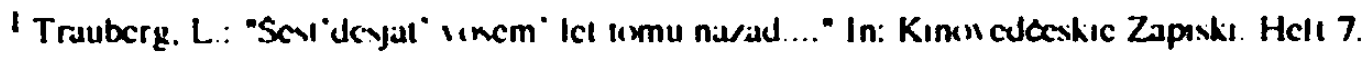
Mexkiau $\mid(x)$. S. 5.

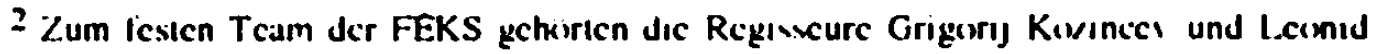
Trauberg. Jer S'hauspicter und yatere Drehbushautor Alekseg Kapler und der Kameramann Andres Minhion. Die behanntesten Sihauspicler Jer Gruppe waren Seryej Gerasimon.

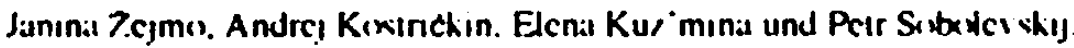

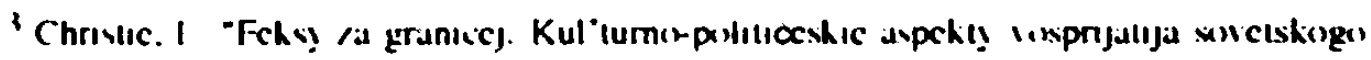

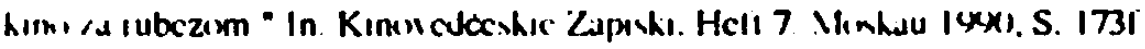


Ausland vermehr bei Retrospektiven gezeigt, und im Dezember 1989 fand in Moskau eine eigene Konferenz zum Thema "FEKS und Exzentrismus" statt.

Die Hauptthemen dieser Konferenz waren "Die FEKS und die Kultur der 20er Jahre", "Der Exzentrismus in der Kultur des 20. Jahrhunderts", eine Reihe von Vorträgen über wichtige Künstler und Kunsttheoretiker der zwanziger Jahre in ihrem Verhältnis zur FEKS, sowie eine Retrospektive erhaltener Filme. ${ }^{4}$

Diese Konferenz war vor allem für Kenner, die mit dem Wesen und der Arbeit der Gruppe vertraut sind. von Interesse. In der vorliegenden Arbeit dagegen soll versucht werden, ein Gesamtbild der FEKS in ihrer Entwicklung vom Exzentrismus zur Poetik des Films zu erstellen.

Auf den ersten Blick scheinen sich in dieser Entwicklung. aber auch in den Thesen und Forderungen der Feksy unvereinbare Widerspriche zu ergeben. Schon der von Kozincev. Trauberg und ihren Mitarbeitem geschaffene Begriff "Exzentrismus" setzt sich aus Elementen zusammen. die nicht recht zueinander zu passen scheinen. Im Manifest "Ekscentrizm" von 1922 werden beispielsweise im gleichen Atemzug der russische Kubofuturist Vladimir Majkovskij und der italienische Futurist Filippo Tommaso Marinetti zitiert. obwohl die russischen Futuristen den italienischen Futurismus stark ablehnten und ihre eigene Form des Futurismus propagierten. Die Autoren des Manifestes selbst äußern in ihren Artikeln teilweise recht unterschiedliche Forderungen für die Kunst der Zukunft. Und schließlich vermittelt die Wandlung in der praktischen Arbeit von der alles und jeden parodierenden exzentrischen Theaterkomödie zur Tragödie im Film einen Eindruck von eher sprunghafter Entwicklung.

$\mathrm{Da} B$ unvereinbar erscheinende Aspekte für die Fëksy durchaus zu verbinden waren, und die Entwicklung der Gruppe von ihrer Gruindung bis zu ihrem letzten Film als konsequentes Fortschreiten bei der Findung einer neuen Kunstform zu betrachten ist. dies soll im Folgenden anhand von Einflüssen, theoretischen Grundlagen und praktischer Arbeit der FEKS gezeigt werden, um damit deren Leistung und Bedeutung für die frühe sowjetische Kultur zu klären.

4 Vgl. allgemein diw.u: Kinureddeskic Zipiski. Hefi 7. Muskiau 19yx). 
0.1. Methode

Die Methode der Untersuchung ist die Rekonstruktion, d.h. das Zusammensetzen der verschiedenen theoretischen und praktischen Teile. um daraus ein Gesamtbild der FEKS und eben ihrer Bedeutung für die frühe Sowjetkultur entstehen zu lassen.

Dafür ist zunächst das Auffinden und eine konkrete Definition dieser Teile notwendig. $\mathrm{Zu}$ finden sind sie im kulturhistorischen Kontext. denn gerade in der experimentier- und diskutierfreudigen Situation, die das erste Viertel dieses Jahrhunderts in Rußland kennzeichnete, kann die Entwicklung eines Künstlers oder auch einer Künstlergruppe nicht isolient betrachtet werden. Nur wenn man die Künstler im Verhältnis zueinander betrachtet. wird deutlich, was der einzelne geleistet hat.

Auch die Aussagen und Merkmale der FEKS können nur im Kontext der kulturhistorischen Situation verstanden und bewertet werden. Würde man sie isoliert betrachten. entstünde leicht der Eindruck. man hätte es hier mit der sinnlosen Spielerei unreifer Jugendlicher zu tun.

Da die Fèksy, ebenso wie viele andere Regisseure ihrer Zeit. uber das Theater zum Film kamen, kann davon ausgegangen werden. daß die für sie wichtigsten Finflussen in der Fintwicklung des Theaters zu finden sind.

Aus diesen Grinden beginnt die vorliegende Arbeit mit einer ausführlichen Kontextanalyse. die die Entwicklung des russisch/sowjetischen Theaters von 1900 bis zu den zwanziger Jahren und seine Einflüsse auf die FEKS beleuchtet. Dabei wird u.a. auf die Theaterarbeit Sergej Fjzenstejns näher eingegangen, in der sich der Übergang vom Theater zum Film besonders deutlich zeigt.

Das zueite Kapitel der Untersuchung setzt sich mit dem Begriff "Exzentrismus" auseinander. den die Fèksy prägten. Da es keine konkrete Definition dieses Begriffes gibt. soll seine Bedeutung an den hervorstechendsten Merkmalen untersucht werden. Als Ausgangsbasis dafür dient das Manifest "Ehscentrizm". das die Gründer der FF.KS 1922 verfaßten. Die Übersetzung wurde von mir selbst angefertigt.

Das dritte Kapitel untersucht die praktische Umsetzung der FEKS. Theorien und deren Weiterentwicklung von den ersten Theaterstiicken bis zum letzten Stummfilm "Das Neue Babylon" (1929). Obwohl die Bezeichnung FEKS zu dieser Zeit schon nicht mehr existierte. wird dieser Film doch noch Jem Werk der (iruppe zugeordnet, denn der Name FEKS 
verschwand allmählich und wurde nicht zu einem bestimmten Zeitpunkı für ungültig erklärt. Er wird jedoch allgemein auf die Stummfilmarbeit von Kozincev. Trauberg und ihren Mitarbeitem angewendet.

Das vierte Kapitel schließlich geht auf die Arbeit der Fèksy als Literaturverfilmer ein. Untersucht wird ihre Verfilmung von Gogol's "Mantel" ("Sinel'") aus dem Jahre 1926. Dieser Film ist als einziger nach einer direkten literarischen Vorlage entstanden. während es sich bei "SVD" und "Das Neue Babylon" vor allem um die Übertragung literarischer Stilmittel in die Sprache des Films handell (s. Kap. 3.).

Aber auch bei der Auseinandersetzung mit "Sinel" richtet sich das Hauptaugenmerk auf die filmische Umsetzung von Gogol's Stil der Groteske.

Abschließend wird der Film mit einer späteren Verfilmung des "Mantel" durch Aleksej Batalov aus dem Jahre 1959 verglichen.

Die Schlußbemerkungen befassen sich noch einmal zusammenfassend mit der Entwicklung der Gruppe vom frühen exzentrischen Theater bis zur Anwendung ihrer poetischen Filmsprache und damit ihrer Bedeutung für die fruhe sowjetische Kultur.

\subsection{Materiallage}

Zum Material sei angemerkt. daß es auch an russisch/sowjetischer Literatur nur wenig zum Thema "FEKS" gibt, was als Beleg für die in der Einleitung erwähnte Vermachlässigung der Gruppe anzusehen ist. Dadurch gewinnt die Biographie Grigorij M. Kozincevs "Glubokij Ekran".5 besondere Bedeutung als direkte Aussage uber die Arbeit der FEKS.

Es ist mir zwar gelungen, von den wichtigsten Filmen der FEK S ("Certovo Koleso", "Sinel", "SVD". "Novyj Vavilon") Videokopien zu beschaffen, diese sind jedoch alle absolut stumm. d.h. ohne Musik. Aus diesem Grund wird die Musik zu den Filmen fast gänzlich außer acht gelassen.

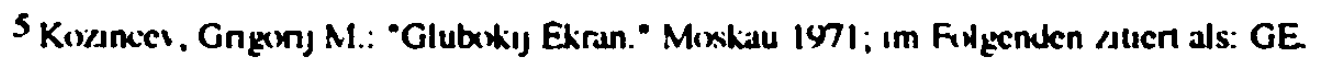


Daneben verfüge ich über eine vollständige Ausgabe des Manifestes "Ekscentrizm", das mit einer von mir angefertigten Übersetzung in die Arbeit eingebunden ist.

Eine wichtige Grundlage für die gesamte Untersuchung bildet das Heft Nr.7 der Filmzeitschrift Kinovedceskie Zapiski. in dem Vorträge und Materialien der oben erwähnten Konferenz "FEKS und Exzentrismus" von 1989 enthalten sind.

Ein wichtiges Werk der Sekundärliteratur stellt auch Vladimir Nedobrovos Artheit uber die FEKS von 1928" dar. weil sie die einzige. umfassende zeitgenössische Untersuchung dieser Gruppe ist und damit noch nicht von den Forderungen der offiziellen sozialistischen Kulturdoktrin ausgeht.

Leider ist es mir nicht mehr gelungen, ein persönliches Gespräch mit Leonid Zacharović Trauberg zu führen. da er im Friihherbst 1990, als ich mit der Materialbeschaffung zur Arbeit begann. schon zu krank war. um mir noch ein Intervieu gewähren zu können.

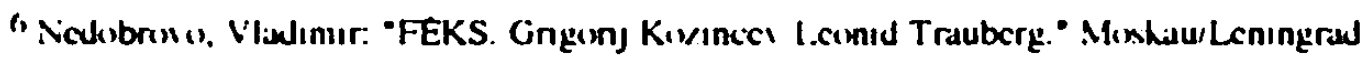
I IIIX
} 
Kapitel 1. Das russische Theater von 1900 bis zu den zwanziger Jahren

1.1. Das Theater vor der Revolution von 1917

1.1.1. Das Moskauer Künstlertheater und Vsevolod Mejerchol'ds Experimente an Konstantin Stanislavskiis 1. Studio

Um die Jahrhundertwende trat das russische Theater aus seiner Position als passiver Nachahmer des europäischen Theaters heraus und entwickelte sich zum aktiven Mitgestalter der modernen Theaterkunst. ${ }^{7}$

Ausgangspunkt für diese Entwicklung war die Gründung des Moskauer Künstlertheaters (MCHAT $=$ MXAT) durch Konstantin Stanislavskij und Vladimir Nemirović-Dancenko im Jahre 1898. Die beiden Regisseure wollten ein allen zugängliches Theater schaffen. das eine "lebendige(n) Fortentwicklung und Weiterfuhrung des Theaters eines Shakespeares. Schepkins. Ostrowskis"8 sein sollte.

"Stanislawski stand. das mag aus den Daten des Grundungszusammenhangs des Künstlertheaters schon erkennbar sein. zu dieser Zeit ganz im Banne der Ideologie der russischen Gründerjahre, die ähnlich wie im Westen Europas den technischen Fortschritt und die wissenschaftliche Durchdringung aller Lebensbereiche zu ihren Leitwerten erhoben hatte. Das Theater, das sich im Umkreis dieser Ideologie und unter der Trägerschaft des russischen Großbürgertums ausbildete, trat dementsprechend mit dem Programm auf, die Theaterkunst auf die Höhe der Ansprüche der als 'wissenschaftliches Zeitalter' empfundenen Gegenwart zu bringen. In diesem Kontext entwickelte sich das theoretische Konzept von Stanislawskis Theaterarbeit dieser Anfangsphase. Es hatte größte Ähnlichkeit mit dem deutschen und französischen Naturalismus und entstammte demselben Geist

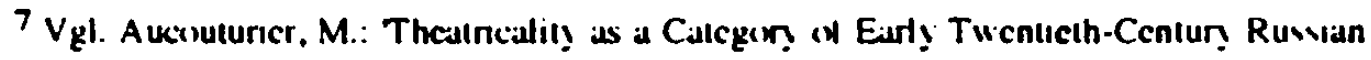
Culture.' In: Kicberg. L./Nilssm. N. (Ed.): "Theater and Literature in Russia 19x) - 19.30." Stoxkholm 1964. S. 9.

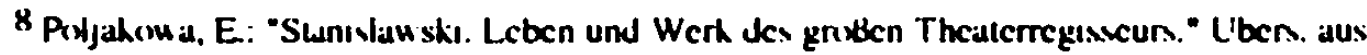
J. Russisthen. Bimn Iwi. S. IIn.
} 
der Wissenschafts- und Fortschrittsgläubigkeit. Das Pariser Thêatre libre und die Freie Bühne Berlin waren für Stanislawski und seinen Kreis die unmittelbaren Vorbilder, an deren naturalistischer Inszenierungstechnik (Otto Brahm) schulten sich Stanislawski selbst und die Regisseure seines Theaters. Die detailgetreue, konsequent illusionistische Reproduktion der Lebenswirklichkeit auf der Bühne war das Prinzip der Inszenierungen am Künstlertheater." ")

Den ersten großen Erfolg hatte das Künstlertheater im Dezember $1898 \mathrm{mit}$ der Inszenierung von Cechovs Drama "Die Möwe", das zwei Jahre zuvor in St. Petersburg durchgefallen war. Der triumphale Erfolg der "Möwe" begriundete die enge Zusammenarbeit zwischen Stanislavskij und Cechov bis zu dessen Tod 1904. Neben den Stücken von Cechov wurden am Kuinstlertheater vor allem Dramen von Ibsen. Hauptmann und Gor'kij inszeniert.

1904/05 geriet das MCHAT in eine Krise.

"Stanislawski fühlte die Erschöpfung der Formen des realistischen. psychologischen Theaters. in dem er selbst eine solche Vollkommenheit erreicht hatte und das er emeuern. weiterentwickeln und zu den Fragen hinlenken wolllte. auf die das Theater seinem ureigensten Wesen nach zu antworten hat." I"

Auf der Suche nach einem neuen Weg für das Theater wandte Stanislavskij sich dem symbolistischen Drama zu. Am Beginn der Saison 1904/05 inszenierte er Maurice Maeterlincks Trilogie "Les aveugles". "L'intruse" und "Interieur". Er verzichtete bei der Ausarbeitung jedoch nicht auf die realistische Gestaltung der Bühne. Auch konnten sich die Schauspieler nicht von der gewohnten "natürlichen" Spielweise lösen und "wurden bei der Darstellung der Schrecken des Todes schwülstig-geschmacklos." II

Um Raum für Experimente und für die Ausbildung junger Schauspieler zu schaffen. plante Stanislavskij 1905 . ein dem MCHAT angegliedertes Theaterstudio einzurichten. Mit der künstlerischen Leitung des Studios heauftragte er Vsevolod Mejerchol'd. der das Künstlertheater 1902 als Schauspieler verlassen und in der Zwischenzeit selbst Erfahrungen als Regisseur gesammelt hatte. In der Abwendung von Stanislavskijs natura-

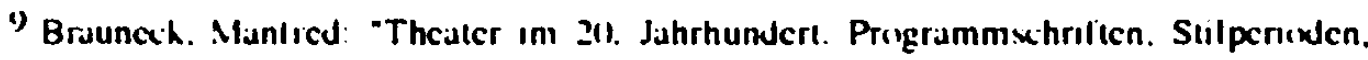

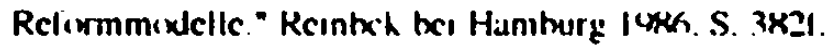

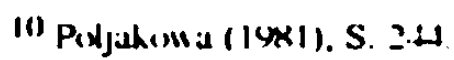

11 lbid.. S. 24th
} 
listischem Inszenienungsstil hatte sich auch Mejerchol'd schon mit der Inszenierungsproblematik symbolistischer Dramen beschäftigt. ${ }^{12}$

Bei der Auswahl des Repertoires arbeitete er zusammen mit dem symbolistischen Schriftsteller Valerij Brjusov, dessen Artikel "Nenużnaja Pravda" ("Die unnötige Wahrheit") von 1902 die theoretische Grundlage für Mejerchol'ds Experimente an diesem Theaterstudio bilden sollte. ${ }^{13}$ Brjusov forderte darin die Abkehr von der unnötigen Realität im zeitgenössischen Theater und die Rückkehr zu den Regeln des antiken Theaters. ${ }^{1+}$ So wollten Mejerchol'd und Brjusov gemeinsam einen antinaturalistischen Spielstil entwickeln. Mit Stanislavskij hatten sie sich zunächst auf vier Inszenierungen. darunter Maeterlincks "Der Tod des Tentagiles" und Hauptmanns "Schluck und Jau" geeinigt. Mejerchol'd glaubte schon 1905/06 während seiner Arbeit an Stanislavskijs Studio in Moskau:

"Das Problem des neuen Theaters ist nicht nur das Problem
des neuen Schauspielers und des neuen Autors. sondem es ist
genauso das Problem des Buhnenraumes. der neuen Gestal-
ung des Handlungsortes." 1.5

Schon damals lehrte er die Schauspieler, daß menschliche Wechselbeziehungen sich weniger in Worten. sondern vielmehr mit Gesten. Posen. Blicken und Schweigen ausdrücken. Der Zuschauer sollte durch plastische Bewegungen uberzeugt werden.

Diese Ideen wollte Mejerchol' $d$ bei den Inszenierungen am Theaterstudio in die Praxis umsetzen. Stanislavskij ließ ihm beim Experimentieren völlige Freiheit. Als er das erste Mal an einer Kostiumprobe zum "Tod des Tentagiles" teilnahm. war er jedoch keineswegs einverstanden mit dem Inszenierungsstil, so daß er das Stück vom Spielplan nahm. Die offizielle Eröffnung des Studios wurde wegen der durch die Revolution von 1905 bedingten Schwierigkeiten immer wieder verschoben und kurze Zeit später schloß Stanislavskij es unter erheblichem finanziellen Verlust, ohne daß eines der inszenierten Stücke zur öffentlichen Auffuhrung gekommen wäre.

\footnotetext{
12 Vgl. Braun. Edward: "The Theitre ox Meyerbold. Revolution on the Mextern Sluge." Londen 1979. S. 3urf.

13 Ibid., S. 37.

It Ibid., S. 38.

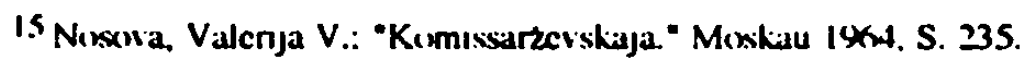


1.1.2. Meierchol'ds Inszenierung von Bloks "Balagancik" am Theater von Vera Komissarzevskaja und das stilisiente Theater

1906 ging Mejerchol'd nach St. Petersburg, wo er von Vera Komissarżevskaja als Chefregisseur ihres Theaters engagien worden war. In ungefähr einem Jahr inszenierte er dort dreizehn Theatersticke. Doch die Zusammenarbeit zwischen Mejerchol'd und der Komissarzevskaja gestaltete sich konfliktreich. Der einzige. allgemein anerkannte. gemeinsame Erfolg war die Inszenierung von Maeterlincks "Schwester Beatrice" vom 22. November 1906. Ende 1907 verließ Mejerchol'd das Theater der Komissarżevskaja. "die ebenso wie Stanislavskij der Meinung war. daß Mejerchol'd dem Schauspieler auf der Bühne keine Bedeutung zumesse. "16"

Als Schliisselinszenierung fur das symbolistische Theater, aber auch als Vorlage für die Theaterinszenierungen und frühen Filme der FEKS, kann jedoch Mejerchol'ds Inszenierung von Bloks "Balagancik" ("Die Schaubude") am Theater von Vera Komissarzevskaja angesehen werden.

Auf Anregung aus dem Kreis um Vjačeslav Ivanov hatte Aleksandr Blok im Frühjahr 1906 sein Gedicht "Balagancik" zu einem Theaterstiick im Stil der Commedia dell'arte umgeschrieben, dessen Hauptthema die klassische Dreiecksgeschichte zwischen den Figuren Harlekin. Columbine und Pierrot war. Damit hatte er eine fast vergessene Form des Theaters wiederentdeckt.

"Bevor Blok die 'Schaubude' geschrieben hatte, hatten die Figuren der italienischen Commedia dell'Arte weder in russische noch in westeuropäische Dramen Eingang gefunden. |...| Erst im Drama 'Die Schaubude' eroberte sich die Harlekinade die russische Bühne." ${ }^{17}$

\footnotetext{
I6 Masland-Hansen. Chnstian: "Mejerchest ds Thesterasthelik in den 192 (ker Jahren, thr

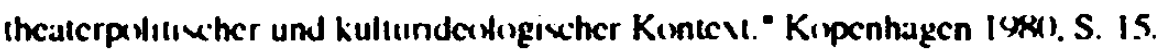

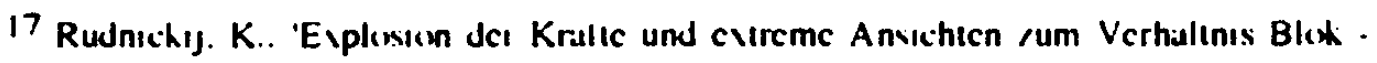
Meycrholds.' In: "Sicg uther dic Sornnc." Aupckic russischer Kunst au Beginn des 20. Jahihunderts. Auwiellung des Ahademic der Kunsic. Berlin. und der Beriner Festwexhen Iom 1. Scpt. bys 9 . Oht. I'm3. Berlin. S. 2(144. Im Original des Aul sut/cs wird Jer Name des Auturs 'Rudmckij' mit Jer Schreibwase 'Rudnishi' wicuergegeben. gleichzeltig "ird in der vorlicgenden IIntersuchung cin cnglixthsprachiges Werk des Autors herangesgen. in

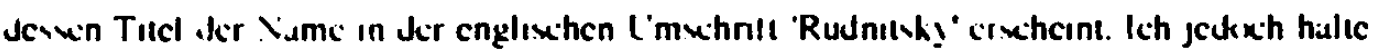


Mejerchol'd inszenierte eine Groteske. wie man sie später - zu Beginn der zwanziger Jahre - bei ihm selbst, aber auch bei Radlov, Ejzenstejn und der FEKS oder Foregger wiedersah. Die Aufführung war eine Parodie und Provokation des gesamten emsthaften Theaters.

"Dort, wo man sich gerade eben noch sehr geistreich unterhalten oder voller Gram gebetet hatte, sollten nun Possen gerissen werden, sollte getanzt und Spott getrieben werden. Wobei - und darin bestand die größte Neuerung der *Schaubude" - gerade die heiligen Handlungen zur Zielscheibe des Spottes wurden." 18

Selbst das symbolistische Theater. an dessen Inszenierungsmöglichkeiten Mejerchol'd arbeitete und dem er mit dieser Aufführung zum Durchbruch verhalf, wurde parodien in der Darstellungsweise der Mystiker, die plötzlich ohne Köpfe dasitzen. Blok hatte die Mystiker als typische Gestalten der Dramen Maeterlincks und Verhaerens konzipiert. Doch auch die russischen Symbolisten erkannten sich in diesen Figuren wieder, und Andrej Belij bezeichnete das Stuick als Verrat am Symbolismus. 19 Nach Braun hatte Blok jedoch mit poetischer Sensitivität in erster Linie die vorherrschende Stimmung der Orientierungslosigkeit getroffen, in der sich die russische Intelligensija nach den blutigen Ereignissen des Jahres 1905 befand. An empfindlichster Stelle getroffen, wandte sie sich deshalb so heftig gegen das Stuick. ${ }^{20}$

Andere Figuren aus dem "Balgancik" von 1906, wie etwa der Clown oder der Autor, der mehrmals auftritt. um sich über die Verfälschung seines Stückes zu beschweren, tauchen gut 15 Jahre später in der ersten FEKSInszenierung ("Zenit "ba". 1922) wieder auf.21 Nicht zuletzt war es auch die Form der Parodierung des ernsten Theaters, die Mejerchol'd als erster anwendete, die die Fèksy später übernahmen und auf das gesamte gesellschaftliche und politische Leben ihrer Zeit ausweiteten.

mich an die wissenschaflilithe Umschnifi des russischen Namens, dic 'Rudnichij' lautel. Ebensu, wird mit allen anderen russischen Namen verfahren.

18 lbid., S. Z(K.

19) Vgl. Braun (1979). S. 73.

20 Lx: cill.

21 Siche: Kupitel 3. 
Mejerchol'ds Inszenierung entfachte einen enormen Streit bei Publikum und Kritik. Die Verehrer des Regisseurs waren hellauf begeistert, andere waren entsetzt und erklärten das Stück für unsinnig. 22

Mejerchol "ds "Balagancik" und seine Aufführung von Andreevs "Das Leben des Menschen" ("Zizn celoveka", Februar 1907) sind aber auch die besten Beispiele für seine Theorie des "uslovnij teatr", der "stilisierten Bühne".

In der Abwendung vom Naturalismus war er zu der Ansicht gekommen. daB das Theater seinem Wesen nach nicht die Wirklichkeit darstellen kann und soll. da seine Gesetze von Raum und Zeit gänzlich andere sind. als die der Realität.

"Mejerchol'd war (um 1905/06) der Auffassung, daß man. um die Quintessenz der Wirklichkeit auf der Bühne ausdrucken zu können, die Wirklichkeit stilisieren und daB man die Kunst der Andeutung beherrschen müsse. "23

Die Basis des neuen Theaters sollte der dreidimensionale Bühnenraum ohne Dekoration sein. dessen Mittelpunkt der zu einer beweglichen Plastik stilisierte Schauspieler bildete. Dabei hatte der Schauspieler seinen gesamten Körper einzusetzen und nicht nur in erster Linie das Gesicht wie im Naturalismus üblich. Hier findet sich der Ausgangspunkt für Mejerchol'ds spatere Theoric der "Biomechanik" und die vun der FEKS. Kulesov und anderen übernommene Auffassung von der Wichtigkeit sportlichen Korpertrainings beı der Schauspielerausbildung.

Mejerchol'd war bei der Entwicklung seiner Theorie der "Stilbuihne" inspirien worden von Brjusov (s.o.). Georg Fuchs. Edward Gordon Craig. der später (1912) auch in Zusammenarbeit mit Stanislavskij in Moskau den "Hamlet" inszenierte, und nicht zuletzt von Vjaceslav Ivanov.

"For Vyacheslav Ivanov the theatre - potentially the most powerful of all the arts - was fully capable of replacing religion and the church for a humanity which had lost its faith." $2-1$

Damit das Theater dieses erreichen könne. hielt Ivanov es für notwendig ausgehend von Nietzsches "Gebun der Tragödie aus dem Geiste der Musik"-.

\footnotetext{
22 Siche diva: Braun ( (Y79). S. 67II.

23 Mialand-Hancen ( $(4(x))$. S .19.

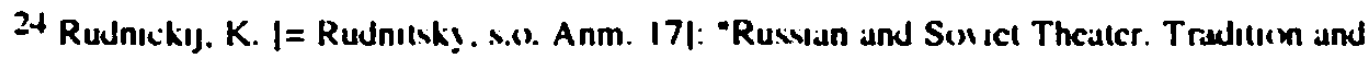

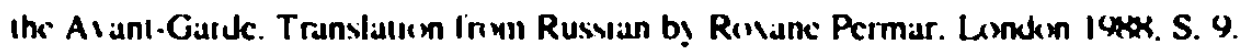


daß es zu seinen alten Wurzeln zurückkehre, zur klassischen Tragödie und zum mittelalterlichen Mysterienspiel.

Für Mejerchol'd war eine dieser Wurzeln auch die Commedia dell'arte, die er durch Bloks Balagancik entdeckt hatte. "for it was here that he broke away from Maeterlinck's 'static theatre' to create his own 'grotesque theatre' of movement and surprise." 2.5 Denn in der Groteske sah er die Weiterentwicklung der Stilisierung, die nur eine analytische Elappe bilde. welcher die Groteske mit ihrer streng synthetischen Methode folge.

"Die Groteske kennt nicht $n$ u $r$ das Niedrige oder $n$ u $r$ das Hohe. Sie vermischt die Gegensätze. spitzt die Widerspriiche bewußt zu und läßt mit ihrer Originalität spielen. |...| Die Hauptsache bei der Groteske ist das stăndige Streben des Künstlers. das Publikum aus einer gerade von ih $\mathrm{m}$ begriffenen Sphäre in eine andere zu fuhren. die es absolut nicht erwartet hat. |... | Die Kunst der Groteske beruht auf dem Kampf zwischen Inhalt und Form." 26

Die Technik der Groteske sah er am deutlichsten vertreten in den volkstümlichen. "niedrigen" Theaterformen von Balagan. Varieté. Cabaret oder music-hall. So hatte Mejerchol'd schon 1910, neben seiner Arbeit an den Kaiserlichen Bühnen. Marinskij und Aleksandrinskij Teatr. das intime Theater des "Interludienhauses" ("Dom intermedii") gegründet, dessen Räumlichkeiten mehr an ein Varieté erinnerten als an ein Theater und in dem Stücke dieser volkstümlichen Theaterformen gespielt wurden. Zur Eröffnung wurde unter anderem ein Stuick mit dem Titel "Der Schal der Columbine" aufgeführt. dem Schnitzlers Pantomimenstuck "Der Schleier der Pierrette" zugrunde lag. Mejerchol'd hatte jedoch einschneidende Veränderungen vorgenommen und eine Groteske im Geiste Gogol's und E.T.A. Hoffmanns daraus gemache.

"The three scenes were broken down into fourteen brief episodes, in order that the spectator should be shocked by the constant abrupt switches of mood and have no time to doubt the play's own ghastly logic."27

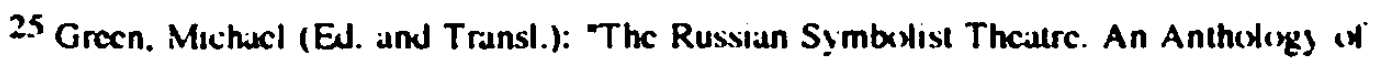
Plaỵs and Crnlical Texts." Ardis Publıshers Heatherw ạ̣ (Michigan) 1986. S. 15.

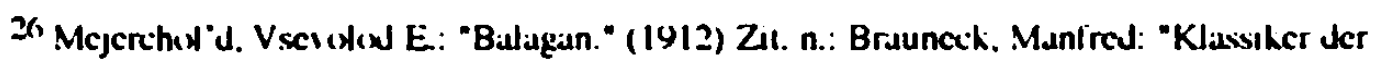
Schauspiciregic. Pisilionen und Kommentare um Theater im 21). Jahrhundert." Reinbek bei Hambury 19\%s. S. 174.

27 Braun (1979). S. 102. 
Diese Aufsplitterung in zahlreiche gegensätzliche Episoden und die Schockierung der Zuschauer war ein weiterer Teil aus Mejerchol'ds vorrevolutionärer Theaterarbeit. den die Regisseure der fruhen zwanziger Jahre wieder aufnahmen.

\subsubsection{Theaterexperimente}

Das gleiche Stuick Schnitzlers - jedoch unter dem Originaltitel "Der Schleier der Pierrette" - inszeniente 1913 der junge Regisseur Aleksandr Tairov am Freien Theater von Konstantin Mardzanov in Moskau. Auch Tairov. der Mejerchol'd als Schauspieler am Theater der Komissarżevskaja kennengelernt und u.a. in "Balagancik" mitgewirkt hatte. wandte sich in seiner Arbeit gegen den Naturalismus Stanislavskijs und orientiente sich an der Tradition des Volkstheaters, des Mysterienspiels und der Commedia dell arte. ${ }^{2 K}$

Während Mejerchol'd sich mit seiner Inszenierung "Der Schal der Columbine" der Groteske zuwandte. machte Tairov sich die Darstellung des reinen. unvermischten Genres zum Prinzip und inszenierte den "Schleier der Pierrelte" als Tragödie. ${ }^{x)}$

"...he did not want to mix the humorous with the terrible. but required a genre of virgin purity where comedy would be comedy and (ragedy would remain (ragedy.

Obwohl Mejerchol'd und Tairov in ihren theoretischen Schriften zum Theater das Verhältnis zwischen Schauspieler und Regisseur ähnlich wichten, zeigt sich doch gerade hier der wichtigste Unterschied zwischen beiden. Während es bei Mejerchol' $d$ heißt.

"Der Regisseur des stilisierten Theaters macht es sich zur Aufgabe, den Schauspieler nur zu führen, nicht aber zu regieren (im Gegensatz zum Meininger Regisseur). Er ist nur eine Brucke. die Autor und Schauspieler verbindet. Hat der

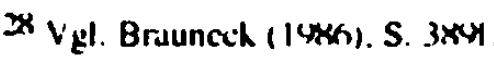

29 Zu dicser Ins/eniciung siche: Herexch. Eliwbeth "Schnit/ler in RulHand". Wien I9x?.

S. $\mid(|4|$.

3) Rudnichis ( Iux). S. 15.
} 
Schauspieler die künstlerischen Vorstellungen des Regisseurs umgesetzt. steht er dem Publikum a 1 l e i n gegenuiber $|. . .|^{n .31}$ schreibt Tairov,

Das erste Element, das Element des Suchens nach dem szenischen Gebilde, unterliegt keinen bestimmten Regeln und läBt sich in kein System fassen. Es ist ein tief individualistisches Element, das sich bei jedem Schauspieler anders kund tut. [... Naturlich kann und soll der Spielleiter dem Schauspieler bei diesem Prozeß behilflich sein. Er muß aber mit der äußersten Vorsicht vorgehen und sich feinfühlig der Individualität des Schauspielers anpassen. ${ }^{\text {"32 }}$

Tairov lehnte Mejerchol'ds Arbeit ab als "graphic forcing the actor to serve again not his own but another field, painting." 33 Seiner Meinung nach dienten die Schauspieler sowohl in Stanislavskijs Künstlertheater, als auch in Mejerchol 'ds Theater, mit ihrer Schauspielerei nur anderen Künsten: "At the Art Theatre the actor is in the end only a slave to the writer and in Meyerholds theatre only a slave to the artist-designer.".4 Tairov wollte das grundlegend ändern und vertrat die völlige Unabhängigkeit des Theaters von anderen Künsten. trotz der Tendenz zum Gesamtkunstwerk, die in dieser Zeit vorherrschte.

Im Dezember 1915 eröffnete Tairov sein eigenes Theater, das Kammertheater, mit der Premiere des altindischen Mysterienspiels "Sakuntala". An diesem Theater entwickelte er seinen Stil des "Synthetischen Theaters" weiter, denn "wie es schon Mardschanow geforden hatte. war auch sein Ziel, allein auf den Schauspieler, der Tänzer, Artist, Clown. Sänger, Mime und Darsteller in einem sein sollte, ${ }^{n 35}$ zu vertrauen.

Andere Wege zur Erneuerung des Theaters suchten die russischen Futuristen. deren namhafteste Vertreter Vladimir Majakovskij. Velimir Chlebnikov. Aleksej Krucenych, die Brider David und Vladimir Burljuk und

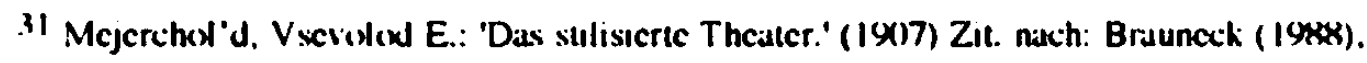
S. 166.

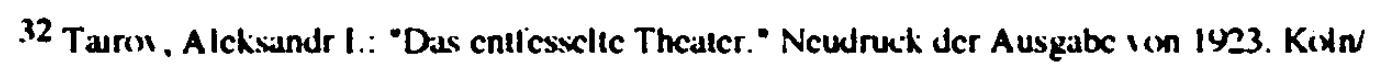
Berin 1964, S. YRI.

33 Rudniclitj (19x3). S. 15.

it Lox. cill.

35 Mejerched'd. V.E./ Tairos, A.J./ Vadhuingol, J.B.: 'Thealcrokiluber.' In: Braunceh (I9)(x). S. 229. 
Vasilij Kamenskij waren. Sie experimentierten direkt auf der Bühne. Die ersten zwei futuristischen Inszenierungen. die im Dezember 1913 im Luna Park Theater (dem ehemaligen Theater von Vera Komissarżevskaja) in Petersburg aufgeführt wurden, waren Majakovskijs Tragödie "Vladimir Majakovskij" und Matjuśins Oper "Sieg über die Sonne" mil dem Libretto von Krucenych. Diese Aufführung erlangte große Reputation. Nach Rudnickijs Meinung ist der Erfolg jedoch ausschließlich auf Kazimir Malevičs Zeichnungen für Bühnenausstattung und Kostüme zurückzuführen. ${ }^{3 *}$

Die Tragödie "Vladimir Majakovskij" erwies sich als noch erfolgreicher durch die außerordentliche Wirkung von Majakovskijs Persönlichkeit auf das Publikum. Er selbst spielte die Hauptrolle in seiner Tragödie. Das Ziel, mil der ästhetischen Tradition $z u$ brechen. stattdessen Dynamik und Geschwindigkeit als Hauptprinzip der Kunst zu etablieren ${ }^{37}$ - was gleichzeitig die wichtigste Gemeinsamkeil der russischen und italienischen Futuristen darstellte - wurde jedoch in beiden Inszenierungen konsequent verfolgt.

Im Hinblick auf die FEKS weist also besonders die vorrevolutionäre Theaterarbeit Mejerchol'ds verschiedene Erscheinungen auf, die die Gruppe in ihrer gesamten Entwicklung beeinflußten. Das waren die Wiederbelebung volkstumlicher Theaterformen wie Balagan. Commedia dell arte u.a., die Zerstückelung eines Theaterstuckes in viele kurze Szenen und deren standiger Wechsel, sowie die Ausarbeitung des Stils der Groteske als Darstellungsform. Mejerchol'd sah ebenso wie die Feksy zu ihrer Zeit in diesem exzentrischen und respektlosen Umgang mit dem Theater. durch den er als erster in Rußland die alte. erhabene Kunst parodierte und das Publikum schockierte, den Ausgangspunkt für die Erneuerung des Theaters. Die Bedeulung des Einflusses von Mejerchol'd auf die FEKS hat E. Levin in seinem Artikel "Mejerchol'd, Ekscentrizm i FEKS" sehr treffend zusammengefaßt:

"ФЭКС, конечно, был рождсн и сформирован временем и испытывал множество влияний. Однако Мейерхольд прямо и косвенно (...) более всего растил эту молодую группу самим свонм громким супествованием, пропиской на свосй территории, насквозь продуваемой моциыми вихрями его

\footnotetext{
M. Ibid. S. 13.

in vil. Ibid.. S. II
} 
новаторства. И проблема, мне кажется, не в том, чтобы установить признаки несомненного влияния; важно увидеть, что ФЭКС возникла самостоятельно, развивалась по свонм законам и шла свокм путем, но в художественном поле Мейерхольда."

"Die FEKS wurde natülich von der Zeit geboren und geprägt und unterlag einer Vielzahl von Einflüssen. Aber besonders Mejerchol'd hat direkt und indirekt |... | diese junge Gruppe vor allem durch seine eigene laute Existenz geprägt. durch die Einbindung in sein Territorium, das gänzlich von den mächtigen Stürmen seines Neuerertums durchdrungen war. Und das Problem. scheint mir, liegt nicht darin. die Merkmale des zweifellosen Einflusses zu bestimmen: wichtig ist. zu sehen, daß die FEKS selbständig entstand, sich nach ihren eigenen Gesetzen entwickelte und ihren eigenen Weg ging. aber - auf dem künstlerischen Feld Mejerchol "ds." "38

So gingen die Fèksy ihren Weg im Film, während Mejerchol'd immer dem Theater verbunden blieb, trotz seiner zwei vielversprechenden Literaturverfilmungen von Oscar Wildes "The Picture of Dorian Gray" (1915) und Stanislaw Przybyszewskis "Der starke Mann" (1916). 30

Aber auch im Gesamtbild des vorrevolutionären Theaters sind Tendenzen zu finden, die wichtige Voraussetzungen für Theater und Film in den zwanziger Jahren (nicht nur in Bezug auf die FEKS) schufen. Eine der bedeutendsten war die der ästhetischen Theatralisierung.

Die Vervollkommnung des Realismus hatte diesen an seine eigenen Grenzen geführt und gleichzeitig gezeigt, daß eine Widerspiegelung der Realität nicht dem Wesen des Theaters entspricht. sondern daß es eine Kunstform mit eigenen Regeln und Gesetzen ist. die nur hier Gültigkeit haben.

"The specificity of theater, according to Evreinov. is theatricality, i.e. the innate instinct of transfiguration which impels us to transform ourselves into someone else. The purpose of acting is not the reproduction of a completed image. but the creation of a new being; not the duplication of existing reality, but the creation of a new, theatrical world. "*)

Nikolaj Evreinov hatte das 1912 in seinem Artikel "Das Theater als solches" ("Teatr kak takovoj") festgehalten. Stanislavskij. Brjusov. Ivanov.

\footnotetext{
38 Leiın. E: 'Mejerchol 'd, Ekscentnzm I FEKS.' In: "Kınovedoeskic Zipıskı." Hefi 7. Mosikau 1990. S. 99.

39) Siche daru: Leyda. Jay: "Kıno. A Histoxy of the Russtan and Sivict Film." Princelon. New Jerse! 1963, S. 81f. und 87 .

*) Akcouturier (1)44), S. 12f.
} 
Mejerchol'd. Tairov und andere hatten das bereits erkannt und auf verschiedene Weise umzusetzen versucht. Dabei betonten sie alle. trotz ihrer oft sehr unterschiedlichen ästhetischen Ansätze, die Unabhängigkeit des Theaters von der Literatur. ${ }^{+1}$

Die Futuristen, von denen die Fëksy viele ihrer Forderungen zur Emeuerung von Kunst und Gesellschaft ubernahmen, wandten Evreinovs Erkenntnis in dem Artikel "Das Wort als solches" ("Slovo kak takovoe". 1913) von Krucenych und Chlebnikov auch auf die Dichtung an und entwickelten daraus die Theatralisierung des Lebens. ${ }^{+2}$ Nicht nur eine neue Theaterwelt sollte ihrer Ansicht nach geschaffen werden, sondern eine theatralisiene Welt. Der Dichter wurde zum Schauspieler und das poetische Werk Teil seiner Rolle. Besonders deutlich zeigte sich dies im Verhalten Majakovskijs, dessen Leben eine permanente öffentliche Demonstration seiner selbst in der Rolle des Dichters war. ${ }^{+3}$ Das zeigte sich gerade in seinem Fruhwerk wie dem Zyklus "Ja" ("Ich". 1913). der Tragödie "Vladimir Majakovskij" (1913) oder der Verserzählung "Oblako v stanach" ( "Wolke in Hosen". 1915), aber auch in den provozierenden öffentlichen Auftritten aller Futuristen. In diesem Verhalten lag natürlich die Gefahr, daß die Grenzen zwischen Kunst und Realität aufgehoben werden.

"This corresponds to one of the decpest aspirations of modern an as expressed by Russian futurism, but at the same time it conceals the danger of a theatricalization of life that is tantamount to its suppression." $H$

Doch die Futuristen sahen die Kunst vor allem als Transformation der Realität und forderten nicht nur die Theatralisierung des Lebens eines Individuums, sondern der ganzen Gesellschaft. Diese versuchten sie in den ersten Jahren nach der Revolution im Massentheater zu verwirklichen (s.u.).

Diese Vermischung von Leben und Kunst übernahmen die Feksy nicht. Trotz ihrer Begeisterung für die Futuristen waren diese Bereiche bei ihnen

\footnotetext{
+1 vigl. ibid., S. I(1).12.

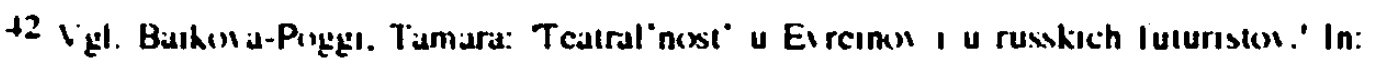

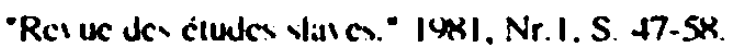

t.3 Vgl. Ibid.. S 1.5.

4 Ibid.. S. I8.
} 
immer getrennt. was auf ihre ironische Einstellung zur Kunst. wie zu sich selbst, zurückzuführen sein dürte. ${ }^{+5}$

Wichtig war für sie vor allem das Bestreben um Erneuerung des Theaters und der Kunst allgemein. das wie hier gezeigt. nicht erst durch die sozialpolitischen Ereignisse der Revolution. sondern als logische Entwicklung der Theaterkunst bereits zu Beginn des Jahrhunderts entstanden war. Inwieweit die einzelnen Künstler dabei auch vom Gefühl oder Wissen um die Notwendigkeit einer gesellschaftlichen Veränderung beeinflußt waren. soll hier nicht untersucht werden, da es den Rahmen dieser Arbeit sprengen würde. Auch war die FEKS trotz aller Zeitbezogenheit eine im Grunde unpolitische Gruppe, wie im weiteren Verlauf dieser Untersuchung gezeigt werden soll.

\subsection{Das Theater nach der Revolution von 1917}

Nach der Revolution von 1917 wurde das Theater zu Schule und Informationsort für das Proletariat, was Rudnickij folgendermaßen erklärt:

"For the light which the theatre radiated could reach everyone. The language of the theatre was comprehensive to everyone. Every peasant. every worker, every soldier sought to find out on whose side the truth lay: it was a question of life or death for them. The theatre was of real help to millions of such spectators as they orientated themselves in the complex political conflict of the period." "tw

Für dieses neue Publikum mußte eine neue Sprache gefunden werden. Jeder Künstler suchte dabei nach seinem eigenen Weg. seiner eigenen Sprache, um das neue Publikum anzusprechen. sich ihm verständlich zu machen. Es war eine Zeit des Suchens. Experimentierens und lebhafter Debatten unter den Kunstschaffenden. Daher ist es, wie Rudnickij schreibr. unmöglich die Arbeit eines Regisseurs oder einer Gruppe von Kunstschaffenden isoliert zu betrachten, da sie nur im Verhältnis zueinander verstanden werden können. ${ }^{+7}$ Soziale Bedürnisse und Publikumsgeschmack

\footnotetext{
45 Siche divu: Kipilel 2.

* Rudnickis (1928), S. 41.

t? Vgl. lox. cill.
} 
mußten erkannt und neu definient werden. Dabei waren die Künstler vor das Problem gestellt, sich persönlich in der neuen Situation orientieren zu müssen. So trat zum Beispiel Mejerchol'd im August 1918 der Bolschewistischen Partei bei und verkundete, daß er seine Kunst in den Dienst der Revolution stelle. ${ }^{+*}$ Dieser Schritt brachte ihm in den nächsten Jahren viel Kritik sowie den Vorwurf des Opportunismus ein, und kein namhafter Theaterregisseur dieser Zeit folgte seinem Beispiel. Ein Standpunkt jedoch war allen gemeinsam: auch das Theater sollte revolutioniert werden. Mit allen bisher geltenden Theaterregeln und -gesetzen sollte gebrochen werden. Es sollte etwas völlig Neues entstehen. So kam es zu der oben bereits erwähnten Zeit des Experimentierens und Suchens. Im Gegensatz zu den futuristischen Manifesten, die laut den Bruch mit allen Traditionen verkündeten, erwiesen sich jedoch viele dieser Experimente auch bei den Futuristen als Wiederbelebung und Vermischung vergangener Theaterformen. Ein gutes Beispiel dafür ist das Schauspiel "Mysterium buffo" von Vladimir Majakovskij, das am 7. November 1918, dem ersten Jahrestag der Revolution. im Musikdramatischen Theater in Petrograd uraufgefuihrt wurde. Regie fuhrte Mejerchol'd. das Bühnenbild schuf Kazimir Malevic. +') "Durch die Verknüpfung von Elementen des religiösen mittelalterlichen Mysterienspiels mit den grob komischen Elementen aus der Volkstheatertradition..."., läßt sich "Mysterium buffo" keiner Gattung zuordnen. Diese Tatsache war jedoch von Majakovskij beabsichtigt. da es ihm als Vertreter des Futurismus "nicht um eine Emeuerung oder zeitgemäße Transformation |... | der Kunst und Literatur, sondern um ihre Überwindung und Abschaffung"51 ging. Gleichzeitig sollte mit "Mysterium buffo" die Revolution gefeiert werden. In der ersten Fassung seines Stuckes hatte Majakovskij offenbar noch nicht die richtige Sprache sowohl für das Publikum als auch für die Partei gefunden. denn die Reaktion auf das Stück war so negativ. "daß die Vorsitzende der Petrograder Theaterkomission das Stuck nach drei

H Lix. cil.

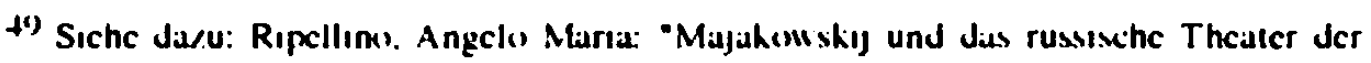

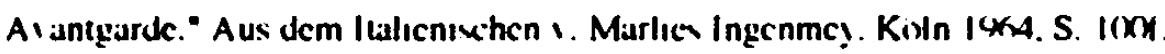

".) Hicluther. Karta: "Mỵsenum bullo" und dic Antange des linhen Al antgardetheaters.' In: "Majahow shyj: 20) Jahre Arbe1t. Neuc Gesellwhali fur bildende Kunst Berlin 1978. S. 74.

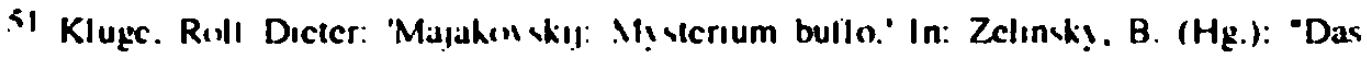

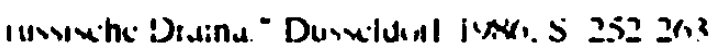


Aufführungen mit der Begrundung. es sei für Proletarier ungeeignet und unverständlich, vom Spielplan absetzen ließ.".52 Es bedurfte einer zweiten uberarbeiteten Fassung. bis "Mysterium buffo" drei Jahre nach der Uraufführung mit Erfolg gespielt werden konnte.

Obwohl auch in späteren Zeiten nur selten gespielt, kann Majakovskijs Schauspiel als eines der grundlegenden Dramen der fruhen Sowjetliteratur gelten. da zu dieser Zeit nur wenig nennenswerte Revolutionsdramen entstanden. "Only a very few literati such as the futurists, wrote plays immediately after the Revolution which celebrated the event..".53 Eines von diesen war Vasilij Kamenskijs Drama "Sten "ka Razin" (1918 in Moskau uraufgeführt), "das eine Mischung von futuristischer Dichtung und politischen Losungen darstellt. 5 Ein anderes frühsowjetisches und häufig für die Bühne adaptiertes Werk war Aleksandr Bloks Poem "Die Zwölf", das noch heute von der russischen und westlichen Literaturwissenschaft sehr geschätzt wird.

\subsubsection{Revolution des Theaters}

Doch nicht nur die professionellen Literaten und Theaterleute beschäftigten sich mit der Revolution des Theaters: noch während des Bürgerkrieges entstand eine Theatereuphorie in Rußland. die auch Arbeiter. Soldaten und Bauern erfaßte. In erster Linie war es das Theaterspielen selbst, das Agieren. das die Massen zunächst begeisterte.

"The amateur and semi-professional theatres enthusiastically performed the classical plays as well as they could. but their productions were usually of a propagandist character. This was primarily a propagandist theatre, and the classics did not al ways suit their purposes. ${ }^{.55}$

52 Ibid., S. 252. Die damalige Vorsit/ende der Petrograder Thealertomission 11 ar Gor Kijs Frau Marija Fedorovna Andreeva. Vgl. Paech, Juachım: "Das Theater Jer russischen Reiolution. Theoric und Pravis des proletarisch-kuliurrevolutionaren Theaters in RuBland 1917.1924." Kromberg/Ts. 1974. S. 329.

53 Rudnickij (19R8). S. 44.

54 Holthusen. Johannes: "Russiscthe Litcralur im 20. Jahrhundert." Munchen 1977. S. 95.

5.5 Rudnickij (1) S. 44. 
Diese Theaterbegeisterung wollten die neuen politischen Führer organisieren und in geregelte Bahnen lenken. So wurden von den entstehenden Sowjets. Gewerkschaften. Betriebs- und Fabrikkomitees Arbeiterclubs eingerichtet, die kulturelle Aufklärungsarbeit leisten sollten.

"Integraler Teil dieser Kulturarbeit waren jene Theaterzirkel. in denen der spontane Versuch gemacht wurde. aus der Basis des proletarischen Lebenszusammenhanges heraus Darstellungsformen zu entwickeln, die den Bedurfnissen des siegreichen Proletariats nach selbstbewußter Selbstdarstellung und Verstandigung über ein proletarisches Selbstverständnis. das ihm bisher von den herrschenden Klassen verweigert wurde. entgegenkommen sollten. Wenn es dabei vor allem um die Bewaltigung des proletarischen Alltagslebens ging. dieser Alltag jedoch fast vollkommen von der Verteidigung der Revolution im Bürgerkrieg ausgefullt war. ist verständlich, daB sich dieses Theater vornehmlich als 'Theater der kulturellen Front' artikulieren konnte und daher Bürerkrieg und Klassenkampf seine Hauplinhalte bildeten." . $_{\text {t }}$

Als Dachverband und Gesamtorganisator der proletarisch-kulturrevolutionären Organisationen verstand sich der bereits im Oktober 1917 gegrundete Proletkul' $($ (proletarskaja kul'tura). dessen Leiter der marxistische Sozialphilosoph und Idealist Aleksandr Bogdanov. der Kritiker und Theoretiker Platon Kerzencev und der Dramatiker Valerijan Pletnev waren. Finanziert wurde der Proletkul't vom Narkompros (Narodnij komissariat po prosveśceniju). dem Volkskomissariat für Aufklärung.

\subsubsection{Massentheater}

Die auffallendsten Erscheinungen des propagandistischen Theaters waren Massenspektakel und Masseninszenierungen. Diese Massentheateraktionen fanden in der Regel an Feiertagen statl und wurden in Fabrikhallen. auf Straßen. öffentlichen Plätzen. Bahnhöfen und an ähnlichen für Großveranstaltungen geeigneten Orten abgehalten. Bezeichnend fiir diese Form des Theaters war u.a. der Wegfall der Grenze zwischen Schauspielern und Publikum. Die Menschen. die an diesen Veranstaltungen teilnahmen. $u$ aren gleichzeitig Agierende und Rezipierende.

ix. Pacch $(1474)$. S. II). 
"Das Massenpublikum wurde zum Mitakteur seines Theaters. ihm sollte das Bewußtsein. selber Produzent zu sein. im Theater vermittelt werden. Dieses ProduzentenbewuBtsein in jedem einzelnen Individuum zu erwecken, war eine der zentralen Aufgaben der politischen Pädagogik der neuen Sowjetgesellschaft.".57

Produziert wurden allerdings nur die vorgefertigten Mythen der Revolution. Kennzeichnend für diese Idee war jedoch der Begriff der "Theatralisierung des Lebens". Der stilistischen Form nach waren alle Massenstücke beeinfluBt von Majakovskijs "Mysterium buffo". Der schematische Zentralkonflikt all dieser Spektakel war der Kampf zwischen "Reinen" und "Unreinen", "Roten" und "Weißen", Unterdrickten und Unterdruckern. Da dieses Thema jeden Bürger der jungen Sowjetgesellschaft betraf, erscheint es geradezu selbstverständlich. daB die Aufforderung zum Mitspielen einen enormen Anklang in der Bevölkerung fand.

"Eine der größten Massentheateraktionen war das Spiel von der "Erstuimung des Winterpalais" am 7. November 1920. zum dritten Jahrestag der Oktoberrevolution in Leningrad. An der Veranstaltung waren 15000 Spieler mit festen Rollen beteiligt. Spielort war fast der ganze Stadtteil. der um das Palais gelegen war: aktives, das heißt voll in die Regiekonzeption durch Aufmärsche und Gesänge einbezogenes Publikum waren über 100000 Menschen. Einwohner der Stadt (I eningrad hatte zu jener Zeit $\mathbf{8 0 0} 000$ Einwohner)." 58

Das Szenarium zu dieser Inszenierung hatte Evreinov geschrieben. Der Künstler Jurij Annenkov hatte auf dem Platz vor dem Winterpalais zwei durch eine Brücke verbundene Bühnen errichtet, auf denen sich "Rote" und "Weiße" gegenuberstanden. Vor diesem Hintergrund wurden die Ereignisse des November 1917, die Zerschlagung der Provisorischen Regierung und Eroberung des Winterpalastes, in mythisch verklärter Auswahl szenisch dargestellt. Das Spektakel endete mit dem Anstimmen der Internationale und einem großartigen Feuerwerk.

\footnotetext{
57 Brauncel ( (1)6). S. 319.

58 Ibid., S. 319x.
} 


\subsubsection{Proletkul't}

Um das rein proletarische Theater zu verwirklichen. forderten die Führer des Proletkul't eine größtmögliche Bewahrung des Laientheaters. das heißt feste Ensembles und professionelle Schauspieler sollten möglichst abgeschafft werden und an ihrer Stelle sollten Arbeiter und Bauern selbst Stücke schreiben. inszenieren und darin agieren. Gleichzeitig sollten sie an ihren eigentlichen Arbeitsplätzen weiterarbeiten, um ihre Zugehörigkeit und den direkten Zugang zum Proletariat nicht zu verlieren.

Die Ziel- und Wunschvorstellung dieser Forderungen durch den Proletkul 't war die Idee der "lebensformenden" Kunst, die sowohl ihre Schöpfer. als auch ihre Rezipienten und damit die gesamte menschliche Gemeinschaft umwandeln sollte in eine Gesellschaft harmonisch zusammenlebender Individuen. Das war - wie bereits erwähnt - eine der Ideen. die Vjaceslav Ivanov zum neuen Theater entwickelt hatte. (x) Den Bolschewiken erschien diese Vision jedoch zu wenig realistisch. Lunacarskij. Grundungsmitglied des Proletkul't und Volkskommissar für Erziehung und Aufklärung. beurteilte einerseits die Massenspektakel, wegen ihres Nutzens fur die Bolschewiken positiv, kritisierte aber andererseits den Verlust von Feinheiten und Individualismus in diesen Massenaufführungen. Lunarcarskij trat für die Erhaltung der konventionellen Theater. der gesamten bestehenden bourgeoisen Kultur ein. um auf deren Basis und mittels ihrer Überarbeitung die neue proletarische Kultur aufzubauen. Ein weiterer Streitpunkt zwischen der Partei und Lunaćarskij auf der einen Seite und dem Proletkul't auf der anderen. war die Selbsttätigkeit. die der Proletkul' $i$ fur das Theater forderte. Joachim Paech nennt als eine der künftigen postrevolutionären Positionen in Lenins Kulturpolitik folgende:

"In der Konzeption der Partei als Avantgarde ist impliziert. daß einem im wesentlichen unmundigen Proletariat der Anstoß zur revolutionären Aktion nur 'von außen'gegeben werden kann, daß jegliche Selbsttätigkeit der Massen unterbunden und der Fuhrung durch die Partei untergeordnet werden musse."

Doch die Führer des Proletkul't gaben nicht nach. Mit der Begründung. da $B$ alle bisher entstandenen Theaterstucke und -auffiuhrungen unter den

\footnotetext{
59) $\backslash$ pl. Rudnichil ( I (Nox). S. th

(w) Vigl. Ib. S. W

1.1 Pacih (1974). S. 34
} 
Bedingungen einer bourgeoisen Gesellschaft entstanden seien. die auf die neue proletarische nicht mehr zuträfen. erklärten sie alle vor der Revolution entstandenen Werke für unbrauchbar. Diese Position war jedoch auch innerhalb des Proletkul't umstritten, bzw. wurde einfach aus praktischen Erwägungen nicht verfolgt. Zahlreiche Proletkul't-Organisationen spielten weiterhin klassische Stücke, die mit Hilfe professioneller Regisseure und Schauspieler inszeniert wurden. Lenin vertrat weiterhin den Standpunkt, daß die Massen erst den Anschluß an die bestehende Kultur gewinnen sollten. Obwohl der Proletkul 't. wie bereits erwähnt, vom Narkompros finanziert wurde, sah er sich jedoch keineswegs von diesem abhängig.

"Im April 1918 wurde formell festgelegt. daß der Proletkul't sich der kulturellen und kreativen Aktivitäten der Arbeiterklasse anzunehmen habe. wahrend das Narkompros eher generell fur die Bildung und Aufklärungsarbeit verantworlich war. " 62

Die beiden bedeutendsten Theater des Proletkul't waren die Proletkul ' $t$ Theater in Petrograd und Moskau. wobei Paech das Moskauer Theater als das interessantere bezeichnet. "schon wegen seiner Regisseure Eisenstein. Tret "jakow und Arvatov". ${ }^{1.3}$ durch deren Arbeit "sich das Moskauer 1. Arbeitertheater des Proltkul't allmählich aus der Studioarbeit heraus profilierte. "rat

Das Petrograder Proletkul ' $t$-Theater wurde aus bereits seit der Februarrevolution 1917 bestehenden Arbeitertheatem und -klubs gebildet. Am I. Mai 1918 nahm es unter der Leitung der Schauspieler Mgrebov. Cekan und Ignatov die Arbeit auf. Die Aufführungen des Theaters waren vor allem szenische Lesungen der Werke von Arbeiterdichtern, die - meist von Industrialisierung und Mechanisierung handelnd - in symbolischer oder allegorischer Form geschrieben waren. Die erfolgreichsten Stücke waren Besal "kovs "Der Maurer" ("Kamenścik") oder Kozlovs "Die Legende vom Kommunarden". aber auch Romain Rollands "Die Einnahme der Bastille". Das Studio des Petrograder Proletkul't war mit seinen Stücken sehr viel unterwegs und entwickelte sich nach und nach zum Fronttheater. "Die expressionistische. mystisch-symbolische Verherrlichung des Proletariats"

\footnotetext{
62 Malland-Hansen (1 $(x)$ )) S. 32.

(.3 Pacch (1974). S. 289.

at Lox. cil.

6.5 Ibid., S. 291.
} 
seiner Inszenierungen führte jedoch 1919 zu schwerwiegenden Auseinandersetzungen zwischen Mgrebov und dem Proletkul 't, und erst im Frühjahr 1921 nach der Neuorientierung des Proletkul't konnte hier eine Einigung erzielt werden.

"Im Februar 1918 wurde der Moskauer Proletkul't gegriindet. deren fuhrender Ideologe und Theoretiker, Alexander Bogdanov, als geistiger Vater der dem Proletkul't zugeschriebenen Kulturideologie bezeichnet werden muB."

Nach dieser Ideologie sollte der Begriff des "Schöpferischen" auf das gesamte Alltagsleben, also auch auf die Arbeit ausgedehnt werden. Durch gemeinsame schöpferische Arbeit wiederum sollten Kameradschaftlichkeit und Kollektivismus gestärkt werden.

In der ersten Zeit ergab sich für den Moskauer Proletkul't die Schwierigkeit. daß die Studios keinen festen Ort für ihre Arbeit hatten. Die organisierte Arbeit begann erst 1919 mit der Einrichtung eines Zentralstudios.

"An diesem zentralen dramatischen Studio inszenierten neben Smyśljaev auch Pletnev und gelegentlich Ignatov und andere.

- entsprechend unterschiedlich waren stilistische Ebenen und Repertoire."

So wurde beispielsweise Gogol's "Heirat" ("Zenit'ba") naturalistisch inszeniert. aber die Fabeln Krylovs agitatorisch für Massenspektakel umfunktioniert. Als das Zentralstudio an die Front geschickt wurde, baute Smyśljaev ein zweites. cbenfalls für das Fronttheater bestimmtes Studio auf. Dieses zweite Studio entwickelte sich nach dem Bürgerkrieg zu Smyšljaevs Zentralstudio und in der Folge zum I. Arbeitertheater des Proletkul't.

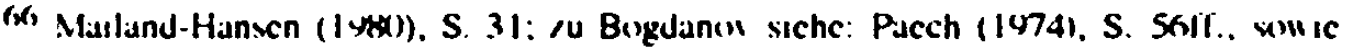
Gorsen. P.: Knodlier-Bunte, E.: "Proletkult 1. System einer proletarischen Kulturdokumentatson." Dics.: "Proletkult 2. Zur Pravis und Theoric einer proletarischen Kulturreciolution in Silu jetrulbiand 1917-1425." Bcide Stullgall - Bad Cannvtall 1974; dann:

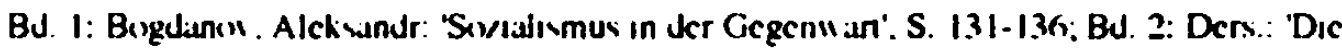
proletarische L'nis ersitat'. S. 7-2x. Bd. 2: Ders.: 'Wege des proletarischen Schalfens. Thesen. S 47.51.

(1) Parih (1074). S. 2us
} 


\subsubsection{Selbsttätiges Theater}

Während des Bürgerkrieges gewann die selbsttätige Theaterarbeit jedoch immer mehr an Bedeutung. Nachdem das professionelle Theater an den Schwierigkeiten der Truppenbetreuung gescheitert war. wurden die Rotarmisten selbst zur aktiven schöpferischen Theaterarbeit aufgerufen. Von Rotarmisten geschriebene Stucke wurden ins Repertoire aufgenommen und rotarmistische Laientheater in sogenannte schöpferische "selbstätige" Theater umgewandelt. ${ }^{\text {(N) denn }}$

"Die Umstellung des Fronttheaters von der Betreuung durch professionelle Theater auf die 'selbsttätige' Theaterarbeit der Rotarmisten traf auf ein allgemeines Bedurfnis an der Front." ${ }^{\text {"19 }}$

Zwar waren die Rotarmisten unerfahrene Autoren, sie wußten jedoch am besten. was ihr Publikum von ihnen erwartete.

"...unambiguous, clear and naive. yet honest, were the plays and spectacles of the propaganda theatre which presented 'propaganda through facts', showing genre sketches from the life of the people. ${ }^{-\pi)}$

Egal, ob das harte Leben der Arbeiter und Bauern in der vorrevolutionären Zeit gezeigt wurde, oder die heroischen Einsätze der Roten Armee im Bürgerkrieg. alle Agit-Stuicke waren von dem Bemühen um eine realistische Darstellung der Ereignisse geprägt. Zu den besten realistischen Agit-Stücken zählt Rudnickij das Stück "Mariana" von Aleksandr Zerafimović. der als Autor bereits bekannt war. sowie die "Rote Wahrheit" von Aleksandr Vermišev, einem Kommissar der Roten Armee. Beide Stucke beinhalten den Kampf des von bolschewistischen Ideen beeinflußten Volkes gegen die Unterdrückung. ${ }^{71}$ Weiterhin schreibt Rudnickij zu den Agit-Stücken:

"However naive and simple-minded the agit-plays were. a number of important characteristics emerged in them which were later developed in the drama of the 1920s."72

\footnotetext{
(88 Vgl. Ibid.. S. 139.

(19) Ibid., S. 14).

70 Rudnickij (1) S. 47.

71 Vgl. lox. cit.

72 Lxx. cilt.
} 


\subsubsection{Die traditionellen Theater nach der Revolution von 1917}

Während sich an der Front das Agitationstheater entwickelte. herrschte an den traditionellen großen Theatern in Moskau und Petrograd Unsicherheit uber die Zukunft dieser Theater.

"At first the most experienced actors and directors in the Russian theatre had only a very hazy idea of what kind of plays should now be produced and how they should be performed. They did not know how the 'simple' public now filling the auditoriums would react to their ant."7n

Es zeigte sich jedoch in den ersten Jahren nach der Revolution, daß ein großes Bedurfnis nach klassischen Theaterstucken beim Publikum bestand. So ergab sich in diesen Jahren die Aufgabe für das traditionelle Theater, den Übergang von der Vergangenheit zur Gegenwart zu finden. Dabei waren die Inszenierungen in zunehmendem Maße davon bestimmt. die Sympathie für Rechtlose und Unterdrückte hervorzuheben und somit der revolutionären Ideologie und Propaganda genúge zu tun. Bei der Inszenierung klassischer Stucke hielten sich altere Regisseure in der Regel enger an den Text als die jüngeren. Häufig gespielt wurden Lope de Vegas "Fuenteovejuna". Shakeapeares "Othello". Schillers "Kabale und Liebe" und "Die Räuber". Ciogol's "Revisor" und Tolstojs "Macht der Finstemis". um nur einige zu nennen.

"From the point of view of consonance with the Revolution Schiller, and not Shakespeare. exemplified one of the most suitable writers. ${ }^{\text {nt }}$ So hatten zum Beispiel die beiden Schiller-Inszenierungen "Don Carlos" durch Andrej Lavrentjev und "Die Räuber" durch Boris Sužkević großen Erfolg am Bol 'soj Dramaticeskij Teatr in Petrograd. während die Inszenierungen von "Othello" und "King Lear" keinen besonderen Anklang fanden.

\footnotetext{
73 Ibrd.. S. 471

-+ Ibld.. S . 5 )
} 


\subsubsection{Evgenii Vachtangov:}

Während das Künstlertheater in Moskau Probleme hatte, da es als Hort bürgerlicher, vorrevolutionärer Kulturpflege galt.75 gewannen seine Studios immer mehr Bedeutung. Großen Erfolg hatte vor allem Stanislavkijs Schüler Jevgenij B. Vachtangov als Leiter des dritten Studios.

"Wachtangow übermahm 1914 die Leitung einer Studentenbühne. die 1917 die Bezeichnung 'Moskauer Dramatisches Studio unter Leitung J.B. Wachtangows' erhielt. Mit der Oktoberrevolution sympathisierte Wachtangov von der ersten Stunde an. In seinen Inszenierungen spielte das politische Moment jedoch keine Rolle. Sein Stil wird als 'phantasievoller' Realismus charakterisient. er entwickelte ihn in der Auseinandersetzung mit Meyerhold und seinem Lehrer Stanislawski." 76

"Er verzichtete auf die völlige Identifikation von Schauspieler und Rolle und betonte das artistische Moment in der Darstellung. dabei viele traditionelle Formen (Commedia dell'arte) ubbernehmend. Von Meyerhold unterschied ihn jedoch u.a. die feinere Individualisierung der Gestalten, der Verzicht auf soziologische Schemata und mechanische Spielelemente, worin Wachtangow seinem Lehrer Stanislawski verbunden blieb. Seine Inszenierungen waren von großer Sensibilitäı und Musikalität. voller Lyrismus und Phanlastik." $n$

Einen der größten Erfolge halte Vachtangov mil der Inszenierung von Carlo Gozzis Märchen "Prinzessin Turandot", die am 28. Februar 1922 im dritten Studio des MCHAT Premiere hatte, wenige Wochen vor dem Tod des Regisseurs.

\subsubsection{Sergej Radiov}

1920 gründete der junge Regisseur Sergej Radlov in Petrograd das kleine Theater der "Populären Komödie". Radlov, ein Schüler Mejerchol 'ds. vertrat den Standpunkt, daß eine zeitgenössische Theaterform nur durch "Theater-

\footnotetext{
75 Brauncik (1\%). S. 54.

76 Braunecti (19\%6). S. 368.

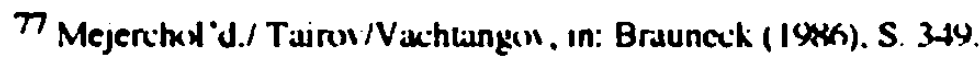


traditionalismus" und "verbale Improvisation des Schauspielers" erreicht werden könne.

'The principle of 'theatrical traditionalism' was meant to bring about the immediacy of the so-called primitive, popular work of art, the ideal of which Radlov associated with the clowning of the circus artist." 78

Nach dem Prinzip der "verbalen Improvisation" sollten die Schauspieler nur die Art des Dialoges. den äußeren Handlungsrahmen vorgegeben bekommen. der eigentliche Wortaustausch während des Stückes sollte jedoch durch spontane Improvisation entstehen. Da die ernsten Dramengenres aber vollkommen durch den festgesetzten Text bestimmt werden, beschränkte Radlov sich ausschließlich auf die Komödie.

"Every member of the cast was allowed. and in fact obliged. to say everything that came to mind.The main criterion for success lay in the audience response: the more often and the more loudly they burst out laughing. the better. Topical jokes about current events. remarks unexpectedly directed at the audience and informal, familiar banter with spectators were encouraged." 7 )

Radlov engagierte die namhaftesten Zirkuskünstler dieser Zeit. Die Vorstellungen der "Populären Komödie" entfernten sich immer mehr von ihrem IIrsprung der Commedia dell'arte und entwickelten sich schnell zu Varieté- und Zirkusvorstellungen. Selbst kurze Filmsequenzen baute er in seine Produktionen ein, wie es schon vom italienischen Futurismus her bekannt war. Radlov war es auch, der den italienischen Futurismus in das nachrevolutionäre Theater einfuhrte. um es dadurch seiner Zeit anzupassen.

Die Inszenierung seines Stückes "das Plegekind" ("Priemys") von 1920 war "a Futurist thriller and action drama based on the model of dime store detective novels with all the ingredients Marinetti could ever have wished for. ${ }^{n(x)}$ Inhaltlich dreht sich das Stuick um die Verfolgung eines Diehes. der fur die Sowjets wichtige Papiere gestohlen hat. Sie beginnt mit der Jagd um die Tische eines Restaurants, die sich auf der Straße und uber Hausdächer fortsetzt..

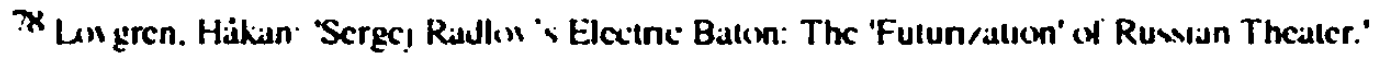

In. Klcbery Nils:un (1944). S. 105.

") Rudnickis ( I $\$$ Sx). S. 57.

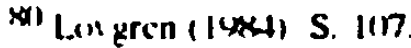


"The theme of the stolen documents was clearly no more than
a pretext for realizing an 'urban spectacle' in which the stage
decorations, the death-defying feats of the thief and the
'cinematographic speed' (kinematograficeskaja skorost') with
which they were performed played the leading role."

Die Rolle des Diebes spielte der Clown Serz. der kurze Zeit später auch bei der FEKS mitarbeitete. Besonders deren erste Theater- und Filmproduktionen haben so große Ähnlichkeit mit Radlovs Inszenierungen, daß dieser 1922 nach der Aufführung des FEKS-Stückes "Die Heirat" sich beklagte, sie hätte sein Patent gestohlen. Und der erste Film der FEKS "Die Abenteuer der Oktjabrina" ("Pochozdenija Oktjabriny") erscheint fast wie ein Remake des "Pllegekindes".

Radlov wurde für seine Entwicklung heftig kritisien und aufgefordert, sich um die politische Satire zu kümmern. Wie die FEKS. die seinen Stil teilweise ubbernahm und ausbaute, paßte er nicht in die offizielle sowjetische Kunstdoktrin. weil er zu unpolitisch war und Späße trieb statt Propaganda.

Nur einmal versuchte er sich an der Inszenierung einer politischen Satire. Es war das Stück "Rabotjaga Slovocotov". das Gor`kij für die "Populäre Komödie" geschrieben hatte. ${ }^{* 2}$ Radlovs Schauspieler waren jedoch so auf ihre Possen eingespielt, daB die Satire zum Slapstick gedieh. Von nun an inszenierte Radlov nur noch klassische Stücke. jedoch ohne Erfolg und 1922 w urde die "Populare Komodie" geschlossen. Die Idee der Futurisierung und damit Aktualisierung des Theaters durch den Zirkus hatte aber auch andere Regisseure überzeugt und wurde noch im gleichen Jahr nicht nur von der FEKS in Petrograd, sondem auch von Mejerchol' $d$ und Ejzenstejn in Moskau aufgegriffen. ${ }^{\mathrm{X}}$

\subsubsection{Theateroktober}

Im August 1920 übergab Lunacarskij Mejerchol'd die Leitung der

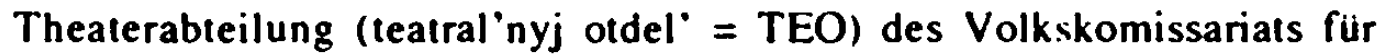

XI Lex. cill.

62 Siche: Sklor skij. V. In: Naubbrowo (1928). S. S.

83 Siche dayu den Absichnitl uber Ej/enstcjns Theatcrarbeit an Mlcrkiaus Proletiul't. 1.2.11. 
"Theateroktober" gegeben. den Mejerchol'd am 27. August 1920 in der Izvestija proklamierte.

"Meyerhold's actions were no less dramatic than his appearance: he transformed the bureaucratic and ineffectual Theatre Department into a military headquarters and proclaimed the advent of the October Revolution in the theatre."

Mejerchol'd teilte nach dem Vorbild des Burgerkriegs die Theaterwelt in "Links" und "Rechts". d.h. revolutionär und reaktionär. Uneingeschränkt unterstützte er alle Künstler, die sich der Revolution verschrieben hatten, und startete einen polemischen Feldzug gegen die traditionelle Kunst. vor allem gegen die akademischen Theater.

'The 'leftists' were essentially guided by a very simple criterion: whatever is new is good. Everything old. everything which existed before the revolution, all the plays, traditions, methods and skills of the craft. must, in their opinion, be discarded and destroyed, and the sooner the better. (...) The programme Theatrical October'. advanced by the 'leftists' as its name suggests. presupposed that theatrical 'revolution' should directly follow the social revolution. that the old an must be destroyed without delay and a new ant created on its ruins. "8.5

Die Zeitschrift "Vestnik teatra", die bisher völlig unpolitisch über Ereignisse in der Theaterwelt berichtet hatte. wurde unter Mejerchol 'ds Einfluß zum Sprachrohr des "Theateroktober" und publizierte äußerst scharfe und aggressive Angriffe gegen die akademischen Theater und ihre Künstler. ${ }^{8 \%}$ Hier geriet Mejerchol'd in Konflikt mit Lunačarskij und dem Narkompros. Zwar sah das Narkompros eine seiner beiden Hauptaufgaben in der revolutionär-kreativen Formierung eines neuen Theaters, auf der anderen Seite hielt es aber die Erhaltung der besten traditionellen Theater als Zeugen und Venwalter der künstlerischen Tradition für unerläßlich.\$7

Zur Realisierung des "Theateroktober" eröffnete Mejerchol'd sein eigenes Theater, das er "RSFSR Theater Nr.I" nannte und mit jungen. unerfahrenen Schauspielem besetzte. Eingeweihı wurde das Theater am 7. November 1920 mit einer Inszenierung des Stückes "Morgenröte" des belgischen Symbolisten Emile Verhaeren. Mit der Wahl dieses Stückes hatte Mejerchol'd genau das

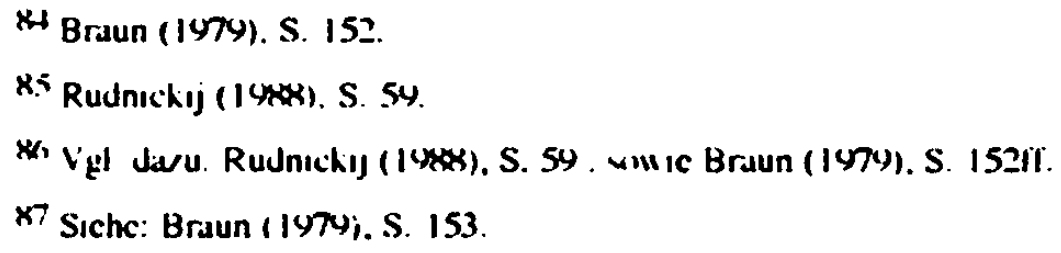


getan. was er in seiner Eröffnungsrede des Theaters angekundigt hatte. Darin hatte er gesagt: "We shall need scenarios and we shall often utilise even the classics as a basis for our theatrical creations. We shall tackle the task of adaptation without fear, and fully confident of its necessity. "

Die "Morgenröte" ("Les aubes", 1898) bildete zusammen mit "Les campagnes hallucinées" (1893) und "Les villes tentaculaires" (1895) Verhaerens soziale Trilogie. Das Stück ist ein episches Versdrama. "depicting the transformation of a capitalist war into an intermational proletarian uprising by the opposing soldiers in the mythical town of Oppidomagne. "w)

Für Mejerchol'd war einzig der soziale Aspekt des Stuickes von Bedeutung. So nahm er gemeinsam mit seinem Co-Regisseur Bebutov einschneidende Veränderungen am Text vor, um das Stück zu aktualisieren und der Situation des Bürgerkrieges in RuBland anzupassen. ${ }^{\text {x) }}$

'|... |: everything was 'just like a mass meeting'. At times two orators addressed the public at once. The lights in the auditorium were not turned off during the performances but the beams of two military searchlights. placed in the boxes. were directed on the actor/orators' faces.

Actors seated among the public were to react to the action on stage and thus draw the audience into direct interaction with the heroes. They would applaud one speaker then interrupt another's speeches with booing and hissing."

Die Produktion wurde sehr unterschiedlich aufgenommen. Lunacarskij erklärte in Zusammenhang mit der "Morgenröte", daß die Zeit des Massentheaters vorbei sei, erklärte aber auch, das Stuck sei im Großen und Ganzen ein Erfolg. Trotz Lunacarskijs Aussagen zum Massentheater inszenierte Mejerchol'd zum I. Mai 1921 am RSFSR Theater Nr.l Majakovskijs uberarteitete Version von "Mysterium buffo". Dieses Mal war der Erfolg des Stuckes so groß, daß es täglich bis zum Ende der Saison gespielt wurde. Nach dem Erfolg von "Mysterium buffo" ging jedoch die Zeit des Theateroktober langsam zu Ende.

"Meanwhile the real Civil War ended, and history drew a line under the brief period of war Communism. The victory over

\footnotetext{
\$8 'On 31 Octuber 1920), yuuted in Vestinik teatra : 1920. Nr. 72-73. S. 19/20; Att. naxh Braun (1979). S. 154.

\$) Ibid., S. 155.

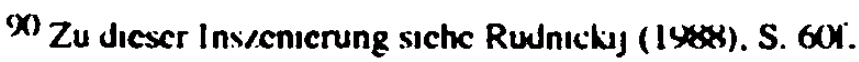

91 Ibid.. S. (x).
} 
the enemies of the Revolution which Mystery Bouffe celebrated meant the art which had arisen under the conditions of armed class struggle must now change. No one in the Theatrical October' camp comprehended this yet. Meyerhold himself was the first to realize it. or in any case. to feel the inevitability of change since he was always acutely sensitive to the shifts of the times." 92

Im Februar 1921 setzte Lunacarskij Mejerchol'd von seiner Position als Leiter der Theaterabteilung des Narkompros ab und bald verließ Mejerchol'd die TEO ganz.

Im Juni 1921 befahl der Moskauer Stadtsowjet die Schließung des RSFSR Theaters Nr. I. Nur dank Lunaçarskijs Intervention blieb es den Sommer hindurch noch geöffnet und brachte eine Inszenierung von Ibsens "Bund der Jugend" auf die Bühne. Eine revolutionierte Version von Wagners "Rienzi" jedoch wurde schon nach der zweiten Vorstellung abgesetzt. am 6. September 1921 schloß es endgültig und Mejerchol'd war ohne Theater.

\subsubsection{Das Theater zur Zeil der NEP}

Im März 1921 wurde die von Lenin verordnete Wirtschaftsform der "Neuen Ökonomischen Politik" (Novaja Ekkonomićeskaja Politika = NEP) proklamiert. Mit der NEP wurde eine begrenzte Privatwirtschaft zugelassen. gleichzeitig aber eine strikte Einsparung staatlicher Mittel diktiert. Die Wirtschaft der Sowjetunion nahm damit einen gewissen Aufschwung. für das Theater jedoch bedeutete diese Politik ungewohnte Schwierigkeiten, denn die staatlichen Subventionen wurden radikal gekürt, für manche Theater sogar gänzlich eingestellt.

"Will man die theaterpulitischen Ereignisse vom Herbst 1921 beurteilen. dann muß man sich selbstverständlich die wirtschaftliche I age des 1 andes vor Augen führen. die den Theatern nur einen minimalen Stellenwert auf der Tagesordnung zugestehen konnte. Im Bereich der Kulturpolitik mußte die vordringliche Aufgabe darin bestehen, da $B$ man dem Analphabetismus zu Leibe rückte und das Elementarwissen und kulturelle Niveau der Arbeiter- und Bauembevölkerung verbesserte. $|\ldots|^{(n) .3}$

\footnotetext{
12 Ibid.. S. 64.

"3? Vtauland-Hansen (I (xw1), S. 71
} 
Dennoch setzte sich Lunačarskij sehr für die Theater ein. vor allem für die traditionellen. So konnte er durchsetzen, daß gerade diese nicht geschlossen, sondern weiter subventionien wurden. Die avantgardistischen Theater jedoch hatten mit großen finanziellen Schwierigkeiten zu kämpfen. Als Mejerchol'd am 3. Oktober 1921 zum Leiter der Staatlichen höheren Regiewerkstätten (Gosudarstvennye vy̌̌čee režisserskie masterskie = GVRM: GVRYM) emannt wurde, atmeten die Kïnstler der Avantgarde auf, denn das bedeutete, daß Mejerchol'd und seine Anhänger ihre Arbeit weiterführen konnten, wenn auch ohne den offiziellen Status. ${ }^{24}$

\subsubsection{Mejerchol'ds Biomechanik}

Mejerchol'd versammelte einen Kreis von Studenten. die sich für die Errichtung eines proletarischen Theaters und damit für sein eigenes Ziel begeisterten.

"Amongst those who enrolled the first course were the future
filmdirectors Sergei Eisenstein. Sergei Yutkevich. and Nikolai
Ekk. together with many others who were to become leading
actors and directors in the Soviet theatre and cinema."

Mejerchol'd wandte sich jetzt ganz der pädagogischen Tätigkeit zu und "arbeitete ein physisches Trainingsprogramm aus. das unter der Bezeichnung BIOMECHANIK in die Theatergeschichte des 20. Jahrhunderts einging. " ${ }^{\text {'K }}$ In der Biomechanik sah Mejerchol'd die logische Konsequenz der sich verändernden Arbeits- und Produktionsbedingungen dieser Zeit. Die Einstellung zur Arbeit würde sich grundlegend ändem in einer Zeit,

"...wo die Arbeit nicht mehr als Fluch empfunden wird. sondem als freudige Lebensnotwendigkeit.

Unter diesen idealen Arbeitsbedingungen muß die Kunst natïrtich ein neues Fundament erhalten." "n

\footnotetext{
24 Vgl. ibid., S. 72.

95 Braun ( (979). S. 162.

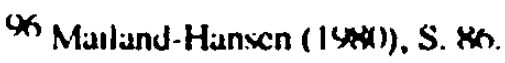

'77 Mejercher'd. Vscictlod: 'Der Schiluspicler der Zukunli und dic Bismechannik.' (1922) In:

Tictze. Rexemanc (Hg.): "Wseu olded Meyerheld: Theatcrarbeit 1917-19.30." Munchen 1074. S. 72.
} 
Die Grundlagen dafür waren offensichtlich die Theorien der wissenschaftlichen Organisation von Arbeit, wie sie von dem Amerikaner Frederick W. Taylor, sowie dem Metallarbeiter und proletarischen Dichter A.K. Gastev vertreten wurden. Taylor hatte zu Beginn des Jahrhunderts eine "allgemein als Taylorismus bekannte Methode |entwickelt|. durch Zeit- und Bewegungsstudien Verlustzeiten bei der industriellen Fertigung einzuschränken....'p. Taylor ging es dabei natürlich vor allem um die größtmögliche Nutzung menschlicher Arbeitskraft und einer damit verbundenen Steigerung des wirtschaftlichen Profits und weniger um die Freude des Arbeiters an seiner Arbeit.

Gastev gehörte der "vom Proletkul't abgespaltenen Gruppe proletarischer Dichter 'Kuznica' (Die Schmiede) an"(x) und grüdete 1920 das Zentrale Institut fur Arbeit CIT. "in dem versucht wurde, das amerikanische Taylorsystem der Arteitsorganisation auf russische Verhältnisse anzuwenden. "1100 Mejerchol'd wollte den Taylorismus nun auch auf die Schauspieler anwenden.

"...denn die Kunst ist laut Mejerchol'd die Organisation von Material, das heißt fur den Schauspieler. die Beherrschung der Ausdrucksmittel seines Körpers. Mejerchol'd führt die Forderung der Konstruktivisten an, wonach der Künstler Ingenieur zu sein habe. und verlangt selbst. daß die Kunst auf einer wissenschaftlichen Grundlage zu ruhen habe." 101

Vor allem aber ging es um die "Beherrschung der mechanischen Gesetze des Körpers. die spezifische Körpersprache des Schauspielers und die theatralischen Grundbegriffe" ${ }^{\prime \prime 2}$ die dieser zu lernen habe. Mejerchol' $d$ brachte das Ganze auf folgende Formel:

${ }^{n} N=A 1+A 2$, wobei $N$ der Schauspieler ist. Al der Konstrukteur. der eine bestimmte Absicht hat und Anweisungen zur Realisierung dieser Absicht gibt. A2 ist der Körper des Schauspielers, der die Aufgaben des Konstrukteurs (des ersten $A$ ) ausfuhrt und realisiert. "1(1).3

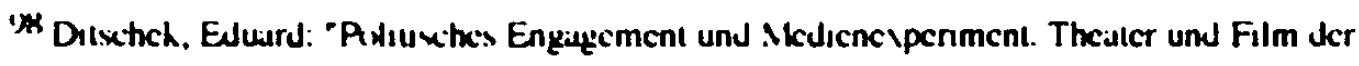

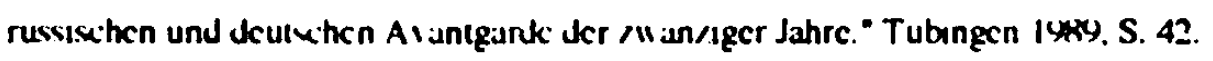

P) Pacch (1974). S. $3(1) 3$.

1(x) Lex: (ill.

IIII Mauland-Hansen ( I $x \times 1)$. S. $\$ x$

1112 Ibid.. S. XX1

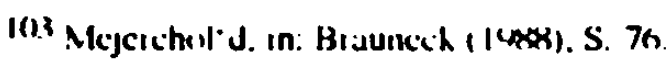


Praktisch bestand die Biomechanik aus einer Reihe von Grundübungen. die einerseits der Verinnerlichung von zweckorientierten Bewegungen und andererseits der Wiederbelebung natürlicher Bewegungen dienen sollte. wie sie bei Kindern oder Tieren noch zu beobachten sind. Diese Übungen wurden jedoch nicht auf der Buihne angewandt, sondern waren reine Trainingsmethode. "Die tiefere Grundlage (und das letztliche Ziel) der Biomechanik liegt in dem Schlüsselbegriff 'reflektornaja vozbudimost" (reflektorische Erregbarkeit)" "14 Das bedeutete für Mejerchol' $d$. daß der Schauspieler durch seine Körperhaltung die beim Zuschauer erwünschte Emotion hervorruft. Wenn er beispielsweise die Körperhaltung eines traurigen Menschen einnimmt, wird er als Reflexion das Gefühl von Traurigkeit beim Zuschauer hervorrufen. ${ }^{105}$ Mejerchol'd erklän das folgendermaßen:

"Jeder psychische Zustand wird durch bestimmte physiologische Prozesse hervorgerufen. Indem der Schauspieler die richtige Lösung seines physischen Zustands herausfindet. erreicht er die Ausgangsstellung. wo bei ihm die ERREGBARKEIT aufkommt. die die Zuschauer ansteckt, einbezieht (das. was wir früher 'Erobem des Zuschauers' nannten) und was das Wesen seines Spiels ausmacht." ${ }^{\prime(x,}$

In der Methode der Biomechanik sah Mejerchol' $d$ das genaue Gegenstück zu Stanislavkijs Methode. die er durch das Hineinleben des Schauspielers in seine Rolle als eine Bewegung vom Inneren zum Äußeren sah. während er für seine Schauspieler eine Bewegung vom Äußeren zum Inneren forderte.

"That is. biomechanics allows the actor. perfectly controlling his body and movements. firstly. to be expressive in dialogues: secondly, to be the master of the theatrical space: and thirdly. in integrating with the crowd scene, the grouping. to impart to it his energy and will." 1 (17

Mejerchol'ds erste Inszenierung nach der Methode der Biomechanik war Fernand Crommelyncks "Le Cocu magnifique" ("Velikodusnyj rogonosec": "Der großmütige Hahnrei"), die am 25. April 1922 Premiere hatte. Getreu den Forderungen des Konstruktivismus glich die Bühne einer Werkstatt, die Schauspieler waren ungeschminkt und in Arteitskleidung. sie konnten sich also nicht mehr auf die gewohnten Requisiten stützen. d.h.

\footnotetext{
I(L Mauland-Hanicn. ( $(9 x))$. S. (x).

IOS Vgl. Ibid.. S. YXY.

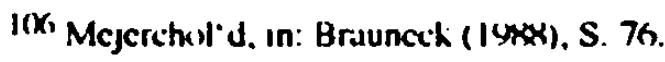

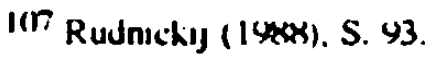


"Der großmütige Hahnrei"), die am 25. April 1922 Premiere hatte. Getreu den Forderungen des Konstruktivismus glich die Bühne einer Werkstatl, die Schauspieler waren ungeschminkt und in Arbeitskleidung. sie konnten sich also nicht mehr auf die gewohnten Requisiten stiutzen. d.h.

"...sie waren gezwungen, ihre Körper ausdrücken zu lassen, was fruher Schminke. Kostume und Perucken geschafft hatten. Um die verschiedenen Rollen markieren zu können. mußten die Schauspieler auch sehr gut zusammenspielen; statt individuell zu brillieren. mußten sie einander helfen. damit die einzelnen Rollen Profil ertielten." ${ }^{103}$

Mejerchol'ds Biomechanik beeinflußte bald auch andere Künstler, wie zum Beispiel Arvatov und Ejzenstejn. Sie waren der Ansicht, daß analog zur Ideologie auch die Kunst geänden werden müsse und sahen eine Möglichkeit dazu in der Methode der Biomechanik.

"Zu diesem Zweck hatten Ejzenstejn und Arvatov am Moskauer Proletkul'ttheater u.a. die Disziplinen wissenschaftliche Arbeitsorganisation. Psychotechnik, individuelle und kollektive kinetische Konstruktionen usw. eingefürt. also das gleiche Programm wie an Mejerchol'ds Theaterschule." I(x)

Ejzenstejn hatte vor seinem Eintritt als Student in Mejerchol 'ds Staalliche Regiewerkstätten bereits Theaterarbeit an der Front und im Moskauer Proletkul't geleistet. den er entscheidend mitprägte.

\subsubsection{Serqej Eizenstejns Theaterarbeil am Moskauer Proletkul'it}

Als eigentlichen geschichtlichen Beginn des I. Arbeitentheaters des Proletkul't nennt Paech die Inszenierung "Der Mexikaner" vom 10. März 1921 durch Smyśljaev und Ejzenstejn. "' Diese Inszenierung einer von Arvatov bearbeiteten Erzählung Jack Londons war aber auch ein Meilenstein in der Theaterarbeit Sergcj M. Ejzenstejns. Er war 1920 als Buhnenbildner ans 1 . Arbeitertheater des Proletkul' $ı$ gekommen. Zuvor hatte er im Fronttheater

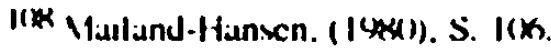

I(x) Ibid. S I(x).

111 Paich (1974). S. 310.
} 
"Eisenstein war eigentlich als Bühnenbildner engagiert worden, hatte aber im Laufe der Arbeit immer mehr in die Regiearbeit eingegriffen. so daB er dann in seinem ersten theoretischen Aufsatz 'Die Montage der Attraktionen' mit gutem Grund von seiner Inszenierung sprechen und den 'Mexikaner' an den Anfang der von ihm vertretenen Linie des 'Agitationstheaters der Attraktionen' stellen konnte." III2

Im "Mexikaner" geht es um eine mexikanische Untergrundgruppe, die einen Aufstand gegen die Regierung plant. Zur Durchfiihrung des Planes benötigt sie jedoch 5000 Dollar zum Kauf von Waffen. Einer der Untergrundkämpfer will das Geld durch einen Boxkampf beschaffen, wobei er fuir die Niederlage Geld bekommen sollte, er kann jedoch nicht iber seinen Schatten springen und gewinnt den Kampf.

"Im Mittelpunkt des Stuickes steht der Boxkampf. Eisenstein erzählt. 113 daß er in typischer MCHAT-Manier hinter den Kulissen stattfinden sollte. |... Eisenstein und Arvatov setzten nun durch. daß der Boxkampf ganz real auf offener Bühne gekämpft wurde. Und zwar nicht auf einer nur nach einer Seite offenen Guckkastenbühne, sondern im Proszenium, wo ein wirklicher Boxring aufgebaut wurde: |... | Das signalisiert genau jene Annäherung von Theater und Leben, die Eisenstein und Arvatov im Varieté. im Zirkus verwirklicht sahen." IIt

Denn dort miissen die Akteure im Gegensatz zum Theater ihre Taten real vollbringen. Mit dieser Einstellung lagen sie analog zu Radlov. Die Konkretheit ist zudem eine Voraussetzung für die direkte Einbeziehung und Beeinflussung des Publikums, woraus Ejzenštejn in Zusammenarbeit mit Arvatov und Tret "jakov später seine "Montage der Attraktionen" entwickelte. So wurde im "Mexikaner" ein fiktives aus Schauspielern bestehendes Publikum direkt um den Boxring herum plaziert, das den Champion anfeuerte, während das wirkliche Publikum natürlich zu dem Helden des Stückes, dem Untergrundkämpfer hielt. Es entstand also eine Situation wie bei einem realen Boxkampf, "und man kann sich gut vorstellen. zu welch mitreißenden Anfeuerungsschlachten es dabei gekommen sein mag. "115

\footnotetext{
112 Lox. cit.

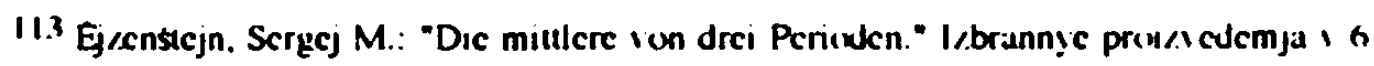
tomach. Bd.5. Moskiau 1968. S. 53-78.

114 Hiclscher (1973), S. 65.

115 Lx: cit.
} 
Während der "Mexikaner" beim Publikum großen Erfolg hatte. wurde er von offizieller Seite als zu bürgerlich abgelehnt, da er nicht den Existenzkampf der Massen zeige. sondem nur den Kampf eines einzelnen Boxers. ${ }^{116}$ Bei den Inszenierungen "Morgenröte des Proletkul't" (eine Zusammenstellung von Werken proletarischer Dichter) vom Mai 1921 und Pletnevs "Lena" durch Smyśljaev im Oktober 1921 arbeitete Ejzenśtejn uieder als Bühnenbildner. Als er Ende 1921 in Zusammenarbeit mit Smysljaev Pletnevs Stuick "Über die Schlucht" inszenieren sollte, entstanden unuiberwindliche Schwierigkeiten zwischen beiden. sodaß Ejzenštejn noch vor der Premiere den Proletkul't verließ und. wie bereits erwähnt, in Mejerchol'ds Staatliche Regiewerkstätten eintrat, wo er bis Winter 1922 als Bühnenbildner und später als Regieassistent arbeitete. Gleichzeitig arbeitete er in der Werkstatt Nikolaj Foreggers (Masterskaja Foreggera, Mastfor), wo er mit Zirkus, Varieté und Akrobatik als Theaterformen bekannt wurde. 117 So erwies sich diese "Pause" vom Proletkul't als sehr ergiebig für Ejzenštejn, was sich nach seiner Rückkehr dorthin in seiner weiteren Theaterarbeit zeigte. Nach seiner Rückkehr zum Proletkul't begaben sich Arvatov und Ejzenśtejn an die Umorientierung des Moskauer Proletkul't.

"Die Theaterarbeit haben Boris Arvatov und Sergej Eisenstein gemeinsam auf eine neue Grundlage gestellt. $|\ldots|$ "'Die Grundlagen dieses Entwurfs' - heißt es in einer Chronik der Arbeit des Moskauer Proletkul ${ }^{\prime}$ I' ${ }^{\prime K}$. bilden auf der einen Seite das Prinzip der Anwendung der sog. 'kleinen Formen' des Theaters (Kabarell. Varieté) und des Zirkus - als der Formen. die bei entsprechender Bearteitung die größte soziale Wirkung haben - auf der anderen Seite das Prinzip der Erziehung eines neuen Schauspielers und Regisseurs. die in Zukunft nicht nur auf den Brettern des Theaters Handlung organisieren werden. sondern auch unmittelbar im Leben (Meetings. Demonstrationszuge. Feste u.a. $)^{\text {"1 } 14}$

Fur Ejzenstejn und Arvatov ging es dabei besonders um die verstarkte Konzentration auf den Zuschauer.

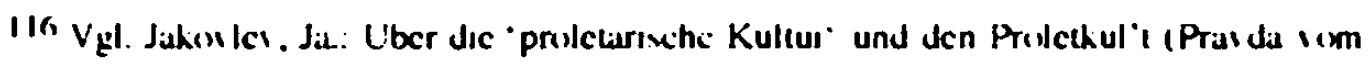
24. 25. Okluber 1922: nach V.l.Lenin: "O litcrature I 1/husstic." Mlixhia 197h. S. 5\% 612) Uben. 1. Karl Eimeinseher, in Girsen/Knowler-Bunte: Prolethult I (1974). S. 22111.

117 Vyl. Hiclscher ( 1973). S. 17

IIX "Grorm VIII." Mindisu 1423. S. 241.

111) Hiclucther (14731. S. ox.
} 
"Als Hauptmaterial des Theaters wird der Zuschauer herausgestellt: die Formung des Zuschauers in eine gewünschte Richtung (Gestimmtheit) - die Aufgabe jedes utilitaren Theaters (Agitation. Reklame, Gesundheitsaufklärung usw.).Werkzeug zur Bearbeitung sind alle Bestandteile des Theaterapparats (das 'Gemurmel' Ostużevs nicht mehr als die Farbe des Trikots der Primadonna, (...|). die in all ihrer Verschiedenartigkeit auf eine Einheit zuruick führbar sind. die ihr Vorhandensein legitimiert, auf ihren Attraktionscha. rakter." 120

Damit hatte Ejzenštejn die "Montage der Attraktionen" entwickelt. Er schrieb diesen Aufsatz jedoch erst nach der Inszenierung von Ostrovskijs Stiuck "Eine Dummheit macht auch der Gescheiteste" im Mai 1923. Diese Inszenierung war Ejzenstejns erste selbständige Regiearbeit. In Zusammenarbeit mit Sergej Tret'jakov arbeitete er Ostrovskijs Komödie zu einer aktuellen politischen Satire um, in der Absicht gegen den 1923 - anläßlich seines 100. Geburtstages - wieder gefeierten Schriftsteller zu polemisieren. Die Handlung wurde in die NEP-Zeit verlegt.

"Der Text von Tret 'jakov war voller aktueller politischer und kulturpolitischer Anspielungen. die Ostrovskijschen Figuren wurden in Karikaturen der Feindgestalten Joffre. Miljukov. Curzon, des NEP-manns, des Faschisten usw. umgestaltet. Man arbeitete mit Clownerien. Parodien. Couplets, Tanz. akrobatischen Kunststuicken. Wort- und Sprachspielen usw." 121

In diesen Inszenierungen entwickelte Ejzenstejn, wie bereits erwähnt. seine "Montage der Attraktionen" und versuchte die wichtigsten Punkte, die Arvatov für das neue Theater forderte, in die Praxis umzusetzen, nämlich die Ablösung des realistisch darstellenden Theaters durch realistisch handelndes Theater, Ablegung festgelegter ästhetischer Richtlinien. Entfernung von überkommenem Theaterrepertoire und Loslösung der Handlung vom geschlossenen Sujet. ${ }^{122}$ Wenn auch die Wirkung der Attraktionen nicht immer die beabsichtigte war - die Zuschauer bewunderten auch die akrobatischen Leistungen der negativen Charaktere - so kann man doch davon ausgehen. "daß die Inszenierung eine wichtige Etappe darstellt auf dem Weg

120 Ejzenstejn. Scrgej M.: 'Dic Muntage Jer Auraktuonen. Zur Ins/cnicrung vin A.N. Ostrovskijs 'Eine Dummheit macht auch der Gescheıtestc im Moskaucr Prolctivult'.' In: "Ästhetık und Kımmunikation." Heli 13, Jg. 4. Des. 1973. S. 76.

121 Hiclscher (1973), S. 6*8.

122 vgl. Ibid., S. 69. 
zu einer neu verstandenen Funktionalität /d. h. Agitation und Propaganda, d. Verf.| des Theaters." 123

Die nächste Inszenierung Ejzenštejns und Tret'jakovs "Hörst du, Moskau?!", uraufgeführt am 7. November 1923, zeigt, wie sehr sie sich um eine Verbesserung und Weiterführung der Montage der Altraktionen bemühten. Tret jakov hatte dieses Stück in Anlehnung an die Arbeiteraufstände in Hamburg und Sachsen 1923 geschrieben. "Die Solidarität mit dem Kampf der deutschen Arbeiter würde die bisher vermißte psychische Vereinigung der Zuschauer bewirken." 124 Die erhoffte Wirkung trat aber offenbar nur vordergründig ein. Karia Hielscher beschreibt, wie sich die aufgeladenen Emotionen des Publikums im 4. Akt, beim Sturm der Arbeiter auf die Bühne. explosionsartig entladen, sie bezweifelt jedoch. daß diese unmittelbare, heftige Reaktion des Publikums von Ejzenštejn beabsichtigt war.

"Dabei war doch das Ziel der Aufführung. die intemationale Solidarität der Arbeiter zu stärken, ja zur direkten Waffenhilfe für die deutschen Revolutionäre aufzurufen." 125

Daß dieses Ziel mit "Hörst du, Moskau?!" noch nicht erreicht wurde, erklärt Tret'jakov damit, daß für das Publikum eine direkte Beteiligung an den historischen Freignissen nicht mehr möglich, und daß das Publikum in sich nicht einheitlich war. ${ }^{126}$ Aus diesem Grund wählten Tret jakov und Ejzenstejn für die nächste Inszenierung ein Stück und einen Aufführungsort, durch die das Publikum unmittelbar angesprochen werden sollte.

Dieses Stück - "Gasmasken" ("Protivogazy") - wurde am 29. Februar 1924 im Moskauer Gaswerk uraufgeführt. Es spielt in der NEP-Zeit und handelt von Arbeitern eines Gaswerkes, die unter Einsatz ihres Lebens die Hauptgasleitung reparieren, obwohl der Fabrikdirektor keine Gasmasken zur Verfügung stellt.

Mit dieser Inszenierung hatten Ejzenštejn und Tret ’jakov den Sprung vom Theater ins Leben gewagt. "Hier wurde auf unmittelbare und sicherlich fragwürdige Weise versucht, auf dem Gebiet des Theaters Kunst und

\footnotetext{
123 Lox. cit.

124 Pacch (1974). S. 316.

125 Hiclscher (1973), S. 72.

126 Treljakion. Sergej: 'Das Thealer Jer Altrakuonen. dic Auffuhrung "Eine Dummheil maxht auch der Geschetieste" und "Horst du. Minkiau?!" Im Enten Arbeiteriheater des Proleckult: In: Gorsen Knexdler-Bunic (1974), Bd.2. S. 217.
} 
Produktion zu verschmelzen. "127 Karla Hielscher erläutert weiterhin. daß dieser Versuch nicht gelingen konnte. denn "eine wirkliche Verschmelzung der Elemente des Faktischen, der Produktion und der Produktionsumgebung und der schließlich doch gespielten fiktiven Handlung konnte es nicht geben. " 138 Ejzenštejn hatte das sehr bald erkannt. Er sah hier die Grenzen des Theaters, das an reale Zeit und realen Raum gebunden ist. Als logische Konsequenz ergab sich für ihn hier der Übergang vom Theater zum Film, da dieser auf optischer Täuschung basiert, die durch die Montage der Bilder entsteht. deren Reihenfolge wiederum der Regisseur nach der von ihm verfolgten Absicht bestimmt.

"Die filmische Aussage entsteht durch Aneinanderreihung von Einzelbildern und Bildsequenzen, die sukzessiv und kontinuierlich. die aber auch kontrastiv und kommentierend verlaufen kann. Montage ist somit, anders als im Theater, ein Wesensmerkmal des Films." 129

Die Montage der Attraktionen umso mehr, als die Attraktionen durch filmische Mittel wirkungsvoller und gezielter erartheitet werden können. So ging Ejzenstejns Theaterarbeit logisch konsequent in seine Filmarbeit über.

\subsubsection{LEF}

Einige Grundgedanken. die der Arbeit von Ejzenstejn aber auch Arvatov. Tret 'jakov. Majakovskij und nicht zuletzt der Fèksy zugrunde lagen, wurden vertreten in der Gruppe der LEF (Levyj front iskusstv. Linke Front der Kïnste), die von 1923 bis 1925 auch eine gleichnamige Zeitschrift herausbrachte. "Dieser (zuweilen heterogene) Kreis bestand aus ehemaligen Futuristen, Proletkul't-Leuten. Produktionskinstlern, Konstruktivisten, Formalisten u.a. ${ }^{n}{ }^{1.30}$

\footnotetext{
127 Hiclseher (1973). S. 73.

128 Lox. cit.

129 Dilschek (1985). S. 111.

${ }^{1.30}$ Mauland-Hansen ( I $\left.4(x)\right)$. S. 83.
} 
Einer der wichtigsten Punkte für die LEF-I cule war der enge Bezug der Kunst zur sozialen Wirklichkeit. Die Kunst als solche lehnten sie ab und vertraten die Auffassung, daß Kunst utilitaristisch sein solle.

"They considered a newspaper story to be much more important than a poem or a novel, a documentary film more ne-

- cessary than an art film and applied ar (ceramics. design) more useful than easel painting. In their view an should be used to make all human activities more intelligent, rational. functionally precise and economical. When the members of L.EF called for 'revolution of form'. they had in mind the creation of asthetic forms which could be infused into everyday life and which would then quickly change that life. Art was seen as an instrument capable of transforming both man and society in accordance with 'clear thinking and intellect'." 1.31

Gefordert wurde also eine Produktionkunst, wie sie sich im Konstruktivismus der bildenden Künste gezeigt hatte. Die Literatur sollte hier nachziehen und unter dem von Cuzak geprägten Begriff "ziznestroenie" (Lebenbauen) bearbeitet werden. ${ }^{132}$ Auf Kosten der Ästhetik sollte die Kunst zum Werkzeug werden. mittels dessen die Kiinstler am politischen und sozialen Entwicklıngsprozess der Gesellschaft mitarbeiten wïrden.

In Bezug auf das Theater wurde von den meisten LEF-Leuten die Meinung vertreten. das Theater sei nutzlos und könne überhaupt abgeschafft werden. Das einzige. was man iibernehmen solle. sei Mejerchol'ds Methode der Biomechanik. nach der man die Arbeiter unterrichten könne. damit sie lemen wiirden ihren Körper zu beherrschen und sich die für den Arbeitsprozess effektivsten Bewegungen anzueignen. Trotz dieser negativen Einstellung zum Theater waren viele I.EF-Leute vom Theater gefesselt und arbeiteten dort. wie z.B. Tret jakov. Ejzenstejn. die Fèksy oder Ljubov` Popova.

Auch entwickelte sich das Theater zu jener Zeit in alle Richtungen der verschiedensten Nachbargenres. "The theatre was 'music-hallized'. 'circusized' and 'cinematographized'." 1.3.3

\footnotetext{
131 RuJnichis I I (yx). S. X4.

$132 \mathrm{Vgl}$. Malland-Hansen ( $\mid(x)$ ). S. X.5.

133 Ibid. S. "1
} 


\subsubsection{Mastfor}

Der Name des deutschstämmigen Barons Nikolaj Michajlovič Foregger von Greifentun ist untrennbar verbunden mit dem Versuch. Theater und music-hall zu verbinden. Beruihmtheit erlangte er vor allem mit seiner 1921 in Moskau gegründeten Theaterwerkstatt (Mastfor=Masterskaja Foreggera). Foregger. der urspringlich klassische Philologie studiert und sich danach intensiv mit dem antiken und mittelalterlichen Theater heschäftigt hatte. war der Meinung. man könne die traditionellen Formen der Kunst und besonders des Theaters am besten durch Parodierung dieser Formen überwinden. So parodierte er alles, was jemals im russischen Theater Bedeutung erlangt hatte. seien es die traditionellen Schauspielformen des MCHAT. Opern. AgitStiicke, oder sogar Mejerchol'ds Biomechanik-Inszenierung des "Großmuitigen Hahnrei" ("Velikodusnyj rogonosec"). Dabei gab es gewisse Ähnlichkeiten zwischen Foreggers Bewegungslehre und Mejerchol'ds Biomechanik.

"A certain, simplified similiarity to Meyerhold's principles of biomechanics was cultivated in Masffor, only with the proviso that movement obeyed the rythm of dance." 1.34

Damit verbunden war auch seine Überzeugung. daß jede Art von Auffuhrung musikalisch begleitet und organisiert sein sollte. Diese Uberzeugung stammte vermutlich aus der Zeit vor seiner aktiven Regiearbeit. als er sich mit dem antiken und dem mittelalterlichen Theater beschäftigte, in denen Tanz, Rhythmus und Musik eine wichtige Rolle spielten.

Gleichzeitig war Foregger ebenso begeistert von der Technik wie die LEFLeute und sah im menschlichen Körper ein zu beherrschendes Werkzeug. das durch die Ausdrucksmöglichkeiten des Tanzes zu einem expressiven Instrument wurde. Die Einbeziehung von Akrobatik und kinematographischen Elementen sollte diese Ausdrucksmöglichkeiten verstärken. Ähnlich wie Ejzenstejn und die Fèksy 1.35 sah auch Foregger die Zukunft des Theaters im Film, aber auch in der music-hall. 136

Neben Parodien auf bestehende Stiicke wurden auch Sticke eigens für die Mastfor geschrieben.

\footnotetext{
1.34 Ibid.. S. 97.

135 Siche hier/u die lidyenden Kipilel.

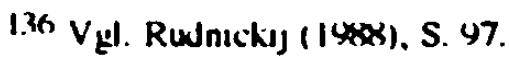


"The plays for Mastfor were written by the witty dramatist Vladimir Mass. and the music was composed by the talented Matvei Blanter. The collaborative creations of Mass and Blanter were commonly called 'parades'." 1.37

Als "best and most sensational of the Mastfor programmes" $1.3 \times$. bezeichnet Rudnickij die Inszenierung "Gutes Verhalten zu Pferden" ("Chorosee olnośenie $k$ loścadjam") nach dem Gedicht von Vladimir Majakovskij, für die Jutkevic die Dekoration erarbeitete und Ejzenstejn die Kostüme. Die Premiere fand in der Neujahrsnacht 1921/22 statt. In seinem Buch "Kontrapunkt Režissera" beschreibt Sergej Jutkevič die Kostüme. die Ejzenstejn für dieses Stiick entworfen hatte.

"Für die Schauspielerinnen, die mit liedern auftraten, hatte er an Stelle von Röcken große Drahtgestelle entworfen. an denen bunte Bänder hingen. Die Bänder waren in großen Intervallen angebracht, so daß sich dem erstaunten Blick des asketisch erzogenen Moskauer Zuschauers dieser Jahre der Anblick wohlgestalteter Schauspielerinnenbeine bot. Den Poet-Imaginist (das Programm beinhaltete eine Parodie auf Esenin Kusikov - Mariengof) kleidete er genauso geistreich. Ejzenstejn teilte ihn in zwei Hälften: auf der linken - ein gepunktetes Bauemhemd. Pumphosen und Stiefel, rechts - ein stilisierter Frack und Lackschuhe." 139

Die "Imaginisten" waren eine Gruppe von Schriftstellern. ähnlich den Futuristen. \&u denen Kusikov. Mariengof und vorubergehend auch Esenin gehörten. Das geteilte Kostüm diiffe dabei in erster Linie auf Esenin gemünzt sein. dessen Dichtung trotz seines großstädtisch ausschweifenden Lebensstils immer ländlich. volksliedhaft geprägt war.

So war vieles in Foreggers Theater neu und ungewohnt für das Moskauer Publikum und die Kritik. Dementsprechend unterschiedlich waren auch die Reaktionen auf die Einführung der music-hall in das Theater. Dem Vorwurf der Darstellung verkommener bourgeoiser Vergnügungen. sowie der Forderung nach Ideologie im Tanz, begegnete Foregger mit der Entwicklung der sog. "Mechanischen Tänze" ("Mechaničeskie tancy").

"It was a fairly typical music-hall dance show. To an accompaniment which imitated the swelling noise of a factory. a

\footnotetext{
1.37 Lx. cill.

1.38 Lex: cit.

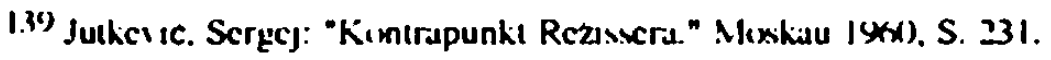


similiarity to a complex mechanism was created from human bodies." $1+(1)$

Dieses Tanzprogramm wurde ein allgemeiner Erfolg. der sogar bis nach New York drang. $1+1$

Doch Foreggers Erfolg hielt nicht lange an. In der Mastfor entstand nichts Neues mehr.

"Aus ihren Stücken verschwanden Aktualität und parodistische Schärfe. Die Suchen nach Unterhaltungen. die Foregger unternahn. untergruben die Prinzipien. die er selbst zwei Jahre zuvor verkundet hatte. "1+2

Im Zuge dieser Entwicklung verließen die besten Mitarbeiter die Mastfor; als erster Ejzenstejn, darauf Jutkevič und Mass. Im Januar 1924 zerstörte ein Feuer sämtliche Räumlichkeiten und Kostime der Mastfor."Nach diesem Schlag gelang es dem Theater nicht mehr wirklich von neuem auf die Beine zu kommen." $1+3$

Die Revolutionierung des Theaters als Folge der Oktoberrevolution. die "den provokativen Antitraditionalismus der zehner Jahre zu rechtfertigen "IH schien. war also zum bestimmenden Faktor geworden. Dabei sah ein Teil der Theater- und Kulturschaffenden seine wichtigste Aufgabe darin, das Theater zum Mittel der politischen Schulung, der Agitation und Propaganda zu machen, während ein anderer Teil vor allem für eine zeitgemäße Transformation der Theaterkunst eintrat. Ein dritter Teil versuchte beides zu verbinden.

Bei der Transformation des Theaters ging es kaum um die Erreichung der Massen und die damit verbundene politische Bedeutung des Theaters. sondern vielmehr um die Kunst an sich. Sie sollte der neuen Zeit entsprechen und durch Iitherwindung der alten Traditionen dieser Zeit angepaßt werden. Zu diesem zweiten Teil der Theater- und Kulturschaffenden gehörte auch die Gruppe der FEKS. In ihren Theaterinszenierungen und Filmen waren politische Ereignisse wie Revolution oder Bürgerkrieg nie Gegenstand der Handlung, sondern immer nur Hintergrund. So waren sie auch nie an die

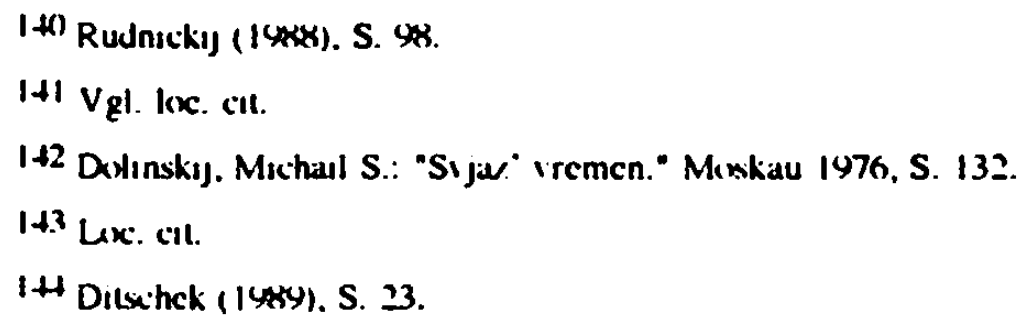


und durch Überwindung der alten Traditionen dieser Zeit angepaßt werden. Zu diesem zweiten Teil der Theater- und Kulturschaffenden gehörte auch die Gruppe der FEKS. In ihren Theaterinszenierungen und Filmen waren politische Ereignisse wie Revolution oder Bürgerkrieg nie Gegenstand der Handlung. sondern immer nur Hintergrund. So waren sie auch nie an die Masse gerichtet, oder machten diese zum Helden ihrer Produktionen. Alle FEKS-Inszenierungen hatten Individuen als Helden. Klassische Literaturvorlagen bearbeiteten sie nicht bis zur (lnkenntlichkeit. um ihnen politische Aussage zu vermitteln, sondern um sie zu parodieren (s. "Zenit"ba"). Obwohl sie in vielen Punkten mit dem Programm der LEF übereinstimmten, haben sie nicht deren Forderung nach ciner Verbindung von Kunst und Produktion im Sinne des "žiznestroenie" übemommen.

Von Mejerchol'd uibernahmen sie die wichtigsten Grundzüge seiner "Biomechanik". waren aber noch stärker von dem Teil seiner, schon in vorrevolutionärer Zeit begonnenen Arbeit beeinflußt, der sich mit den volkstümlichen Theaterformen auseinandersetzte.

Obwohl die Entwicklung der FEKS vom Theater zum Film ähnlich verlief $u$ ie hei Ejzenstejn und in ihrem Verständnis des Films grundlegende Analogien bestehen. gab es doch einen wichtigen Unterschied bei diesem Übergang. Während es Ejzenštejn u.a. um die bessere "Formung des $\mathrm{Zu}$ schauers in eine gewiinschte Richtung" (s. Anm.120) ging. sahen die Feksy im Film zunächst in erster Linie eine zeitgemäße Form der niedrigen Kunst, die ganz ihrer futuristisch geprägten Vorliebe für Technik und Geschwindigkeit entsprach und zudem bessere Möglichkeiten für die Episodisierung von Theaterstücken. sowie die Anwendung von Prinzipien aus Zirkus, music-hall und Varieté zu bieten schien.

Die größte Bedeutung im Theater zwischen 1917 und den frühen zwanziger Jahren hatten zweifellos Radlov und Foregger für die FEKS. Begeistert übernahm sie deren honsequente Parodierung der gesamten Theaterkunst mit Mitteln aus music-hall. Varieté und Zirkus. Beide gehörten auch zu dem oben beschriebenen Teil der Theater- und Kulturschaffenden. denen es weniger um die Politisierung des Theaters als um dessen Transformation ging. Von ihnen übernahmen die Fèksy die Ansicht, daß die Transformation in ein zeitgemäßes Theater und die Überwindung der klassischen Traditionen nur durch deren Parodierung erreicht werden könne. Ebenso wie später die Fèksy wurden auch Radlov und Foregger für ihre "Spielereien" und mangelnde Ernsthaftigkeit kritisiert. was im Klartexı 
Wie Kozincev. Trauberg und ihre Mitarbeiter die Vielzahl der beschriebenen Einflüssen aufnahmen und ihren eigenen Stil daraus schufen. das soll in den folgenden Kapiteln untersucht werden. 
Kapitel 2. Die Gruppe FEKS und der Begriff des "Exzentrismus"

\subsection{Die Anfänge}

\subsubsection{Die Gründung der FEKS}

Erwa zur gleichen Zeit wie die Mastfor in Moskau wurde in Petrograd die "Fabrik des exzentrischen Schauspielers" (Fabrika èkscentriceskogo aktera= FEKS) durch die Regiestudenten Grigorij Kozincev (1905-1973) und Leonid Trauberg (1902-1990), den Bühnenbildstudenten Sergej Jutkevic (1904. 1985) und den späteren Theaterkritiker Georgij Kryžickij gegründet. Die Gründung erfolgte am 5. 12. 1921 in den Räumen des Theaters "Freie Komödie" mit einem "Disput uber das exzentrische Theater". Im Frühjahr 1922 erschien dann das 'Manifest des Exzentrismus'. Die Grundlagen dieses Manifestes waren in einem Artikel Kozincers mit dem Titel "AB" enthalten. der in Form von Aphorismen geschrieben war, wie z.B.:

Gestern - Museen. Tempel. Bibliotheken.

Heute - Werke. Fabriken. Werften.

Gestem - Salons. Verbeugungen. Barone.

Heute - Geschrei von Zeitungsjungen. Skandale.

Iäm. Kulaken. Stampfen. Gerenne. ${ }^{1+5}$

Schon an diesem kurzen Beispiel zeigt sich die Begeisterung der jungen Künstler für das Varietétheater, die sog. "Straßenkunst" wie Zirkus, musichall etc. Als Erscheinungsort ihres Manifestes gaben die Feksy die Stadt "Exzentropolis' ehemals Petrograd" an und als Autoren des Manifestes wurden Grigorij Kozincev. Georgij Kryżickij, Leonid Trauberg und Sergej Jutkević genannt. Auch Ejzenśtejn war an der FEKS interessient und wollte an einer auf der letzten Seite des Manifestes angekindigten Ausstellung mitarbeiten. die jedoch nicht zustande kam. Jutkevič und Ejzenštejn verließen zudem schon bald Petrograd und die FEKS. um in Moskau ihre Arbeit fortzusetzen. Die einzige Veranstaltung der FEKS, an der sie gemeinsam teilnahmen. war der Disput "Die Kunst auf dem elektrischen Stuhl" am 24. Juli 1922. Auch Georgij Kryżickij blieb nicht lange bei der Gruppe. Als

${ }^{145}$ I 
einziger 'Erwachsener' in der Gruppe (er war 28 Jahre alt) glauble er zu erfahren für eine ernsthafte Zusammenarbeit mit den Jugendlichen zu sein. denen er Unwissenheit und Stümperei vorwarf. ${ }^{\text {thr }}$ So erfolgte der eigentliche Aufbau, sowie die spätere Leitung der "Fabrik des exzentrischen Schauspielers" durch Grigorij Kozincev und Leonid Trauberg.

Zum besseren Verständnis der Ausgangssituation der FEKS möchte ich an dieser Stelle einen kurzen Werdegang der beiden Regisseure bis zur Gründung der Gruppe einfügen. $1+7$

\subsubsection{Der Werdegane von Grigorii Kozincev und Leonid Traubere bis zur Gründung der FEKS}

Grigorij Michailovic Kozincev wurde am 22. 3. 1905 in Kiev geboren. wo er während der Kriegs- und Revolutionsjahre das Gymnasium und ab 1919 auch die Malereischule von Aleksandra Aleksandror na Ekster besuchte. Der Unterricht in ihrem Atelier war auf dem Studium der Maler Cezanne. Matisse und Picasso aufgebaut. Kozincev jedoch war am klassischen Studium der Malerei wenig interessien. Er verfaßte lieber Parodien und malte Karikaturen. Als eine besondere Auszeichnung empfand er es. als er - der Schüler - I un seinen alteren Kullegen Viśneveckaja. Rabinovic. Ty sler und Sifrin aufgeforden wurde. bei der Bemalung eines Agitzuges und der malerischen Ausgestaltung der Stadt mitzuwirken. Diese Aufgabe erfüllte ihn mit Begeisterung. hier sah er seine Bestimmung. ${ }^{\text {th }}$

Als der Bühnenbildner Isaak Rabinović nach Kiev ans Solocovskij-Theater (heute Lenin-Theater) ging, nahm er Kozincev als Gehilfen mit. Dieser lemte dort den Regisseur und Lehrer Tairovs Konstantin Mardżanov (1872-1933)

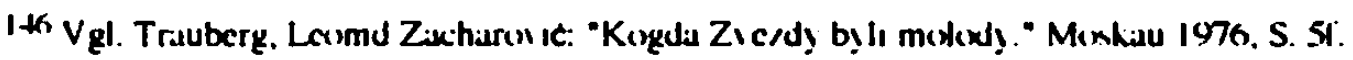

It? Es sel jedexh angemerk!. talB es sich dabel in erster Linic um den Werdegang Kossncels handelt. da die Infiormallicmen uber Traubergs Theaterarbelt vor Grundung der FEKS auBcrst sparlich sind. Im Gegensill. a Kozinces hat er keine ausfuhrtichen Memerren gesethneben und die soujetische Filmliteratur behandelt ihn nur im Zusimmenhang mıt Kosınerı. "was

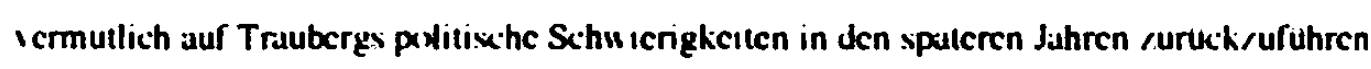
14.

ItK GE, S. II.
} 
kennen, als er an der Bühnendekoration für dessen Inszenierung von lope de Vegas "Fuente Ovejuna" mitarbeitete. Kozincev $u$ ar fasziniert von Mard. Zanor:

"Величайшая ясность отличала его труд. В часы
работы он чувствовал себя в вымышленном мире
обстоятельств и характеров пьесы, как в реальности. В
чудившемся ему пространстве и времени он жил со
всей полнотой духовното суиествования."
"Seine Arbeit zeichnete sich durch große Klarheit aus.
Während der Arbeitsstunden fühlte er sich in der erdachten
Welt der Verhältnisse und Charaktere eines Stückes wie in der
Realität. In Raum und Zeit. die ihm erschienen. lebte er mit
der gesamten Fülle geistiger Existenz." $1+9$

Lope de Vegas Stuck wurde unter Mardżanovs Regie in Revolutionstheater umgewandelt. Die Arbeit an der Inszenierung und der Erfolg des Stückes am Ende stimmte das Publikum dic "Internationale" an - vermittelten Kozincev das Gefühl. an epochemachender Kunst mitzuwirken. ${ }^{150}$

Der Auffiihrung von "Fuente Ov ejuna" folgte eine Inszenienung von Oscar Wildes "Salome", die in keiner Weise den vorrevolutionären Aufführungen dieses Stuickes glich.

1919. während noch die Proben zu "Fuente Ovejuna" liefen, machte MardZanor Kozincer mit Sergej Jukkevic bekannt und übertrug den beiden jungen Kuinstlern die Aufgabe, die Dekoration für die Operette "Maskolle" zu erstellen. Beide. Kozinces und Jutkevic beschreiben spater ihr freudiges Erstaunen in diesem Moment, als Mardzanov sie - zwci Halbwüchsige gewissermaßen - in den Kreis der professionellen Künstler aufnahm. ${ }^{151}$

Sie begannen an Skizzen und dem von Mardzanov umgeschriebenen Text zu arbeiten. Obwohl sie gut vorankamen und Mardżanov mit Ihrer Arbeit sehr zufrieden war, kam die Inszenierung der Operette nicht zustande. 1.52

Mehr Gliick hatten Kosincev und Jutkevic bei der Realisierung ihres Traumes vom eigenen Theater.

\footnotetext{
14) Ibid.. S. 1.3.

1.i) Vil. ibld. S. in.

1.51 GE. S. 211 .

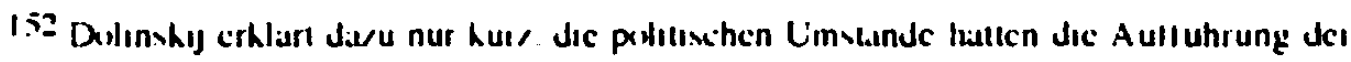
Opercite icrhinderi. Delinskif (1976). S. 72. Ko/ıncel en ahnt dic Fortscl/ung Jer Arbeil

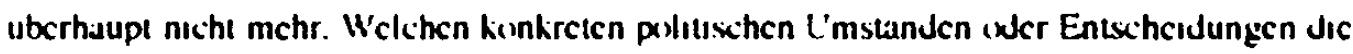

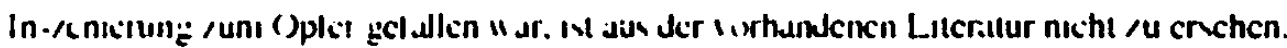


Als in Kiev bekannt wurde, daB der berühmte Puppenspieler Monsieur Charles erkrankt war und seine Puppen verkaufen wollte. kam den jungen Künstlern die Idee, ein Puppentheater zu eröffnen.

"Was könnte besser sein - mit eigenen Kräften eine Puppenaufführung zu schaffen, den ganzen Reiz einer Schaubude in der Praxis zu erleben. den Herzen der jungen Künstler freundlich die Welt des bunten Bildes zu vergegenwärtigen. diese Welt allen zu öffnen, die Kunst auf die Straße hinauszutragen." 153

Es fanden sich sehr bald einige Gleichgesinnte, die an diesem Theater mitarbeiten wollten, unter ihnen Aleksej Kapler, der spätere Drehbuchautor und Dramaturg, der auch in verschiedenen Filmen der FEKS mitwirkte. Die Realisierung dieser Idee wäre aus finanziellen Gründen gescheitert. hätte hier nicht II ja Erenburg geholfen. Er beschaffte das Geld aus dem Sozialfond. So kamen Kozincev und Jutkevič in den Besitz einiger Handpuppen, einen Schaukasten zimmerten sie sich selbst. Als erstes Stück spielten sie Puśkins "Märchen vom Popen und seinem Knecht Balda", wobei Jutkevič den Leierkasten bediente, wăhrend Kozincev und Kapler mit den Puppen agierten. Sie spielten in Kinderheimen, auf offenen Kleinkunstbühnen. in Parks, in Klubs etc.

Bald jedoch wurden ihnen auf Mardżanovs Initiative vom TEO die Räumlichkeiten zur Verfugung gestellt, in denen das Theater "Schräger Jimmy" (krivoj Dżimmi) spielte.
"Репертуар мы составили без труда: трагедия «Владимир Маяковский» и „Балаганчик* А. Блока должны были открывать сезон. Театр мы окрестили прекрасным именем «Арлекинж. Труппа состояла из пяти человек не старше пятнадцатилетното возраста." "Das Repertoire stellten wir ohne Schwierigkeiten zusammen: die Tragödie "Vladimir Majakovskij" und Bloks "Balagancik" sollten die Saison eröffnen. Wir tauften das Theater auf den wunderbaren Namen 'Harlekin'. Die Truppe bestand aus fünf Leuten, von denen keiner älter als fünfzehn war." 15.

Alle Mitglieder des neuen Theaters waren begeisterte Anhänger Majakovskijs. Jedes seiner Gedichte, das sie auftreiben konnten, lemten sie auswendig. Besonders begeisterten sie sich für das Gedicht "150.000.000" und träumten sogar davon, ein Ballett nach den Gedichten Majakovskijs zu in-

1.53 Deyinskij (1976). S. 74.

1.54 GE. S. 23. 
szenieren. ${ }^{155}$ Gemäß ihrem großen Vorbild wollten sie ein neues. volksnahes Theater schaffen. das in seiner Form "an die klingende. kühne und aufregende Poesie Majakovskijs erinnem" sollte. ${ }^{\mid x_{\text {. }}}$

Die Inszenierung des Stückes "Vladimir Majakovskij" gestaltete sich allerdings um vieles schwieriger, als die jungen Künstler in ihrer Begeisterung angenommen hatten. "Man muß offen sagen. daß der Inhalt der Tragödie allen fünf Darstellern ein großes Geheimnis war." 1.57

Als sie sich nach längerer unergiebiger Probenzeit an Mardzanov um Rat wandten, riet dieser ihnen. das Stück fallenzulassen und stattdessen selbst irgendeine Clownade zu schreiben. So verfaßte Kozincev innerhalb weniger Tage Text und Szenarium eines einfachen aber fröhlichen kleinen Stijckes mit dem Titel "Schaubudenvorstellung für vier Clowns".

Zu dieser Zeit gaben die beiden spanischen Clowns Fernando und Friko ein Gastspiel im Kiever Zirkus. Jutkevic und Kozincev wandten sich mit der Bitte an sie. alte Kostüme für ihre Vorstellung von ihnen ausleihen zu dürfen. Die beiden Clowns - angetan von den Plänen der jungen Leute - liehen ihnen die Kostüme. Das Stiick wurde der erste Erfolg des Theaters 'Harlekin'. Auch Bloks "Balagancik" wurde in diesem Theater aufgeführt. Einzelheiten zu dieser Inszenierung werden jedoch weder von Kozincev. noch von Jutkević erwähnt.

Das Theater 'Harlekin' existiene aber nur wenige Monate. Als die Kämpfe um Kiev immer erbitterter w urden. floh Mardżanov nach Georgien. Jutkevic fuhr mit seiner Familie zu Veruandten auf die Krim und Kozincev blieb praktisch allein in Kiev zurück. Zunachst versuchte er so gut wie möglich weiterzuarbeiten. Er inszenierte ein Stiick "Über Kaiser Maximilian und seinen ungehorsamen Sohn Adolf", in dem Aleksej Kapler die Hauptrolle spielte und Nataša Mass die Zarin. Kozincev nennt es eine "echte Aufführung mit Dekoration. Kostumen und sogar mit einem gedruckten Plakat." "Isk An der Premiere konnte er jedoch nicht teilnehmen, da er kurz zuvor an Hecktyphus erkrankte.

\footnotetext{
155 Vgl. Dibin. Edim S.: "Ko/sncos I Trauberg". Lenıngrad/ Moskiau 19K3. S. 12.

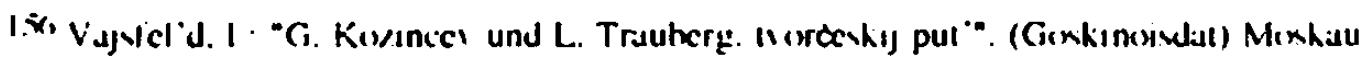
1941). S. 12.

$15-\mathrm{GE} . \mathrm{S} 23$

I.K CIE. S. 2 i
} 
Als Kozincev wieder gesund war, beschloß auch er, Kiev zu verlassen und nach Petrograd zu gehen, zumal inzwischen auch Kapler fortgegangen war. In Petrograd traf er Mardżanov wieder, der das "Theater der komischen Oper" leitete und veranlaßte. daß Kozincev als Regisseur im Studio dieses Theaters aufgenommen wurde. In diesem Studio lemten sich Kozincev und Trauberg kennen.

Leonid Zacharovic Trauberg wurde an 17.01.1902 in Odessa geboren. Noch vor Beendigung des Gymnasiums begann er mit der Theaterarbeit im "Theaterstudio der ästhetisch-traditionalistischen Richtung" in Odessa, das von K. Miklasevskij geleitet wurde. Trauberg arbeitete dort als RegisseurVolontär. 1920 ging er zusammen mit seinem jüngeren Bruder Il ja nach Petrograd und wurde dort im Studio des "Theaters der komischen Oper" von Mardżanov als Assistent aufgenommen.

Kozincev beschreibt Trauberg zum Zeitpunkt ihres Kennenlernens mit einem Satz:

"Он сочинил щьесу в стихах, стремился к театру, был полон рассказов о Багрицком, а пока служил в какомто учреждении под названием «Упродпитокрж."

"Er schrieb ein Stuick in Versen, strebte dem Theater zu, war voller Erzählungen uber Bagrickij und arbeitete zur Zeit in irgendeiner Behörde mit der Bezeichnung "Uprodpitokn." 1.45)

Die Arbeit an dieser Behörde hinderte Trauberg jedoch nicht daran. mit dem gleichen Einsatz wie Kozincev bei Mardżanov zu arbeiten. Zwischen Kozincev und Trauberg entwickelte sich bald eine enge Freundschaft. basierend auf gleichen Ideen und Vorstellungen von einem neuen Theater. So beschreibt Kozincev, daß sie ihre gesamte Freizeit gemeinsam verbrachten. in der Trauberg nie dagewesene Stücke schrieb. zu denen er sich die Inszenierungen ausdachte, "eine immer unglaublicher als die andere." $1(x)$

Als Kozincevs Freunde nach Petrograd zurückkamen, griffen sie die Idee vom eigenen Theater wieder auf und beschlossen gemeinsam ein Theaterstudio zu eröffnen.

159) Ibid., S. 31; Eduard Bagnchij (1895-193.4), der ciner armen Judischen Familie aus Odessa entstammtc, war der grisbte rein lỵische Dichter unter den Konstruktivisten. siehe: Holthusen. (1978). S. 166.

|(S) GE. S.31. 
Jutkevič hatte in Sevastopol einen Artikel mit dem Titel "Theater der Exzentriker" geschrieben. ${ }^{\mid(\mid l}$ den er jetzt seinen Freunden vorlegte, bei denen er allgemeine Zustimmung fand. Kozincev erinnen sich. daß eines Tages, mitten in einer heißen Diskussion das Wort "Exzentrismus" fiel, das ihnen ungewöhnlich ausdrucksstark erschien. ${ }^{162}$

Als es um die Benennung ihres Unternehmens ging. schien ihnen das Wort 'Studio' unpassend, da es zu eng verbunden war mit der traditionellen Auffassung von Kunst. die ihrer Meinung nach überholt war (wobei sie selbst das Wort 'Kunst' ablehnten).Schließlich einigten sie sich auf die Bezeichnung "Fabrik des exzentrischen Schauspielers", denn "die Benennung wird ähnlich treffend sein wie die modernen Begriffe, komprimiert. elastisch im kurzen, energievollen Zusammenklang: FEKS." 1/23

In Anlehnung an den Begriff 'Fabrik' nannten sich deren Griinder auch nicht Regisseure, sondern 'Maschinisten'. Als Motto ihrer Werkstatt übernahmen sie einen Ausspruch, der Mark Twain zugeschrieben wird: "Lieber ein junger Grïnschnabel sein, als ein alter Paradiesvogel."

Erste konkrete Arbeitsschritte sollten die folgenden fünf Punkte bilden:

1. Einen Disput organisieren.

2. Finen Sammelband herausgeben.

3. Eine Werkstatt eröffnen.

4. Ein Theaterstiick inszenieren.

5. Eine Austellung organisieren. Irs

Mit Ausnahme der Ausstellung veruirklichten sie alle genannten Punkte innerhalb eines Jahres.

Bevor wir uns der Theater- und dann Filmarbeit der FEKS zuwenden, soll zunächst der Begriff 'Exzentrismus' geklärt werden. Es soll untersucht werden. was er fiir Kozincev und Trauberg beinhaltete und wie er von der sowjetischen Filmwissenschaft interpretien wurde. ${ }^{1 / 25}$ um dann Anwendung

161 Dilinskij (1976), S. 103: Nisch meincr Inf(romalien ist dicser Artikcl nicht mehr auflindbar. so dall ich hecr lexder nicht muher daraul eingechen kann.

162 GE. S. 32.

IC,3 Lex: cill.

Int Lix: ill

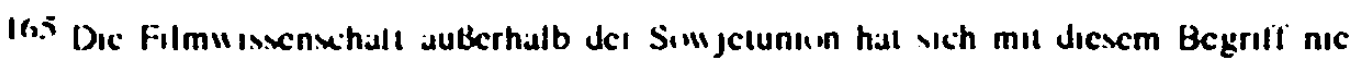
cingechend bexihidugl. 
und Merkmale des 'Exzentrismus' an den praktischen Beispielen, d.h. Theaterstücken und Filmen untersuchen zu können.

\subsection{Exzentrismus}

\subsubsection{Der Begriff "Exzentrismus"}

Direkt im Anschluß an die Beschreibung der Entdeckung des Begriffes 'Exzentrismus' schreibt Kozincev:

"В искусстве тех лет переход от слов к делу был мгновенным, а слова не произносились, а скорее выпаливались. Молодежь говорила тогда на особом жаргоне, если какие-то выражения и не были понятны, то все равно привлекала звучность слов и агрессивность интонаций."

"In der Kunst dieser Jahre erfolgte der Übergang von Worten zur Tat blitzschnell und Worte wurden nicht ausgesprochen, sondern vielmehr herausgeplatzt. Die Jugend sprach damals in einem besonderen Jargon: wenn irgendwelche Ausdrucke nicht verstanden wurden, so begeisterte trotzdem der Klang der Worte und die Aggressivitat der Intonation. "I(x)

Diese Erklärung läßt den Schluß zu, daß sie zu diesem Zeitpunkt noch keine konkrete Vorstellung von den Inhalten des Begriffes 'Exzentrismus' hatten und erst im Laufe weiterer Übertegungen und vor allem der praktischen Arbeit Inhalt und Bedeutung dieses Begriffes für sich festlegten.

Kozincev gibt an, er habe sich von Anfang an für das äußerste Linke in der Kunst begeistert, ${ }^{167}$ was sein Lebenslauf bis zur Gründung der FEKS bestätigt. Die gleiche Begeisterung herrschte bei seinen Freunden und Mitbegründem.

Hierbei muß man auch die in Kapitel 1. dieser Arbeit beschriebenen historischen und politischen Aspekte für diese Begeisterung beachten. die sich nicht auf die Kunst allein beschränkte. Sie wurde getragen vom Glauben an eine humanere und sozialere Gesellschaft. die nach der Revolution von 1917 in der jungen Sowjetunion aufgebaut werden sollte. Wie dargestellt, hatte

I6x GE. S. 32.

167 Vgl. IbId.. S. 10. 
gerade bei den 'Linken' die uneingeschränkte Sympathie für die Revolution die ebenso uneingeschränkte Antipathie gegenuber allem, was davor von Wert gewesen war, zur Folge. So vertraten auch die Féksy die Meinung, daß die klassische Literatur und das traditionelle Theater wertlos geworden seien. Diese Einstellung erklärt Kozincev in einem Interview mit Ulrich Gregor und Marcel Martin. bei dem er unter anderem auf den Ausdruck 'Fabrik' angesprochen wurde:

"Das richtete sich speziell gegen den Begriff des 'Schöpferischen'. Unsere Generation liebte keine hochtrabenden Sätze. keine Ausdrücke wie 'Schöpfung' und 'Große Kunst' - daher nannten wir unser Ensemble 'Fabrik'. Damals wollten wir wie immer in der Jugend und besonders in einer Revolution uberhaupt jegliche Kunst zerstoren. IInseren Gefühlen schien es nicht möglich, sich alter Formen zu bedienen. Wir wollten alles Alte zerstören und aus den Trummern des Alten eine neue Kunst machen. "Iox

lnd wie viele ihrer Kollegen wollten Kozincev und Trauberg ein neues. der neuen Gesellschaft entsprechendes Theater schaffen. Alle ihre Vorstellungen von diesem Theater sollten unter dem Begriff 'Exzentrismus' zusammengefaßt werden.

Während der Beschäftigung mit der Literatur zur FEKS und dem fruhen sowjetischen Film wurde deutlich. daß es keine konkrete Definition für diesen Begriff gibt. Beispielsweise fuhr Nedobrovo nur ein Hauptmerkmal des Exzentrismus an. Das Prinzip der Verfremdung (Ostranenie oder Ostrannenie. die Schreibweise differien bei den verschiedenen Autoren). Zuvor erklär er. der Exzentrismus bestehe nicht einfach aus weiten. harierten Hosen, grunen Haaren, einem eingedrückten Zylinder o.ä., was man aus mucic-hall oder Varieté kenne und sei auch nicht gleichzusetzen mit Marinettis Vorstellungen lom Varietétheater. "Der Exzentrismus der Fèksy ist nicht der Exzentrismus der music-hall. Das darf man nicht verwechseln. ${ }^{n} \mid(t)$

Dobin wiederum konzentriert sich in seinem Buch über Kozincev und Trauherg auf den Unterschied zwischen Exzentrik und Exzentrismus. Dabei gibt er der Exzentrik eindeutig künstlerischen und ästhetischen Vorrang vor dem Exzentrismus. Der Exzentrismus kompromittiere die Wirklichkeit und schließe Ähnlichkeit mit ihr aus. Während die Exzentrik die Verbindung mit

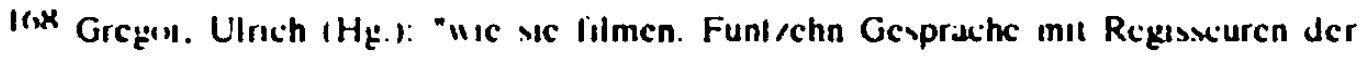
Gicgenw arr". Gutcrsileh IY(xh. S. I(x).

l(1") Nicdibronu(192x). S. X
} 
der Wirklichkeit suche, begnüge sich der Exzentrismus mit der Verfremdung. "Exzentrismus - das ist die falsche künstlerische Weltanschauung. Exzentrik - das ist eine rechtmäßige und reiche Form der Kunst. " 170 Als Beispiel für gelungene Exzentrik im Film nennt er die Stummfilme von Charlie Chaplin, an denen sich allerdings auch Kozincev und Trauberg orientierten. Laut Dobin fanden die Fèksy erst im Verlauf ihrer praktischen Filmarbeit zu einer bedingten Exzentrik und in der Folge zum Realismus, der die Maxim-Trilogie kennzeichnet.

Wieder ein anderer Filmwissenschaftler, I.Vajsfel'd. kritisiert an den frühen Arbeiten der FEKS. sie seien auf die Imitation des amerikanischen Filmes fixiert gewesen. Auch er stelit die Exzentrik der Chaplin-Filme den ersten praktischen Werken der Fëksy gegeniiber, wobei er den grundlegenden Unterschied darin sieht, daß Chaplin "vor allem ein feiner Beobachter des Lebens [war], der das Komische im Menschen bemerken konnte...." 171 , während die Inszenierungen der FEKS zu formalistisch und publikumsferm gewesen seien. Bei diesem Vorwurf muß man jedoch berücksichtigen, daß Begriffe wie "Formalismus" oder "formalistisch" nach der Unterdrückung der literaturtheoretischen Bewegung des Formalismus zu Beginn der dreißiger Jahre, zu allgemeingültigen Vokabeln negativer Kritik verkamen. die immer dann benutzt wurden, wenn in Kultur oder auch Politik jemand von der offiziellen Doktrin abwich.

Kozincev und Trauberg selbst geben in ihren Artikeln bzw. Aufsätzen zum Thema Exzentrismus auch keine klare Definition des Begriffes, sondern umschreiben ihn anhand zahlreicher Beispiele und stilistischer Merkmale aus Literatur und Film.

Die verschiedenen Perspektiven. von denen hier nur einige als Beispiele herausgegriffen wurden, zeigen also, da $B$ der Begriff mit einer konkreten Definition nicht zu erfassen ist. Da die angeführten Erklärungen verschiedenste Schwerpunkte setzen, wird deutlich. daß der Exzentrismus nicht als Kunstströmung wie etwa Symbolismus oder Futurismus anzusehen ist. sondern als Definition von Kunst, die sich aus verschiedenen Gesichtspunkten zusammensetzt. wobei der Ausdruck 'Exzentrismus' als iibergeordneter Arbeitsbegriff zu verstehen ist, den die Fèksy für ihre Arbeit auf-

\footnotetext{
170 Dubin (1963). S. 30 ).

$17 \mid$ Vijsiel d ( $194(1))$. S. 9.
} 
stellten. Aus diesem Grunde soll im Folgenden anhand von Vergleichen mit unterschiedlichen Kunstformen. -strömungen. -theorien und -merkmalen untersucht werden, aus welchen Gesichtspunkten sich der Begriff 'Exzentrismus' zusammensetzt. Besonders konzentriert sind seine verschiedenen Merkmale und die Einflüsse, denen die Fèksy unterlagen in dem Manifest 172 "Ekscentrizm" von 1922 zu finden. das auf den nächsten Seiten angeführt ist und als Untersuchungsbasis im oben erwähnten Vergleich dienen soll.

172 In Jer Lilcralur fur FEKS wild Jicso Manilest "Ehsecntri/m" uuch als 'Sbornik"

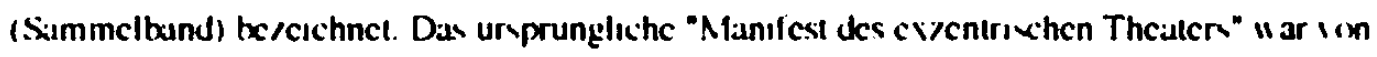
Korsmiel. Kryzstskij und Trauberg gesihneben worden fur den "Dispul uber das ci/entnsiche Theater". Jen eriten bflientlichen Aultnit der Feks! am 5. De/ember 1921. Dieses Manifest "urde me icrisfentlicht. Aus/uge daraus sind getix.h in Jer Iorlicgenden Sihrift mil Jem

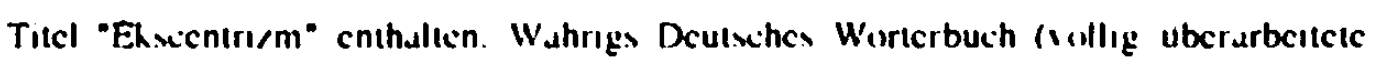

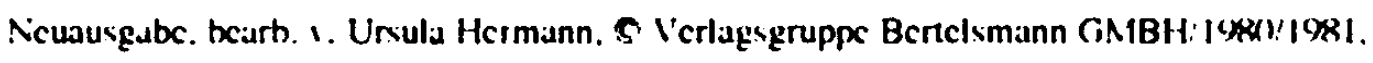
S. 3161$)$ deliniert Jen Begnff 'Sammelband' als "Buch. das cine Sammlung icrishicuener

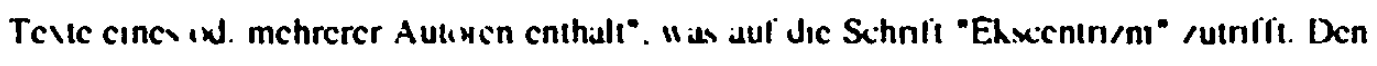
Begrilf 'Manılest' definicrt Wahng (ibid.. S. 24.5.) als "officntl. Erhlarung. Rrchticrigung:

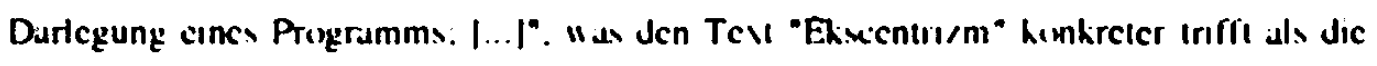
Bercichnung 'Sammeltand'. Es handelt wch hicr durchaus um cinc "ifflentl. Erklarung" und dic "Dallegung cincs "Pripela anmer". Da auch dic Schundarlitcratur ar FEKS in Jer

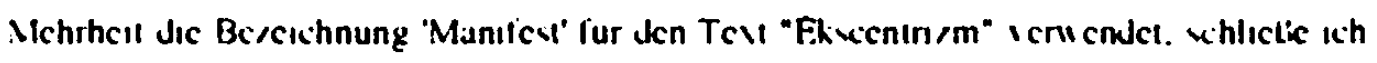

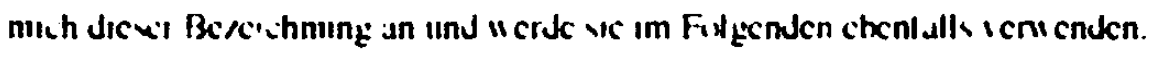


2.3. Das Manifest „Ékscentrizm“ 

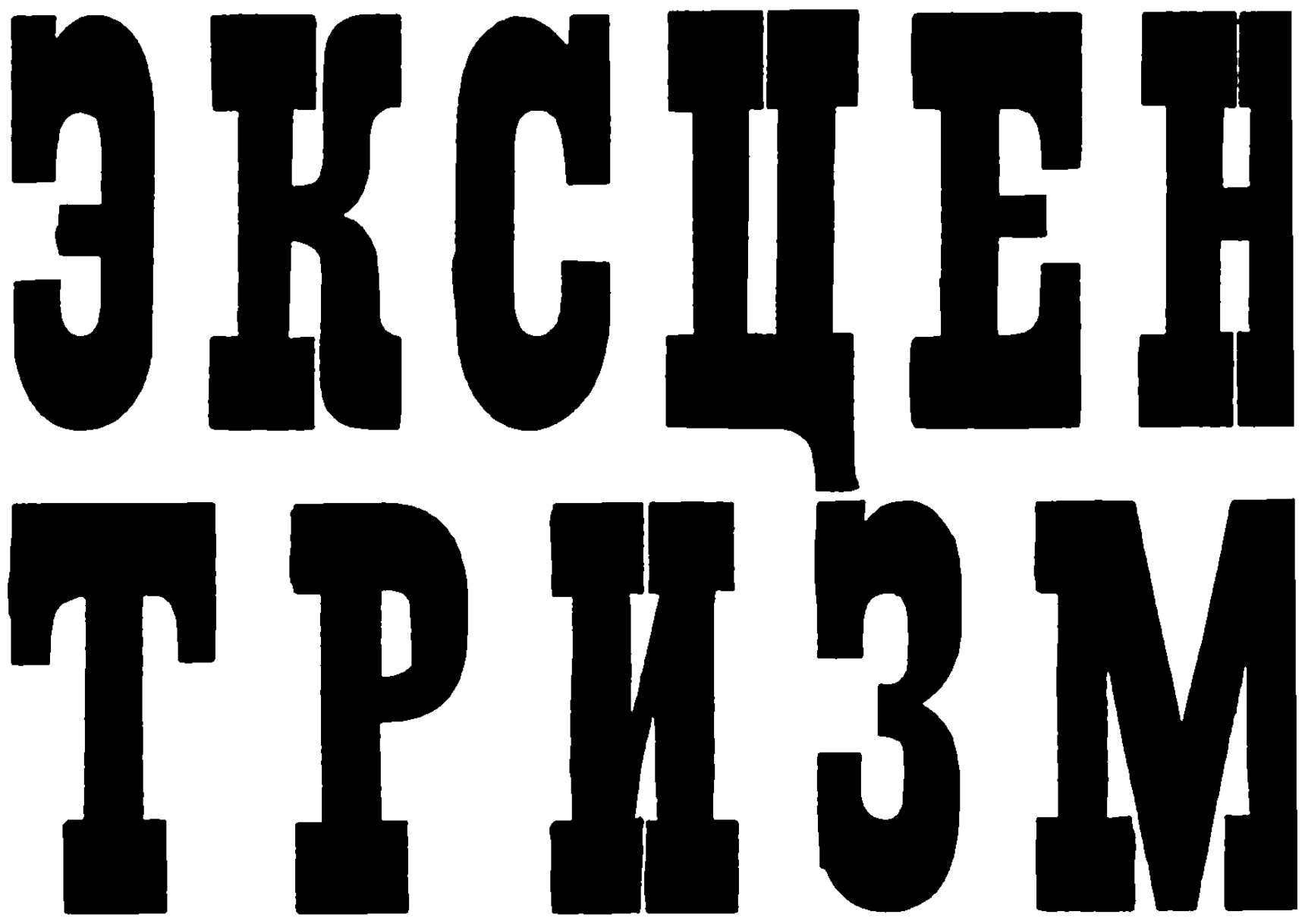

\section{ГРИГОРИЙ \\ КОЗИНЦОВ}

$$
\text { ГЕОРГИЙ }
$$

КРЫЖИЦКИЙ

$$
\begin{aligned}
& \text { ЛЕОНИД } \\
& \text { TРАУБЕРГ } \\
& \text { СЕРГЕЙ } \\
& \text { ЮТКЕВ И } 4
\end{aligned}
$$
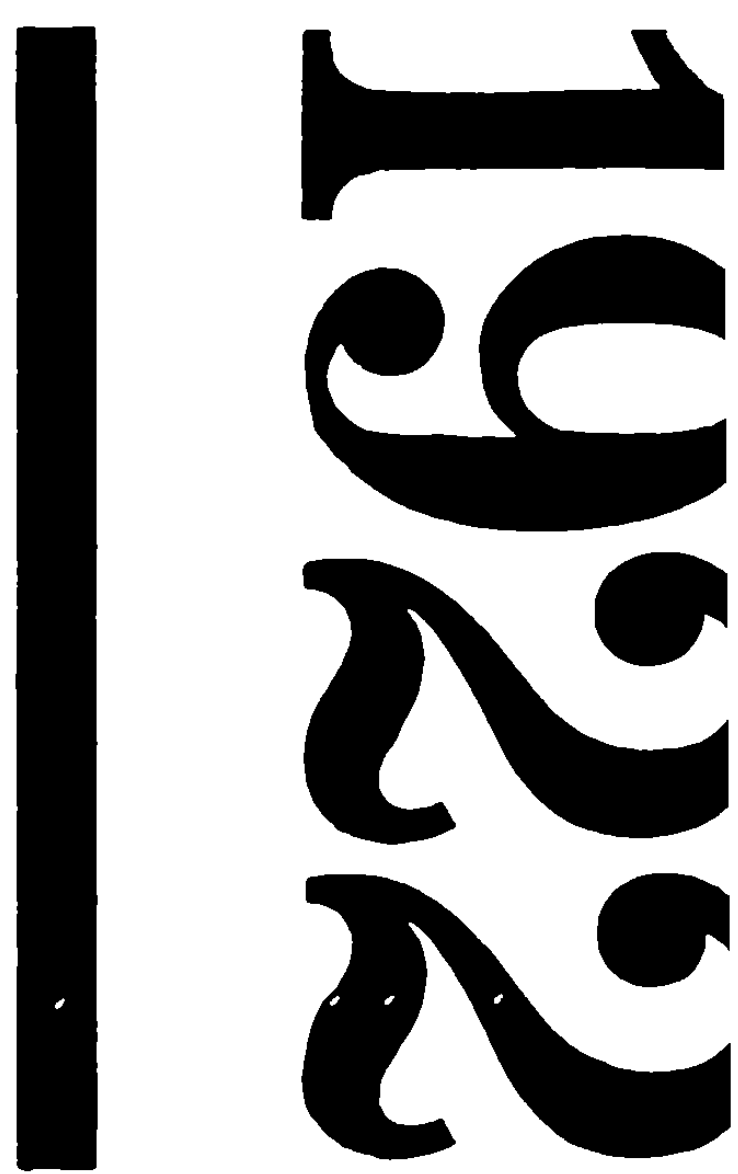

\section{ЭКСЦЕНТРОПОЛИС}



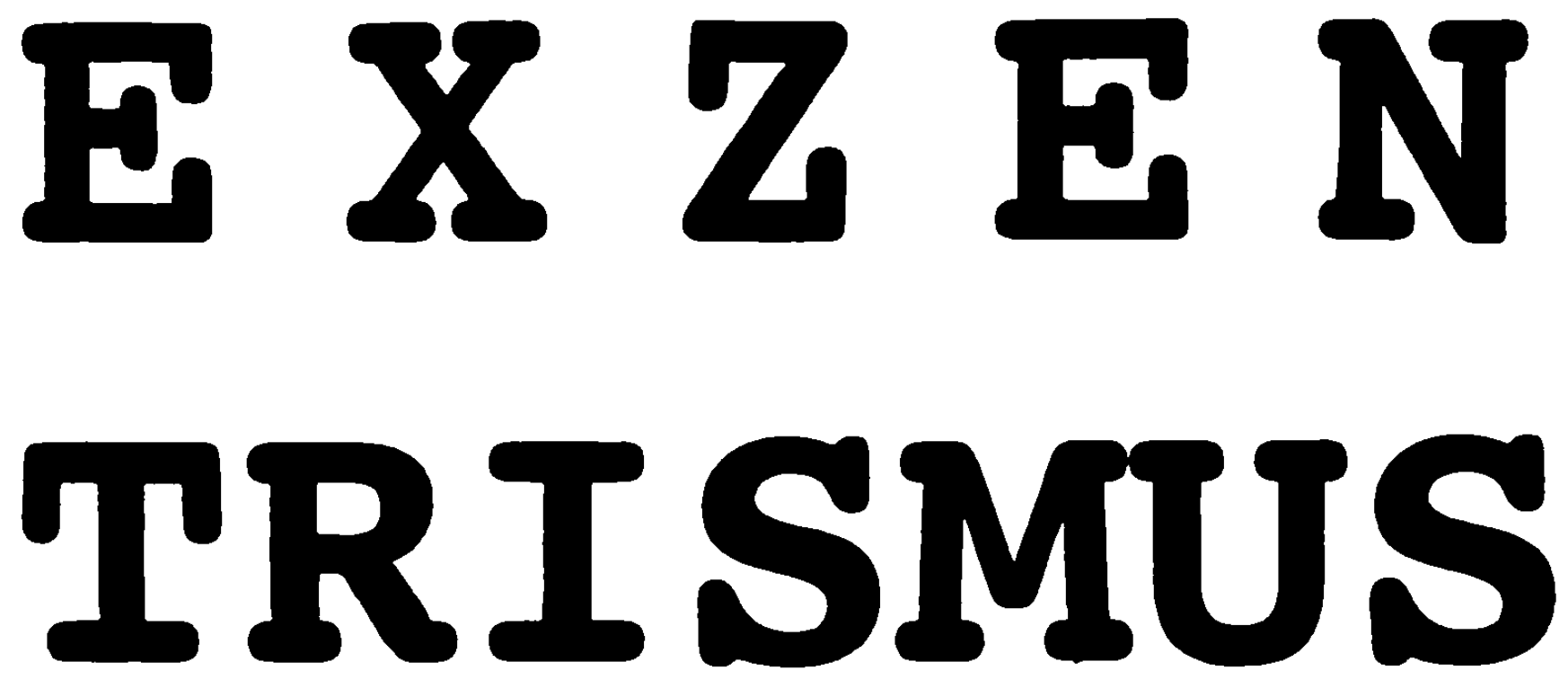

\section{GRIGORIJ KOZINCOV}

\section{GEORGIJ KRYŽITSKIJ}

\section{LEONID TRAUBERG}

\section{SERGEJ JUTKEVIC}

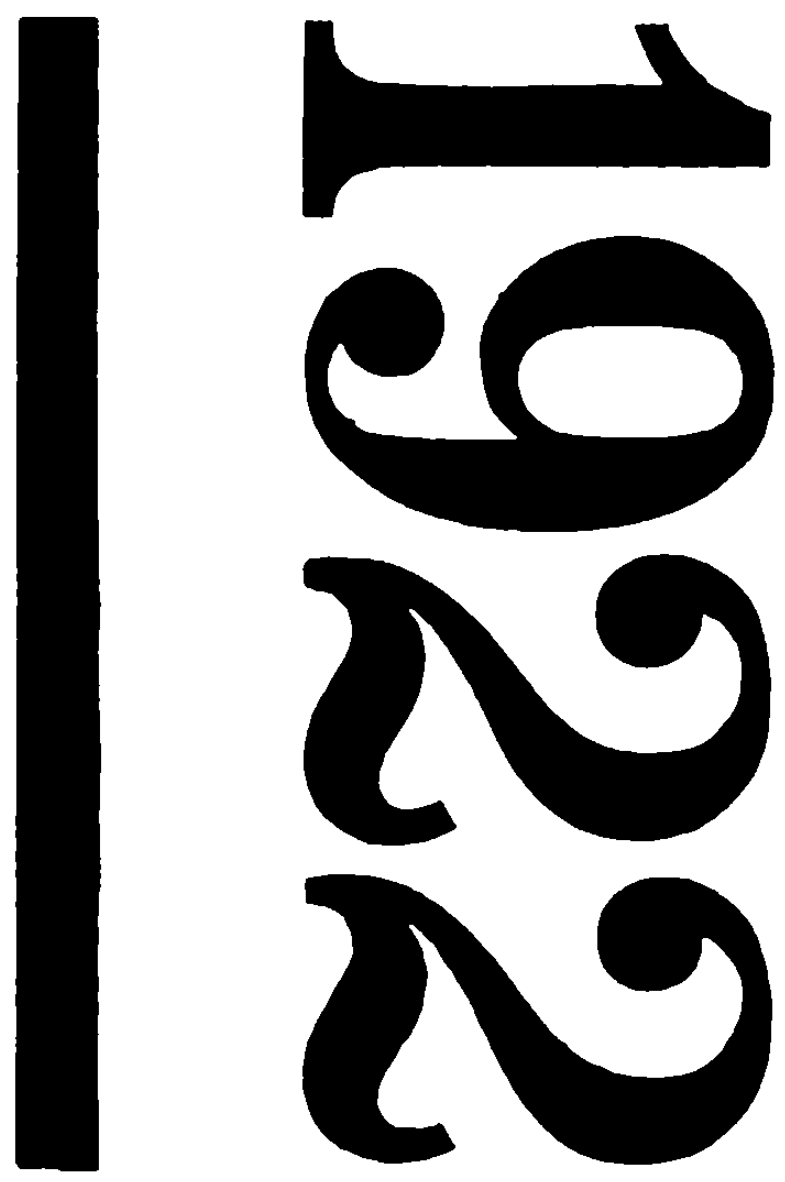




\section{CПACEHИE B WTAHAX}

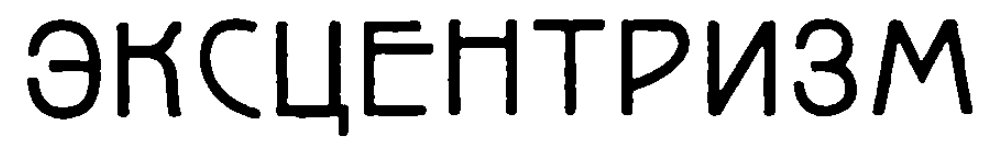

ППTENT 3АЯBתEN

$$
\begin{aligned}
& 5 \text { AEKAEF⿱ } \\
& 1921
\end{aligned}
$$

В помещении театра „Вольная Комедия“, П. Т. Г.

Hs мамифеста Эисиентрич. теarpa.

B nерbaŭ paз! 5 декавря 5 ЭКсиентризм!

\section{Mu noatem netwpe conctкa:}

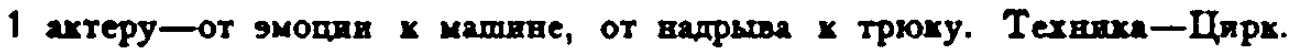

Псмхология-вьерх потами.

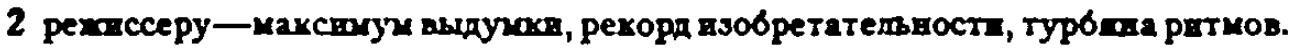

3 драматургу-сцепщшх тркохов.

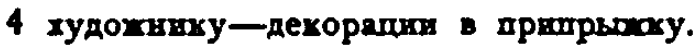

K casctкy antomy-or публихв-мs rotoss.

И поминте: америкамец MAPK ТВЭН сказап:

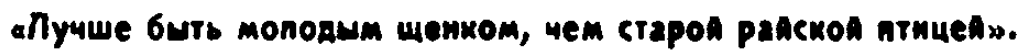




\title{
ERRETTUNG IN HOSEN
}

\section{EXZENTRISMUS}

PATENT ANGEMELDET

\author{
5 DEZEMBER 5 \\ 1921
}

In den Räumen des Theaters "Freie Komödie". P. T .G. aus dem Manifest d. exzentr. Theaters

\section{Wir servieren vier Pfiffe:}

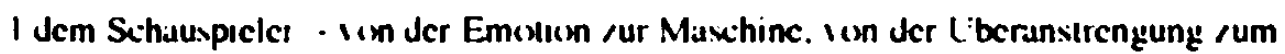
Trick. Dic Technık - Jer Zirkus. Dic Piychologic - aul sen Kispl gesiclit.

$2 \mathrm{Jcm}$ Regisscur - cın Mavimum an Ertindung. cın Rekord Jes Erfindungsgessies. cine Turbine an Rh! thmen.

$3 \mathrm{Jcm}$ Dramaturgen - cen Rangıcrer ı

$4 \mathrm{dem}$ Buhnenbiluner - Dekirationen in kleınen Sprungen.

Zum funfien Prifr - aus dem Publikum - sind wir bereil.

Ind denken Sie daran: der Amerikaner Mark Twain sagte:

"Lieber ein junger Grünschnabel sein. als ein alter Paradiesvogel".

\section{Exzentrik}

'Anspiclung aut Majakiorskijss Gedicht "Wolke in Hoscn" Ion 1915. 
Truropin Mosmmas

\begin{abstract}
$\mathbf{A B}$
Rapan seescurnman.

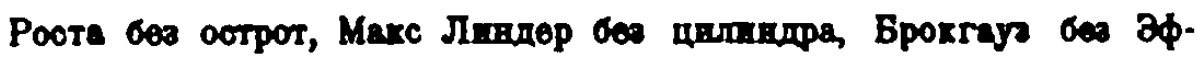
рова - тто велепев?

1921 Дехабрь 5 (девь всторвв)

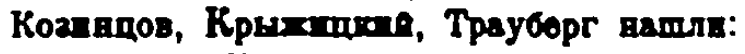

$x x \operatorname{con}$ cen..

\section{AHKBTA.}

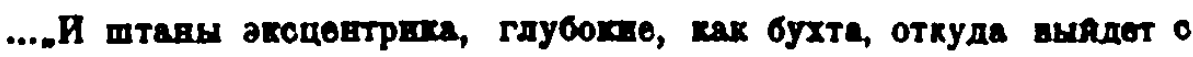

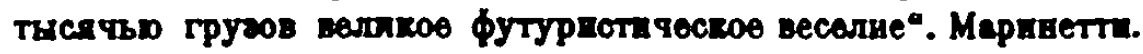

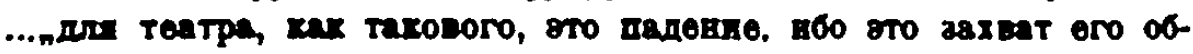
дасти өхсцовтрхәмом мозих-холла". Лувачарския.

.... Уa-ya-ya!* zлоув Copz

$$
60
$$

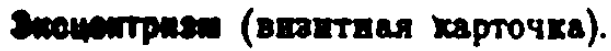

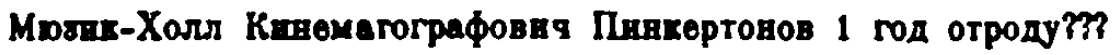

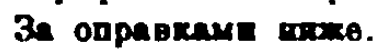

\section{KJIOY B ФAKTAM.}

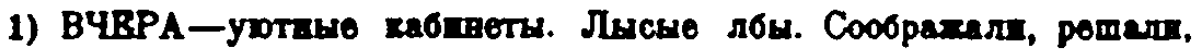
думелв.

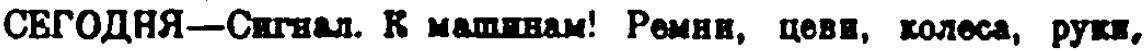
norm, anextprqeotro. Patм провз80дотве.

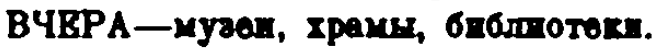

СЕТОДНЯ-фебршх, амводы, верфя.

2) ВЧВРА-хультура Варопн.

СВТОДНЯ-технтка Амершхн.

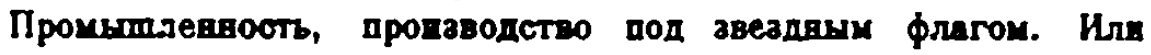
амергхавнвация, вли боро вогороввых процессия.

3) ВЧЕРРА-Саловы. Погловьг Баровн.

СЕТОДНЯ-Крив гевтвхов, скавдаль, палке подвсмева, шум, хршx, топот, бor.

$$
\text { Tema ceranan: }
$$
\end{abstract}

capon.

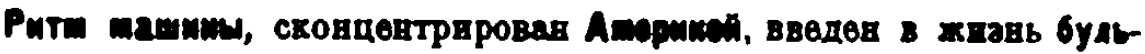




\title{
Grigorij Kozincov
}

\author{
AB! \\ Parade des Exxentrikers \\ Rexida shne Sitharien, Mal Linder" shne Zụlinder, Brixikhaus othne Elront. \\ "as is unsinniger? \\ 1921 De/cmber 5. (cen histinnx.her Tag) \\ Kurıneror. Kngzlsijus. Trauberg lianden: \\ Das XX Jahrhundert ohne... \\ Umiraze.

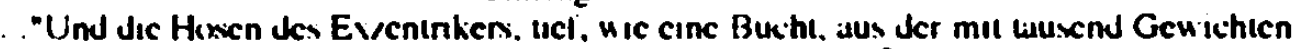 \\ Jic grible fulunstlisithe Heiterkell herausstelgt". Muninelli.5

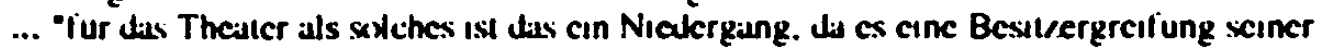 \\ Gebicic durcth den Evientrismus der musse-hudl ist". Luniacarstiy. \\ ... "U\} - uj - uj!" Clown Scrz.
}

\section{ohne-}

\section{Exzentrismus (Visitenharle).}

Music-Hall Kinemallogeraluo ic Pinkcriomes I Jahr der Sprikblıng:??" Fur Auskunite siche unien

\section{SCHLÜSSEL ZU DEN FAKTEN}

1) GESTERN - gemulliche Kabınetlc. Stumglatien. Man ubertegic. man entsehicd. man dachic.

HEUTE - cin Signal. An Jic Masichinen! Ricmen, Kellen. Raider. Arme. Bcine. Elckitristal. Produkillonsithy thmus.

GESTERN - Muscen. Tempel. Biblickhelen.

HEUTE - Fubriken. Werke, Werticn.

2) GESTERN - dic Kultur Euripas.

HEUTE - Jic Technik Amerikis.

Indusiric. Produkition unter dem Sicrnenbanner. Entucder Amenkinnisicrung. ider Bestillungsinstutut.

3) GESTERN - Sulums. Verbeugungen. Barrone.

HEUTE - Schreic ion Zeilungsjungen. Skiandalc. der Slixih Jes Pilliceman. Lurm. Geschrel. Stampien. Rennen.

Das Tempo heute:

Der Rhythmus der Maschine. Kinsentricr Jurch Amerika. ins Leben cingeluhn Iom Boulevard.

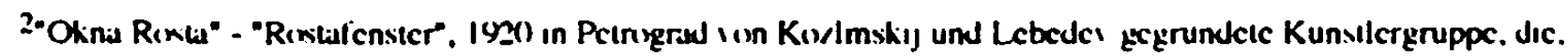
icm Suprematlsmus becinflubi. Reiclutlınsplatialc hersicllic.

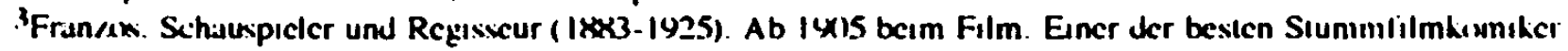
Becinllubic aluch Chaplin.

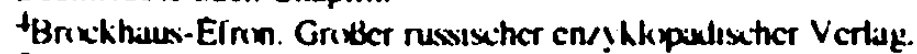

5 Dieses Zilal lautel nichlig: "Aul jede crdenkliche Weixe mub man die ciallimeng der Clouns und del

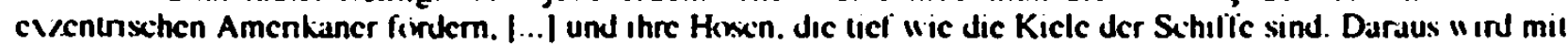

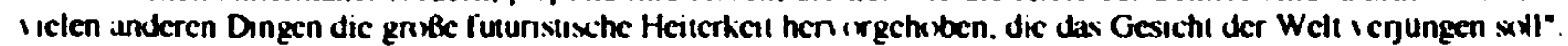

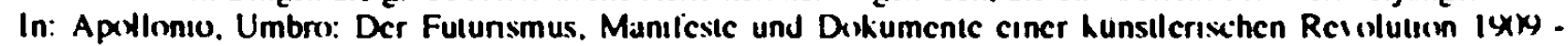
1918. Kilin 1972, S.176 


\section{I. ИСКУССТВО БЕЗ БОЛЬШОЙ БУКВЫ, ПЬЕДЕСТАЛА И ФИГОВОГО ЛИСТКА}

Жизнь требуст искусство

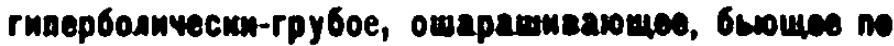

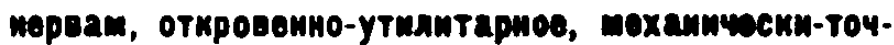
ное, пгиовениое, бшстрое,

ина'ле вс услышат, не уввдят, ве остввовятая. Bсе әто в суммө равняется: искусство ХX века, искусство 1922 года, искусотво последнеп секунды

\section{3ксиентризап.}

III. НАIIИ РОДИТЕЛИ.

Парап ал.ла!

В слове-тансонетка, Пивкертов, выкрак аукциониста, удичная брань.

в живопнси-цирковоя пдакат, обложка будьвврвого ромава.

в муаыке- Джез-банд (негрнтявския оркестр-переполох), цирковые марти.

В балете-американскни павтаввыя танец.

в тевтре-мозик-хол.7, кино, цирк, тантав, бокс.

IV. МЫ-ӘКСЦЕНТРНЗМ В ДЕЙСТВИК.

1) Представление-ритмичөское оптье по вервам.

2) Выстая точка-тргк.

3) Автор - изобретатель-выдумщик.

4) Актер-мехавизировавное двихевие, ве котурвы, а раликп, не маскв, а захигариияся вос. Игрв-ве двихевне, а крнвляние, не мимика, а гримаса, ве слово, в выкрик.

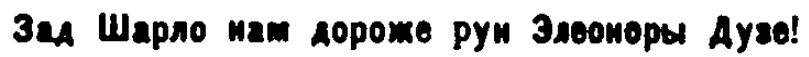

5) Пьеса-нагроможденпе трюков. Темп 1000 лотадивых свл. Погови, преследования, бегства Форма-дивертисскевт.

6) Выростающие горбы, надувающиеся животы, встающие парики рыжих-нача.то нового сценического костюма. Освова-беспрерывная трансформация.

7) Гудкд, выстрелы, питущие машанки, свистки, сврены-әксцентрическая музыка. Чечетка-вачало нового ритма.

Авоймые подошеы америхамского тамиора мам дороше патисот инетрушентов маримиского тедтра.

ह) Синтез движенип: акробатического, спортиввого, тавцеввльвого, конструктввно-механического. 


\section{KUNST OHNE GROBBUCHSTABEN, PODEST UND FEIGENBLAT}

Das Leben fircken Jic Kunsi

hyperboliseh-grob, verblurfend, auf die Nerven einschlagend, offen-utilltaristisch. mechanisch-genau. augenblieklich, schnell.

anderenlaalts wird man micht huren. nicht schen. nicht sichenbleiben. All dils makeht in der Summe: Dic Kunst Jes XX. Jahrhunderts, dic Kunst Jes Jahres 1922. dic Kunst ser levien Sctionde

\section{den Exzentrismus}

\section{UNSERE ELTERN.}

\section{Parack illcs:}

Im Wert - Jic Chanmmetic. Pinkertin". Jer Ausrul des Aukllimaltoms. Siratiengekicilc.

in der Malcrei - dias Zarkusplabial. der Umschlag des Bewlet ardromians.

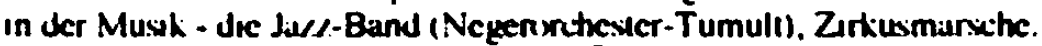
Im Ballell - Jer amenkianische Chantiant ${ }^{7}$ Tane

im Thealter - music-hall. Kino. Zirkus. Chantant. Bossen.

\section{WIR - DER EXZENTRISMUS IN AKTION}

1) Theuter orstellung - Wuithmısehes Einsehlagen auf die Nen en.

2) Sprnngender Punki - der Trick.

3) Autcr - Entinder, Aul wehneider.

4) Schauspicler - mechanisicric Bewezung. keine Kothurne. windern Rollen. kicinc Maskic. sundem cinc ent/undetc Nase. Das Spicl - keıne Bewcgung. sondern Falen. keıne Mimik. sondern Grimasse. nichi Wort. sinndern Aufsehres.

Des Hinterted von Chritot ist uns lieber, ids de Amme von Bleonom Duse!

5) Jas Stuck - Anhaufung i on Tricks. Tempu l(x) PS. Nachsicllungen. Verfolgungsjageden. Flucht. Dic Form - Diicritssement.

6) Herauswachsende Buckel. aul teblisene Baucte. a Berge stehende Clow nsperuelien Jer Bezinn des neuen Buhnonkiniums. Grundlaze - peusenline Tranvivnultien.

7) Hupen. Schussc. Sichreibmaschınen. Plillic. Sirenen - Jie elientnseche Musik.

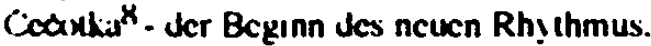

Die doppetten Sohten eines amerikenisctien Tireers sind uns lieber.

ds de Rinfmundert Musibinstrumente des Morinskj Theaters.

8) Synthese der Bew cqungen: Jer akrubalisetien. Jer spertlichen. der tan/ensetien. der kinnstrukill-mechanisithen.

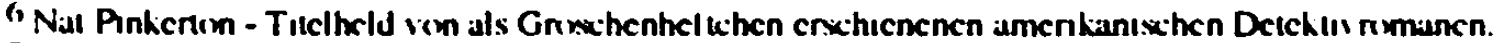

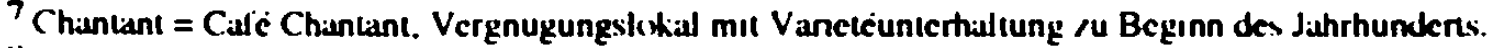

${ }^{8}$ Russisctier Vollkstan/ mit haufigem Autsliamplen.
} 


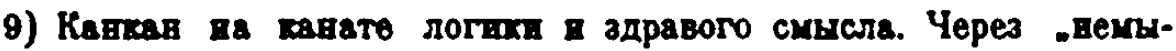
слимое в .вевозховвое $x$ әхсдевтрнческому.

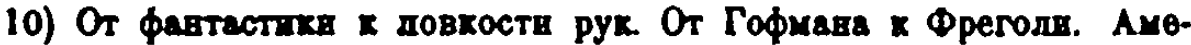

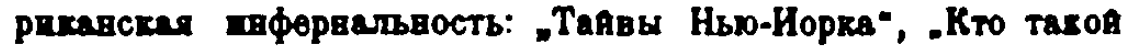
racxa, xotopas areotas"?

11) Руга Всеобучy. Спорт в театре. Левты чемпвова в перчапки бохсоров. Парад алто-театратьвее уднкох арлехина.

12) Исподьзовавве првехов амеракавсков рехламы.

18) Кудь парга аттракциовов, чертовых халес и америхавских rор, поучарщих подростарще погалевне пОДЛИННОМУ TBMIIY өnoxn.

Paтm qечетб. Тресх кино. Пинхертов. Гах амервхавски тор.

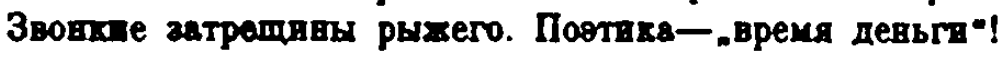

Haen panced:

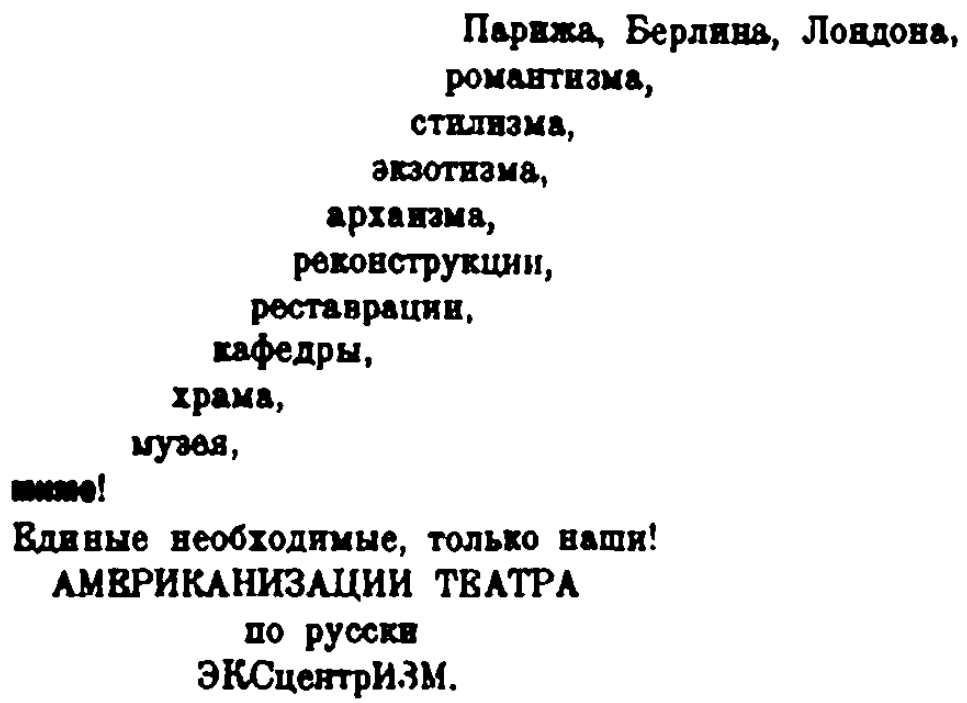

\section{ЭКСЦЕНТРИЗМ \\ ПРИВЕТСТВУET

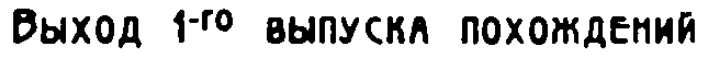 \\ Hata ПинKeptoma. Короля СЫщиков \\ Выход N⿴囗1 журнала "BЕЩЬ"}


9) Cankan auf Jem Scil Jer Logik und Jes gesunden Menscheni crstandes. Durch diss das "Undenkbare" und das "Unmisglıche" num EV/entricchen.

I(1) Von der Phantastik aur Fingertertigkeit. Von Hodiman /u Fregedi.

II) Die Hand rur allgemeinen Schulptlicht. Spart im Theater. Dic Bander Jer Chitmpions und dic Handsehuhe jer Boicr. Parale-allez - thealtalischer Jic Harlckinsenmiase.

12) Venicndung umenlianix:her Werbemetheden.

13) Der Kult der Vergnugunsparts, der Ricsenrader (Teuiclsrivke) und Achterbahnen. Jic Jic heranwathsende Gencrallin das WAHRE TEMPO der Epxite tehren.

Der Rhythmus der Ceastkis. Der Krach des Kinss. Pinkerton. Der Larm Jer Achterbahnen.

Dic whallenule Ohrteige Jes Hirlelins. Dic Pixetik - "Zcil ist Geld"!

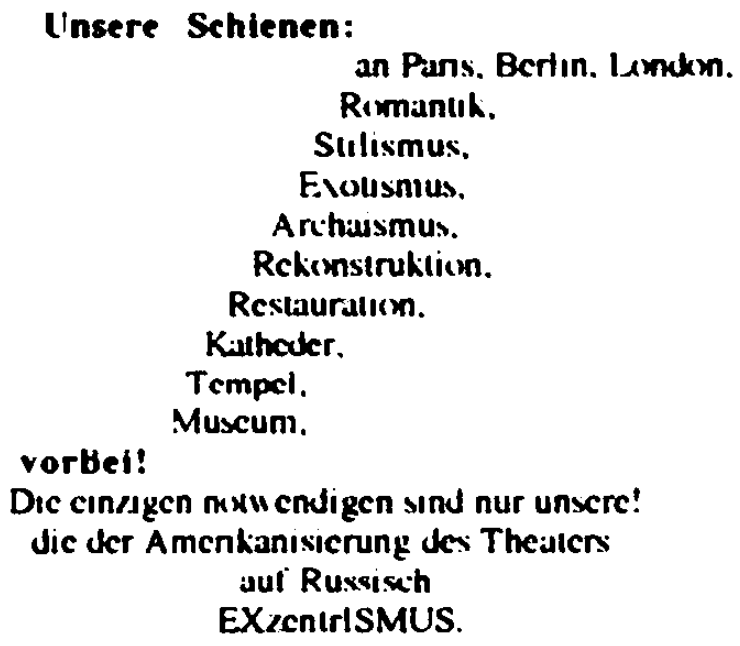

\section{DER EXZENTRISMUS BEGRUßBT}

DAS ERSCHEINEN DER 1. AUSGABE DER ABENTEUER VON NAT PINKERTON, DEM KONIG DER DETEKTIVE 


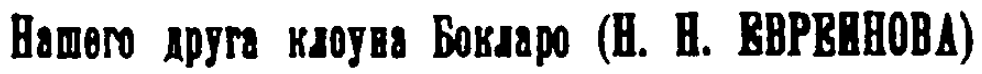 ГЕНИАЛЬНОГО ЧАП}

CM. CTP. 9.

reopnal

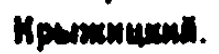

\section{TEATP ABAPTA.}

.Чувство театратьности, как векая өстетическая мовстрация явво тевдевциозвого гарактера *.

Плювул, растер, преобразвлсл,一и стал ТЕАТР.

A \& говорю:

Да.

\section{4o-ny-xa.}

Никаквх перевоп.оопения, нвкаких преображевия, викакиг котурн n никакиг мacok.

Есть только одно -

\section{Aaspr.}

Чувство Театра - әто чувство каната, тувство взарта. Здоровая радоствая напружнненность всего натего существа, всея натея жнзпевноя әнергии.

Когда захватыввет дух, в зобу спирает дыхание, а в мозгаз танцукт рыжеватые чертенята.

Как в ЦИРКЕ

под самым куполом,-точно на волоске,-балансврует әквилибрист, и весь зал замер, затаив дыханне...

Вот... вот... еще!..

$$
-A x !-
$$

- Цовиљьно! - Довольно!! - Довольво!!!-

Театр, ото - азарт; это аукиион, аәроплан, лото, лотторея, гонки, рулетка.

Театр, नто-тотализатор, бетеная азвртвая игра, скачки с препятствняли, в которых на прнзы бегут актеры. Как лопіадн. И на них нужво и хочется ставить.

- Вы на Цавыдова? Бросьтс, перепадает ва левую заднюш. Ходотов? 1Орцев: Не рискну и в двояном, ве то, что в ординаре. 


\title{
Unseren Freund den Clown Boklaro (N. N. Evreinov) DEN GENIALEN CHAP'
}

\author{
siehe. S. 9
}

\section{Georgij Kryzitskij}

\section{Theater des Hazard}

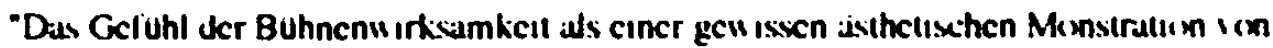
oflensichulich tenden/suxem Charakiter".

Es spuckic. Icritischic, I criviandelic sich. - und w urde DAS THEATER.

Aber ich sage:

$$
\text { dum - mes - Zeug. }
$$

Ji.

Keinerleı L!mgestaltung. Keinericı Verw andlung. Keinerieı Koxhume und keınerlei Mustion.

Es evistien nur cines -

Hazard.

Das Geluhl des Thealers - dias ist das Geluhl Jes Sciles, das Gefuhl Jes Havard. Eınc Ircudige Angespannihell unscres gesamien Scıns, unserer gesamien Lebensenergic

Wenn es den Geist lassell. Im Kropl den Alem i crischlagl, und im Gehım roulicite Teulclchen tanzen.

Wic im ZIRKUS:

direki unter Jer Kuppel, - genialu auf cinem Haiar, - balanciert der Aquilibnst, und der ganze Sial crstarre. den Alem anhadtend...

Da... di... nuxh!..

- Ach! -

$$
\text { - Genug! - Genug!! - Genug'!! - }
$$

Theatcr. Jas ist Hazard: das ist cine Aukition. cin Flug/cug. Lotto. cinc Lexienc. Rennen. Risulctle.

Thealer, Jas ist cin Totalisalor. cin rasendes Roulcticspiel. cin Hindernisrennen. bei Jem dic Schauspieler um dic Preise laulen. Wic Pficrde. U'nd aut sic muk und mexhic min seven.

- Sic aul Dalydow? Lissen sic, der falle vion Zcil au Zeil auls linke Hintericil. - Chedexor? Jur ev? Ich riskiere dkxch nicht doppett und schen gar nicht im cin/cinen. 
И, похелуяста, не думавте, тто өто только так, остроумая ралт: еще в Әлладе авторов в актеров венчали, как прнзовых лотадея.

Ставилв, рнсковяли, хдали, с захираннем хдали:

- Ну, кто же? кто аке?! кто?!!! -

Все лица прнховавы х черным точхам мчащнхся лотадея. Перегвулись через барьер. Глухоя говор. Напряжение растет, растет...

$$
\text { Eme - eme - emo!... }
$$

И вдрут, - все заволновались, зааплодвровали, захричали; толпа закольхалась в звходнла; лнца радостно-разгорячевнье, а из угольков сотев глаs смотрвт

\section{Asspt.}

Расхрывар первяя попавшнися театральныя журнат и ваутад пробегар рецензио:

-Г-ха Мичурива дала трогательныя образ нехнон матерн. Ооняно извежево-иашскан Юрьев, сумевшия с бальmоя путкостьо уловить все товкие психологи-

В хлозет. ческне вравсы увядалщсн страсти". oymara. -

Вдрочем, даже и для әтоя цели предпочтительнее наждачияя

A теперь предлагаш отрывох ва будупих рецопзил иастоящето Teatpa Aзарта.

-После четьрех фальстартов далеко оторвалась Тамара; с палуверсты блихаяшен сбившаяся ввпчало Юревева, далее Коовев; борьба иа всеп вынгришноя прямоп; здесь у Юреневоя сбоя и пренмущество у Коовев, которая у столба выпгрывает голову".

Или вот:

.Со старта, постепенво увеличивая просвет. оторванво первенствовал Монахов; второе место сторо заняла Ведрнвская и так держалась половиву двстввцин; по выходе на прямур, она тут же, за Монаховых, на фнимше, уверенно обходит его, сдавшего, и у столба вынгрывает тею. Из остлыьых ближаяmuN $\Gamma e^{u}$.

В театральвых программах будут указывать последнии рехорд артиста и его „резвеяшие сөкунды“.

Чувство Театра - ото чувство движения, судорожное напряцение иервов и воли, вачало актввное, динакическое. двитительное. А тут приходит Нгипто и начинает продонедідвать. "то чувство 
Und. bulle. denken Sic nicht. dab es nur $\$$ is ist um des Wit/es willen: Vexch in Helliss schmuctic man Auluren und Alitcure wic Preispicrite.

Man setfle, risticrte, wartete. mul Suxiken warncte mian:

- Nal wer denn? Wer denn?! Wer?!!! -

Alle Gesichter waren gelesselt an die sehwar/en Punkite der dahinrasenden Picrde. Man beugle sich uber die Barnere. Dumples Gemurmel. Dic Spiennung "ishst, Wikhst...

$$
\text { Nkx/h - maxch - mxih!... }
$$

Und plixslich, - alle gericien in Erregung. begannen Bcilall 10 blutxihen. 10 sehreien: dic Menge geriet in Bellegung und schwentile: Irewlig erhitale Gesichice. und aus den Winkeln humderer Augen sechilut

\section{Hazard.}

Ich ofline die erste beste Thealereellxihnli und auts Geratewothl uberllicge ich cine Rejensurn:

"Mme. Micunnil gab cin bew cgendes Bild Jer /ärtlichen Mutler. Gewchnt icreartcll - rallinien ist Jur $\mathrm{Cl}$. Jer mil grobser Feinluhlıglicil alle leınen

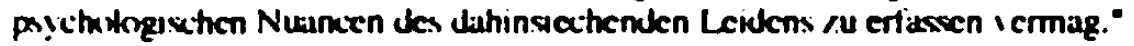

Ins Klosell (damil).

Ubngens. selbst fur diesen Zwati ware Schmirgelpapier /u beicr/ugen. -

Und jeift unterbreite ich cinen Aus/ug dus ciner /ukunl ligen Rejension des Theaters der Loidensetidit.

"Naxh vier Fehlstirts ist Tamara "cil abyexchlagen: um cine halbe Werst erit abgeschlagen Jie nachsic Jurenel a. Weiler Kixinen: Jer Kampl um alle Presse ist oflen: hier Durchsil

Oder $\times$ : Kixinen. dic an der Zıclsaule mil cinem Kinpt gell innt." 111

-Vom Start weg den Abstiand standig icrgribernd. halle Mfonachon lesgelexi den Vorrang: den aweiten Plav belegte bald Vednnstidja und hicll inn uber dic Hallice der Distans: beim Ausging aul dic Gerrecte ist sic mexh dist.

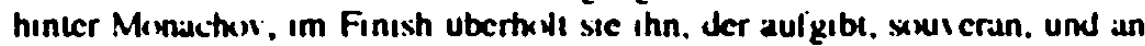
Jer Ziclsiale gewinnt sic mil einem Hals. Von den ubrigen ist Ge Jer nixhstc".

In den Thealerprogrammen wird der Iet/ie Rekiord des Kunstlers angegeben sein und seine "whnellsten Sckinden".

Das Geluhl des Theaters - dias Ist dis Geluhl I 1 m Bew ckung. I erkrampl te Spannung Jer Nerien und Jes Willens. ein ahliles. dinamiscties, mottorisches Prinsap.

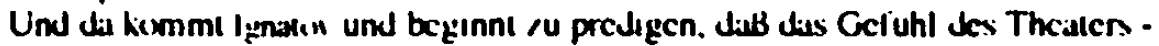

IOUnter Jer Regie ion A. Tün) spiclte Alisi Kixmen 1917 am Kammertheater die Sillome in Oxar Wildes

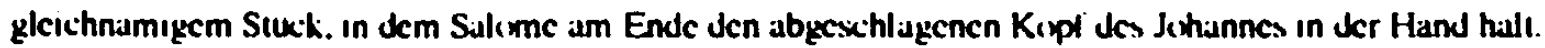




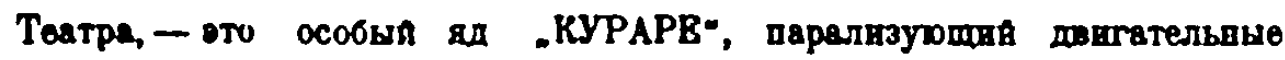
нервы!

Tax позводьте zе Вам схазвть, г. Игватов, что Вы ровво-тахи вичегошеньки ве смыслите в Тевтре! Ибо Вы вакогда ве сходнли с ума, ве аверели в ве бесвлись, ве улолюкали, ве ревели в не гоготали.

А так, просто, чввво „ПВРЕЖИВАЛИ“, взучая программу.

И тевтральва ве чопорвая публикв асовемевтов, оовщаяся разрушить вллюаво, а диквя оразвливвед, выстрелом углопьвахщия вөнавиствого еху Отелло.

Здесь вет ни .сопереживания", ви .сотворчества", вн даме мвлого перешучввавия с публихоя в ивтимвом габара,

\section{saecb rasuso Asapt.}

И каквми отсталыми кағутся советы "безумного" МАРИНЕТТИ намазывать клеем свдевня для арателея вди рассьпвть в публике чнхательныя поропок! Точво мвлое саловвое petst јеU...

Нет! Мы хотим вө мальчншесквх выгтодох, -

$$
\text { YBu! a-Asapta! }
$$

Из Теятра чувство язарта убежкало ва иторвые столь, ва әеленоө поле, ва беговоя круг, взввлось под купол цврка: туда еше ве успеди провиквуть премив вмени Островского.

Театр ровво вдчего не взобралдет в ровво внчего ве преобрахвает. Ов просто овет по голове.

По самоя мakовке.

Пlo caxomy черепy.

Ибо чувство Тевтра, едивое чувство Тевтра, это -

Asapt.

И викаких вспапиев. 
dias ist em besumuleres Gill "CURARE" 11, diss die Bell cgungenen en paraly sert!

So crlauben Sie mir Ihnen eu sagen. Herr Ignallov, dab Sic geniau wie dic Nicel isen ${ }^{~}{ }^{1}{ }^{12}$ nichts iom Theater versichen! Weil Sic niemals um den Verstand gekommen sind, nic grausam und me wild geworden sind, niemals gejohlt. nic ectrulli und nic gewietien haben.

Und so, cinfiach dias Programm studierend, haben sie manierlich"ERLEBT".

Und theatralisch ist nicht das mule Publikum der Abennenten. dies furchict dic Illusion fu /ersitioren. sendern der wilde Brasilianer, Jer mit cinem Schuß den ihm i crhilken Othello umbringl.

Hier gibt es kein "Mitericben". kein "Milcrsithalfen". nichi einmal eine nelte Veriauberung des Publikums im intımen Caburet.

\section{hier gibt es nur Hazard.}

Und wic ruckistindig erseheinen die Ratschlige des "I erruckien" MIARINETTI dic Zuschauersitze mil Kleber au beschmicren isder Juckpulser im Publikum au rerstreucn! Wic cin nelles Salom petit jeu...

Neın! Wir widlien keine Dummejungenstreıche. -

$$
\text { undern - Hazard! }
$$

\section{Ach!}

Dis Getiuhl des Havard hel weg aus dem Theater an die Spaclix.he, an das grune Spiclield, gur Rennbathn. es sucg iul unter dic Zirkuskuppel: derthin kemnicn dic Ostrus stiy-Preise mixh nicht verdnngen.

Das Thealer sicll uberhiaupe nichts dar und i eru andell ubcrhiaupl nichts.

Es sehlidzt cinfiach auf iden Kippt.

Direlit aur den S. heitel.

Direlit auf den Schindel.

Denn das Gefuhl des Theaters, dus cinsage Geluhl Jes Theaten. dis Is: -

\section{Hazard.}

Und nicht irgendwelche Spanier.

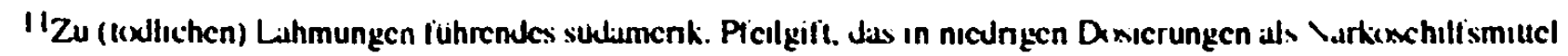
veruendet wind.

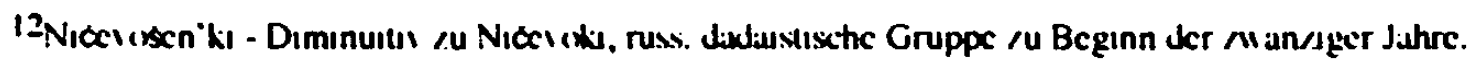


Isouna

Tpaybepr.

\section{Канематограф \\ В роли обличвтөля.}

1. Все мосят камоши "Tpoyronbнак".

Калошв, ках взвество, служат прнзваком зажвточности и хорошего това.

Оправдывало вытявувшуюся крокодилом у магазввов очередь.

-Cnеmво запасаятесь калошами Треугольвик!“

Сегодвя в калошаг торотего тона и зажиточвости зашагали всөлюдв, вещт, иден, төатры.

Девиз: „Уберечься от улпчвои грязи; в погово за калотами!“

\section{2. Похимение детей : Cан-Фраминеко.}

5 декабря 1921 года, швыряясь ЭКСЦЕНТРИЗМОМ В ПУБЛИКУ, как мячом, мы и ве звали, что ввезапво-Фрегали! allez-bopl-трансформация!

На наших глазах мяч чьвхи-то рукахя-разрезав, выкровн, сппт в, получапте без Пеповскоя картотки, - новая блестящая калота.

Согодвя повятне „әксиевтрпзм“ во всех тевтрах, Петроградах, P. C. Ф. С. P-ах, Евродах треплетса, словно Твме по халтурам.

Еледвевно учащавтся сообщевня: Эксцевтрнов, әксцевтрическия дарад, әксцевтро-Хлестаков, өксцевтризация Шоу, Якулов + әксцөвтризм, өхсцевтризм - в вскусстве, в пвделах, в резиновоя промытлеввости.

Завтра - едут, блғзки, здесь!: 1) афишв: поведельвичныя выезд александривского „Мәзов-Төльө“ с участием ЗАСЛУЖЕННОЙ СИСТЕМЫ өксцевтризка, 2) передовици .Жвзви Искусства“ об өксцевтрнзке, 3) лекция Чуковского с рисувками Добуживского, 4) обязательвое появленве на рабфаках с звqислевпек на ак-паек.

...ЛИНА-ШАРЛО ч. ร. ค.

ОТКРЫTИЕ АТTPAKЦИОНОВ

И AMEPИKAHCKUX ГOP. NETPORAA 


\section{Leonid}

Trauberg.

\section{Der Kinematograph in der Rolle des Anklägers.}

\section{Alle tragen die Galoschen "Dreieck".}

Galinsehen dienen. wic bekinnt, als Zeichen Jes Wohlstandes und des guten Tones.

lich rechtfertige die au cinem Krokidil angewachsene Schlange vor Jen Geschillien.

"Versurgen Sic sich schlcunigst mit den Galosechen Dreicik!"

Heule maxhen sich alle in ikn Galexithen des guten Tines und des Wohlstin-

des auf dic Beine.

Menschen. Dinge. Ideen. Thealer.

Dic Devise: "Hule Dich ver dem Stralbensehmut: gur Jaged aul Jie Galenechen!"

\section{Kinderraub in San Francisco.}

Am 5. De/cmber Jes Jahres 1921 xhlcuderten wir den EXZENTRISMLS INS PL'BLIKUM wie cinen Ball und wulsten nicht. dats plesilich - Fregeni! allez-herp! Tramslixmatien!

Vier unweren Augen w urde der Ball - Ion jemandes Handen rerschnillen. eugexihnillen und /usimmengeniaht, bezichen Sic ihne Pepoil Karle. - cine neue prochlige Gallositic.

Heule "ird der Begriff "Ev<cnirismus" in allen Theatern. Petrugraden. R. S. F. S. R.en. Europen abgenutal, wic Thicme ${ }^{1.3}$ im Kitsch.

Taglich wiedertulen sich Bekiannimachungen: Ev/entnon. ex/entrnsche Parade. Ev/entro-Chlestakos. Exyentrisicrung Shaws. Jakulosit + Eventrismus. Eventrismus in Jer Kunst, in auswärligen Angelegenheilen, in Jer Gummindustric.

Morgen - fahren sic, nah. hicr!: 1) Plakiale: montiglteche Ausliahrt des alevundnnischen "Maswm-Tellicr" unter Milwirkung des VERDIENTEN SYSTEMS des Ev/entrismus, 2) cin Lcilurtikel "Dic Leben der Kunst" uber Jen Ev/entnsmus. 3) eine Vortesung Cukovskijs mit Zeichnungen von Dobuzinskij. unbedıngtes Erscheinen in Jen Arbeiterfatultalten mit Anrechnung auf Jie SchauspiclerZutcilung.

\section{...LIN-CHARLOT U.S. A. \\ EROFFNUNG DER ATTRAKTIONEN UND ACHTERBAHN. PETROGRAD}

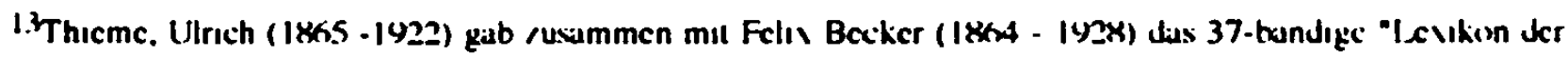

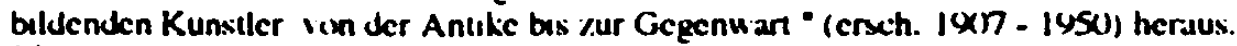

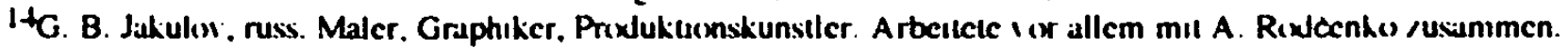
Milbegrunder der ion 1919-1922 besichenden Moskiduer "Gemeinsethaft Jer jungen Kunstier" (Obsoestlo mokex/ych chukrznikis, OBMOCHU).
} 


\section{A y Bac ectb 4то npenzuswtb?}

Театр-ве комнссарнат промншлеввости (сожалөех!). Бюро изобретателеи вет. Патенты ве выдаются. И ве вуждаехся.

Мы ве бонмся повсемествого растаскиваввя вазвавня, тезвсов, провктов „Әксцевтрнческого театра": просто белых домов - мвого, Белыя Дом-одив, в Вашингтове.

Мы протестуем только пролив смазьвавия аксцевтризмом ветодных $x$ определевному делу нвструхевтов; прнводнм свидетельство доктора Автова Меяера: -әксцевтризм привнмается ввутрь; прнемлотадиньми дозами; варудное употребление ве помогает против-бессвлвя, впваса, мелавхогвя, раввея лысивы в др.“.

\section{3arosop nokoinnukos.}

Репетвции, гевералки, премьеры. Журналы, статьи, цисскусспи. Мокументанноо, ГРАНДИОЗНОЕ, плаветарвое. Калоши, калоши, калоши.

Спрос ва галоти превысил предлозевие.

Постедние, заметавпнеся в повсках скачут, как скәтя, по магазввах. Последвим-калоши ве по воге. Не калошн, целья детсквя тробик. Атитречь приказчика: „Последняя мода! Нывче всем калоши вмөсто гробов. Проядете-тапки свимать будут. Как-же можно ве уважать поковников?"

\section{B погоне a2 spмтелеп от Шоксамра до шамтама.}

Кто может ве присоедивиться $\mathrm{x}$ приказчику? Я очевь присоединаюсь. Я люоло покояников. Чехов, сходящияся со мвоя в әтом, выразил мое мвевие:

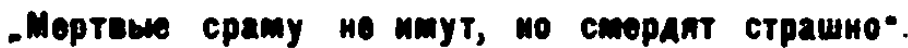

Мвевня әтото вторая половина ве мевее верва, чех первая. Еслв-бы дело бшло тольхо в сраме, так в быть, пусть ве вмут. Но когда ови смердят, и творят әто тут-де под соком, вельая не восстать против. Протест обязателев, как усы Чарли Чаплива. Совершается веподходящее дело. Из обллеевных ЈИКАМИ келия вызолакввяются колымаги в вовые оонтели-посмердөтъ в атмосфере столиков.

\section{6. Ноудавшеся покушемме.}

„Я годагар, и В әтом В. В. Камевския поддержал мевя, что если публвкв требует легвомыслия в пошлости в убегает в кафе, то мы е долхвы очвстить там म застввтт, ОСВРЬЕ- 


\section{Und haben Sie etwas vorzuwcisen?}

Das Thealer ist niche das Kemmissunat der Industric (wir bedaucrn)! Es gubt kein Burs der Erfinder. Patente werden nicht erieilt. Und bratkiten wit nicht.

Wir furchien nk'ht die all gemeine Veruntreuung der Betachnung. der Thesen. der Projekic des "Exzentrischen Theaters". Einfach weibe Hauser gibl es vicle. Dis Wcilic Haus - allein, in Washington.

Wir prosestieren nur exegen die Vermisihung Ion lur cinc besummic Sixithe unbrauchbaren Instrumenten mil $\mathrm{Jem}$ Eventrismus: wir fuhren cine Bescheinigung von Duwux Antun Merer an: "Ev/eninsmus wird innertich angew cnukl: Anu cndung in Plerde-Dussen: auberliche Anwendung hilfi nicht gegen - Schiliche. Ischias. Melientudie, frube Gluken u.i2.".

\section{Zauberspruch der Verstorbenen.}

Pruben. Generalproben. Premieren. Zeilsxhriften. Aufsit/c. Distiussionen. Monumentales. GRANDIOSES. Planclarisches. Galoschen. Galoschen. Gadinxihen.

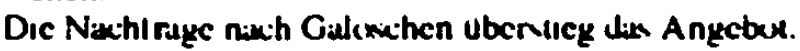

Dic Ictalen. dic sich aul dic Suche gemiacht hiben. zialippicren. Wic im Stectch.

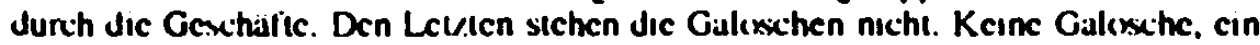

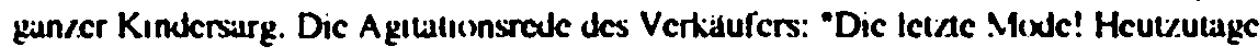
brauchen alle Galloxichen still Sarge. Kommen Sie durch - Sie Weruen die Mutaen abnehmen. Wie kunn man ienn die Versioxtenen mehi chren?"

\section{Bei der Jagd auf den Zuschauer von Shakespeare zu Chantant.}

Wer kiann sich nicht dem Verkijulicr anschlicBen? Ich sehlicBe mich giane an. lch liebe die Verstorbenen. Cectow. Jer darn mil mir ubereinstımmic. Jrukitic meine Mcinung aus:

-Die Toten trim die Schande nicht, aber sie stinken schrecklich." Is

Dic Auberung Jer aweiten Halfic isl niche weniger richlig als dic criste. Wenn cs nur um die Schiunue ginge. meineluegen. soll vie sie nichi trefien. Aber wenn sic stınken und schafien das gerade da in allemixihsier Nähe. diann kiann man dagegen keinen Einspruch erheben. Prokest ist $(x)$ unumzanglich wie der Schnurrbart ion Charlic Chiplin. Es Iollaschi sich cine unpassende Angelegenheit. Aus Jen mit Ikimen betilebien Klexicrielien sehleppen sich Wraths heraus in neus Klisier - um in

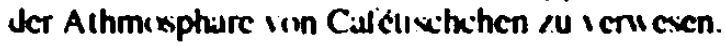

\section{Ein miBglückter Anschiag.}

"Ich meinc. und in dem unterstut/I mich V.V. Kamenskij. dab wenn dis Publikum Lecichtientigkest und Binallitit liorder und dis inlault in die Calks. dann mussen wir cs dkrt luutern und moligen. SERIOS ZU

1.5 Er handell sich hicr keinesw cys um cin Zilit win Cathll. sondern um ein Geflugelles Wort.

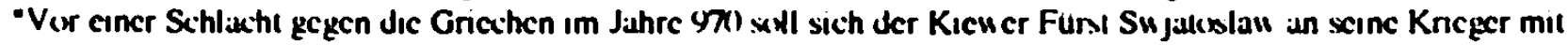
den Wirten eew andi haben: 'Wir Jurien dem Russenland keine Sshande maxhen: lieber lassen wir unser Leben aut dem Schlachtield: Jenn dic Toxen kiennen sich mil Schande nicht bedciken (mertiye sramu ne imul. d. Verf.).' Atien nikch: Ju. N. Afonkin: Russisch-Deutsches Worterbuch der Getlugelten Worte: 2. unicrand. Aulluge: Muskilu. Leıpag 19(x). 
ЗНТЬСЯ. Всли ми не в состоянии удержать публику в театре, мы должны из-за угла заставить ее воспрнять ПОДЛИННОВ ХУ ДОЖЕСТВО“.

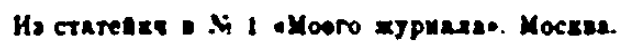

Шерлок Халмс: вынув түубку изо рта, ировичесви ответвл: „Скотлөнд-Ярд, Агптпропы и вообе Компросы! Вы часто ошибаетерь! Вы вндите, кто гонвтся за зрителем, василуя өго вкусы?*

Oтвет: сернознье люди в калотах.

Лозувг ихвего двя: .Революция весет искусство хорошего тона из дворцов на бульвары!“ Крестныя ход, свимаяте шапки, восприниmarte!
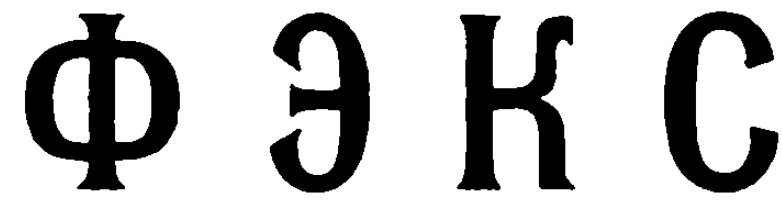

C... 05ложиу

Виноват, товарищи! Не то! $\mathrm{K}$ азбуке! С бульваров во дворцьреволюциея! Бульвар несет революцию в искусство. Сегодня ваша уличная грязь: цирк, кино, мюзиг-холл, Пинкертов.

Схромные, как америкавская реклама, ВЫСОКОНРАВСТВЕННЫЕ, КАК БЕНВДИКТИН, прямые, мак памятимк Татямиа. мы катеторнчески не хотим калош на воги.

А если насильно натявут, что-жн!

Сөвсацвя! Эксцентрическая калота: срывается с ловкоя ноги и летит-в кривые рожи достояных.

Петух

ก 2 เ 3. 
WERDEN. Wenn wir nicht in ser Luge sind, dis Publikum im Thealer au halten. mussen wir es aus Jem Hinicrhalt a wingen ECHTE KUNST "ahssunchmen.

$$
\text { Ius dem Iufisw/ Nr. } 1 \text { "Mlaines burnats" Mlixkau }
$$

Sherlexit Holmes, dic Preife aus dem Mund nehmend. antuortele ironisch: "Scrilland - Yard. dic Agitprop und uberhaupe dic Kompros! Ihr ime Euch cxit! Schen Sic. wer den Zuschauce jagt. wahrend cr ihm Geschmivek auf iningt?"

$$
\text { Antwort: crnsthafic Leuic in Gallexsehen. }
$$

Dic Lusung ithres Tages: - Jic Revolutuon tragt dic Kunst des guten Tons aus den

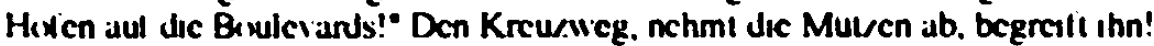
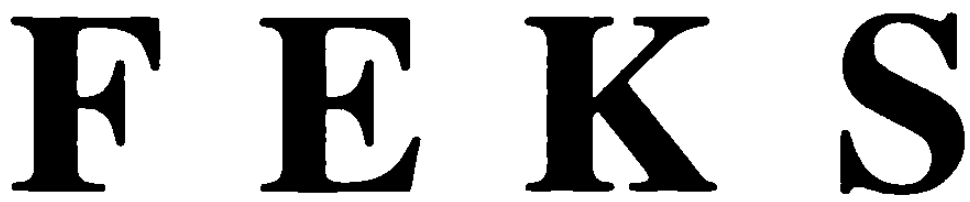

S. L'MSCHLAG

Schuldly. Kameraden! Nicht das! Zum Alphabct! Vinn den Bevuleiards in die

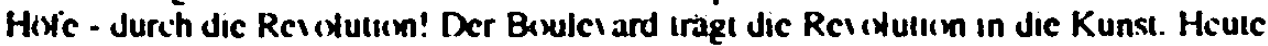
Ist unser Stralkenxihmut:: Zirkus. Kino, music-hall. Pinkerton.

Bescheiden wie amerikanische Werbung. HOCHMORALISCH WIE EIN BENEDIKTINER, direkt wie das Denkmal Tatlins, "ullen wir entschicden keine Galusichen an Jen Fulben.

Und " enn man sic uns gewaltsam anescht. was dunn?!

Sensatuon! Dic ex/entrische Galische: reibe sich lisx vom bequemen Bein und tliegt - in die schiefen Fraven der Gerechien.

\section{Ein Gickser \\ Pathels}

\footnotetext{
16 Pathe und Gaumenl. Weliwell openerender franess. Ken/ern. Jer um die Jahrhunderiw ende als erster Filme niach Rubliand i ertidufte.
} 


\title{
ЭнсцентризМ- Hивопись- P енла м $A$
}

\author{
.Вое ва Фровт травспорта-! \\ 1909, \\ смевив расглябанвье ковкв старото исхусства, носятся огодтелье \\ zелтье, красние трамвав Футуризма, \\ 1921
}

в вот овд веуклюше, верх колесауи, валяотся в трвмваяных пархах Совремеввого Искусства,

\section{2}

Иs Депо Әхсцевтркков-Мотоцилет Новоя Живописк.

Победво громвохала Револичня Живописн, во что осталось веселым мотоциклвстам от яее сегодвя, ках ве:

„Традвинв Әнгра" (Пикассо), автвкварвая руглядь в обонх лавочках .Мар Искусства“ (быв. „Бубвовыя Валет“ и прочне Бөвуа), рукоделья супрематистов п

бесчислеввье кипы прогнивших теория, где есть все, начняая от метафнавки в ковчая математическимп формулаки, во где вет ни словя

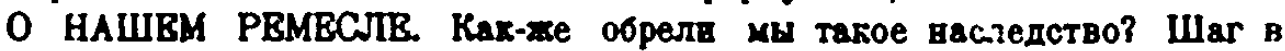
проплое:

$$
\begin{aligned}
& \text { Импрессвоввам } \\
& \text { пуәвтеллвах } \\
& \text { Футурвах } \\
& \text { кубвзх } \\
& \text { әкспрессповнак. }
\end{aligned}
$$

Раздроблевве әлемевтов формы в содержаввя. Полвыя разрыв с зизвьу. Созет провзведеввя - форма. Крев корябля европеяскоя худьтуры.

Утопазощие тщетво пытартся ухватвться 38 содомивкп мистицвзма в сихволизма.

Но властвы ревом врывается в вадушеввые будуары әстетствующего вскусства адектрическая сирева Соврсхеввости! Все требовательнее и упорвее звучит призыв: вияти вз рахок картввы в приблазвться $\mathrm{x}$

$$
\text { момиретиооти, ощуттиоости, вощи. }
$$




\title{
ExzentrismuS- Malere I - Rekl a m E
}

\author{
"Alle an dic Verkchrsinme"! \\ ISXY.
}

auszewechsele sınd dic /ertiahrenen Pierdebuhnen der alien Kunsl, min liegl diahın in den augellwsen. zelben. ruxen Strabenbahnen des Futunsmus. 1921

und w) liegen sic plump. mil den Risdem nixch (ben. in den SIrabenbuhngaragen der Mixdemen Kunst.

$$
1922
$$

Aus dem Depox der Eventriker - Das Mentrrrad der Neuen Mialeret.

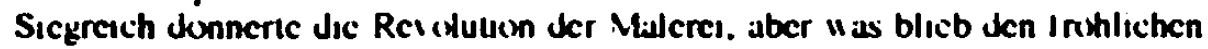
Misturradlem heule vien ihr, wenn nkeht:

"Dic Tradition ion Ingres" (PI(dasx)), antiquarisches Gerumpel in beiden Kramliasten" 17 "Dic Well Jer Kunsi" (ehem. "Karn Bube" 18 ) Jund andere Bentia) ${ }^{1 "}$. dic Handarbetien der Suprematusten und un/uhlige Stiste verfaulter Therrien, Wo cs alles gibl. angelangen ion Meluphi sik und endend mil mathematusetien Formeln, aber wo es nichi cin Wort UBER UNSER HANDWERK gibl. Wic kionnten wir au so ciner Erbschidl gelangen? Edn Sichnil in die Vergangenhest:

$$
\begin{aligned}
& \text { Impressionismus } \\
& \text { Pointilismus } \\
& \text { Futurismus } \\
& \text { Kubismus } \\
& \text { Expressiconismus. }
\end{aligned}
$$

Eine Zeritikikelung der Elemente von Furm und Inhialt. Ein wolliger Bruch mit dem Leben. Das Sujel eines Wertes ist die Form. Die Schlagselie Jes Dampiers Jer curspuschen Kultur.

Dic Versinkenden icrsuchen iergeblich. sich in Jem Sirohhalm Jes My siliasmus und Sy mbohlismus Iesteukliammem.

Dexh mil herrisithem Gebrull sturmi Jic elekiriscthe Sirene der Gegenwiant in Jic

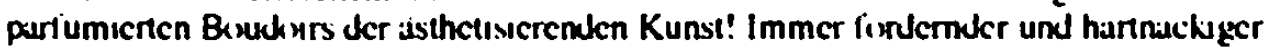
Wingt der Rut: A us den Bildertahmen herausirelen und sich nishem der

Konkrethelt, der Wahrnehmbarkeit, der Sache.

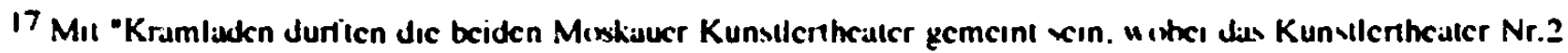
1922 aus dem I. Sludio des unsprungdichen Kunsilerthealers her ox yejg.

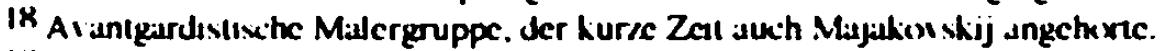

19) Alcksandr Benua (Alevandre Benuls. 1870 - | $(x \times())$. Graphiker. BuhnenbilJner und Milbegrunder der cinflubreichen Schauspiclergruppe "Well der Kunst", halle 1915 drei Pustin-Stlkike ("Mo/ant und Sillien", "Der stcinerne Giast". "Dis Festmahl wahreind der Pest") am M("hAT als Milsenilg ins/eniert. 
От Сезанва до Пихассо -овеществлевие спжөтв. Натор-морты, певзвхв, подражание вывескам, подделка матерналов, клеяка прөдметов ва поверхвость холста. Картияы ве существует-из рам топорщатся угль, сдвагя, предметы, краска.

\section{ИЗОБРАЗИТЕЛЬНОСТИ НАСТУПИЛ КОНВЦ.}

Калиф вв час, Супрематвам, сам того не зелая, сделался .утилитаринм-, перекочевав на сумочкв барышен из кафе и ва подушки возрождаюmехся тостввных - приличвых домов". Ковстругтиввзм выстушвл с отрицавием плоскости и цвивул лозувг:

ЧЕРЕЗ РАСКРЫТИЕ МАТЕРИАЛА $K$ НОВОЙ ВВЩИ.

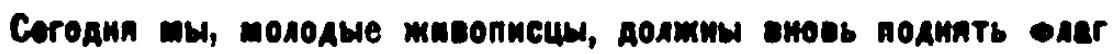
Hocoll Husonmen!

Такме бесцельво утверждать бөсполезность плоскости, как отрицать утилитарность киво аа отсутствнем фильм с фнзиовомнея вовот фрввцузското президевта.

Плоскость в нзобризттельность ие умерли, во веобходим хоренчоя перескотр нашего отношения $\mathrm{K}$ всхусству. Не превебрежевне Жизвьо ради вскусства, а через вовое миросозерцавне

ЖИЗНЬ, КАК ТРЮК

х новому Исхусству. Мы зивом всех из лиоривтов Интеллектв х восприятви Совремеввости!

Довольно самоуслахдевяя, мы требуем от Нскусства тенденция и утилитарвоств!

Вяеряшвне революциоверы, сегодятвне академики, ках быстро ови прнобрели маверы заслугенных .метров" и рөкомевдуют молодому искусству свои рецепты, как едивствевво верные. Но мы предупреждевы, мы видим: в буржудзвых саловах ва стеввх вместо Сомовьх - Яхулов.

Мы утверждаем-раво одочнвать ва лаврах!

Posannumn npososmeetcn!

\section{ДЕМОНСТРАЦИЮ КИНО-ФИЛЬМ

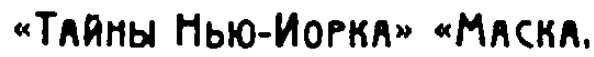 \\ KOTOPAR CMEETCR". P.C...S...}


Vun Cc/anne au Plicasix) - Jie Vergegenstiandlichung des Sujcts. Stılleben. Lindschalien. Nachahmung des Firmenschildes. Faluchung der Mailenalien. das

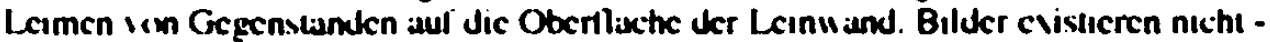

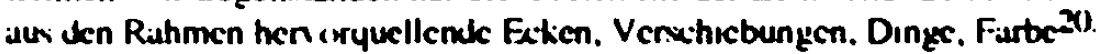

\section{DAS ENDE DER DARSTELLLING IST GEKONIMEN.}

Kallif aul kur/e Dauer. Jer Supremaltsmus hall sich unwillentlich "utillianstisch"

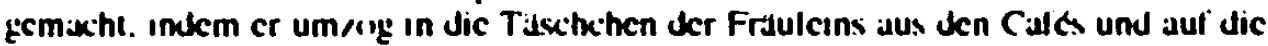
Kissen Jer "iedererstandenen Gast/ımmer "ansiandiger Häuser". Der Konsitrukilisismus Iral aul mil Ablehnung der Plattlude und incb dic Devise icran:

\section{DURCH DIE ERSCHL.IEBUNG DES MIATERIALS ZUR NEUEN SACHE.}

\section{Heute müssen wir. die jungen Maler, wieder die Fahne der Neven Makerel ertheben!}

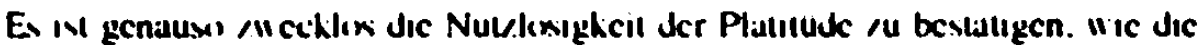
Nut/lichlicit des Kınes a icrneinen 1 egen des Fehlens eines Filmes mat Jer

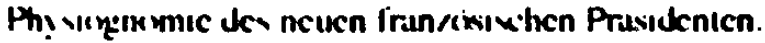

Platilude und Darsicllung sind nicht pesiorben. Jixh wir himmen nicht um cinc grundsit/lictic Uberprulung unserer Einsicllung /ur Kunst herum. Nithi Jic Vicinachlisssigung Jes Lebens " "geen Jer Kunve. sendern Jurch cine incue IVcllanschauung.

\section{DAS LEBEN ALS TRICK}

a ciner neucn Kunst. Wir rulen alle aUs den lib!rinthen Jes Intcllchts fur Wathrnetimung der Gezenw:art! Nut/lichlikcil!

Genug imit dei Selbsicrgot/ung. "Ir lordern ion dei Kunst Tenden/ und

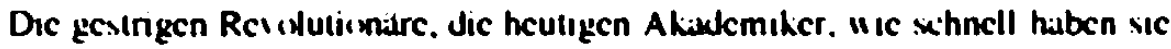
die Nanier Jer icrdienten "Versmalte" angenommen und emplichlen ver jungen Kunst ihre Re/epte als dic cin/sg wahren. Aber wir sind gewarnt. Wir sehen: in Jen beurgermeen Sillems an den Wanden

still der Simoss. - Jahulow.

"It ienichem - es ist /u fruh in den Klisilem fu sterben!

Die Revolution geht weiter :

\section{Demon stration des K INO-FILMS \\ "Das Geheimnis von New-York" \\ "Die Maske. die lacht". R.S.F.S R.}


II.

Mb

ОЦЕНИВАЕА ИСКУССТВО, КАК НВУТОМИМЫЙ ТАРАН, ВДРЕБЕЗГИ РАЗБИВАЮЩИЙ СТЕНЫ ПРИВЫЧЕК И ДОГМАТОВ.

Но мы также вмеөм предков!

BOT:

Гевиальвые творцы плакатов кнво, цврка, варьето, без'вәвествые ввторы пблпжек $\mathrm{K}$ похохдевиям королея сыщнков и ввавторнстов; от Bamem прекрасного, гак клоувская рахх, Искусства, хзк от аластичного трамплина, отталкивяемая, для того, чтобы совершить вапө бөсстрашвоө сальто Эксцевтрнама!

Единственное, что иәбегло растлеварщего скальпеля анализа и ввтеллектв-ПЛАКАТ, Сохет и форма вервздельвы. Что воспевается B них?

Риск, отвагя, василие, потовя, революция, золото, кровь, слабятельвые пилюля, Чарльз Чаплия, крушевня ва земле, впде, воздухе, удивательвые сигары, опереточныс првмадонны, ававторы всех сортов, гкатииг-рингт. американские ботввки, лотапи, борьба, таясоветки,

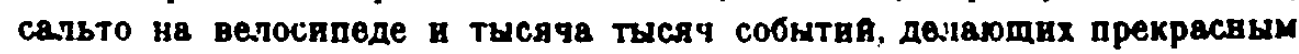
same Ceroдвa!

ВСЕ ЛВЕСТИ ТОМОВ ФИЛПСОФИИ НВМЕЦКОГО ЭКСПРВССИОНИЗМА НЕ ДАДУГ НАМ ВЫРАЗИТЕЛЬНОСТИ ЦИРКОВОГО ПЛАKATA!!!

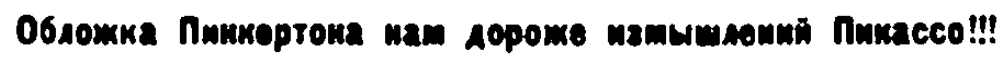

Мы не желаем пичкать новыми редептами молодую живопясь во зваем

YTO:

1) Матернал пронзведения-сохет, форма.

2) Вместо сожетк мы утверждаем-трок.

3) Трюк-внсшөе вапражевне в использоваввв мвтервала.

4) Фактура-степень напрязеняи обработки матернала.

5) Повятием -фактура“ мы обозначаем не только степевь напряженяя обработкн холста, во и обработхи тркіка (сожет).

6) Фактура трюка требует раввоя фактуры форм.

III.

Mb

РЕКПАМИРУЕМ СОВРЕМЕННОСТЬ! СОвременвость-трох, ослепительвыл в своея веожндаяностиседнвственвая форма живопися Cөгодн: эксиестринесий алакат. 
II.

WIR

SCHATZEN DIE KUNST ALS UNERMUUDLICHEN RAMMSPORN. DER DIE WANDE DER GEWOHNHEIT UND DOGMFN IN KLEINE STUCKE SCHLAGT.

Aber w ir huben auch Vorfiahren!

DA:

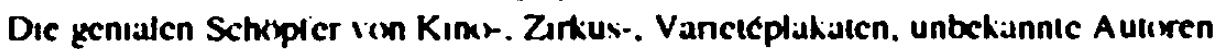
irm Buchumichlugen a Abenteuem der Kimize der Detekitic und Abentcurer: irm Eurer w undertaren Kunst. Jie wic cine Clom nstraue ist, wie I in einem elastixithen Trampolin abgestobsen. um unseren lurchelusen Salto Jes Exacntrismus au irdlbnngen!

Das Ennage. das dem entehrenden Skalpell der Analyse und des Intellekis auswerchen kismnic - Ist das PLAKAT: Sujet und Form vind untrennbar. Was wird in thnen gepnesen?

Rivikio. Kuhnheil, Geilall. Rescolution. Gestd. Blut. Abluhrpillen. Charles Chaplin. Kaltastruphen eu Linde. au Wisser. in der Lult. erstiunliche Ziguarren.

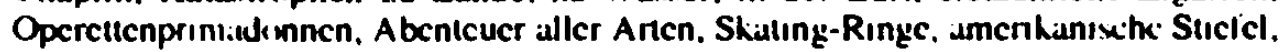
Pierde. Kampl. Chansunctien. Sallos aul Jem Fahrrad und tausend mal tausend Ereignisuc. dre unser licule w undertar mixhen!

ALLE ZWEIHUNDERT BANDE DER PHILOSOPHIIE DES DEUTSCHEN EXPRESSIONISMUS GEBEN UNS NICHT DIE ALISDRLICKSKRAFT DES ZIRKUSPLAKATES!!!

\section{Der Buchumschlag von Pinkerton ist uns lieber als die Hirngespinate PIcassos!:!}

Wir wollien dic junge Malferel nicht mil neuen Re/cpien villstuplicn. aber wir wisien

\section{DASS:}

1) Das Matcnal des Werkes diss Sujet ist. dic Furm.

2) Wir ansiclle des Sujels den Trick bestiarken.

3) Der Tnck twethere Spxinnunge ist in der Ausnute ung des Mialerials.

4) Fakitur Jer Spannungus grad ier Malenalbearbeilung ist.

5) Wir mil Jem Begrifl "Faklur" nicht nur den Spunnungsgrad der

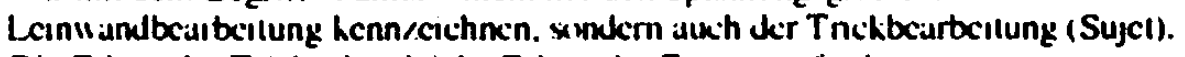

h) Dic Faktur Jes Tneks die giciche Fakitur der Formen erfiorden.

III.

WIR

MACHEN REKLAME FIR DIE GEGENWART! Dic Gcyenwart - das w Tinck. blendend in seiner Überrawihung = Jic cin/ige Form der Malerei ist Heule:

\section{Das exzentrische Plakat.}

Bayerlsche Staatsbibliothek München 
Старая жнвопвсь умерла сама. ӘКСЦЕНТРИЧЕСКИЙ ПЛАКАТ УНИЧТОЖАВТ ЖИВОПИСЬ ВООБЩЕ.

\section{Mpensaraem:}

1) Бульварнаапио всех форм вчерашнея жввописи. Кубвам-футурнзм-әкспрессвоввзм чөрез фильтр: лаковнчвости-әкіпресСви-точноств-веохвдаввоств.

2) Максвмалввое исподъзовавне форм лубка, плаката, облохек удвчвых издавив, реклам, трифтов, отихеток.

8) Эксцентрическия плакат ВСЕ ВИДИТ-ВСЕ ЗНАЕТ! Использование живопнсвых прнөмов в целях агттация и пропвганды. ІІоследниө нзобретевия, вовости, моды.

4) Поотревне жанрв художвиков-момевталистов. Шаржи, каррикатуры, revue.

Б) Иаучевве лохомотивов, аяо, пароходов, двигатөлев, мехвмвамов.

Научиш nо6ить mamnнy!

Иаделвя фнрмы „Искусство“ НВ ГОДНЫ К УПОТРВБЛЕНИЮ.

Bсе долемин убедиться:

ayvean oxpana - mupo . Husus".

Oсторегаятесь подделок!

ЖИЗНЬ НУЖНА НАМ, НАДО СДЕЛАТЬ, ЧТО-БЫ МЫ БЫЛИ нужны жизНИ!

Машивы, мосты, здавья-хдут Вас, конструктивисты! Мозня-голль, цирки, стевы вебоскребов - свободны для Вашей гигантскон кисти әхсцевтрнческпе живопвсцы!

\section{ЭКСЩЕНТРИЗМ \\ Ж И В О И С В \\ P B K Л A $M$ A}

ДЛЯ ВСЕХ, КТО ЖИВЕТ СВГОДНЯ!!!

P. S. Почтеввым теоретикам, критдхам, вскусствоведам, добрагелательно сосккамщим об ошвбках нашея горячен молодостибросаек формулу Марвнеттв:-.Старвкв всегда ошнбаются, дамке когда правы, а молодые всегда правы, даже когда отябаштая!- 
Dic altc Malcrei int selbst gestorben. DAS EXZENTRISCHE PLAKAT VERNICHTET DIE MALEREI INSGESAMT.

\section{Wir bieten an:}

1) Die Boules ardisierung aller Firmen der gesingen Malerei. KubismusFuturismus-Expressionismus durch den Filter: Liahonismus-EipressionGoniduigkicil-Libcrisushung.

2) Die mavimale Ausnutgung der Fromen des bunien Bildes, des Plakiales. Jes Buchumichlazes. Jer Strattenausgaben. Jer Reklamen Jer Schrifien. Jer Etikcticn.

3) Das ex/eninuche Plakial SIEHT ALLES - WEISS ALLES! Benut/ung der Malereliertiahren mil Jem Ziel Jer Agltaluon und Propuganda. Neucste Ertimulunzen. Neuighicien. Mexten

4) Forderung des Genres Jer Maler-Mfumentalisten. Grotesken. Kankuturen. Reiuc.

5) Studium Jer Lexismentiven. Aulix. Dampler. Mexeren. Mechantsmen.

Wir lernen die Maschine zu lieben!

Waren Jer Firma "Kunsi" SIND NICHT ZLIM GEBRALCH GEEIGNET.

tlle sollen sich uberzeugen:

Die beste Firma der Welt ist "Das Leben".

Hulcn Sic sich I ir Falschungen!

DAS LEBEN. DAS WIR BRALICHEN. MLIB MIAN HERSTFLLEN. DAMIT DASI.FBEN IINS BRALICHT!

Maschinen. Brukiken. Gebaude - "arten aul Euch. Konsiruktisisten. Music-hills.

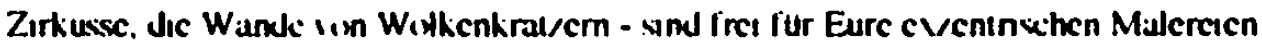
mil gigantiscten Pinseln!

\section{EXZENTRISMI iS \\ MAL.EREI \\ WERBLNNG}

\section{FIR ALLE. DIE HELTTE LEBEN!!!}

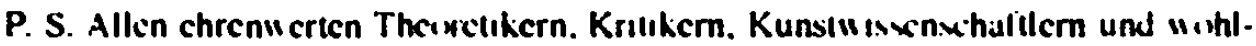
"Ir)llend uber dic Fehler unserer hit/lgen Jugend Lispelnden - wehleudern wir Mannetis Firmel entgegen - "dic Alten irten sich innerer. weltuit "lenn sic recht haben. und die Jungen hiaben immer recht. welmi " wenn we sich imen!" 


\section{ВИТРИНА САМОРЕКЛАМЫ}

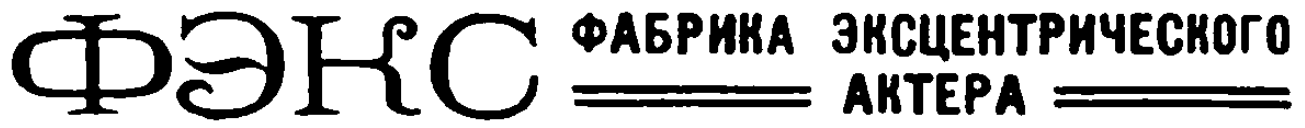

3AHAIMA BEAYY:

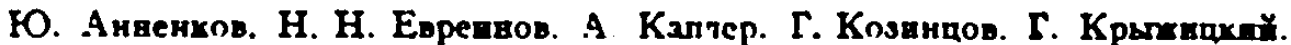

А. Лурье. К. М. Махлашевскиі. С. Митусов. А. Орлов. Н. Пувшв.

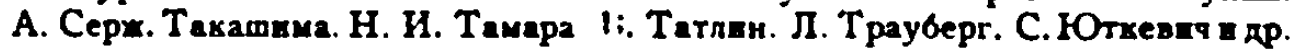

\section{ЭКСЦЕНТРИЧЕСКИЙ ТЕАТР \\ B PAGOTE:}

I. ЖЕНИТЬБА. Севершенно пеобытайтые похохдения эхсц. Серша.

II. ПИНК-ПАНК.

III. ДЖКН-ДЖЕНТЛЬМЕН ः РАСПУТНАЯ БУТЫЛКА.

\section{ИЗДАНИภ}

Гсориий Крохжицкий. Фклософскии Балаган.

Эксиентрвзм No 1.

$$
\text { Готовя TC8: }
$$

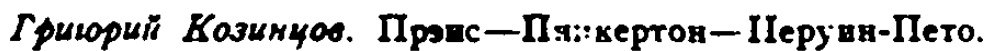

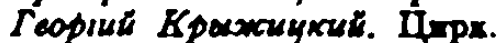

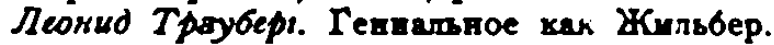

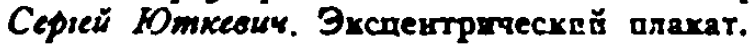

'Эксдеитриsx No 2.

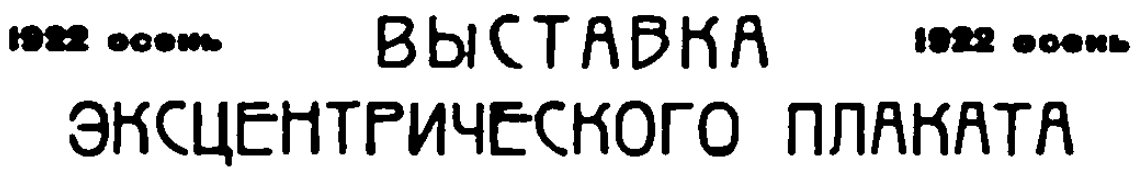

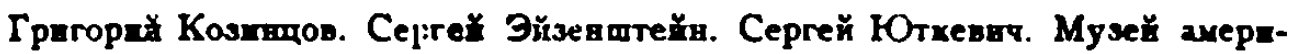
канских плахатов, обтохек бульв. романов а др.

\section{СПРАвКи-3АПись-ПРЕДЛомЕниЯ

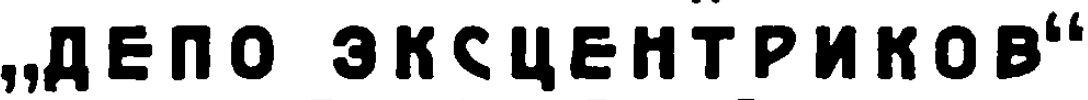
Бอocen̆man, 7. ตอ. 7. 


\section{Schaufenster der Eigenwerbung}

$F E K S \quad$ Fabrik des exzentrischen

$$
===\text { Schauspielers }===
$$

DEN UNTERRICHT FULREN:

Ju. Annenkior. N.N. Jer rejnor. A. Kapler. G.Korincor. G. Kñzutskij. A. Lur'c. K.M. Miklaseviskij. S. Milusws. A.Ortow. N. Punın. A. Serz Takiaschımu. N.I.

Tamara. K.Taulin. L. Traubery. S. Jutkci ic u.iL

\section{EXZENTRISCHES THEATER}

IN ARBEIT:

I. DIE HEIRAT. Die gändich ungewishnlichen Abenteucr des EV. Scrz.

11. PINK - PANK.

III. DZIN - GENTLEMAN Und DIE LINSITTLICHE FLASCHE.

\section{VERÖFFENTLICHUNGEN}

Cieorgij Krizitskij. Philemuphıche Schuubuck.

Ev/cntrinnus Nr.l

ES BEREITEN VOR:

Ciriporij Knziun oll . Prens - Pinkcrlin - Peruin-Pclus.

(ieorgij Krvzisskij . Zurhus

Iermid Trauberg. Geniales Wic Gilbert.

Sergej Julkevic. Ev/entnwhex Plakat.

Eventrismus Nr.2

1922 Herbst A usstellung 1922 Herbst
DES EXZENTRISCHEN PLAKATS

Grigurlj Kosancoi. Sergej Ej/cnsicjn. Sergej Jutkevic. Muscum amerikianisether Plahille. Ulmsethlage som Berules ardromianen u.i.

\footnotetext{
Auskünfte - Anmeldung - Vorschläge

"DEPOT DER EXZENTRIKER"

Bassejnaja, 7. Wohnung 7.
} 


\title{
2.3. Futurismus
}

\subsubsection{Futuristische Elemente in Exzentrismus}

Beim ersten Durchlesen erscheint das vorliegende Manifest als eine Vermischung verschiedenster avantgardistischer Strömungen. Der Großteil. der darin enthaltenen Thesen. ist jedoch eindeutig dem Futurismus zuz.uordnen. Vermischt wurden dabei italienischer und russischer Futurismus. Der italienische Futurismus wurde allerdings von den russischen futuristischen Dichtern abgelehnt. deren Grundeinstellung eine ganz andere war als die der Italiener. Wie Ripellino beschreibt. gab es auch wenig

\begin{abstract}
"hemerkensuerte Analogien zwischen dem russischen und dem italienischen Futurismus. Die stilistische Handschrift Chlebnikow's und Kamenskijs - ganz durchzogen von fruhzeitlichen und asiatischen Motiven. aus einem Klima slawischen Heidentums geboren - steht in offenem Gegensatz zu den italienischen Futuristen. Das verbohrte Erforschen unterirdischer Gänge der Sprache. die Abneigung gegen den Krieg. gegen die imperialistischen Hirngespinste. der Akzent einer sozialen Revolte und andererseits die aufdringliche Farbgebung der Bilder vertiehen dem Schaffen der Kubofuturisten einen ganz eigenständigen Chamkter. ${ }^{\text {"173 }}$
\end{abstract}

Nach der Revolution allerdings sahen viele junge russische Theaterregisseure wie Annenkui. Radlov, Ejzenstejn. Kozincev. Trauberg u.a. die Grundlage für ein neues. zeitgemäßes Theater in Marinettis Manifesten (vor allem in dem über das Varieté von 1913. aus dem auch das Marinetti-Zitat auf S. 2 des Manifestes "Ekscentri $\angle m$ " stammt, sowie in dem über das synthetische Theater von 1915).

"Bekanntlich unterstrichen diese Manifuste die Notwendigkeit. das Prosatheater mit dem Varieté. das einzige. das die Futuristen dem rasenden Rhythmus der Zeit angemessen hielten. zu verknupfen. ${ }^{\text {174 }}$

Dabei sollte das von Marinetti und in der Folge auch von den russischen Regisseuren geforderte Varieté anders aussehen als zur damaligen Zeit iiblich. Zirkusakrobatik. Film, die Einbeciehung des Publikums in das Bühnengeschehen und die Provokation der Zuschauer sollten das neue Varieté cha-

\footnotetext{
173 Ripellino(19xh). S. 310

1.t llind. S. 10.3.
} 
rakterisieren. Klassische Dramen sollten mit diesen Mitteln so auseinandergenommen und parodiert werden. daß nichts mehr von ihrer Feierlichkeit und Eshabenheit bliebe.

Diese Forderungen bilden auch den Schwerpunkt im Manifest der FEKS. Gleichzeitig wird hier aber auch Majakovskij immer wieder zitiert. Die Fèksy haben sowohl von Marinetti als auch von Majakovskij Aussagen entlehnt und daraus den Exzentrismus geformt. Zeitlich gesehen könnte man sie schon als Erben des Futurismus betrachten, der zu Beginn der zwanziger Jahre seinen Höhepunkt bereits ubberschritten hatte. Sie entwickelten sozusagen eine weitere Form des italienischen Futurismus. den Futurismus des Theaters, der von Marinelli in den genannten Manifesten zwar schon gefordert, aber in dieser Form noch nicht realisien worden war. Die Theatersticke der italienischen Futuristen zeichneten sich vor allem durch Kiirze und Wirklichkeitsbezug aus, was in Inszenierungen wie "Heiral" (FEKS) oder "Eine Dummheil macht auch der Gescheiteste" (Ejzenstejn) absichtlich völlig fehlte. Wie Christa Baumgarth beschreibt. handelte es sich bei den italienischen futuristischen Theaterstücken mehr um Sketche, die aus einer alltäglichen Lebenssituation herausgegriffen waren. So handelt beispielsweise Marinettis Stuck "Sie kommen" ("Vengono") ausschließlich davon. wie in einem Haus der Tisch gedeckı wird für die Personen, die erwartet werden. ${ }^{75}$ Durch das Fehlen eines im Drama üblichen Handlungsbogens waren diese Stücke allerdings im wahrsten Sinne des Wortes 'exzentrisch'.

Die Theaterstucke der Kubofuturisten, die in den Jahren 1913 - 1916 inszeniert wurden. waren entweder noch vom Symbolismus geprägt, wie z.B. einige der Werke Chlebnikovs. oder entsprachen voll den Grundsätzen der russischen Kubofuturisten, die vor allem zum Abstrakten im Theater tendienen.

Wie bereits erwähnt waren es nicht die Fèksy allein. die den Futurismus in Form von Varieté- und Zirkusnummem ins Theater einführten. Die in Kapitel I. beschriebenen Regisseure Radlov. und Foregger aber auch Annenkov. der bereits 1919 mit seiner Auffuhrung "Der erste Weinbrenner" (pervij vinokur) von Lev Tolstoj ein Theaterstuck in Varieténummem inszenient hatte. befaßten sich mit der Verbindung von Varieté. Zirkus und music-hall im Theater. So ist Ejzenstejns 'Montage der Altraktionen' letztendlich ein Ergebnis dieser Arbeit. während beispielsweise Radlov und Foregger nur kurze Zeit Erfolg

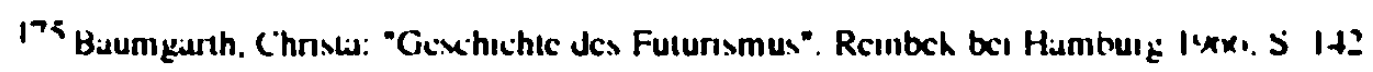


hatten. da sie sich auf die Parodierung des klassischen Theaters beschränkten und ihren einmal gefundenen Stil nicht weiterentwickelten.

Wie groß die Ähnlichkeiten gerade zwischen Marinettis Theorien und denen der Fèksy waren soll hier an einigen Beispielen gezeigt werden.

Wenn es in Punkt 3. von Marinettis "Manifest des Futurismus" heißt:

"Wir wollen preisen die angriffslustige Bewegung. die fiebrige Schlaflosigkeit. den Laufschritt, den Salto mortale. die Ohrfeige und den rausischlag." 176,

dann entsprechen dem zwei Stellen aus Kozincevs Artikel "AB":

"Das Stück - Anhäufung von Tricks. Tempo 1000 PS. Nachstellungen. Verfolgungsjagden. Flucht. (...) Der Rhythmus der Cečtka. Der Krach des Kinos. Pinkerton. Der I arrm der Achterbahnen. Die schallende Ohrfeige des Harlekins.|... $\left.\right|^{\text {"1 }}$ (7)

Oder wenn Marinetti schreibt:

"In den Varietévorstellungen muß die Logik völlig aufgehoben. der Luxus übertrieben. die Kontraste vervielfältigt werden. und auf der Bühne müssen das Unwahrscheinliche und das Absurde herrschen $|\ldots|^{n / 7 x}$

dann läßt sich das mit Kozincevs Fordenıng vergleichen:

"Cancan auf dem Seil der Logik und des gesunden Menschenverstandes. Durch das 'Undenkbare' und das 'Unmögliche' zum txzentrischen." ${ }^{\text {(x) }}$

Doch diese Analogien zu Marinetti sind vor allem bei Kozincev zu finden. während Jutkevic den italienischen Futurismus der Vergangenheit zuordnet. wenn er in seinem Artikel "Exzentrismus - Malerei - Reklame" schreibt:

1909.

ausgewechselt sind die zerfahrenen Pferdebahnen der alten Kunst. man fliegt dahin in den zügellosen, gelben, roten Straßenbahnen des Futurismus.

176 Apallinis. Limbrı: -Der Futurismus. Munileste und Dikumente ciner hunstlensihen

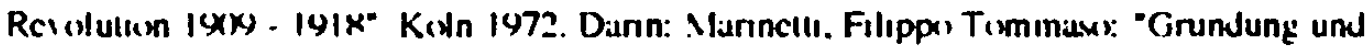
Manilest Jes Futunsmus:. 100\%, S 33.

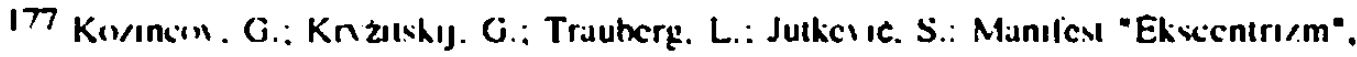
Peirigrad IVI) S. 41.

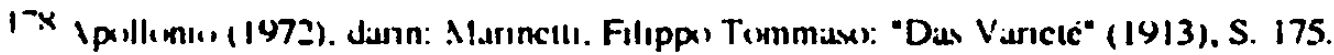

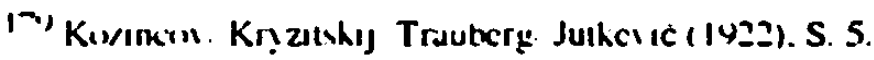


1921

und so liegen sie plump, mit den Rädern nach oben, in den Straßenbahngaragen der Modernen Kunst, " $\mid(x)$.

Dabei werden Kozincev und Jutkevic in ihren das Theater und die Malerei betreffenden Forderungen konkreter als Marinetti zu seiner Zeit. Während Marinetti in seinem Artikel von 1913 die Aufhebung des Theaters durch das Varieté fordert und dessen Möglichkeiten und Mittel theoretisch bespricht. nennt Kozincev konkrete Mittel wie Zirkusclowns. Jazz-Bands. Boxen. Hupen. Verfolgungsjagden etc. ${ }^{\mid 81}$

Jutkevic fordert sogar explizit mit der ästhetisierenden Kunst zu brechen und sich der Konkretheit, der Wahrnehmbarkeit und der Sachlichkeit anzunähern. wobei er auch den Futurismus zur ästhetisierenden Kunst zählt. Die Kunst (Malerei) solle Tendenz und Nitzlichkeit aufweisen und die sieht er zum gegebenen Zeitpunkt nur in Veranstaltungsplakaten und Buchumschlägen von Abenteuerromanen. ${ }^{182}$ Auch Kozincev fordert eine nichtästhetische Kunst ohne Großbuchstaben, Podest und Feigenblatt. Zwar benutzt er nicht das Wort Tendenz', doch in Schlagsätzen wie "Das Hinterteil von Charlot ist uns lieber, als die Arme von Eleonora Duse!" oder "Die doppelten Sohlen eines amerikanischen Tänzers sind uns lieber, als die fünfhunden Musikinstrumente des Marinskij Theaters." 183 kommt diese Tendenz genauso zum Ausdruck wie bei Jutkevič. Die Tendenz der Fèksy nämlich zur Revolutionierung des Theaters durch Anwendung der "niedrigen" Kunstgenres.

Wenn man im Vergleich mit diesen Aussagen die Skizze Kozincevs zum Bühnenbild der Inszenierung von Gogol's "Heirat" ("Zenit "ba") wenige Monate nach Erscheinen des vorliegenden Manifestes betrachtet (s. Anhang). dann ergibt sich auch hier ein Widerspruch in den Aussagen von Kozincev und Jutkevic. Dieses Bühnenbild ist nach Aurbau und Form eindeutig dem Futurismus zuzuordnen. Während Jutkevic den Futurismus in der Malerei ablehnt, befürwortet Kozincev ihn in seiner praktischen Malerei. Auf der anderen Seite beendet Jutkevič seinen Artikel und das Manifest mit einem angeblichen Zitat Marinettis: "Die Alten irren sich immer, selbst wenn sie recht haben. und die Jungen haben immer recht. selbst wenn sie sich

\footnotetext{
180 Ibid.. S. 12.

$181 \mathrm{Vgl.} \mathrm{Ibid..} \mathrm{S.} 41$.

182 Ibud.. S. 121T.

18.3 Ibid. S. 4 .
} 
irren!" IæH Aus all dem läßt sich schließen, daß es wirklich in erster Linie Marinettis Forderungen für das Theater waren, die die Fèksy übernahmen. Eine weitere Erklärung ist, daß sie durch ihre Ausbildungen zu stark von den damals bestehenden Kunstrichtungen geprägt waren, um sich deren Einfluß völlig entziehen zu können.

Wenn es bei Kozincev und Jutkević um eine Auseinandersetzung mit dem italienischen Futurismus geht. so läßt sich bei Trauberg vor allem der Einfluß Majakorskijs und damit des russischen Futurismus erkennen.

Traubergs Artikel "Der Kinematograph in der Rolle des Anklägers" 185 ist ein Zitat aus Majakovskijs Artikel "Auch uns Fleisch!" I\$6 von 1914 und die Anwendung dieses Zitates auf den Begriff "Exzentrismus". Majakovskij schreibt in diesem Artikel:

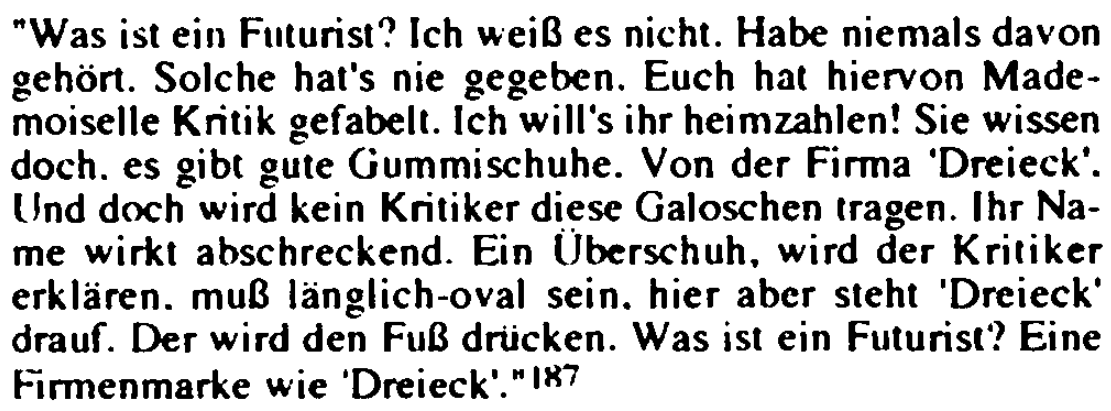

In diesem Vergleich mit den Galoschen der Firma 'Dreieck' erklärt er einerseits die negative Assoziation. die der Begriff "Futurismus" als etwas Fremdes. Unverstandliches und Ungewohntes bei den damaligen Kritikern hervorrief. und andererseits die Belanglosigkeit der Bezeichnung einer Sache für deren Inhalt. Zur Erklärung führt er Zitate zweicr absolut unterschiedlicher Dichter an. die jedoch beide im weitesten Sinne z.u den Futuristen gezählt wurden: den Ego-Futuristen Igor' Severjanin mit seiner 'blumigen Salonsprache'l\&s und den Begrunder der metalogischen Sprache (zaumnij jazyk) Aleksej Krićenych. Es geht ihm dabei vor allem um die neue Dichtkunst. die

\footnotetext{
IRH Ibid., S. 15.

185 Ibid.. S. Mi.

186, Majadiorshif. Vladımır: "Ausgewahlle Werhe in 5 Banden". Hrsg. Ion Leonhard Kexsuth. ubers, im Hugo Huppert. Bd. V: Publisistik. Berlin 1975. S. 3111.

ik7 Ibid., S. 311

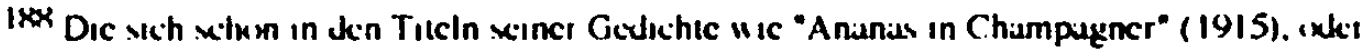

"Crème de indettes" (19)|9) erhennen liell
} 
er als Kunst des Kampfes gegen die traditionelle Dichtung sieht. ${ }^{\text {(*) }}$ So dient ihm der Begriff "Futurismus" in erster Linie zur Provokation der Kritiker. Wenn es dann bei Trauberg heißt:

"Alle tragen die Galoschen 'Dreieck'. |... | Heute machen sich alle in den Galoschen des guten Tones und des Wohlstandes auf die Beine - Menschen. Dinge. Ideen. Theater." $1(x)$

so ist für ihn der Begriff 'Exzentrismus' - im Gegensatz zum 'Futurismus' in Majakovskijs Artikel - schon zu etabliert im allgemeinen Sprachgebrauch und deformiert in Inhalt und Bedeutung. Wie aus dem zweiten Absatz von Traubergs Artikel hervorgeht. wirkt der Gebrauch des Wortes 'Exzentrismus' nicht mehr provozierend, weil der Ausdruck in zu vielen Zusammenhängen benutzt wird. Ähnlich wie Majakovskij distanzien Trauberg sich von der Anwendung des Begriffes auf Inhalte, die die Exzentriker der FEKS ablehnten. In diesem Sinne düften auch Punkt 4. und 5. seines Artikels zu verstehen sein. Er bezieht sich hier vermutlich auf einen offenen Brief Majakovskijs an Lunacarskij von 1920|'|, in dem Majakovskij auf Lunacarskijs Kritik am Futurismus reagien, die der Volkskommissar anläßlich einer Aufführung von "Die Wecktrommel" geübt hatte.

Majakovskij erklärt darin. daß Lunacarskij offenbar die gesamte linke Kunst der Sowjetunion mit dem Futurismus identifiziere. Wenn Lunacarskij sich also durch den Futurismus kompromittien fuhle, dann musse er die gesamte linke Kunst verbieten. Weiter schreibt Majakovskij wörtlich:

"Sind doch gerade diese Leute [die linken Künstler, d. Verf.] die einzigen unter den Kunstschaffenden, die allzeit für die Sowjetmacht arbeiten. ja zum großen Teil Kommunisten sind. Und all das hat sich als 'stinkende Leichname' erwiesen. Anatoli Wassiljewitsch! Wie sagen Sie doch immer so schön: 'Das Proletariat ist Erbfolger der vergangenen Kultur und nicht ihr Totengräber' und 'Das Proletariat wird die Kunst von gestem revidieren und sich das auswählen, was es braucht.' Wenn von Ihrem Gesichtspunkt aus der Futurismus die Krönung einer bourgeoisen Vergangenheit darstellt. so 'revidieren' und 'wählen' Sie doch: theoretisch müßten naturlicherweise die fruiher Verstorbenen auch heftiger stinken.

Wodurch sollte das Tschechow-Stanislawskische Stinken sich besser ausnehmen?"192

\footnotetext{
(8) Vel. Majakiow skij (1975). S. 311 .

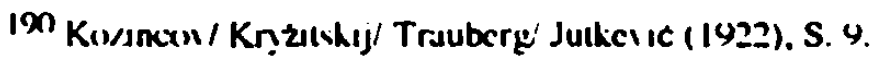

191 Mijabior skij, (1975). S. n7Ir.

192 Ibid., S. ox.
} 
Wenn Trauberg von einem Verkäufer schreibt. der Särge als Galoschen verkauft, meint er damit offensichtlich Lunacarskij. dem Majakovskij unterstellt. er wolle die alte traditionelle Kunst (Die Särge) als revidierte, vom Proletariat ausgewählte Kunst (Galoschen) verkaufen. Das wird vor allem in der Wortwahl deutlich. Die folgenden Sätze und darin das falsche CechovZitat ${ }^{(9)}$ sind geradezu eine Verspottung Lunacarskijs.

"Wenn es nur um die Schande ginge, meinetwegen. soll sie sie [Die Toten, d. Verf.] nicht treffen. Aber wenn sie stinken und schaffen das gerade da in allemächster Nähe. dann kann man dagegen keinen Einspruch erheben. Protest ist unumgänglich wie der Schnumbart von Charlie Chaplin." 1'44

Mit diesen Sätzen stellı Trauberg sich eindeutig auf Majakovskijs Seite und fordert dazu auf, gegen das 'Stinken' der Toten - Cechov und Stanislavskij. die hier für die traditionelle Kunst stehen - mit Hilfe der Kunst Chaplins zu protestieren. Durch das Wort "meinetwegen" demonstriert er eine gleichgültige Haltung zur traditionellen Kunst. Doch die Überschrift zum 5. Absatz des Artikels. die lautet: "Bei der Jagd auf den Zuschauer von Shakespeare zum Chantant.". zeigt deutlich die Forderung nach der Abkehr vom traditionellen - nach Meinung der Fèksy - toten Theater zum neuen Varieté. Im weiteren wehrt Trauberg sich gegen eine Verordnung dieser nur äußerlich revidierten Kunst durch Agitprop oder Narkompros. da diese der Kunst nur die Galoschen "Dreieck" ( das Wort "Exzentrismus") übergezogen und keine Revolution ihrer Inhalte bewirkt haben. ${ }^{195}$

Es geht ihm also darum. eine wirkliche Revolution der Kunst durchzuführen und sich - wie sein Vorbild Majakovskij - nötigenfalls auch gegen die Vorschriften der Obrigkeit zu stellen.

Kryżickij wiederum distanzient sich. ähnlich wie Jutkevic, in seinem Artikel vom italienischen Futurismus. indem er "Die Ratschläge des 'verrückten' Marinetti die Zuschauersitze mit Kleber zu beschmieren oder Juckpulver im Publikum zu verstreuen " $\mid$ ' $x_{0}$, als "Dummejungenstreiche" bezeichnet. Er fordert ein Theater des "Hazard", das nur mittels Umformung traditioneller Theatcraufführungen in Zirkusspiele, Pferderennen. Glücks-

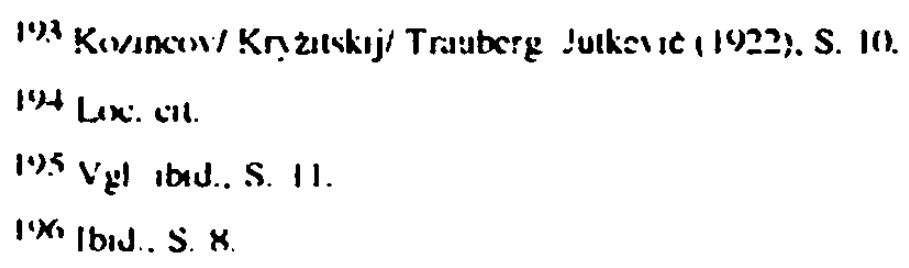


spiele etc. ereicht werden könne. Hier sind viele Ähnlichkeiten zu Kozincevs Artikel zu finden, aber Kryzickij wird noch radikaler, da er streng genommen die Abschaffung des Theaters an sich fordert. Kryżickijs Aussagen dürften jedoch ohne großen Einfluß auf die weitere Arbeit der FEKS geblieben sein. da er diese schon bald nach deren Grindung verließ. Geblieben ist allerdings das von ihm formulierte Prinzip des "Hazard", das in der praktischen Arbeit der Gruppe immer wieder angewendet wurde.

Zwar verhält es sich ähnlich mit Jutkevic. doch verließ er die FEKS, um in Moskau bei Foregger zu arbeiten, dessen Theaterkonzept ja in vielen Punkten dem der FEKS glich. Außerdem hielten Jutkević. Kozincev und Trauberg weiterhin Kontakt und Jutkevic verfolgte auch in der Zukunft die Entwicklung der FEKS mit großem Interesse. In späteren Jahren sagte er einmal:

"Ich habe in den Zeiten der FEKS sehr viel nuitzliches für mich gefunden. Und keiner von uns hälte nur einen bedeutenden Film machen können. wenn er sich nicht auf die FEKS stützen würde." 197

Aus diesem Grunde ist der Beitrag Jutkevics zu Manifest und Arbeit der FEKS als wichtiger zu betrachten als der Kryżickijs.

Doch kehren wir zurück zu den Gemeinsamkeiten der Féksy mit den Futuristen.

Die Verherrlichung der Technik. Geschwindigkeit. die Zerstörung der klassischen Kunsttradition, die Forderung nach Varieté. Zirkus und musichall im Theater. Provokation von Publikum und gesamter Öffentlichkeit hatten die Exzentristen von den Futuristen übernommen. Einen wesentlichen Unterschied zwischen Fèksy und Futuristen jedoch stellt $O$. Bulgakova in ihrem Artikel "Bul'vardizacija Avangarda - Fenomen FEKS"198 heraus. Es ist das Mittel der konsequenten Parodie und die spielerische Einstellung zur Kunst. die die jungen Regisseure hatten. Obwohl sowohl italienische als auch russische Futuristen das Althergebrachte ablehnten, suchten sie doch "krampfhaft nach einem Ersatz für Gott (die hohe Kunst. das Ideal usw.).

197 Aus: Stenegramm des Aufiniles S. I. Julkevics aul dem Semınar der Kritıker in Bol'scio 19xx. Zit. nach Deylinstij (197h). S. 12X.

I"K Bulgation a. O. L.: 'Bull ardi/acija al an zarda - Ienemen FEKS.' In: "KInen culoeshic 7apiski." Hefi 7. Mositau 1990). S. 27.48. 
den sie verehren sollten ${ }^{n}$ (9). Ihr Aktionismus richtete sich nicht gegen den Kult an sich. sondern nur gegen die kultisch verherrlichten alten Werte und ersetzte diese durch neue Werte.

"Die Expressionisten hatten die Extase, die Futuristen - das Pathos. Marinetti verherrlicht den Krieg. Majakovskij sieht sich als Christus. Der Kult war nicht abgeschafft worden, es blieb eine heilige Kuh. die sich anders nannte. Nach 1917 wurde diese für viele die Revolution. die vergöttlichte Maschine, der vergöttlichte sterbende Führer, eine neue kultische Symbolik..."200

Die Fëksy hatten sich den Boulevard zum Gegenstand ihres Kultes erwählt. was in sich schon einer Parodie auf den Kult der neuen Werte gleichkommt. Die Kunst des Boulevards kann schließlich unmöglich mit Begriffen wie Extase. Pathos. Revolution etc. gleichgesetzt werden. In den Aktionen und Theaterstücken der FEKS schienen bei aller Emsthaftigkeit, die sie der Organisation ihres Boulervardkultes widmeten, immer spielerische Einstellung und Selbstironie durch. Die Bezeichnung "Music-Hall Kinematografovic Pinkertonov" für den personifizierten Exzentrismus macht das cbenso deutlich, wie Traubergs Gebrauchsanweisung für den Exzentrismus. der laut Doktor Anton Meyer innerlich und in Pferdedosen anzuwenden sei. 211' Gerade dieses Beispiel zeig! auch, daß die Fèksy unter Exzentrismus eher eine Finstellung zur Kunst. als eine Methode (priem) verstanden.

Auch ihre Kultfiguren wie Charlie Chaplin, oder Nat Pinkerton sind keine heiligen Kühe. sondern werden genauso parodiert wie die Figuren des klassischen Dramas. Das zeigt die Darstellung dieser beiden Figuren in Kozincevs und Traubergs Inszenierung von Gogol's "Ženit 'ba".202 Selbst ihr Idol Majakovskij wird gleich auf der ersten Seite des Manifestes zum Gegenstand ihres spielerischen Umgangs mit der Kunst. ${ }^{203}$ Der politische

\footnotetext{
(x) IbId.. S. 31).

2(x) Lix. cit.

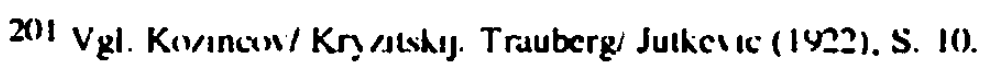

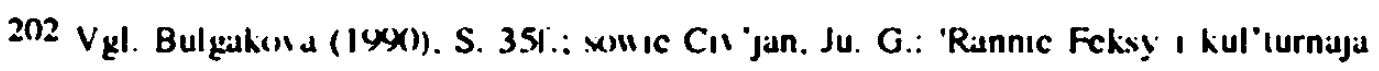

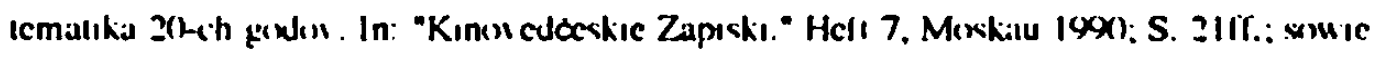
Punki 3.1.1. Jicscr Aibcit.

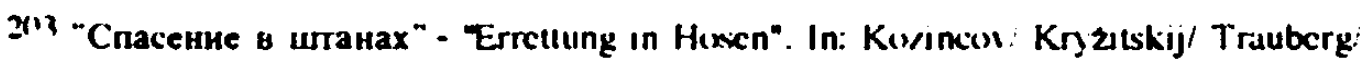
Sulkoric (1422). S I
} 
Protest, den Majakovskij in seinem Gedicht "Wolke in Hosen" äußert ${ }^{204}$. wird von den Feksy in Protest gegen die traditionelle Kunst umgemünzt. Wenn Majakovskij sich in seinem Gedicht nicht als Mann. sondern als "Woilke in Hosen" bezeichnet, dann bezeichnen sich die Exzentristen der FEKS mit dem Satz "Errettung in Hosen" praktisch als Erretter der Kunst. worin sich wieder ihre Selbstironie zeigt.

In diesem spielerischen Verhalten und dem Zweifeln an ästhetisch etablierten Werten vor dem Hintergrund von Weltkatastrophen sieht Bulgakova die Nahe der FEKS zu Dada. Sarkasmus. Ironie und Anarchie waren die Merkmale der Dadaisten.

"Das Mittel der Kunst - das Paradox, die Methode - Zufall. das Material spielte überhaupt keine Rolle und mit dem Rezipienten machten sie sich auf den Weg der terroristischen Bearbeitung. Geheiligtes - ohne Mystifikation. Triviales mystifiziert sich. die Welt - ein Spiel. Ind genau so ein spielerisches Moment wurde die politische Parole. Die Féksy nehmen diese Parole und verthalten sich ihr gegenüber - nehme ich an - völlig ernsthaft. aber was geschieht. wenn diese Parole in die Welt des herabgesetzten Spieles gerät? Der Widerspruch zwischen der Parole und dem ausgewählten Programm ergibt einen ergreifend komischen Effekt. Darin liegt die tiefe Originalität russischen Dadas feksscher Ausfuhrung." 20.5

Im Gegensatz zu Europa und den USA hat sich der Dadaismus in der Sowjetunion allerdings nicht verbreitet. 1920 hatte sich zunächst in Moskau und dann in Rostov am Don die literarische Gruppierung der Nicevoki (abgeleitet von russ. nicego=nichts) gebildet, die sich als blutsverwandt mit den Dadaisten bezeichnete. In ihrem "Dekret über die Poesie des Nichts" hatten sie die "Verbreitung des Kunstwerkes im Namen des Nichts" als ihr Ziel angegeben. Die wichtigsten Mitglieder dieser Gruppe waren S. Mar. O.Erberg und R. Rok. ${ }^{20}$, Während sie von den westeuropäischen Dadaisten durchaus geschätzt wurden. erlangten die Nicevoki im eigenen Land nur geringe Beachtung.

\footnotetext{
204 Majakiriskij. Vladimir. "Wolke in Hinen." Mill c. Vorwort I. Stephan Hermlın.

Deutsch 、. A. E. Therk. Verlag Vollk und Well. Berlin 1949. S. 26.

20)5 Bulgakiova ( $1(x)(0)$. S. 31 .

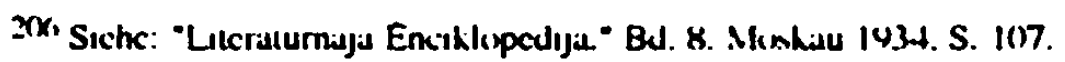


Kryżickij erwähnt sie in seinem Artikel des Manifestes auf ironische Art. indem er behauptet, daß sie nichts vom Theater verstiunden. ${ }^{217}$ Es ist also anzunehmen, daß die Feksy die Nicevoki nicht sehr schätzten.

Die Ähnlichkeit zum westlichen Dadaismus läßt sich jedoch nicht leugnen. Die aleatorisch bestimmte künstlerische Gestaltung und das Bemühen um eine Wiedergeburt der Volkskunst als der sozialen Kunst waren wohl die wichtigsten Gemeinsamkeiten von FEKS und Dada.

"Dada verneinte alle Werte, die bis dahin als heilig und unantastbar gegolten hatten. |... | und riss den zu Abgöttem gewordenen Werten die Maske herunter. |... Form und Sinn. Politik und Moral sollten von Grund auf zerstört, negiert werden. um aus ihren Grundelementen Neues, Reines. Natüliches zu schaffen." 21\%

Hierin stimmen Dadaismus und fẻksscher Exzentrismus überein. Der wichtigste Unterschied liegt aber in den verschiedenen Zeitpunkten ihres Entstehens. Der Dadaismus entstand während des Ersten Weltkriegs und war

"I... eine spezifische Form des Widerspruches von Künstlem. Dichtem, Malem. Bildhauem. Musikem gegen die Kulturschöpfungen einer Gesellschaft. die aus selbstsuichtigen Beweggründen imstande war. am Anfang des 20. Jahrhunderts Millionen von Menschen abzuschlachten. Dada war der hektische Aufschrei des gequälten Geschöpfes im Künstler, der Aufschrei seines ahnenden, mahnenden. verzweifelnden Gewissens." 2(r)

Der Exzentrismus wurde dagegen nach Weltkrieg. Revolution und Bügerkrieg geschaffen. Zwar herrschte immer noch Chaos im Land. trotzdem erschien die Zukunft den jungen Künstlem hoffnungsvoll, was auf die Dadaisten wenige Jahre zuvor nicht zutraf. Die von Dada angeprangerte Ordnung war zum Grüdungszeitpunkt der FEKS in Rußland faktisch zerschlagen. man mußte sich nicht länger gegen sie auflehnen. Doch jetzt ging es um die tatsächliche geistige l̈berwindung der alten Werte, um ihre Vertreibung aus den Küpfen der Menschen und dafür schien die Parodie das beste Mittel. Der Ausgangspunkt des Exzentrismus war also ein anderer. optimistischerer als der des Dadaismus.

\footnotetext{
2117 Korincill Kiszlshij Trauberg/ Jutkci ic (1922). S. $R$

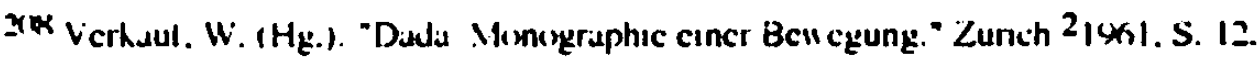

$2(r)$ Ibid.. S. $12 \cdot 13$
} 
Große Ähnlichkeit bestand allerdings auch zwischen der FEKS und den Ansichten der französischen literarischen Avantgarde, wie Paech sie in seinem Buch "Literatur und Film" beschreibt:

"Nicht anders als die deutschen literarischen Expressionisten haben die Schriftsteller der Avantgarde in Frankreich schon vor dem Ersten Weltkrieg in den Kinos gesessen und sich für Feuillades 'Fantômas' oder Jassets französischen 'Nick Carter' (1907 - 1911) 1.... Westernserien und allen voran Charlie/Chartot begeistert. Und wie in Deutschland hat sich diese Kinoerfahrung in der französischen Literaturproduktion bemerkbar gemacht: hier war es vor allem Guillaume Apollinaire, der Kinokultur (einschließlich der dort verarbeiteten Literatur der Ladenmädchen) und avantgardistische Literatur miteinander verbunden und als Ausdruck der von Technik und Urbanität geprägten Modeme begrißt hat."210

Dieses Verhalten stand naturlich im Widerspruch zur offiziell gefordenen Revolutionskunst, die die neuen Werte aut höchster Ebene verherrlichen und mit der gebuhrenden Ernsthaftigkeit behandeln sollte. Deshalb war die respektlose und aleatorische Bearbeitungsweise dieser neuen Werte einer der wichtigsten Gründe, warum den Feksy innerhalb der Sowjetunion nur mäBige Beachtung geschenkt wurde und sie im Ausland fast unbekannt blieben. Ins Ausland gelangte nur die anerkannte Revolutionskunst, die eindeutig für Propagandazwecke geeignet war, was sich von den Produktionen der FEKS nicht sagen läßt.

\subsubsection{Amerikanismus}

Ein besonderes Merkmal des féksschen Exzentrismus ist der Amerikanismus, der das gesamte Manifest durchzieht. Diese Begeisterung für Amerika - wobei offensichtlich nur die USA gemeint sind - ist ein vom futuristischen Denken herrührendes Phänomen, das in dieser ausgeprägten Form nur bei den Fèksy zu finden war. Mit Amerika verbanden sie technischen Fortschritt. Geschwindigkeit, die Überwindung der alten europäischen Kultur und Kunst. Jugend und die Freiheit zu experimentieren. Nicht umsonst machten sie den Ausspruch des Amerikaners Mark Twain

210 Pacch. Jexk:hım: "Litcratur und Film." Stultgant Istax. S. 152. 
"Lieber ein junger Grünschnabel sein, als ein alter Paradiesvogel"211 zu ihrem Motto. wobei es völlig irrelevant war, ob dieser Ausspruch tatsächlich von Mark Twain stammte, oder ihm nur von den Fejsy in den Mund gelegt worden war. Wichtig war allein, daß es sich bei dem Zitierten um einen Amerikaner handelte. Mit diesem Motto rechtfertigten sie sowohl die durch ihre Jugend bedingte relative Unerfahrenheit im Bereich der praktischen künstlerischen Arbeit. als auch ihre Ablehnung der traditonellen Kunst. Kozincevs Artikel "AB!" gipfelt in der Gegenüberstellung: "Gestern - die Kultur Europas. Heute - die Technik Amerikas. Industrie. Produktion unter dem Stemenbanner. Entweder Amerikanisierung oder Bestattungsinstitut." 212 Dabei war es mehr ihre Vorstellung von Amerika als reale Kenntnisse des Landes. die sie begeisterten. Leonid Trauberg erklärte diesen Amerikanismus in seiner Eröffnungsrede zur Konferenz "FEKS und Exzentrismus" im Dezember 1989 in Moskau damit. daß die Fèksy Amerika als Symbol für einen technischen Fortschritt sahen. der die Menschen freier und menschlicher machen wurde.

"XX век, казалось, обещал не автоматизацию, не роботов, а человечность. В понсках этой человечности вставал вопрос и о революции, вставал вопрос о том, чтобы освоКодить людей от гнетя, от чнновников, от мертвечины."

"Das zwanzigste Jahrhundert. schien es. versprach nicht Automatisierung, nicht Roboter, sondern Menschlichkeit . Auf der Suche nach dieser Menschlichkeit entstand auch die Frage nach der Revolution. entstand auch die Frage dariber. daß die Menschen befreit werden von Unterdrickung. von Bürokraten, von Erstarrung." 213

Doch die Geschichte entwickelte sich nicht so, wie die Féksy in ihrer jugendlichen Euphorie geglaubt hatten.

"И вот мы, вместо того чтобы заниматься настоящими добрыми картинами, часто долхны были заниматься прославлением недоброго в нашей жизни."

"Und so mußten auch wir, anstatt uns mit wirklich guten Filmen zu beschäftigen. oft mit der Glorifizierung des Schlechten in unserem Lehen beschäftigen." 214

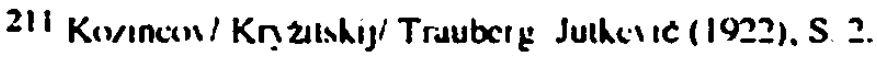

212 Ibid.. S. 3.

21.3 Trauberg (1(x) $)$. S. 7.

$21+$ ibid. S. $x$ 
Auch der Amerikanismus der Fèksy ist -wie ihr Verhalten zur gesamten Kunst - durch eine spielerische Einstellung gekennzeichnet. Bulgakova bezeichnet ihn als "Sachkult", der sich nicht aus Parolen der neuen Lebensweise und Industrialisierung zusammensetze, sondem aus ausländischem Inventar und Merkmalen der 'roaring twenties'. Das amerikanische Inventar der Fèksy bestehe nicht aus realen Gegenständen, sondern aus Zeichen für Amerika. was die spielerische Einstellung erst ermögliche. Die Welt der FEKS sei imaginär, in ihr könnten Dinge verbunden werden, die nicht zueinander passen, wobei in den Filmen der FEKS durch die Gegenubberstellung dieser nicht zueinanderpassenden Dinge und ästhetisierenden Klischees die Geschichte zerstört werde. ${ }^{215}$ Das zeigt, daB es wie in ihrer Einstellung zu Kunst und Exzentrismus an sich, auch hier eher um die innerliche Amerikanisierung durch die äußerliche Anwendung amerikanischer Methoden in der Unterhaltungskunst geht. Denn vor allem um die Einführung der verschiedensten Formen von Unterhaltungskunst handelt es sich bei der Forderung nach Amerikanisierung und nicht um die tatsächliche Industrialisierung nach kapitalistisch amerikanischem Vorbild. das ja schon damals den absoluten Gegensatz zum Gesellschaftsbild der revolutionsbegeisterten Russen bildete.

Die fortschreitende Technisierung dieser Zeit hatte auch die Unterhaltungskunst ergriffen und zwar zunächst in Amerika. "The 'roaring twenties' also implied the growth of an entertainment industry manifesting itself most visibly in the rapid development of the new media radio and film (sound movie since 1927). .216

Die USA waren also nach dem Ersten Weltkrieg zur führenden Film- und Radionation avanciert, folglich mußte Neues, das die Kultur Europas ablösen konnte. aus Amerika kommen und der Amerikanismus stellt eine logische Konsequenz in den Forderungen der FEKS zur Erneuerung der Kunst dar. Genauso logisch konsequent wie bei Ejzenstejn mußte dann auch bei den Fẻksy der Übergang vom Theater zum Film erfolgen.

215 Bul gatiova (1 $(x)$ )). S. 381 .

216 Herms. Dicter. "Grundkurs Englisch. Eine Einluhrung in dic Amerikanistik:" Argument Studienheftc. SH 49. Berlin 192. S. 67. 


\subsubsection{Exzentrismus und Charles Chaplin}

Music-Hall Kinematografovic Pinkertonov war die irreale Verkörperung des Exzentrismus und eine Allegorie der niedrigen Künste Varieté. Film und Groschenroman. Ejzenstejn erwähnt in seinen Memoiren den Romandetektiv Nat Pinkerton, dessen Abenteuer er als Schuljunge verschlungen habe. ${ }^{217} \mathrm{Nat}$ Pinkerton. Nick Carter, Ethel King und ähnliche Romanhelden genossen bei der damaligen Jugend (und vermutlich nicht nur in Rußland) ungeheure Popularität. So griffen die Feksy mit dieser Gestalt ein Stück Kindheit auf.

Im Gegensatz zu dieser fiktiven Romanfigur hatten sie in Charles Chaplin und seinem Filmhelden Charlie. oder Charlot wie er in Frankreich genannt wurde, die gleichzeitig reale und irreale Personifizierung ihres Amerikanismus gefunden. Ähnlich wie beim gesamten feksschen Amerikanismus ging es dabei nicht um die tatsächliche Kenntnis und Verbreitung von Chaplins Filmen oder Schauspielkunst, sondem um die persönlichen Assoziationen der Feksy mit den Namen Chaplin und Charlot. Im 1920/21 war Charles Chaplin in der Sowjetunion noch nahezu unbekannt. Die ersten Vorstellungen von Chaplin-Filmen hatten 1919 in Sibirien stattgefunden. doch in den großen Städten waren diese Filme nicht zu sehen gewesen und selbst von den Filmemachem kannte bis Mitte der zwanziger Jahre kaum einer Chaplins Filme.218 Die Fèksy hatten von Charlot und seinem großen Erfolg in Westeuropa und den USA durch Kozincevs Schwester, die Frau Il'ja Erenburgs, erfahren, die in Paris lebte. Sie hatte ihrem Bruder geschrieben. daß ganz Frankreich verriuckt sei nach Charlot und man seine Popularität schon mit der Mohammeds oder Luthers verglichen habe.21) Civ'jan

217 Vyl. F.jensicjn. S. 11." "YO- Ich Sclbut. Meminicn." Hrsg. Ion Niaum Klcjman und Walcnuna Korschunowi. Eunleitung ion Sergej Jutkewitsch. Aus dem Russ. Ion Regine Kuhn und Rita Braun. Frankfurt Al 196. Bd.2. S. reazi.

Allcrdings crwahnt Ejacnstejn Nat Pinherion und ahnliche Romandetektisc in Zusummenhang mit seinen jugendlichen Eindruciken con Sudismus. Wothe thn in ersier Linic die (imxihlagbilder dieser Romane fesselten. aut denen der jewcilige Held immer in cincr wheinbar ausweglisen Lage darzestellt ist. die ihm einen grausamen Tod verheißt ("g!. thid.. S. frxw!r.).

21K Vgl. di2us: Lẹda ( $19 \times 3)$. S. 145. 171

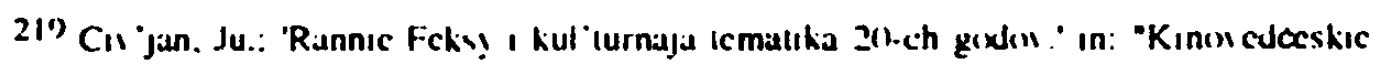

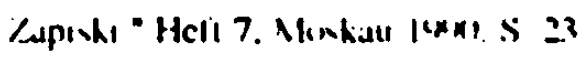


schreibt. daß Chaplin damals in Rußland. das vom italienischen Kino geprägt war, für vulgär gehalten wurde. 20 Schon allein aus diesem Grunde muß er das wohlwollende Interesse der Feksy erweckt haben. Sie hatten in dieser Gestalt - entsprechend zu Nat Pinkerton im Roman - ihren Helden der niedrigen Kunst im Film gefunden. So waren sie diejenigen, die mit ihrem "Disput uber das exzentrische Theater"221, ihrem Manifest und der Inszenierung "Die Heirat"222 (in allen spielte Chaplin eine wichtige Rolle) den Chaplin-Kult in der Sowjetunion einfürten. Dabei waren es wiederum - wie in ihrem gesamten Amerikanismus - Zeichen für Charlot, wie der Schnurrbart, die Melone oder der Stock, die sie verwendeten und nicht die Chaplin-Filme oder die Person des Schauspielers und Regisseurs an sich.

Wenn Chaplins Filme später von Kozincev. Trauberg und anderen auf ihren Exzentrismus hin untersucht werden, so geschieht das im Rückblick und dadurch vor einem ganz anderen Kenntnis- und Erfahrungshintergrund als zur Gründungszeit der FEKS, zu der viele der berühmtesten Filme Chaplins noch gar nicht gedreht worden waren. Erst im Laufe der Zeit wurde deutlich, wie nah die Fèksy ihm tatsächlich waren.

Trauberg beschreibt im ersten seiner zwei Artikel über Chaplin zunächst dessen Werdegang und die Merkmale seines besonderen Talentes, während er im zweiten Artikel hauptsächlich die Frage nach der Sozialkritik in Chaplins Filmen behandelt. ${ }^{223}$ In seinem Artikel "Ekscentrizm" geht er im Vergleich mit vielen Schriftstellem der Weltliteratur auf den Exzentrismus Chaplins ein und gibt hier zum einzigen Mal und nur in Bezug auf dessen Filme eine Definition des Exzentrismus:

\section{"Эксцснтризм - это напоминание о том, что мы живём в абсурдном мире." \\ "Exzentrismus - das ist die Erinnerung daran. daß wir in einer absurden Welt leben." $22 t$}

Eine absurde Welt wurde in Chaplins Filmen immer wieder gezeigt. sowohl in den fruihen Keystone-Produktionen, als auch in der Serie der

\footnotetext{
220 Lx: cit.

221 Vgl. Lox: CHL.

222 Sichc:dinu: Kap. 3.1.1. diescer Arbert.

223 Trauberg. Lecmid: 'Caplin 1." Caplin 2." Beide in: "I/brannic Privsicatenija V 2-ch Inmach." Mixkiau 1988. im Folgenden mitien als: IP: hicr. S. 36K-376: S. 376-398.

22+ Truuberg. L.: "Ekixientrim." In: IP: S. 524.
} 
sozialen Satire, beginnend mit "Easy Street" (1917).225 Auch und vor allem die Theaterstucke der FEKS zeigten eine absurde Welt. jedoch ergeben sich hier verschiedene Bedeutungen des Wortes. Wahrigs Deutsches Wörterbuch definiert "absurd" als "abwegig, widersinnig, unsinnig. unvernüftig $\mid<$ lat. ahsurdus "mißtönend"1.22" Auf Chaplins sozialsatirische Filme Iriffı die Bezeichnung 'absurd' eher im urspringlichen Sinn des lateinischen Wortes "absurdus" = "mißıönend" zu, da in diesen Filmen Mißstände - und im ubertragenen Sinne Mißtöne - im gesellschaftlichen Leben aufgedeckt wurden. Die Theaterstuicke der Fèksy genauso wie Chaplins Keystone-Filme waren dagegen in erster Linie "abwegig" und "unsinnig".

Im weiteren verweist Trauberg auf einen Artikel Kozincevs über die "Volkskunst Charlie Chaplins" ("Narodnoe iskusstvo Carli Caplina").227 Kozincev beschreibı darin zunächst die Figur des Clowns und Narren. die Chaplin erschaffen hat (s. dazu Punkt 2.3.4.) und erläutert später die ebenso von Chaplin geschaffene neue exzentrische Kunst. Er habe sich nicht in der Fortsetzung von Tortenschlachten. Schlägereien. Verfolgungsjagden u.ä. verloren. sondem für seine neue Kunst das Gesetz des Kontrastes deklariert.

“Первые два когтраста, определившие сто искусство, были:

человек, попавший в затруднительнос положенис;

человек, пытающийся в этом затруднительном положенин сохранить собственное достоннство."

"Die ersten zwei Kontraste. die seine Kunst bestimmten. waren:

der Mensch. der in eine schwierige Lage gerät:

der Mensch, der versucht in dieser schwierigen Lage seine persönliche Würde zu bewahren." $22 x$

Dabei handelte es sich immer um Situationen, die das Publikum, das in erster Linie aus "einfachen. kleinen Leuten" bestand. gut nachvollziehen konnte. Auch seine geringe körperliche Größe machte sich Chaplin beim

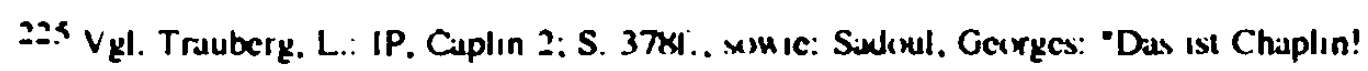
Sem Leben Scine Filme. Seine Zeit." Aus dem Fran/sx. von Peter Lexx. Wien 1954. S.

75.

226 Wahne (|x) 1 (1). S. 276.

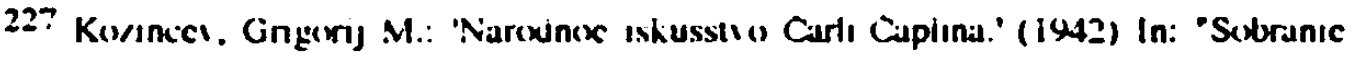

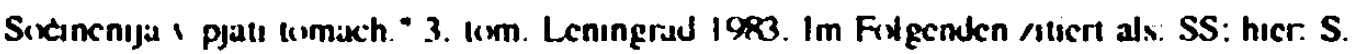
x7i1. 
Spiel mit den Kontrasten zunutze, indem er sich große. kräftige Partner auswählte. Ein noch stärkerer Kontrast bestand laut Kozincev in der Gegenuberstellung des kleinen Mannes mit dem großen. feindseligen Leben.

Ein weiteres Merkmal von Chaplins Kunst sah Kozincev darin. daß er den Unsinn zum System machte.

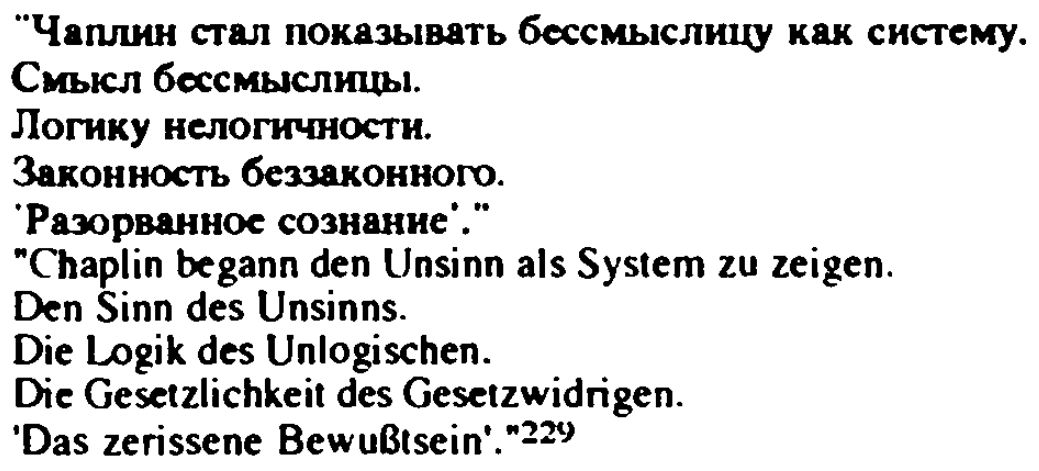

Mit all dem habe Chaplin erkannt. daß Exzentrismus nicht nur mechanische Betäubung mit einem Wortschwall von Absurditäten und erfundener Geschichten sei. sondern eine von Leben selbst hervorgebrachte Form. eine widergespiegelte Erscheinung des Lebens. die sich ins Absurde gewandelt hatte.230 Diese Aussage Kozincevs steht im absoluten Widerspruch mit dem. was er $\mathbf{2 0}$ Jahre zuvor im Manifest "Ekscentrizm" geforder hatte. Nämlich das mythmische Einschlagen auf die Nerven und die Efindung absurder Geschichten.

Die einzige Gemeinsamkeit in Kozincevs späteren Aussagen zu Chaplin und dem Bild. das die Fèksy zu Beginn der zwanziger Jahre propagierten. ist im Motiv des Clowns zu finden. Wie viele Biographen stellt auch Kozincev fest, daß Chaplin sich im Laufe seiner Arbeit vom fröhlichen zum 'bitteren' Clown gewandelt habe.231 (Der Beginn dieser Wandlung wurde oben mit dem Film "Easy Street" (1917) festgelegt.) Die Fèksy hatten ihn zu ihrer Zeit vor allem als fröhlichen Clown gesehen. der in ihre Zirkus- und Straßenkunst paßte. Zur Klärung dieses Motives soll an dieser Stelle näher auf die Figur des Clowns eingegangen werden.

229 Ibid.. $\dot{S}$. II8.

230 Ibid.. S. 116.

231 Ibid., S. 41. 


\subsubsection{Die Fiour des Clowns}

Chaplins Filmfigur des Charlie (franz. Charlot) ist zuriick \&ufuhren auf die Figur des Narren. die im europäischen Theater eine lange Tradition hat.Auch im englischen Theater spielt diese Figur seit der elisabethanischen Zeit in den verschiedensten Entwicklungen und Variationen eine wichtige Rolle. ${ }^{232}$ Fine dieser Variationen ist der Clown. der seine charakteristische Ausprägung erst gegen Ende des 18. und zu Beginn des 19. Jahrhunderts erfuhr. Der Unterschied zwischen Clown und Narr liegt nach Elisabeth Frenzel darin, daß der Narr durch einen psychischen oder physischen Defekt von Anfang an zum Narrentum verurteilt ist, denn "sein Auftreten erregt Gelächter und Schauder zugleich, er ist geliebt und gefurchtet. erreicht aber nie den Status eines normalen Mitglieds der Gesellschaft."23.3 Beim Clown handelt es sich eher um einen berufsmäBigen Narren. der sein zeitlich begrenztes Narrentum selbst wählt. Elisabeth Frenzel erklärt dazu:

"Nicht eigentlich als weiser, wenn auch als 'künstlicher' Narr ist der den Narren mimende Schauspieler oder Zirkusclown anzusehen. der nicht als Narr lebt, sondern nur für die Dauer seines Buhnenauftrittes seine Maske trăgt. Von der Sonderexistenz des Narren bleibt ihm nur die Divergenz zwischen einem möglichen traurigen Privatschicksal und berufsmäßig lachendem Gesicht. $\mid$... $\left.\right|^{m 234}$

In England waren es die Schauspieler Joseph Grimaldi (Vater), William Parson und Jean-Baptiste Dubois. die der Clownsfigur erste Popularität verliehen. 235

232 Es wurse hicr a weil fuhren. diese Entwicklungen und Vartalienen ausfuhrlich dar/ulegen. Aus diesem Grunck mixthic ich an dieser Siclle nur auf Luleratur fum Thema

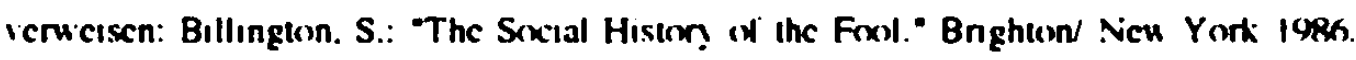
Willeford. W.: "The foxy and his sucpire." Nerrthwestern University press. 1969. Konneker. B.: "Wesen und Wandlung Jer Narrenictec im Zeitulier Jes Humanısmus." Wiesbaden. I Hohenemicr. H.: "Pulcinella. Harlekin. Hansw urst." Emsdetten 194n. Nicoll. A.: "The

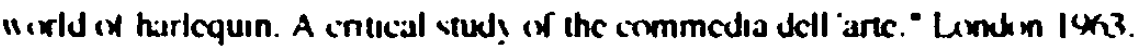

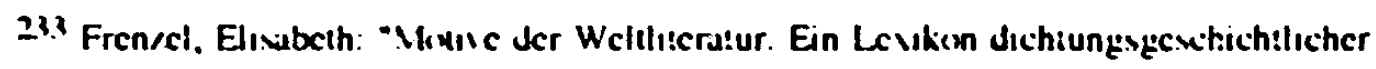
Lingischniltc." 3. ubcrarb. u. cru. Aufl. Stultgart 19xk. S. Sk1.

234 Ibid. S. 574.

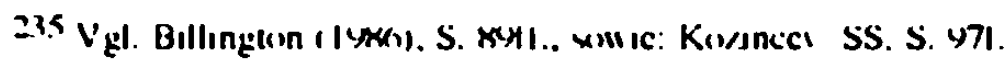


"Dubois began his career in England with the famous equestrian show of Astley. who opened his new venture in 1770 and Dubois joined about 1780. Astley's Amphitheatre combined trick shows. horsemanship and clowns and is the famous birthplace of the circus." 236

Die Tradition dieser Schauspieler wurde zu Beginn des 19. Jahrhunderts von Grimaldis Sohn fortgesetzt und ausgebaut, der mit seinen pantomimischen Satiren und Parodien weder vor dem König noch vor Bettlern haltmachte. Aber auch die Wanderbühnen übernahmen die Figur des Clowns.

Sandra Billington beschreibt die äußere Ähnlichkeit eines solchen Wanderbühnenschauspielers in der zweiten Hälfte des 19. Jahrhunderts mit Chaplin:

"His outdoor dress is reminiscent of the mountebank or mumming doctor, or even of Chaplin. rather than a painted clown. As he led the procession. the town saw a gravelooking individual. but with a twinkle in his eye - always carrying an umbrella, with its point infront of himself, $|\ldots|^{\ln 2.37}$

Zur Entstehung oder Erfindung des Kostüms von Chaplins Figur des Charlie gibt es zahlreiche Geschichten und Erklärungen. Mir scheint die Variante plausibel. daß er - bewußt oder unhewußt - die charakteristischen Merkmale Charlies von historischen englischen Clownsfiguren ijbernommen hat. Als Sohn von Komödianten, der schon früh im Varieté auftrat, sind ihm mit Sicherheit zahlreiche Clowns in verschiedensten Kostümen begegnet. Das Kostüm des Charlie hatte er während seiner Arbeit bei Keystone im Laufe mehrerer Monate entwickelt, in denen er die verschiedensten Requisiten ausprobierte, bis er sich auf die für seine Filmfigur charakteristischen (kleiner Schnurrbart. Melone, Stöckchen etc.) festlegte. Es war das Kostiim eines Clowns, wie man ihn im Varieté findet. Aus diesem ursprünglichen Clown, der entwickelt worden war für die Slapstick-Komödien, die unter der Regie des Filmproduzenten und Gründers der Keystone-Studios Mack Sennell gedreht wurden, entwickelte sich im I aufe der Zeit ein Narr. Die SlapstickKomödien jedoch waren von Inhalt und Aussage her nichts anderes als gefilmte Nummern von Zirkusclowns.

'Sennet schrieb die 'systematische Zerstörung' vor. Die komische Vernichtung ... Alles zerstören, zerbrechen.

\footnotetext{
236 Billinglom (1986). S. 91.

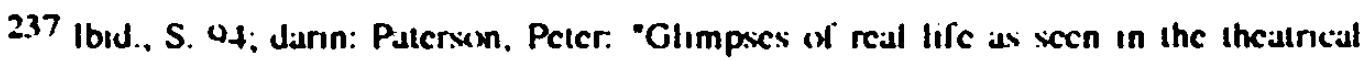
"Iirld." Edinburgh isk4. S. 5.
} 
beschmutzen. vernichten - in einem verrickten Tempo und mit grotesker Geschwindigkeit." 236

Dieses Motto könnte ohne weiteres von den Fèksy stammen. Vermutlich waren es diese Slapstick-Komödien - mit denen Chaplin seinen Ruhm begrindet hatte - die ihre Sympathie für Charlot hervorriefen, obwohl Chaplin zu Beginn der zwanziger Jahre längst seine eigenen und künstlerisch anspruchsvolleren Filme drehte.

Man kann allerdings davon ausgehen. daß die amerikanischen Filme auch damals mit nicht geringer Verspätung nach Europa kamen, soda $B$ die Keystone-Komödien hier sehr viel später in den Kinos gezeigt wurden und damit auch Chaplins Ruhm in Europa auf einem anderen Stand war als in den USA. Wichtig ist dabei aber nur, daß der "Keystone-Charlie" wie maßgeschneidert in das Programm der FEKS paßte. Er negierte Autoritäten, indem er Polizisten und gesellschaftliche Wiurdenträger mit Cremetorten bewarf, oder ihnen Tritte ins Hinterteil versetzte. Als Clown im Film verband er Zirkus. Varieté und music-hall mit der zukunftsorlentierten Technik. Und er machte Volkskunst im wahrsten Sinne des Wortes.

Erst in den späteren Filmen wurde die Figur Charlie zum Narren. der vom Schicksal zu dieser Rolle bestimmt war. Auch in dieser Entwicklung liegt eine Gemeinsamkeit zwischen Chaplins Filmen und den Arbeiten der FEKS. Fhenso wie bei Chaplin waren die Theaterstücke und frihen Filme der Fèksy reine Clownerien und erst in den späteren Filmen tauchte auch hier die Figur des Narren (z.B. Akakij Akakievic in "Sinel'" oder der Soldat Jean in "Novij Vavilon") auf.

\subsection{Formalismus}

\subsubsection{Exzentrismus und Formalismus}

Da die Formalisten L.iteraturwissenschaftler und damit Theoretiker waren. ist der Einfluß des Formalismus auf die FEKS im Manifest nicht so deutlich

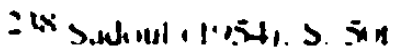


zu erkennen. wie der des Futurismus. Wie eng die Beziehung zwischen Formalisten und Fèksy war, zeigt sich deutlich erst in ihrer Filmarbeit.

Lediglich Viktor Sklovskijs Artikel "Gamburgskij Scet" von 1928 erinnent in seiner Forderung. Schauspieler wie Rennpferde zu beurteilen, an Kryżickijs Artikel im Manifest.

Sklovskij fordert darin, die russischen Schriftsteller wie die Ringkämpfer zu beurteilen, die alljährlich in einer Hamburger Schenke schwere und lange Kämpfe zu bestreiten hätten. Nach Art eines Sportreporters beurteilt er Babel' hier als Leichtgewicht und Gor'kij als zweifelhaft, da er oft nicht in Form sei.239

Beiden Artikeln liegt der gleiche Gedanke zugrunde: der Kiinstler tegal ob Schauspieler oder Schriftsteller) muß sich von Neuem und unter Anlegung strenger Maßstäbe profilieren, um vor der neuen Kunst bestehen zu können. Auch hier zeigt sich die grundlegende Analogie zwischen Formalisten, Fxzentristen und Futuristen ( die im Grunde allen Avantgardebewegungen dieser Zeit gemein war): Die Abschaffung der traditionellen Kunst zugunsten einer neuen. So schrieb Sklovskij 1914 in seinem Artikel "Die Erweckung des Wortes" ("Voskresenie slova"):

"Heute ist die alte Kunst tot. eine neue noch nicht geboren; tot sind auch die Dinge. wir haben das Gefühl fiir die Welt verloren .... Im alltaglichen l.eben sind wir nicht mehr Kiinstler, wir lieben unsere Häuser und Kleider nicht mehr und trennen uns leicht von einem Leben. das wir nicht mehr empfinden. Nur das Schaffen neuer Formen in der Kunst kann dem Menschen das Erleben der Welt (pereżivanie mira) zurückgewinnen. die Dinge auferwecken(voskresit ${ }^{*}$ veśći) und den Pessimismus töten."2-4)

Die Filmtheorie der Formalisten ist auf ihren literaturtheoretischen Erkenntnissen aufgebaut. Dabei uird Viktor Sklovskijs Definition vom Kunstcharakter eines Textes. der im Wandel von praktischer zu poetischer Sprache liegt, wie er es in seinem Artikel "Kunst als Kunstgriff" ("Iskusstvo kak priem") von 1914 dargelegt hat, zur operativen Basis. Entscheidend ist für Sklouskij dabei der Prozeß der Entautomatisierung der Wahmehmung.

239 S.lon skij. V.: 'Gamburgskij Scel.' In: "Gamburgskij Scel Stal"i-Voxpeminanıja-Essc (1914-1933)." Moskiau 19xx). S. 331.

2H) Skioskij, V.: 'Vinkresenic slowa.' Zil. nach: Hanicn-Luxic. A.: "Der Russische Formalismus. Methodologische Rekinsirukion scincr Entwicklung aus Jem Prin/ıp der

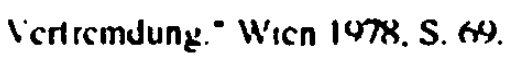


der erreicht wird durch die Anwendung von Kunstgriffen oder Verfahren (russ. priem):

"Kunstwerke werden wir die Dinge nennen, die mit Hilfe besonderer Kunstgriffe geschaffen werden. mit Kunstgriffen. die bewirken sollen, daß diese Dinge als Kunst wahrgenommen werden." $2+1$

Das Wesen dieser Kunstgriffe, die die Wahrnehmung wieder herstellen sollten, sah er in der Verfremdung der Dinge und der Komplizierung der Form (s.u.). ${ }^{2+2}$ Mit der Festlegung des Verfahrensbegriffes rechtfertigten die Formalisten ihren Standpunkt, daß ein Kunstwerk immer etwas künstlich Geschaffenes sei ${ }^{2+3}$ und wandien sich gleichzeitig von der bis dahin in der Literaturwissenschaft ublichen Trennung zwischen Inhalt und Form ab.

Basierend auf dieser Ansicht entwickelten sie die Hypothese, daß Literatur ein System ist, das aus einer Reihe konstruktiver Faktoren besteht. "Die Korrelation eines jeden Faktors zu den übrigen ist seine Funktion in bezug auf das ganze System." $2+$ Hierbei handelt es sich nicht um ein statisches. sondern um ein dynamisches System, da die Literatur eine Evolution durchmacht. die nur dann untersucht werden kann, wenn man sie "als Reihe. als System nimmt. das auf andere Reihen und Systeme bezogen und durch sie bedingt ist. Man hat dabei von der konstruktiven zur literarischen, von der literarischen zur Redefunktion vorzugehen. "2+5

Der Ausgangspunkı für die formalistische F:Imtheorie war dann die Untersuchung der Wechselbeziehungen der beiden Systeme Literatur und Film. So versuchten sie zunächst auch ihre Sujettheorie auf den Film anzuwenden und Sklovskij unterstrich die Tatsache. daß die Fabel im Film eine noch geringere Rolle spiele als in der Literatur.

$2+1$ Sklor skis. V'.: 'Kunit al Kunstgriff.' In: Helmers. H. (Hg.): "Vert remulung in der Litcratur." Darmulindt ICxs. S. 72.

$2+2$ Ibid. S. 76.

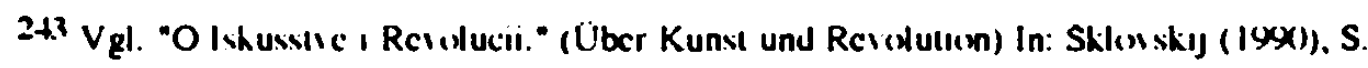
7xii.

2H Tynjanux. J.: 'Dic Odc als (rallonisehes Genre.' In: Sicmpel. W. -D. (Hg.): "Terte der ruswethen Formaltsten." Bd. II. Mfurethen 1972. S. 273.

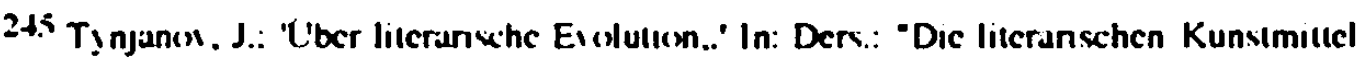
und dic Evolution in der Literalur." Ausgewahli und aus dem Russischen ubersetzi von $A$. Kacmple. Franklurtill. 14\%7. S 54. 
"Das Sujet (nach Sklovskij und Tynjanov) ist das wichtigste Unterscheidungsmerkmal des Films, das sich in der Wahl der Aufnahmeperspektive, der Montage. des Lichts usw. zeigt. Die Fabel. im Film oft nur ausgedruickt in der Intrige und der unmittelbaren Handlung. spielt, ihrer Meinung nach, nur eine periphere Rolle." 2 ks

Zugleich waren die Formalisten faszinien von der Technik des Kinos und den neuen Ausdrucksmöglichkeiten. die der Film bot. unterstrichen dabei aber immer die gegenseitige Unabhängigkeit von Literatur und Film.

Die Zusammenarbeit zwischen sowjetischen Regisseuren und Formalisten (vor allem Ejchenbaum. Sklovskij und Tynjanov) erwies sich als äußerst fruchtbar. Zahlreiche Filme der zwanziger Jahre entstanden nach Drehbuichem formalistischer Autoren. Und auch die theoretischen Schriften fanden Eingang in die praktische Filmarbeit.

"Es ist bemerkenswert. daB die avantgardistischen sowjetischen Regisseure in ihrer Praxis die Theorie der Formalisten bestätigten: Sie schafften die Dominanz der Thematik im Film ab. entwickelten ein System von Verzögerungen, deformierten die Gegenstände stilistisch (Vermerkwürdigung!). entwickelten eine Vielschichtigkeit von Bedeutungen in ihren Metaphern und bauten die Prinzipien der "Montage« aus. um sie als semantische Gegensätze zu verwenden." $2+7$

Für die FEKS war vor allem die Zusammenarbeit mit Jurij Tynjanov von großer Bedeutung. Er schrieb die Drehbuicher zu "Sinel'" (1926) und "SVD" (1929). Seine praktische Filmarbeit vermittelt ein anschauliches Bild der gelungenen Verbindung von Theorie und Praxis, da er seine literaturwissenschaftlichen Erkenntnisse in den Film einbrachte, wobei er sich voll auf den Film und seine Ausdrucksmöglichkeiten konzentrieren und die Literatur außer acht lassen konnte. "Его интересовал не сценарий, а фильм." "Thn interessierte nicht das Drehbuch. sondern der Film." 2+8

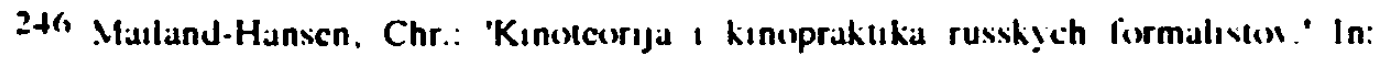
"Kinor cdoeskic Zapiski." Hefi 7. Minkau 1900), S. 115.

2+7 Fliher, A.: 'Der russische Formalismus - Theoric und Wirkung.' In: Zmegac. V.

Skreb. Z.(Hg.): "Zur Krilik literaturnissensehalilicher Mechedelegge." Frankfurl:M 1473.

S. 126.

2+K GE. S. 76. 
Als Tynjanov und die Fèksy zu Beginn des Jahres 1926 ihre Zusammenarbeit begannen, hatten diese die Phase des stürmischen Exzentrismus bereits mit ihren Theaterinszenierungen und den ersten Filmen überwunden und wandten sich jetzt mehr der Poetik im Film zu. So erklärt Kozinces:
"Не пересказ, а поетическое выражение - $\mathrm{x}$ этому тогда все мы стремились. Пространство, движенне, связь вещей - во всём этом хотелось найти не бытовую, внешнюю связь, а внутреннее едннство. Вот почему приход Тыняновя в 'Севзапкино' был для нас так важкен. Он обладал в превосходной степени чувством глубины зритсльных образов."
"Nicht nach Nacherzählung, sondem nach poetischem Aus- druck - danach strebten wir alle zu jener Zeit. Der Raum. die Bewegung, der Zusammenhang der Dinge - in all dem wollte man nicht den alltäglichen äußeren Zusammenhang. sondern die innere Einheit finden. Eben deshalb war der Eintritt Tynjanovs ins 'Sevzapkino' für uns so wichtig. Er besaß in hohem Maße ein Gefuhl fur die Tiefe visueller Bilder." ${ }^{\text {2*4 }}$

Deshalb war für Tynjanov vor allem die Bildkomposition wichtig bei der Beantwortung der Frage nach dem Zusammenhang von Sujet und Stil im Film. ${ }^{2 n}$ Dabei bestimmt der Stil das semantische System des Werkes, und es besteht ein unmittelbarer Zusammenhang zwischen diesem System und dem Sujet. Im Film wird dieses System bestimmt durch dic Komposition der einzelnen und die Verknüpfung aller Bilder.

'Die 'tiefe Leinwand' wird zum Konvergenzpunkt und gleichzeitigen Ausgangspunkt der für die Entwicklung des sowjetischen Films in der 2. Hälfte der zwanziger Jahre wichtigen Zusammenarbeit zwischen Tynjanov und der FEKS." 251

Interessant im Verhältnis zwischen FEKS und Tynjanov sind die konträren Wege. die sie nach 1 . Sepmans Beschreibung in der Entwicklungsgeschichte des Films gingen. Während sich die Fèksy im Laufe der Zeit vom Exzentrismus entfernten, ging Tynjanov den umgekehrten Weg und gelangte auf der Suche nach szenaristischer Form zum Exzentrismus als Organi-

\footnotetext{
24") GE, S. $\pi$.

250) Vyl. Tynjan:». J.: 'Lber dic Grundlagen Jes Films.' In: Beilenhor!,W.: "Pixulk des Films. Deulwehe Erstauspabe des lilmtherretixchen Tevie der russisethen Formalisten mut cinem Vions ort und Anmeriungen." Munchen 1974. S. S997.

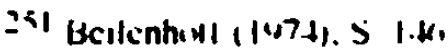


sationsform des Filmsujets. ${ }^{252}$ Dabei verwendete er in Anlehnung an Gogol die Anekdote als künstlerische Form der Annäherung an ein historisches Thema. Die Verwendung féksscher Kunstgriffe in seinen Drehbuichern "Der Affe und die Glocke" ("Obez'jana i kolokol") und "Oberleutnant Kiže" ("Porucik Kiže") sieht Sèpman jedoch nicht als Wiederholung. sondem als Weiterentwicklung der exzentrischen Tradition. ${ }^{253}$

Aber auch andere Formalisten arbeiteten mit der FEKS zusammen. Der Literatur- und Theaterwissenschaftler $A$. Piotrovskij, fur den die Filmarbeit nur eine Beschäftigung von vielen war. schrieb das Drehbuch zu "Das Teufelsrad" ("Certovo koleso") und bat die Fèksy, den Film zu inszenieren. was diese erstaunte, da Piotrovskij zu Zeiten von "Z.enit "ba" harte, aber gerechte Kritik an der FEKS geuibt hatte. 25

Viktor Sklovskij, das enfant terrible der Formalisten. wie Erlich ihn nennt, hatte allerdings keine besonders enge Beziehung zur FEKS. Zwar schrieb er einige Aufsatze über sie. doch. wie Nikita Lary schreibt, schien sie ihn nicht so intensiv zu beschäftigen wie beispielsweise Ejzenṡtejn oder Room. 255

Sklovskij war mehr an den Produktionsbedingungen des Films und ihrer Wirkung auf das fertige Produkt interessien. Er verteidigte die Art der Filmproduktion bei den Fèksy ${ }^{25}$ ' aus seiner Begeisterung für das Kino als "... Fabrik der Beziehungen zu den Dingen..."257. kritisierte jedoch ihre Sujets. Nähe zur FEKS sah er vor allem in ähnlich gearteten schöpferischen Bemuihungen bei der Anwendung des Kunstgriffes der Verfremdung.

"Der Exzentrismus beruht auf der Auswahl von Eindrucksmomenten und ihrer neuartigen. nicht automatisierten Ver-

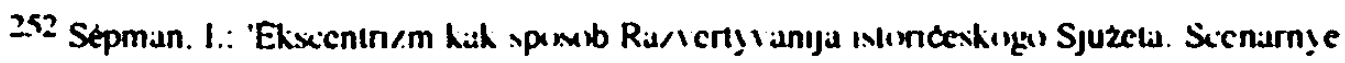

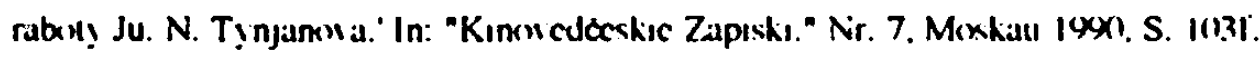

25.3 Ibid., S. 107.

254 GE. S. 6.5 .

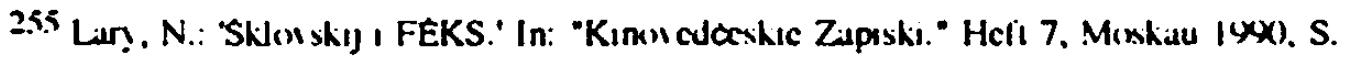

110.

2.5 Ibid., S. 112.

25 Zit. n. Beilenturli (1974). S. 1th.
} 
bindung. Exzentrismus heißt Kampf gegen Gewöhnung, Aufgabe der traditionellen Sicht und Darbietung des Lebens. "208

Das Wesen dieses Kunstgriffes und die ihn betreffenden Gemeinsamkeiten zwischen FEKS und Formalisten sollen im folgenden untersucht werden.

\subsubsection{Das Prinzip der Verfremdune (Ostranenic)}

In dem bereits erwähnten Aufsatz "Kunst als Kunstgriff" ("Iskusstvo kak priem") widerlegt Sklovskij die Definition von Dichtung "Kunst ist Denken in Bildern" (nach Belinskij), indem er darauf hinweist, daß poetische Diktion und bildhafter Ausdruck nicht unbedingt einander entsprechen. Einerseits ist die bildhafte Ausdrucksform nicht auf die poetische Sprache beschränkt. sondern auch in der Prosa oder sogar der Umgangssprache zu finden, andererseits kann auch die poetische Sprache ohne Bilder auskommen. ${ }^{2 *)}$ So würden die Dichterschulen auch nicht neue Bilder schaffen, sondern nur alte anhäufen und ins Gedächtnis zurückrufen.

"Das Denken in Bildern ist jedenfalls nicht das Glied. das alle Zweige der Kunst oder auch nur alle Gattungen der Wortkunst miteinander verbindet, der Wandel der Bilder ist nicht das Wesentliche in der EntwickJung der Kunst." $2(-1)$

Im Folgenden definiert Sklovskij Dichtung und die gesamte Kunst als abhängig von der Art menschlicher Wahrnehmung. ${ }^{201}$

Die menschliche Umgangssprache mit ihren unvollendeten Sätzen und halb ausgesprochenen Wörtem habe, laut Sklovskij, einen Automatisierungsproze $B$ hervorgerufen, unter dessen Einfluß der Mensch die Dinge nur noch oberflächlich registrient, sie jedoch nicht mehr wahmimmt und aus diesem Grunde auch nicht mehr reproduzieren kann. 20,2 Das Ziel der Kunst sei es jetzt. die Wahmehmung der Dinge - und damit des Lebens uiberhaupt - wieder

\footnotetext{
2.58 Sklor skij. V.: 'Gchurt und Daseın der FEKSc.' In: Micrau. F.: "Dic Enveckung des Wortes. Essa! s der russischen formalen Schulc." Leipzsg 1987. S. 144.

259 Vgl. Erlich, V.: "Russischer Formalısmus." Mıt cinem Geleıtu ort ion Renc Wellek. Frankfurt/M. 1967. S. 193.

260 Stiluskifj (1964), S. 72.

$2 n$ Lix. cill.

26,2 vil. ibid. S. 7311.
} 
herzustellen. Dafur brauche die Kunst zwei Verfahren: das der Verfremdung und das der Komplizierung der Form. Als Beispiel für Verfremdung führ Sklovskij Auszuige aus Tolstojs Werk an, in dem sich zahlreiche Stellen finden, wo der Schriftsteller Dinge "so beschreibt, als sähe er sie zum erstenmal." ${ }^{2 k_{2} 3}$ Bei der Verfremdung geht es Sklovskij in erster Linie um das Stattfinden einer semantischen Verschiebung (russ. sdvig), egal ob vom Verfeinerten ins Einfache, oder vom Einfachen ins Verfeinerte. In der Sprache der Dichtung erfolgt in der Regel eine Verschiebung vom Einfachen ins Komplizierte. denn diese Sprache ist schwierig. konstruiert und gewunden, ihr Rhythmus retardierend und ein Verstoß gegen den Rhythmus der Prosa. ${ }^{20+}$ Diese Verschiebung ist ein Beispiel für den Kunstgriff der erschwerten Form. da er den Leser veranlaßt, sich intensiver und daher bewußter mit dem Kunstwerk auseinanderzusetzen.

Im Kunstgriff der Verfremdung und der erschwerten Form findet sich die größte Gemeinsamkeit zwischen Sklovskij und der FEKS, und Nedobrovo sieht in diesen Kunstgriffen die Methode26.5 des feksschen Exzentrismus. Der Sinn dieser Methode liegt in der Herausführung von Dingen und Begriffen aus der Automatisation. damit der Leser das Gefühl für eine Sache durch das "Neue Sehen" und nicht nur durch das bloße Wiedererkennen erlangt. Weiterhin in Anlehnung an Sklovskij erklärt Nedobrovo:

\begin{abstract}
"Их эксцентрический прием есть прнем 'затрудненной формы'. 'Затрудненная форма' раздвигает на больший временной отрезок восприятие зрителем вещи и осложняет весь воспринимательский процесс."

"Ihre exzentrische Methode ist der Kunstgriff der "erschwerten Form".Die "erschwerte Form" zieht die Wahmehmung einer Sache durch den Zuschauer auf eine längere Zeitspanne auseinander und erschwert den gesamten Wahrnehmungsprozess." 266,
\end{abstract}

\footnotetext{
26.3 Ibid.. S. 77ir.

204 Ibid., S. 8kit.

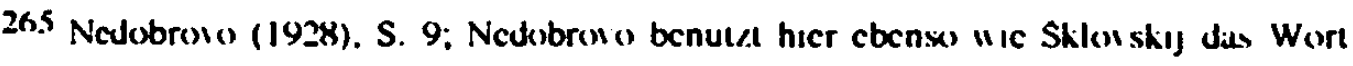
"Pnem". Im welleren spncht er auch iom "pnem nstranentja" (Kunstgnff der Verfremdung) und "pnem zatrudnenney form!" (Kunstgnff Jer crschwerten Form). Da der Evzentnsmus in seincr Gesamiheil aber nicht nur cin Kunstgnif ist. habe ich mich an dicscr Stclle fur uic Uberscluung "Methexte" enischieden. da das Wort "priem" hicr cher Jic Beucutung ciner. naxh Art des Vorgchens. Iestgelegien Arbeitswetse hat.
}

$26 x$. Lx: cit. 
Wenn er im weiteren erklärt. das Verfremdungsverfahren der Fëksy bestehe ausschlieBlich in der Heraushebung eines Gegenstandes aus seiner gewohnten Umgebung, wobei die realistische Form des Gegenstandes erhalten bleibe. ${ }^{267}$ so mag das auf die Theaterstucke oder friben Filme zutreffen. Die Einrichtung eines Büros mit Schreibmaschine. Schreibtisch etc. auf einem Motorrad, wie sie in den "Abenteuem der Oktjabrina" stattfindet, ist sicher ein gutes Beispiel für die obige Erklärung. Sie trifft jedoch nicht auf abstrakte Dinge zu. Auf "Sinel" "beispielsweise. kann diese Theorie nicht angewendet werden. Nedobrovo schreibt, man könne den gewünschten exzentrischen Effekı durch die Verbindung eines Menschen mit Dingen erreichen. wie es bei der Wiedergabe der Art Gogol's und der Atmosphäre der Nikolaitischen Epoche gelungen sei. ${ }^{2 k}$ Bei der Gegenüberstellung der kleinen menschlichen Figur des Akakij Akakievič mit dem großen Leben ist die Verfremdung realer Dinge aber nur ein Miltel zur Erreichung der gewünschten Darstellung. Der kleinwüchsige Akakij Akakievic wird nicht nur großen, teilweise überdimensionalen Dingen (wie z.B. einer riesigen Teekanne) gegenübergestellt. sondem auch großgewachsenen Personen. wobei sich sowohl diese Personen als auch Akakij Akakkievic in einer durchaus "passenden" oder gewohnten Umgebung befinden. In "Sinel"" wird durch die Verfremdung von Gegenständen vor allem der gewünschte Kontrast verstärkt, der zwischen Mensch und Umwelt besteht. Die eigentliche Kontrastierung erfolgt jedoch durch Anwendung filmspezifischer Stilmittel. was im vienen Kapitel näher untersucht werden soll.

Wie in diesem Kapitel gezeigt wurde. setzt sich der fekssche Exzentrismus aus einer ganzen Reihe von Merkmalen zusammen, von denen die Verfremdung nur eines. wenn auch mit den anderen korrelierendes ist. Die futuristische Verherrlichung von Technik und Geschwindigl.cit. die Zerstörung der klassischen Kunsttradition und Provokation des Publikums betrieben die Fèksy miltels konsequenter Parodierung. wie Bulgakova es beschrieben hat.26") Diese Parodierung erfolgte durch die Anwendung von Amerikanismus und niedrigen Kunstgenres auf die klassische Kunst, was wiederum die Verfremdung in der gewohnten Darstellung dieser Kunstwerke

\footnotetext{
20.7 Lex. cit.

z(k Jbid. S. I1

2(i) I gl $S$ exil.
} 
ausmachte. So war auch der Film, den die Fèksy ebenso wie Ejzenstejn schon in ihre Theaterstücke einarbeiteten, zunächst als Kunstgriff zum Erlangen des "Neuen Sehens" angewandt, das Futuristen. friihe Formalisten und Exzentristen ja gemeinsam für die Kunst forderten. $\mathrm{DaB}$ er bald aus seiner Funktion als Kunstgriff innerhalb des Theaters heraustrat und zum eigenständigen Schaffensgebiet wurde, ist logisch begrundet in seiner Entwicklung als Kunstform. 


\section{Kapitel 3. Die Theatersticke und Filme der FEKS}

\subsection{Die Theaterstücke}

\subsubsection{Die Heirat (Zenit ba)}

Das erste Theaterstuck, das Kozincev und Trauberg als Leiter der FEKS inszenierten, war Gogol's "Heirat" ("Zenit "ba"), das am 25. September 1922 im Saal des Proletkul't aufgefuihrt wurde. Im August 1921, noch vor der offiziellen Gründung der FEKS, hatten sie schon ein Theaterstuick geschrieben mit dem Titel "Gin Gentleman und die unsittliche Flasche" ("Díin Dzentl 'men i rasputnaja butylka"). Dieses Stück kam jedoch nicht zur Aufführung.

In Zusammenhang mit "Zenit 'ba" erklärt Civ'jan. es gäbe exklusive und inklusive Texte. Ein exklusiver Text nehme die Teile bzw. Erscheinungen der ihn umgebenden Kultur nicht in sich auf, sondern stoße sie ab. während ein inklusiver Text viele Einzelheiten der ihn umgebenden kulturellen Thematik anziehe, sie verbinde. wieder zerlege und dann dazu bringe ihre Funktionen zu verändern. So ein Text sei das von Kozincev und Tauberg fast völlig umgeschriebene Stück "Zenit ba" $2 \pi$ ), das mit dem ursprünglichen Drama von Gogol' nur noch den Titel gemeinsam hat. Tatsächlich findet sich in diesem Theaterstuck eine Reihe avantgardistischer Zeichen der damaligen Zeit. Schon der Untertitel der Inszenierung "Elektrifizierung Gogol's" ("Elektrifikacija Gogol "ja") erinnert an Lenins Parole "Sozialismus heißı Sowjetsystem plus Elektrifizierung". Da werden Darstellungsformen aus Zirkus. Varieté und music-hall benutzt, in den beiden Hauptpersonen Albert und Einstein kommt der zu dieser Zeit verbreitete Kult um die Relativitätstheorie zum Ausdruck. Und die Verwendung der Figur Charlie Chaplins war laut Civ'jan die erste Manifestation des Chaplin-Kultes in der Sowjetunion. 271 Nicht zuletzt war hier auch die erste kurze Flmvorfuhrung der FEKS integriert. wobei es sich

\footnotetext{
$27(1)$ Cil jan $(19 x))$. S. $2(1$.

27I Ibid.. S. 221. Tatwichlich whricb auch Sklow skj scinc Artikel uber Chaplin crst 1923. alwi cen Jishr nixhden dic Feth! ihn aul dic Buhne gebracht halten.
} 
um einen Ausschnitt aus einem tatsächlichen Chaplin-Film handelte. Im Finale liegt die Leiche Charlie Chaplins auf der Büne und die Figur wird durch die Einspielung des Filmausschnittes wieder zum Leben erweckt. Civ'jan schreibt dazu: "Wenn man diesen Trick als These bewertet, dann bezieht er sich auf einen Gemeinplatz der ästhetischen Futurologie der 20er Jahre: Das Theater stirbt, um im Kino aufzuerstehen." 2??

Insgesamt war dieses Theaterstück so verfremdet, daß der ursprüngliche Text nichr mehr zu erkennen war. Ähnlich wie Ejzenstejn 1923 in "Eine Dummheit macht auch der Gescheiteste" und Mejerchol 'd 1924 in "Der Wald" (beides Stücke von Ostrovskij) war die Handlung zerteilt worden in eine Aneinanderreihung von Varieté- oder Zirkusnummem. Von den Gogol'schen Figuren war nur noch Agafja Tichonovna am Namen zu erkennen. Sie war in "Miss Agata" ungetauft worden. Die Figur Podkolesins war durch Charlie Chaplin ersetzt worden und die anderen Bewerber um die Braut waren "mechanisiert" als "Elektrizität", "Dampr" und "Radio". Hinzu kamen zwei völlig fiktive Figuren "Albert" und "Einstein". dargestellt von den berühmten Clowns Serż und Taurek. Diese mischten sich ständig in die Handlung ein mit dem Ausruf: "Alles ist relativ!". wobei der eine mit deutschem. der andere mit juidischem Akzent sprach.

"Zenit "ba" ist auf zwei Handlungslinien aufgebaut: Agata wählt zwischen drei mechanischen Freiem und entscheidet sich für den dritten. die Figur von der Leinwand: Charlie Chaplin. In der anderen tötet der Detektiv Nat Pinkerton den Bräutigam (Chaplin). weil er es nicht ertragen kann. daß dieser ihn ebenfalls eine mythische Figur - nicht emstnimmt. Doch einen Mythos kann man nicht töten, so ersteht Charlie auf der Leinwand wieder Lum Leben. und Agata umarmt nicht eine Person, sondern die Leinwand $2 ?$ ? Am Schluß erscheint der Autor Gogol’ selbst. um sich über die Verunstaltung seines Stuikkes zu beschweren.

Kritiker und Zuschauer nahmen die Inszenierung sehr negativ auf. Sowjetische Filmwissenschaftler und Kozincev selbst beurteilen sie im günstigsten Fall als Jugendsünde. ${ }^{77}$ Dennoch erscheint sie mir als wichtiger Schritt in der Entwicklung der FEKS und des sowjetischen Theaters. den man nicht außer acht lassen darf. "Zenit "ba" ist das praktische Beispiel für die

\footnotetext{
272 Cil زjan (1 $(x)(1)$.. S. 24.

273 Bulgakow a ( $19(9))$. S. 35.

$27+$ GE. S. 37.
} 
konsequente Parodierung und die Zerstörung jeglichen Kultes."Persiflage und Trivialisierung erstreckten sich sowohl auf die hohe Kunst. als auch auf die Avantgarde, als auch auf den Boulevard im Aufbau der Handlung, in den Masken, in den Reprisen."275 Durch die Art, in der sie ihre Helden Charlie Chaplin und Nat Pinkerton auf der Bühne darstellten, entmythifizierten die Fèksy sie. "Zenit ba" ist die Realisierung ihres Manifestes und - wie oben gezeigt - als Zeitzeugnis nicht ohne Wert. Immerhin nahm Ejzenstejn 1923 "Zenit'ba" zum Vorbild für seine Inszenierung von Ostrovskijs Stück "Eine Dummheit macht auch der Gescheiteste" ("Na vsjakogo Mudreca est" dovol "no prostoty"). Und im gleichen Jahr wie die FEKS in Petrograd. inszenierte Mejerchol 'd eine "Zirkusfassung" von Suchovo-Kobylins "Tarelkins Tod". $27 \%$

\subsubsection{Außenhandel auf dem Eiffeltum (Vnestore na Ejfelevoj Basne)}

Am 29. Dezemher 1922. dem "Exzentrischen Freitag", wurde die nächste FEKS-Inszenierung "Amerikanische Vorstellung der FEKS" ("Amerikanskoe Predstavlenie FEKSa") im "Freien Theater" ("Svobodnij Teatr") auf geführt. Diese Stück basierte auf realen Ereignissen der Zeit. wie der Revolution in der Türkei. dem Streit um die Kirche. der Arbeitslosigkeit der Schauspieler. der beginnenden Politisierung ästhetischer Werturteile durch Politprosvet etc. ${ }^{277}$ Handlungsaufbau und Ablauf dieses Stückes waren dem von Zenit ba vergleichbar. Am 4. Juni 1923 folgte diesem Stück die Inszenierung der "Amerikanischen Operette in einem Akt" "Drei Trillionen Yen".278 Da diese letzten beiden Stuicke weder in der Literatur zur FEKS, noch von Kozincev oder Trauberg selbst erwähnt werden. seien sie hier nur der Vollständigkeit halber angefün.

Die nächste größere Inszenierung der Fëksy im Juni 1923 war "Außenhandel auf dem Eiffelturm" ("Vnestorg na Ejfelevoj Basne"), eine

27.5 Bul zuakion a $(1)(x)(1)$. S. 35.

27. Vgl. Rudnichif ( $\mid$ S. S. 9.5.

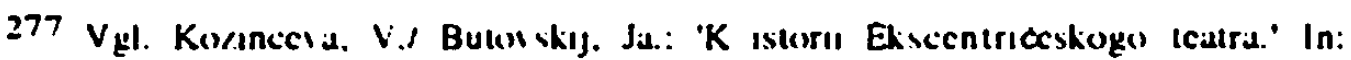

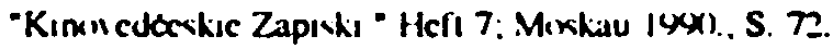

278 Ibid.. S. 73. 
Verbindung von Agitstück und Kriminalgeschichte. Ein kapitalistischer Trust kauft auf der ganzen Welt Kohle, um die Preise dafür in die Höhe zu treiben. In der Folge erfrieren tausende von Menschen. Ein amerikanischer Ingenieur erfindet eine "Blaue Kohle", die durch Nutzung von Windkraft gewonnen wird. Alle Länder, mit Ausnahme der Sowjetunion lehnen diese Erfindung jedoch ab, und der Trust versucht den Ingenieur mit allen Mitteln auszuschaiten. Der sowjetische Außenhandel schickt eine achtjährige Pionierin zu dem Ingenieur, die das Patent für diese Erfindung erwerben soll. Das Treffen findet in Paris auf dem Eiffelturm statt.

"Aber auch da konnten die Fèksy nicht ohne idiotische «Persiflage» auskommen", wie Bulgakova es nennt.27)

Die Pionierin war zur Tarnung geschickt worden. da der Trust in einem kleinen Mädchen nicht die Abgesandte des sowjetischen Außenhandels vermuten würde. Die Rolle jedoch war besetzt mit dem schon bejahrten Clown Serż.

Auch "Außenhandel auf dem Eiffelturm" ist in der gleichen Art inszenien wie "Die Heirat", mit schnellem Wechsel kurzer Szenen. Nummern aus music-hall und Zirkus. sowie exzentrischen und amerikanischen Figuren. Die fekssche Begeisterung für Technik. die sich schon in "Die Heirat" im Austausch von Mensch und Maschine bei den drei Freiern gezeigt hatte. fand sich hier in der Umkehrung wieder: Die Formel für die "Blaue Kohle" war personifizien worden.

"Außenhandel auf dem Eiffelturm" war die letzte Theaterinszenierung der FEKS. Im Herbst 1923 schrieben Kozincev und Trauberg gemeinsam an ihrem ersten Filmdrehbuch mit dem Titel "Edisons Frau" ("Zenšcina Edisona"). da sie beschlossen hatten. ihre Kräfte im Film zu erproben. Einen wichtigen Grund für diese Entscheidung sieht Nedobrovo in der Auseinandersetzung mit den Möglichkeiten der Montage:

"Bei der Arbeit im Theater trafen die Fèksy auf die Montage.

Die Stücke der music-hall Programme, aus denen sie "Zenit ba" machten. waren einfaches Rohmaterial.

Man mußte die Stucke in ein gegenseitiges Verhältnis zueinander bringen." $2 \times(1)$

Zur gleichen Ansicht waren Mejerchol'd und Ejzenštejn gelangt. Die Voraussetzung für die Montage lag in der "Episodisierung". also der Zer-

279 Bulgakiva (19(x)). S. 36.

2X0) Nadibrow.. (142x). S. 17. 
stückelung der Theaterstücke in Nummem. Die gezielte Aneinanderreihung dieser Episoden mittels kontrastierender oder ergänzender Montage bestimmte dann deren Verhältnis zueinander. In der Auseinandersetzung mit der Montage gelangten die Fèksy auf ähnlichem Weg wie Ejzenstejn zum Film. Im Film konnte man aber auch leichter und wirkungsvoller Dinge oder Situationen verbinden, die sich in Zeit und Raum des Theaters nicht verbinden ließen. Aus dieser Erkenntnis heraus gelangten die Fèksy in ihren Filmen zur Anwendung des Prinzips der Verfremdung und Ejzenstejn zur "Konflikt-Montage".

\section{Exkurs:-Der russisch/sowjetische Film bis 1920}

Im Jahr $1886 \mathrm{kam}$ der Film nach Rußland. Am 14. Mai filmten die Brijder Lumière die Krönung des Zaren und wenige Tage später, am 19. Mai, eröffneten sie das erste russische Filmtheater am Nevskij Prospekt in St. Petersburg. In der folgenden Zeit bereisten die Brüder Lumière mit ihrem Kinematographen weite Teile Rußlands und machten ihn im ganzen Land bekannt. Andere auslandische Filmfirmen folgten diesem Beispiel und es entwickelte sich eine lebhafte Konkurrenz um den russischen Markt. Am erfolgreichsten arbeiteten die beiden weltweit operierenden französischen Konzerne Pathé und Gaumont ${ }^{281}$. sodaB in den ersten Jahrzehnten in Rußland fast ausschließlich französische Filmimporte zu sehen waren. Auch die ersten russischen Filmvorführer, die Filme und Vorführgeräte gekauft hatten. zogen damit durch das Land, und es gab zunächst kaum feste Filmtheater. Erst 1903 wurde das erste "Elektrische Theater" im Zentrum Moskaus eröffnet.

Lange Zeit arbeiteten die ausländischen Produktionsfirmen ohne einheimische Konkurrenz. da die ersten russischen Filmproduktionen erst im Jahr 1908 entstanden. Zwar waren Fragmente von Puskins Drama "Boris Godunov" schon 1907 durch den Produzenten Drankov unter der Regie von Zuvalov verfilmt worden, der Film blieb jedoch unvollendet. 1908 produzierte Drankov dann "Sten 'ka Razin". und ein anderer russischer Produzent. Chanžonkov, schloß sich mit dem Film "Drama im Lager der Moskauer

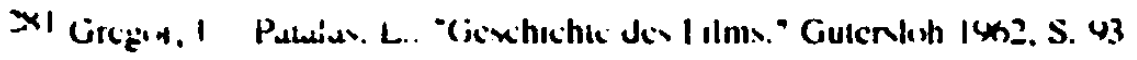


Zigeuner" ("Drama v tabore podmoskovnich Cigan") an. "Auch Pathé startete daraufhin eine Moskauer Produktion, doch gelang es den Russen auf die Dauer besser, die Wüsche ihres Publikums zu erfüllen. ${ }^{n 282}$ Chanžonkov gründete 1904 ein Verleihbüro und 1906 seine eigene Produktionsfirma. mit der es ihm gelang. Pathé emsthafte Konkurtenz zu machen.

Der fruhe russische Film bezog sein Repertoire vor allem aus der heimischen Literatur. Romane. Dramen und sogar russische Volkslieder wurden als Vorlage benutzt. und so entstanden zunächst zahlreiche Roman-oder Dramenadaptionen. $2 \times 3$

"Die Romanadaptionen wurden nach einem 'Illustrationsschema' verfertigt. das heißt. man wählte wesentliche Episoden des Buches aus. inszenierte sie und verband sie mit entsprechenden Zwischentexten. An die Stelle unbeweglicher Illustrationen traten jetzt lebende Bilder." 224

Diese Konzentration von Literaturverfilmungen hatte zu'ei Grüde. Zum einen war es der Wunsch nach Darstellung der eigenen, vertrauten kulturellen Tradition im Gegensatz zur fremden der ausländischen Filme, zum anderen gab es bei diesen literarischen Adaptionen die geringsten Probleme mit der staatlichen Zensur. Denn ebenso wie die Literatur, hatte auch der Film bald Schwierigkeiten mit der Zensur, die nach der Niederlage im Russisch/ Japanischen Krieg von 1905 zwar zunächst gelocken. im April 1906 jedoch umso stärker verschärft worden war. 265

In den Jahren vor Beginn des Ersten Weltkrieges begann man dem Drehbuch im Film größere Bedeutung beizumessen. Als sich auch berühmte Schriftsteller wie Andreev. Amfiteatrov, Kamenskij. Sologub. Dymov u.a. für das neue Medium interessierten. wurden sie von den Produzenten mit offenen Armen aufgenommen. Andreev schrieb nach seinem Stück "Anfisa" das Drehbuch zum Film (1912), bei dem Protazanov Regie führe. Man war sich jedoch noch nicht klar über das Wesen der Drehbuicher, und so stellte sich bald heraus. daß diese bekannten Autoren nicht viel mehr als ihre Namen zum Drehbuch beizutragen hatten. $2 x$.

$2 \times 2$ Lix. vit.

$3 X^{3}$ Vgl. daru: Le!da (ISk3). S. HIHI. (Filmogiaphic).

284 Toxplik., J.: "Geschichic des Film ixus - 1428." Autcrisierte Utertragung aus dem Pilnicitien und Redakition ion Lillı Kidulimann. Munchen 1975. S. 92.

2x.5 V gl. Lọda (1483). S. 29.

$2 \times$ I Ibid.. S. 57i. 
Der Erste Weltkrieg brachte entscheidende Entwicklungen für den russischen Film mit sich. Nach der plötzlichen Befreiung von der ausländischen Konkurrenz, entstand eine große Zahl von neuen Produktionsfirmen. Studios und Laboratorien. Das hatte nicht nur eine Flut von im Land produzienen Filmen zur Folge, sondern auch die industrielle Entwicklung der technischen und künstlerischen Möglichkeiten des russischen Films. Im ersten Kriegsjahr bestand das Repertoire der Kinos hauptsächlich aus propagandistischen Kriegsfilmen. Durch den geringen Erfolg dieser Filme beim Publikum. überwogen aber schon 1915 wieder die Unterhaltungsfilme.

"Nur das staatliche Skobelev-Komitee (genannt nach dem (seneral Skobelev, einem Helden des Tükenkrieges) bemühte sich weiterhin. die Öffentlichkeit mit Hilfe des Films fur 'patriotische' Ziele zu mobilisieren. jedoch ohne nennenswerte Effolge." 287

Grotesken. Komödien, Abenteuer- und Kriminalfilme hatten weitaus mehr Erfolg beim Publikum. Mit diesen Filmen gaben sich die russischen Produzenten allerdings nicht zufrieden. Sie wollten den Film auch für die Intellektuellen interessant machen. die ihn bis dahin als Jahrmarktskunst abgelehnt hatten. So produzierte die Firma Thieman und Reinhardt die "goldene Serie" von psychologischen Dramen. Eine Reihe von Filmen dieser Serie drehte der auch in der späteren Sowjetunion bekannte Regisseur Jakov Protazanov. Eine bemerkenswerte Verfeinerung der filmischen Ausdrucksmittel erteichte er besonders in der Adaption von "Pique Dame" ("Pikovaja Dama". 1916) und dem Film "Der triumphierende Satan" ("Satana likujuścij". 1917), wobei der Reiz dieser Filme "vornehmlich in der subtilen Ausmalung des Makabren und Verhängnisvollen bestand." "200x Sadoul hält den Regisseur Jevgenij Bauer aufgrund seines Filmes "Ein Leben für ein anderes" ("Zizn" za Zizn'", 1916) für den besten dieser Zeit. ${ }^{28 "}$ Bedeutende Regisseure der Zarenzeit waren aber auch Vladimir Gardin. Aleksandr Volkov. Petr Cardinin und Whadysław Starewitsch. der Puppentrickfilmregisseur. Bekanntester Schauspieler der "goldenen Serie" und damit der erste russische "Star" war zweifellos Ivan Mozżuchin.

\footnotetext{
$2 \times 7$ Tixplit/ (1975). S. 1.54

3XX Greg(r; Palalias (1462). S. y5.

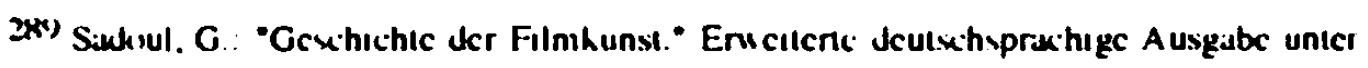
Redakilıon ion Hans Winge. Wien 1957. S. 178.
} 
Tatsächlich begann die Intelligentsija sich jetzt für den Film zu interessieren. Gor'kij und Tolstoj hatten sich bereits positiv zum Film geäußert, als die Futuristen den Film, aufgrund ihrer Ablehnung des zeitgenössischen Theaters. begriiBten. Majakovskij hatte bereits 1913 mehrere Artikel über die Möglichkeit der Ablösung des Theaters durch den Kinematographen geschrieben. ${ }^{2 \times 0}$ Und nach anfänglicher Ablehnung setzten sich auch die Theaterleute mit dem Film auseinander. Mejerchol ${ }^{\circ} \mathrm{d}$ drehte für die "goldene Serie" "Das Bildnis des Dorian Gray" (1915). Toeplitz meint zu dieser Verfilmung. daß Mejerchol'd "unter den Gegebenheiten des Stummfilms keine Äquivalente für die schöne Sprache des Romans und für das ununterbrochene Feuerwerk von Paradoxa finden konnte." 291 Leyda dagegen schreibt zu dieser Verfilmung:

"It was original and daring as few films before it or since have
dared to be. Russian artists who saw it and then The Cahinet
of Dr Caligari a few years later in Europe. tell me that if it had
been shown abroad it would have surpassed Caligari"s repu-
tation as a heightening of film art. It was undoubtedly the
most important Russian film made previous to the February
Re-volution."202

Leider ist der Film verlorengegangen. doch Leydas ausfuhrliche Beschreibung vermittelt einen guten Eindruck von einer sicher hemerkenswerten Verfilmung.

Einem anderen Theaterregisseur. Tairov, war es bei der Vertilmung des Romans "Le Mort" ("Mertvec", 191.5) von Claude Lemonnier gelungen. die Fabel durch eine Pantomime auszudrücken. sodaß dieser Film gänzlich ohne Zwischentitel auskam. ${ }^{20 ?}$

Nach der Revolution von 1917 emigrierten viele der bekannten Regisseure und Schauspieler, aber auch Produzenten und Kinobesitzer. Der russische Film geriet in große materielle Schwierigkeiten. Durch den Bürgerkrieg mangelte es an Elektrizität. Rohfilmmaterial und nicht zuletzt an Verpflegung. Da ein Konzept für die Verstaatlichung des Filmwesens erst geschaffen werden mußte. blieb es zunächst in privater Hand. wobei sich die Privatunternehmer verständlicherweise dem neuen Regime gegenuber ablehnend verhielten.

\footnotetext{
2x) Vel. Majadkondus (1975). S. Si1.

201 Toxpliv (1075). S. 1.56.

292 Lẹdia ( IYx3), S. XIf.

24.8 Toxplit/ (1975). S. 1.5x.
} 
Dennoch wurde 1918 eine ganze Reihe von Filmen produziert. Majakorskij schrieb allein in diesem Jahr drei Drehbücher: "Nicht für Geld geboren" ("Ne dlja deneg rodivsijsja"). "Die junge Dame und der Rowdy" ("Baryšnja $i$ chuligan") und "Vom Film besessen" ("Zakovannaja fil'moj"). In allen drei Filmen spielte er selbst die Hauptrolle.

Als eigentlichen Beginn des sowjetischen Film rechnet man den 27. August 1919, an dem Lenin das Dekret zur Verstaatlichung der Film- und Fotoindustrie unterzeichnete.

Der sowjetische Film begann mit Wochenschauen, die das Leben in dem neugegrundeten Staat dokumentienten. Eine wichtige Rolle spielten dabei die "Agit-Züge". Das waren

"Eisenbahnzige. die, mit einer Druckerei und kompletten Filmeinrichtungen versehen, an die Fronten des Bürgerkriegs entsandt wurden, um dort unter den Truppen revolutionäre Aufklärungsarbeit zu leisten und gleichzeitig Wochenschauszenen zu filmen. "224

Wir erinnern uns. daß auch Kozincev bei der Bemalung eines solchen Agit-Zuges mitgewirkt hatte (s. 2.1.2.).

Der beste sowjetische Dokumentarfilmer Dziga Vertov verlieh diesen Wochenschauen künstlerischen Gehalt. Nachdem er zunächst für die Wochenschau "Kinodelja" ("Filmu oche") gearbeitet hatte. wurde er 1922 mit der Gründung und Leilung der "Kinopravda". einem filmischen Journal als Ergänzung zum Zentralorgan der kommunistischen Partei "Pravda" beauftragt. Es handelte sich hiertei um
"einen ganz neuen Typus Wochenschau, der sich nicht mehr auf bloße Information beschränkte, sondem Aufnahmen aus allen Teilen der Sowjetunion zu einem agitatorisch-publi- zistischen Ganzen verarbeitete. Dabei bediente Wertow sich besonders der formalen Mittel des Films - er benutzte die Großaufnahme. die rhythmische Gliederung einzelner Sequen-zen als Mittel der Aussage: Zwischentexte und Bild setzte er in kontrapunktische Beziehung. Einzelne Einstellungen pflegte Wertow in Rot. Orange. Gelb und Blau zu kolorieren, um sie hervorzuheben." 295

Die Arbeit an der "Kinopravda" brachte Vertov zum Konzept des "KinoGlaz" ("Film-Auge"), in dem er allein dem Dokumentarfilm Sinn und kunstlerischen Wert zugestand. Der Film sollte auf jegliche fiktive Handlung.

\footnotetext{
204 (ircgur, Pallalias (1 $1 \times 2)$. S. ' $*$.

?"il I. ill
} 
auf Schauspieler und Dekoration vollständig verzichten, um das Leben objektiv aufzunehmen. Die Objektivität würde durch das empfindungslose Kameraauge gewährleistet werden. Wichtigstes Kunstmittel dabei war die Montage. "Die Persönlichkeit des Regisseurs zeigte sich in der Auswahl der Dokumente, in der Art ihrer Aneinanderreihung. im Rhythmus. ${ }^{n X_{0}}$

Vertov drehte eine große Zahl bedeutender Filme, deren beruhmtester wohl "Der Mann mit der Kamera" ("Celovek s kinoapparatom", 1929) ist.

Ein anderer bedeutender Regisseur des fruhen sowjetischen Films war l ev Kulešov. Von Beruf Maler, hatte er erste Filmerfahrungen bei Jevgenij Bauer als Architekt und Assistent gesammelt, bevor er 1918 seinen ersten eigenen Film mit dem Titel "Das Projekt des Ingenieurs Prite" ("Proekt inženera Prajta") drehte. Auch Kuleśov sah das Wesentliche des Filnıs in der Montage. Er maß dem einzelnen Bild weniger Bedeutung zu als der Methode, nach der sie zum fertigen Film miteinander verbunden wurden. $2 \%$ :

Im Gegensatz zu Vertov befürwortete er den im Atelier mit Schauspielem gedrehten Spielfilm. Er forderte allerdings die Ablösung des alten psychologischen russischen Films durch eine Art von Spielfilm, die sich am amerikanischen Detektivfilm orientieren sollte. an dem ihn besonders das beherrschende Element der Bewegung faszinierte. ${ }^{2 *}$ Aus dieser Begeisterung fur die Bewegung heraus entwickelte er auch sein Schauspieler-Konzept und grundete eine Werkstatt zur Ausbildung von Schauspielern. Ähnlich wie in Mejerchol'ds Methode der Biomechanik sollte der Schauspieler sich nicht wie bei Stanislavskij in seine Rolle einleben, sondern ihr durch eintrainierte Mimik und Gestik Ausdruck verleihen.

"Kuleschow lehrte in einem von ihm geleiteten Studio - zuerst in der Filmschule. dann am Ferdinandow-Theater in Moskau die Schauspieler, wie sie zu laufen. zu fallen. zu springen und die wesentlichsten Gefühle und Gedanken mimisch auszudruicken haben. |...| Für Kuleschow war die äußere Erscheinung des Schauspielers das Wesentliche. Der Schauspieler war ein vom Regisseur gehandhabter Mechanismus." 2(x)

Kulesov wandte seine theoretischen Überlegungen auch in der Praxis seiner Filme an. So diente der Agit-Film "An der Roten Front" ("Na Krasnom

\footnotetext{
2\%: Sicksul (1957), S. 18x).

297 Vgl. Tocplik (1975), S. 202.

298 Gregor/ Palialas (1962). S. 49.

2X) T(xplı/ (1975), S. 203.
} 
Fronte", 1920) vor allem zur Erprobung der Theorien, die Kulesov mit seinem Team erarbeitet hatte.

"1... For the others - those film-workers who were given their first creative responsibilities by the revolution - the agitka was a technological kindergarten. Kuleshov has remarked that in making On the Red Front, the actors regarded their work rather as students preparing an examination performance. Results were not uppermost in the crew's thoughts, but the finished film must have done his job. for Kuleshov was told that Lenin saw the film twice, and had praised it.".3.3x)

1923 konnte er seine Theorien dann in einem richtigen Spielfilm erproben. Die Komodie "Die ungewöhnlichen Abenteuer des Mr. West im L ande der Bol 'seviki" ("Neobycajnye prikljucenija mistera Vesta v strane bol "sevikov") ist wohl Kuleśovs berihmtester Film. Indem er die Merkmale amerikanischer Western und Komödien auf die Sowjetunion anwandte. schaffte er eine Parodie dieser Filmformen, ironisierte die Vorurteile des Westens gegenüber der Sowjetunion und begründete die Filmform des "Polit-Eastem".

In seinen späteren Filmen verfeinerte Kulesov seine Theorien in zunehmendem Maße. Sein wichtigster Film war wohl "Nach dem Gesetz" ("Po Zakonu". 1926). Zusammen mit Sklovskij hatte er hier Jack Londons Erzählung "The Unexpected" für den Film bearbeitet.

Kuleśovs Montagetheorie wurde später von seinem Schüler Vsevolod Pudovkin weiterentwickelt. Pudovkin. der von Beruf Chemiker war und sich fiir das Theater begeisterte. kam 1920 durch die Bekanntschaft mit Kulesov zum Film. Er gab seinen Beruf auf und begann mit 27 Jahren das Studium an der Staatlichen Filmhochschule. Sein erster Lehrer war Vladimir Gardin. für den er bald als Schauspieler, Assistent und Drehbuchautor arbeitete.1922 ging Pudorkin zuruck zu Kuleśovs Studio.

"Bei Kuleschow lemte Pudowkin die Kunst der Montage. Er ging von Gardins Konzeption vom verfilmten Theater ab und begann den wesentlichen Prozeß bei der Filmproduktion in der Montage zu sehen."..3nI

Da Pudovkin selbst immer wieder als Schauspieler arbeitete, wie beispielsweise auch in dem Film "Die ungewöhnlichen Abenteuer des Mister West im Lande der Bol "seviki". konnte er Kulesovs Auffassung vom Schauspieler als einen gut funktionierenden Mechanismus. dessen der Regisseur

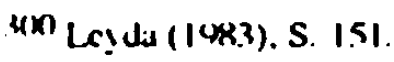

311 T.xplit, 1975), 5 .324.
} 
sich bedient. nicht übernehmen und gestand dem Schauspieler das "Erleben der Rolle" zu. 1925 drehte er seinen ersten eigenen Film "Schachfieber" ("Sachmatnaja gorjacka"), in dem der Einfluß Kuleśovs noch deutlich zu erkennen ist. Während der Dreharbeiten zu dem Film "Die Mechanik des Gehirns" ("Mechanika golovnogo mozga") erhielt er 1926 den Auftrag. Gor'kijs Roman "Die Mutter" ("Mat'n) zu verfilmen. Mit diesem Film schuf Pudovkin ein Meisterwerk. in dem er gekonnt die filmischen Mittel einsetzte. um die psychologische Situation der dargestellten Individuen zu veranschaulichen. Vor allem in der Ausarbeitung des persönlichen Erlebens seiner Helden erhielt der Film seine Bedeutung. "Stets |... $\mid$ ist die Montage bei Pudowkin Ausdruck einer Emotion: sie erzwingt Anteilnahme, weniger Erkenntnis: sie ist immer auf das Erleben einer einzelnen Person bezogen. ${ }^{n .312}$

"Die Mutter" wurde immer wieder in eine Reihe mit Ejzenstejns "Panzerkreuzer Potemkin" ("Bronenosec Potemkin". 1925) gestellt. Ein grundlegender Unterschied zwischen diesen beiden Filme besteht allerdings darin. daß "Panzerkreuzer Potemkin" ein Massenfilm ist. in dem es (abgesehen von der zentralen Figur des Matrosenführers Vakulincuk) keine individuellen Helden gibt. während es in "Die Mutter" in erster Linie um die Personen der Mutter und ihres Sohnes geht. Außerdem ist die Montage bei Ejzenstejn immer Ausdruck eines Konflikts. bei Pudovkin dagegen ein Mittel der Verbindung einzelner Teile zu einem erzählerischen Kontinuum. ${ }^{303}$

Ejzenstejns Filmmontage läßt sich zuruckführen auf die "Montage der Altraktionen", die er während seiner Theaterarbeit entwickelt hatte (s.o.). Eine Attraktion war dabei "jedes aggressive theatralische Moment, jedes Element. das die Gedanken und die Psyche des Zuschauers beeinfluBt". 304 Hier findet sich der bedeutende Unterschied in der Auffassung des Anwendungszweckes von Montage zwischen Pudovkin und Ejzenštejn. Ejzenstejn wollte mil der Montage von Altraktionen die Beeinflussung des Zuschauers in eine bestimmte Richtung erreichen. Zwar war es auch Pudorkins Montageziel zu wirken. doch immer unter der Voraussetzung einzelne Teile zu einer stimmigen Einheit zu verbinden.

\footnotetext{
302 Gregor! Patalas (ISx)2). S. 111.

303 Vgl. Ibid.. S. 110 iti.

304 Scrgeı M. Ej/cnsicjn: Momage of Altractions. In: tilm form the Film Sense. Na" Yord 1959. S. I1-23015.; Al nixch: Greger/ Palalas (1462). S. I105r.
} 
Ejzenstejn wandte seine Montagetheorie 1925 auch in seinem ersten Film "Streik" ("Stacka") an. Dieser Film uber einen Aufstand und dessen Niederschlagung in einer vorrevolutionären Fabrik. erinnert in vielem noch an die Theaterarbeit des Regisseurs. "Die Anlehnung an den Kubismus bei den Dekorationen, die damals beim 'linken' Theater sehr in Mode war. beeinflußte die Bildkomposition des Films. ${ }^{\text {"3165 }}$ Ebenso ist der Varietéstil des Proletkul'ttheaters hier noch deutlich zu erkennen. Auf der anderen Seite zeigen sich in "Streik" schon Merkmale. die auch in "Panzerkreuzer Potemkin" zu finden sind. Dieser Film. der zur Feier des zwanzigsten Jahrestages der Revolution von 1905 gedreht wurde, begrundete den Weltruhm Ejzenstejns.

"Die große Überzeugungskraft des Punzerkreuzer Potemkin gerade auch in den westlichen Ländern rühn unzweifelhaft daher, daß der thematische Kem des Films, die Revolution. in eine so adäquate und dynamische Form übersetzt wurde. Das läßt sich wie in der Dramaturgie auch in der Mikrostruktur des Films nachweisen. Kollision von Gegenständen. Umschlagen eines Zustandes in den anderen bestimmen jede einzelne Phase der beriuhmten Treppensequenz. ${ }^{\text {31K. }}$

So wird die Gesamtheit des Filmes durch den Zusammenprall von zwei Systemen. dem Zarenregime und der Revolution, bestimmt. Alle Einzelszenen stehen hier für dieses Ganze. Eine sorgfältige Analyse dieses Films würde an dieser Stelle zu weit führen (und wurde auch schon von einer Reihe kompetenter Filmwissenschaftler unternommen), deshalb möchte ich hier nur noch eine Aussage von Jay Leyda zitieren:

"The importance of cutting and editing as a creative process was perhaps the most widely recognized revelation of Potemkin. The sensations of fear on the quarter-deck. panic and machine-like murder on the steps. tension on the waiting ship could only have been communicated by this revolutionary culting method." ur

Als Ejzenstejn mit "Panzerkreuzer Potemkin" den größten Erfolg seines Lebens hatte. hatten die Fekssy erst einen Film gedreht und bei weitem nicht den besten. wie sich Trauberg erinner. ${ }^{30 k}$ Der 1924 für Sevzapkino gedrehte

\footnotetext{
305 T(xplik. (1975). S. 305.

30X. Greger/ Patalas ( 1 (K2). S. I(KR.

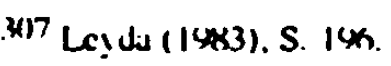

uns Truuberg ( 1976$)$. S. 9.
} 
Film "Die Abenteuer der Oktjabrina" ("Pochożdenija Oktjabriny") bildete für die FEKS den Übergang vom Theater zum Film, wie "Streik" für Ejzenstejn.

In Anlehnung an Kulessov und Mejerchol 'ds Biomechanik entwickelteten die Fèksy ihr System der Schauspielerausbildung. bei dem das körperliche Training im Vordergnund stand.

Die Montagearbeit der FEKS folgte in ihren Filmen eher der von Pudovkin als der von Ejzenstejn. Auch ihre Montage ist eher Ausdruck eines Kontinuums als eines Konflikts und ihre Filme erlangen dadurch. ähnlich wie bei Pudovkin. größere Nähe zur Literatur als die Filme Ejzenstejns.

Ihre Filme mit Revolutionsthematik ("SVD" und "Novij Vavilon") haben immer Individuen als Helden, wie in Pudovkins "Mat" und auch bei der Darstellung des Zusammenpralls zweier Systeme liegt die Betonung mehr auf der Ausarbeitung der psychologischen Situation der Helden. als auf der betonten Kollision der Bilder.

Bei der Ausarbeitung psychologischer Situationen ging ihre eigenständige Entwicklung dahin. durch malerische Bildkomposition und Stilisierung eine poetische Filmsprache zu schaffen. die "Situationen und Gefühle in komprimierter. aufs Grundsätzliche reduzienter Form darzustellen |vermochte |.".3(r)

\subsection{Die Filme}

\subsubsection{Die Abenteuer der Oktiabrina (Pochożdenija Oktjabriny)}

Das erste Filmdrehbuch der FEKS zu "Edisons Frau" wurde nicht umgesetzt. Zu dieser Zeit zerfiel die ursprüngliche Gruppe der FEKS. Jutkevic ging zu Foregger nach Moskau. Kapler kehre in die Ukraine zuruick. Kryżickij hatte sich von der Gruppe schon früher getrennt und auch der Clown Serž verließ mit seinem Zirkus Petrograd. 310 Kozincev und Trauberg blieben als einzige zurück. Überzeugt davon. daß der Film die richtige Kunstform für sie sei. schrieben sie ein neues Drehbuch mit dem Titel "Die Abenteuer der Oktjabrina" ("Pochożdenija Oktjabriny"). Dieses reichten

\footnotetext{
3(9) Gregor: Palialas (1962). S. 117.
}

311 GE. S. 43. 
sie am 5. Mai 1924 bei Sevzapkino ein, wo es auch angenommen wurde. Die Leitung der Inszenierung wurde allerdings dem Regisseur Boris Vital'evic Cajkovskij übertragen, sodaß Kozincev und Trauberg die Position von Regieassistenten innehatten. Diese Situation änderte sich jedoch schon bald nach Beginn der Dreharbeiten. Die schwindelerregende Höhe bei den Außenaufnahmen auf den Dächern von Petrograd, veranlaßte Cajkovskij dazu, sich von den Dreharbeiten zurückzuziehen und den beiden jungen Regisseuren das Feld zu iberlassen. "II

"Die Abenteuer der Oktjabrina" ist die Fortsetzung der feksschen. Theaterarbeit mit den technischen Mitteln des Films. Ohne Hemmungen haben sie hier alle Möglichkeiten ausprobien. die der Film zu dieser Zeit bot: Trickfilmaufnahmen. Beschleunigung. Verlangsamung. Frosch-und Vogelperspektive. Rucklauf und Montagetricks. Der Film hat keine klare Handlungslinie, sondem folgt noch dem im Manifest geforderten Prinzip des "Hazard".

Die Oktjabrina verfolgt vor der Kulisse Petrograds den NEP-Mann und den kapitalistischen Bösewicht Kulidż Kerzonovic Puankare (der Name entstand in Anlehnung an den damaligen Präsidenten der USA. Coolidge. den Außenminister Großbritanniens. Curzon, und den Ministerpräsidenten Frankreichs. Poincaré), die bei einem Bankraub eine Kasse mit 10.000.000 Goldrubel gestohlen haben. Die Handlung wird jedoch ständig unterbrochen von Werbe- oder Agitationsaufrufen. Als der NEP-Mann von der Höhe der Isaakskathedrale die blühende sozialistische Stadt sieht und die Hoffnung auf ein Erstehen des Kapitalismus aufgeben muß, will er sich an seinen eigenen Hosenträgem erhängen. Diese reißen jedoch und es folgt die Einblendung: "Da sehen Sie, was es heißt, seine Hosenträger nicht bei LSPO ${ }^{312}$ zu kaufen!". Da werden Menschen aus dem Flugzeug geworfen, weil sie nicht Mitglieder in der "Gesellschaft der Freunde der Luftflotte" sind. oder ein Kamel weigen sich, seine Reiter zu tragen. weil diese nicht die Kekse einer bestimmten Firma essen. "Werbung wird von den Fèksy als Kunst des Unsinnigen verstanden. Auf diesem Prinzip ist die 'Oktjabrina' aufgebaut." 31.3 So stellt der gesamte Film ein bewegtes Werbc-oder

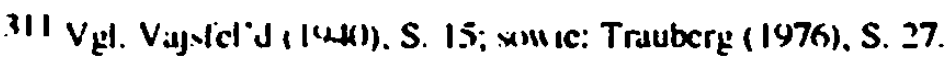

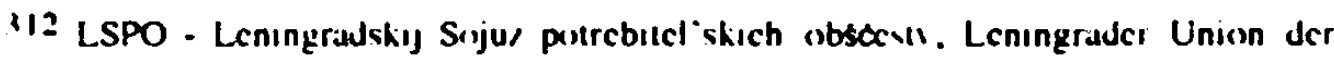
licrnebryexellixtillien.

31.3 Bulgahowa ( $\mid(x)$ )). S. 37
} 
Agitationsplakat im Stil der "Rosta-Fenster" dar. Doch auch dieser Film ist. wie die ihm vorangegangenen Theaterstücke, die praktische Umsetzung des Manifestes "Ekscentrizm". Kozincev und Trauberg blieben ihren darin gestellten Forderungen treu. indem sie einen filmischen "Cancan auf dem Strang der Logik und des gesunden Menschenverstandes".31+ inszenierten. Auch den "Abenteuem der Oktjabrina" fehlt jegliches Pathos. jeglicher Kult. Ebenso wie die Theaterstuicke der FEKS wird auch dieser Film durch konsequente Parodierung der Handlung von der spielerischen Einstellung seiner Regisseure zur Ideologie. zur Kunst und dem Ideal als solchem bestimmt.

Der Film erhielt damals und in späteren Jahren fast ausschließlich negative Kritik und auch Kozincev und Trauberg selbst betrachten ihn als Jugendsünde. Auf das Publikum der zwanziger Jahre muß er mit seinen ungewohnten Perspektiven, seiner rasenden Geschwindigkeit und durch das Fehlen des Sujets verwirrend gewirkt haben. $\mathrm{DaB}$ er auch später nicht positiver hedacht wurde, mag daran liegen. daß dieser Film wenig Angriffsfläche für wissenschaftliche Filmkritik bietet und man ihn nicht als das gelten ließ, was er darstellt: ein Experiment mit Filmmitteln auf der Grundlage exzentrischer Parodie. Ein anderer Grund fur die Ablehnung dieses Filmes liegt zweifellos auch in den Werbe- und Agitationsaufrufen. die auf parodistische Art und Weise jegliche Manipulation des Menschen kritisieren, sei es durch Reklame oder ideologischen Zwang zum Konformismus. Die positivste - und wie mir scheint treffendste - Kritik zu den "Abenteuem der Oktjabtina" schrieb Jurij Tynjanov 1929.

"Dieser kleine, ich weiß nicht wo und wie gedrehte Film gehört nicht zu den hohen Filmgenres. Die bescheidensten Szenen. die ich mir gemerkt habe - da waren wohl Leute. die uber Dächer radeln. Die 'Abenteuer' sind eine zügellose Sammlung aller Tricks. deren sich filmhungrige Regisseure bemächtigen konnten. Und trotzdem haben die FEKSe recht. wenn sie ihre 'Abenteuer' lieben. Sic sind nicht bei den monumentalen 'Epopöen' in die Lehre gegangen. sondern beim elementar 'Komischen'. wo noch die Spuren des Films als einer Erfindung vorhanden sind. Elemente des Films, die es erlauben. ohne ibberfluissige Schuichtermheit und Achtung zu beobachten. zu probieren. anzupacken. was ehrerbietigere. aber weniger aufgeschlossene Leute als Tabu betrachten: Das Wesen des Films als Kunst. Hier erwarben die FEKSe das. was bis heute ihr wertvollster Zug ist: Freiheit des Genres.

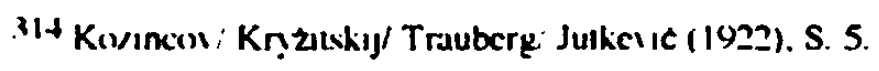


Unverbindlichkeit der Traditionen. die Fähigkeit gegensätzliche Sachen zu sehen. ${ }^{\text {"315 }}$

Der nächste FEKS-Film "Miska gegen Judenic" ähnelte in vielem den "Abenteuern der Oktjabrina". Es handelte sich um eine Episode aus dem Buirgerkrieg. die in Form von Zirkusnummem dargestellt war. Der weißgardistische General Judenic wurde von einem Zirkusclown in Generalsuniform mil angeklebtem Chaplin-Bart verkörpert. Sein Stab wurde dargestellt durch einen langen Zaun. auf den "Judenics Stab" geschrieben war. Als der Zeitungsjunge Miska zu dem Stab vordringt, zieht er sich ebenfalls eine Generalsuniform und einen Schnurrbart an. Sein dressierter Bär (auch Miska genannt) schlägt alle, die zum General wollen, so auf den Kopf, daß sie bewußtlos liegenbleiben. Es beginnt eine Verfolgungsjagd wie in den amerikanischen Keystone-Komödien.

Von allen Biographen der FEKS ist dieser Film nur mit wenigen Worten erwähnt worden. wegen seiner Nähe zu den "Abenteuem der Oktjabrina". Diese Slapstick-Komödie vor revolutionärem Hintergrund spielt zwar keine wichtige Rolle in der Entwicklung der FEKS. ist aber ein interessantes Beispiel fuir die Anwendung des Zirkusprinzips auf Politik und Ideologie.

1924 eröffneten Kozincev und Trauberg auch die Schauspieler-Werkstatt der FEKS, nachdem sie zu der Überzeugung gekommen waren. daß ein Filmschauspieler eine besondere Ausbildung für den Film brauche.

Aus den vielen Bewerbern für diese Werkstatt wählten sie etwa acht bis zehn aus. die dann auch in den nächsten Jahren die feste Schauspielertruppe der FEKS bilden sollten.

Ähnlich wie Kulesov legten auch Kozincev und Trauberg den Schwerpunkt auf die körperliche Ausbildung des Schauspielers und unterrichteten ihre Schuiler in Akrobatik. Fechten. Boxen und anderen Sportarten. Die Beherrschung des Körpers und der Mimik war das oberste Ziel, so daß auch Emotionen und der innere Zustand eines Menschen durch äußerliche Körpersignale dargestellt werden konnten und nicht "durchlebt" werden sollten.

Daß es außer den Studios von Kulesov und der FEKS noch eine weitere Schule für Schauspielerausbildung gab. die mit den gleichen Methoden arbeitete und sich KEM (Kinoeksperimental'naja masterskaja = Film-

"1.5 Ty njunin. J.: 'Lber FEKS.' In. Micrau (I4k7), S. 4364. 
experimentelle Werkstatt) nannte, zeigt, welch großen Einfluß Mejerchol'ds Biomechanik gerade auf den Film hatte.

Die Schauspielschüler der FEKS konnten ihre Kenntnisse zum ersten Mal in dem Film "Das Teufelsrad" ("Certovo Koleso". 1926) praktisch anwenden.

\subsubsection{Das Teufelsrad (Certovo Koleso)}

Der erste abendfüllende Film "Das Teufelsrad" bildet einen entscheidenden Punkt in der Entwicklung der FEKS. Er zeigt die Abwendung rom spielerischen Exzentrismus der ersten Jahre. Zirkus. Varieté und Straßenkunst fungierten hier nicht mehr als Darstellungsform, sondern nur noch als Dekoration. Außerdem war es der erste Versuch, individuelle menschliche Persönlichkeiten im Gegensatz zu den bisherigen Plakatfiguren wie Music-Hall Kinematografović Pinkertonov, Albert und Einstein. Kulidž Kersonovic Puankare oder der Oktjabrina darzustellen.

Die Fabel nach dem Drehbuch des Formalisten Adrian Piotrovskij ist einfach und klar. Der Matrose Vanja Sorin besucht mit seinen Freunden bei einem Landurlaub den Vergnúgungspark von Petrograd. In der Achterbahn verliebt er sich in das Mädchen Valja. Er verpaßt den Zeitpunkt zur Rückkehr auf das Schiff und wird dadurch zum Deserteur. Vanja und Valja geraten in eine Bande von Verbrechern. die in einer Ruine Unterschlupf gefunden haben. Die Verbrecher verleiten sie zur Mithilfe bei einem ihrer Raubziige. Als Vanja das bemerkt. Niichtet er und kehrt zu seinem Kreuzer. der Aurora. dic mittlerueile wieder im Hafen liegt. zurück.

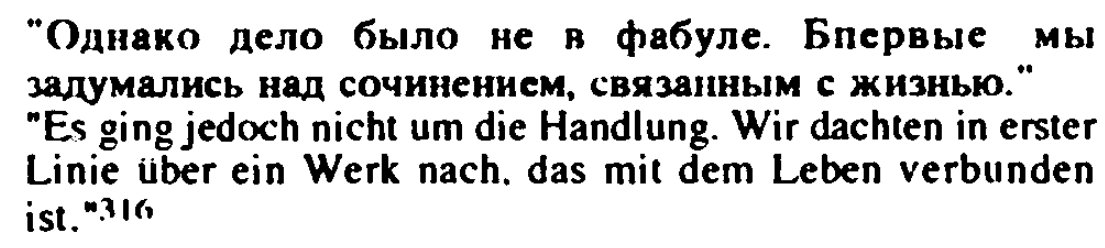

Es war das Leben, wie es in der Mitte der zwanziger Jahre in Leningrad herrschte, das sie darstellen wollten. Aus diesen Grund suchten sie alle Handlungsorte auf. wie den Vergnügungspark. die seltsamen Kneipen, die Ruinen. von denen es zur Zeit der NEP noch eine ganze Reihe gab, und

B1" GE. S. 65. 
nahmen sogar an einer Schulfahrt der Aurora teil. ${ }^{317}$ Diese Orte wurden dann zu "in sich handelnden" Orten im Hintergrund der Fabel, da die Fèksy der Meinung waren, daß es im Film keine Handlungsorte, sondern nur handelnde Orte gibt, die durch ihr Spiel ebenso zur Bedeutung des Filmes beitragen wie die Schauspieler durch ihre Darstellung. ${ }^{318}$ Dementsprechend erklärt Z.uk. daß "Das Teufelsrad" mit seinem aus dem "Großstadtepos" entstandenen Sujel der ausdrucksvollste Film der FEKS in Bezug auf die Aneignung der Stadtkultur sei..19 Er fühn weiter aus, daß die Zeitungen gerade zu dieser Zeit täglich über ähnliche Vorfälle wie die Abenteuer des Matrosen Sorin berichteten. ${ }^{320}$ In diesem Zusammenhang ist "Das Teufelsrad" auch als Zeitzeugnis anzusehen. Gleichzeitig reflektiert dieser Film die damalige Strömung der Literatur. in der die Unterwelt in ihren verschiedensten Erscheinungen Beschreibungsgegenstand war 12.B. die Banden in der Literatur der Odessaer Schule. wie in Babels "Odessaer Erählungen", Slonimskijs "Mittlerem Prospekt", oder Kaverins "Ende der Chaza" etc.).

Zur Darstellungsweise der Stadi Petrograd, aber auch von St. Petersburg in "Sinel" ". sei angemerkt. daß sie in der fremdem Sichtweise des dort nicht Heimischen gezeigt wird. Wie Gogol' vor ihm beschreibt Babel' in seinen Korrespondenzen i un 1918 das Leben in der Metropole aus der Sicht eines Fremden. Kozincev stammte wie Gogol' aus der Ukraine und Trauberg wurde wie Babel' in Odessa geboren. Dieser Umstand mag dazu beigetragen haben. den Regisseuren den fremden Blick auf das Petersburger bzw. Petrograder Leben zutreffend erscheinen zulassen und ihn in ihre Filme zu übernehmen.

Leyda sieht die Stärke von "Das Teufelsrad" in dem Zusammenprall von realistischem Material und dessen exzentrischer Bearbeitung. ${ }^{321}$ Dieser Film war nicht mehr bestimmt von der unruhigen und schnellen Montage ungewohnter Bilder. sondern von der Kombination des Unerwarteten in einzelnen Bildern. die durch eine wesentlich ruhigere Montage zu einem dennoch stimmigen Ganzen zusammengefügt werden. Zwar benutzten die

\footnotetext{
317 Vigl. GE. S. $x$.

$31 \times \mid$ Ibid.. S. 67

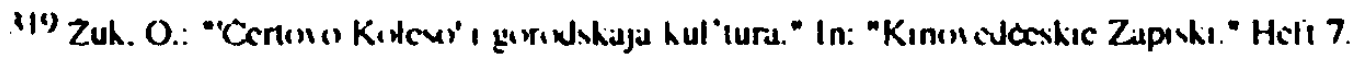

Moxkiau I(xx). S. Sx.

220 Ibid.. S. 571.

321 Le! da ( $14 \times 3)$. 5. 2(1)
} 
Fèksy auch hier wieder exzentrische Perspektiven, die das Publikum schwindlig machen mußten (die Fahrt mit der Achterbahn aus dem Waggon der Bahn heraus aufgenommen, oder die Szene, in der der Anfuhrer der Bande auf das Dach des Hauses nieht, die auf dem Dach spielt), aber diese Perspektiven standen immer im logischen Zusammenhang mit der realistischen Handlung. Die Exzentrik ist beispielsweise in der Entwicklung der Liebesgeschichte zu finden, die sich in der ungewohnten Umgebung der Achterbahn und dem unruhigen Treiben des Vergnigungsparks entwickelt. Ein anderes Beispiel ist die Ruine. die die Bande bewshnt. Es ist cin diusterer Ort. an dem sich der soziale Abschaum versteckt. Gleichzeitig befindet sich hier das "Studio der plastischen Künste". in dem gefeient. getanzt und getrunken wird. In dieser Gegenüberstellung des Ungewohnten wandten die Fèksy das Prinzip der Verfremdung. wie Sklovskij es bei Tolstoj beobachtet hat. auf den Film an.

Zu den oben erwähnten handelnden Orten kommt hinzu. daß auch Gegenstände in die Filmhandlung und den Aufbau des Sujets einbezogen werden. Der Film bekommt dadurch eine ausgeprägte Metaphorik. Zur Besprechung ihres nächsten Raubzuges gehen die Banditen in den Billardraum einer Kneipe und nehmen Vanja Sorin mit. Sie bitten ihn, ihnen bei ihren Geschäften zu helfen, wobei sie nicht erklaren, welcher Art diese Geschäfte sind. In dem Moment. in dem Vanja zustimmt. fällt eine Billardkugel ins Loch, als Metapher für den Fall des Helden. Oder die Verbrecher besprechen einen Raubzug. bei dem viel Blut vergossen werden wird. Im Jargon gibt es dafür den Ausdruck "mokroe delo" (wörtl. "feuchte Sache"). Während dieser Besprechung tropft Wein auf den Fußboden, als szenische Darstellung dieser sprachlichen Metapher. Nicht zuletzt ist auch das Teufelsrad selbst eine Metapher für den Strudel von Ereignissen. in den der Held gerät. Gleichzeitio ist es die bildlich dargestellte Allegorie der Zeit. die ihm davonläuft. Während Vanja und Valja sich auf dem Teufelsrad drehen. verwandelt es sich in ein Zifferblatt, dessen Minutenzeiger zur Zwölf hinwander, wobei Vanja vergeblich versucht. den Zeiger aufzuhalten.

Alle Beispiele zeigen, wie gekonnt die Fèksy die Montage in diesem Film anwandten. Es war nicht mehr eine bloße Aneinanderreihung von Bildern. sondern eine durchdachte Kombination von Einheiten. die in ihrer Zusammenwirkung die gewünschte Bedeutung erhielten. Als letztes veranschaulichendes Beispiel möchte ich hier die Sequenz vor dem Arteiterclub anfiihren: Die Bande will in den Arbeitcrclub eindringen. doch Vanja 
Sorin verstellt ihr den Weg. Er steht der Bande gegenüber ohne zu merken, daß einer daraus hinter ihm steht und die Hand mit einem Schlagring erhebt. In der nächsten Einstellung wird in Großaufnahme die Hand mit dem Schlagring gezeigt. Dann das Gesicht des Mannes mit dem Schlagring. dann Vanjas Nacken. Die folgende Einstellung zeigı wieder die Bande. die nächste wieder Vanja. Die nächsten drei Einstellungen erfassen einen aus der Bande, der raucht. Dann wird das Gesicht des Mannes mit dem Schlagring gezeigt. der ganz langsam die Augen zusammenkneift. In der folgenden Einstellung balle sich die Hand mit dem Schlagring zur Faust. Dann erscheint wieder Vanjas Nacken. Danach wieder ein Rauchender aus der Bande. Die nächste Einstellung zeigt eine Zigarette, von der mit einer knappen Bewegung die Asche abgeschüttelt wird. und in der folgenden Einstellung liegi Vanja bewußilos am Boden.

Hier wird eine an sich dynamische Szene in fast unbewegte Teile aufgelöst. Die Handlung wird also in ihrer Bewegung zurückgenommen und dadurch in ihrem Voranschreiten verzögert. Die Erwartung des Zuschauers wird verlängert, wodurch sich wiederum die Spannung steigert. Hier kam das von Sklovskij beschriebene Verfahren der "erschwerten Form" ("zalrudnitel 'naja forma") zur filmischen Anwendung.

Im "Teufelsrad" wurden die Theorien der feksschen Schauspielschule zum ersten Mal im der Praxis angewandt.

"Die Schauspieler der FEKS bemühten sich, nicht den Charakter, die Gedanken, die seelische Welt des Menschen im Teufelsrad' zu ubermilteln: Mil Gestik. Mimik, Bewegung sollten sie die $H$ a $n$ d I u $\mathrm{n} g$ e $n$ der Helden. ihr Benehmen in der einen oder anderen Sujetsituation ausdrucksvoll gestallen.".322

Dieses Ziel wurde auch erreicht. Die Darstellung von Gedanken und Gefuhlen ist dabei jedoch zu kurz gekommen. Die schauspielerische Leistung bleibt auf das Äußerliche beschränkt. Kozincev und Trauberg hatten zudem eine große Zahl von "Nichischauspielern" eingeseızt, wie das auch Ejzensiejn. Pudovkin, Room und andere Regisseure zu dieser Zeit taten. Durch die sogenannte "Tipaż" (wörtl. Typenreihe) wollte man eine größtmögliche Realitätsnähe und Natülichkeit erreichen, da diese Leute nicht spielen, sondern vor der Kamera leben $u$ uirden. Diese Theoric konnte sich

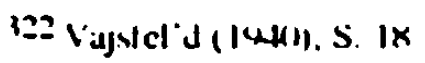


jedoch nicht sehr lange halten, da sie den Film auf die äußerliche und oberflächliche Darstellung des Menschen beschränkte.

"Aber im 'Teufelsrad' entsprach die Verwendung der Typenreihe gänzlich den Überlegungen der Regisseure - eine äußerliche Darstellung des Menschen zu geben. nicht in seine innere Verfassung vorzudringen. ${ }^{.123}$

Wenn Lebedev "Das Teufelsrad" als "Zitatenfilm" bezeichnet. ${ }^{32 t}$ der Auszüge aus Kulešovs. Vertovs. Ejzenśtejns. Griffith' und Ince' Filmen enthalte. so scheint mir das nicht ganz gerechtfertigt. Der angeblich in Vertov-Manier gefilmte Markt steht für die realistische Seite des Films, die, da auf dem wirklichen Markt gefilmt, zwangsläufig dokumentarischen Charakter haben muß. Auch die Schlägereien oder Jagden über die Dächer würde ich nicht unbedingt als Kulešov-Zitat ansehen. da die Fèksy gerade solche Szenen schon in den "Abenteuem der Oktjabrina" verwendet hatten. (Ind die Bande ist woh! weniger ein Zitat aus Ejzenstejns "Streik", als vielmehr - wie oben erwähnt - eine Reflexion der damaligen Literatur, die die (Interwelt als Thema entdeckt hatte und zudem eine realistische Zeiterscheinung ${ }^{325}$ (s.o.). Das "lyrische Kätzchen".32" mag tatsächlich ein Griffith-Zitat sein; insgesamt jedoch ist "Das Teufelsrad" eine in sich schlussige und durchdachte Arbeit. die in ihrem Aufbau trotz des Gegensatzes zu "Den Abenteuern der Oktjabrina" und "Miska gegen Judenic" sehr viel FEKS-Typisches enthält, wobei Ähnlichkeiten sicher nicht von anderen Regisseuren entlehnt wurden. sondern äußerlich bedingt waren.

Mit diesem Film war in der Arbeit der FEKS einerseits der Bezug zum Leben stärker geworden. andererseits aber auch der zur Literatur. Typisch ist dabei schon im "Teufelsrad", daß es sich nicht um eine direkte Adaption einer literarischen Vorlage in den Film handelt, sondem daß ein literarischer Stil in die Sprache des Films übertragen wurde. Die gleiche Methode ist in den ubrigen Filmen der FEKS zu erkennen (s. dazu Kap. 4, sowie die folgenden (Interkapitel).

\footnotetext{
323 Ibid.. S. 20.

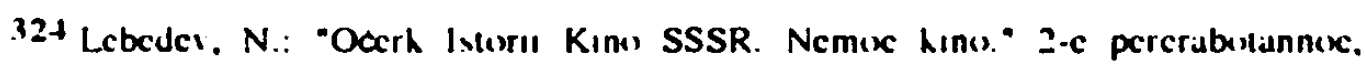
Alupotmennoc i/danic. Miskiau 196.5. S. 373.

$325 \mathrm{~V}$ J. GE. S. 66 .

32 " Lebcule (1) 45$)$. S. 373.
} 


\subsubsection{Der Mantel (Sinel')}

Der nächste Film der FEKS, der ebenso wie "Das Teufelsrad" noch im Jahr 1926 entstand. war die Gogol'-Verfilmung "Sinel"" ("Der Mantel"). Toeplitz bezeichnet diesen Film als weiteren Schritt "zum endgültigen Bruch mit dem Futurismus der Jugendzeit in Abenteuer der Okıjabrina." 327 Jurij Tynjanov hatte Motive aus verschiedenen Erzählungen Gogol's ${ }^{32 x}$, in erster I inie aber die beiden Novellen "Nevskij Prospekt" und "Sinel" als Vorlage für sein Drehbuch benutzt und daraus eine stilisierte. "romantische" Groteske geformt. Inhaltlich stellte er hier die Jugend Akakij Akakievics und seine unglückliche Liebe zu dem "himmlischen Geschöpf" (dem Mädchen vom Nevskij Prospekl) seinem Alter und der ebenso unglücklichen Liebe zu dem Mantel gegenuber.

Der junge (!) Beamte Akakij Akakievic Baśmackin sieht auf dem Nevskij Prospekt eine junge Frau. in die er sich augenblicklich verliebt. Er folgt ihr. als sie in Begleitung eines anderen jungen Mannes - einer zu diesem Zeitpunkt noch unbedeutenden Persönlichkeit - zum Haus des Ausländers Ivan Fedorov geht und sich somit als Prostituierte zu erkennen gibt. Akakij Akakiević geht nach Hause und träumt dort. daß ein fein gekleideter Lakai ihm eine Einladung des "Himmlischen Geschöpfs" vom Nevskij Prospekı uberbring! und ihn in einer goldenen Kutsche zu ihrem Haus fahrt. wo sie ihn erwartet. Als Akakij Akakiević aufwacht. klopft tatsächlich jemand an seine Tür. Es ist ein Bote Ivan Fedorovs, der ihm eine Einladung des Mädchens überbringt. Baśmackin folgt dieser Einladung und wird im Haus des Ausländers aufgefordert. eine Urkundenfalschung zu begehen für einen der Freunde Ivan Fedorovs. Aus Liebe zu dem Mädchen geht Akakij Akakievic darauf ein. Nachdem er die Falschung ausgefühn hat, wird er jedoch von den anderen verspottet. das Mädchen gießt ihm sogar Wein ins Gesicht. Enttäuscht kehrt Baśmackin zu seiner Arbeit in der Kanzlei zuruck. Hier setzt die Handlung von Gogol 's Erzählung "Der Mantel" ein. bei der Tynjanov sich eng an die literarische Vorlage gehalten hat. Es ist die Geschichte des gealterten Titularrats. dessen alter Mantel so zerschlissen ist. daß er nicht mehr geflickt

327 T(xpli1: (1475). S. 344.

328 Dubin (1963. S. 53) erkennt in Jem Film Mexisc aus den "Aulieichnungen cines Wahnsinnıgen". Nedibrowo (1928, S. 34) lındet darin Mexisc aus Jer "Errahlung daruber. wie ve veh stritten" 
werden kann. Nach großen Entbehrungen bekommt er endlich einen neuen. schönen Mantel. der ihm gleich am ersten Abend bei der Rückkehr von einer Teegesellschaft gestohlen wird. Alle Bitten un Hilfe bei der Wiederbeschaffung des Mantels bleiben ungehört und enden schließlich in der seelischen Zerstörung Akakij Akakievičs durch die mittlerweile bedeutende Persönlichkeit, die der Zuschauer bereits im ersten Teil des Filmes kennengelernt hat. Der kleine Beamte wird krank und stirbt. Das Drehbuch verzichtet auf die letzte Passage der Erzählung. in der Akakij Akakiević als Gespenst wiederkehrt. das Mäntel stiehlt.

Auf einer Versammlung der Leningrader Schriftsteller hatte Tynjanov den Antrag gestellt. daß sein Drehbuch von der FEKS inszenient werden sollte. Der Antrag wurde unter der Bedingung genehmigt. daß die Fèksy den Film innerhalb von sechs Wochen fertigstellen würden. ${ }^{32 "}$ was ihnen erstaunlicherweise auch gelang. ${ }^{3}$ )

Während der intensiven Arbeitsphase, die darauf folgte, zeigte sich. daB Tynjanov die Fèksy zu Recht für die Realisierung seines Drehbuchs ausgewählt hatte. da sich ihre Vorstellungen von einer stilisierten romantischen Groteske deckten und ergänzten. Denn es ging auch den Fëksy nicht um eine wortgetreue Wiedergabe Gogol's mit filmischen Mitteln. sondern un dic filmische Adaption der Prinzipien der literarischen Erzählstruktur. ${ }^{3.31}$ So lautete auch der Untertitel des Films "Кино-ıьеса в манере Готолья" ( "Kino-p esa $v$ manere Gogol "ja" - "Filmstuick in der Art Gogols"). Die sowjetische Filmwissenschaft warf der FEKS allerdings vor. sie hätte sich nicht mit den realistischen Tendenzen von "Sinel'" auseinandergesetzt, sondern nur mit der mystisch romantischen Färbung von "Nevskij Prospekt".332 Der expressionistische Stil des Films wird von der westlichen Filmwissenschaft gelobt, ${ }^{3.33}$ während beispielsueise Vajsfel'd kritisiert. daß der menschliche Charakter und auch die konkret-historische Charakteristik St. Petersburgs. die Gogol" in "Sinel"" genial dargestellt habe.

\footnotetext{
329) Viusslel'd ( (14+4)). S. 23.

3.30 GE. S. 87.

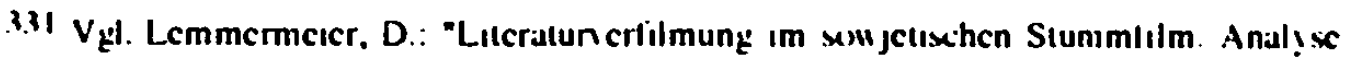
ausgen ahliter Drehbucher." Wiestaden 10w9. S. 64.

3.32 Vgl. Vijstel'd (1941)). S. 24: suw ic: Lebeder (1465). S. 377.

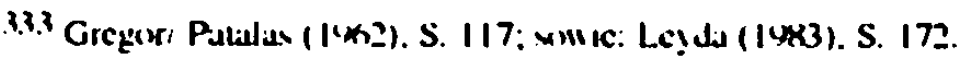


durch diesen Stil abstrahiert würden. ${ }^{3.3+} \mathrm{DaB}$ der Film auch zu seiner Entstehungszeit von der Kritik nicht sehr positiv aufgenommen wurde, mag an der damaligen Einstellung zu Literaturverfilmungen allgemein gelegen haben.

"Da die Gegenwartsthematik aber nach wie vor sehr gefördert und gefordert wurde und der Verdacht des Eskapismus bei Verfilmungen (hauptsachlich von Klassikern) nie ganz ausgeraumt werden konnte. standen Literaturverfilmungen in diesen Jahren oft im Mittelpunkt der Kritik." 33.5

Da "Sinel " in seiner Bedeutung als Literaturverfilmung das gesamte Kapitel 4. gewidmet ist. möchte ich an dieser Stelle nicht näher auf diesen Film eingehen, sondern fortfahren in der Untersuchung der Entwicklungsgeschichte der FEKS und ihrer weiteren Filme.

\subsubsection{Bruderchen (Bratyska)}

Aufgrund der schlechten Kritiken zu "Sinel'" wurden die Fèksy offiziell entlassen. doch die Direktion von Leningradkino war ihnen wohlgesonnen und gab ihnen die Möglichkeit, allerdings ohne Bezahlung. einen Film mit geringem Kostenaufwand zu drehen. ${ }^{3 . *,}$

Als Reaktion auf die Erfahrungen mit "Sinel'" u andten die Fèksy sich jetzt wieder der Gegenwart zu und verfaßten selbst das Drehbuch zu dem Film "Bratyska", in dem sie versuchten. das sowjetische Arbeitsleben in Form einer Komödie darzustellen. Die Handlung ist sehr einfach: Der Direktor einer kleinen Fabrik erklärt einen abgenutzten Lastwagen für irreparabel und will ihn verschrotten lassen. Der Fahrer des Lastuagens ist mit dieser unwirtschaftlichen Anordnung nicht einverstanden, stöbert den Lastwagen auf dem Autofriedhof auf und verabredet sich mit seinen Freunden, den Wagen wieder zu reparieren. Parallel zu dieser "l iebesgeschichte" des Fahrers mit dem Lastwagen. verläuft die Liebesgeschichte zwischen dem Fahrer und einer Straßenbahnschaffnerin. Darin ist der Film ähnlich strukturient wie Sinel', wo

\footnotetext{
3.4 Vajsicl d ( (124)). S. 26.

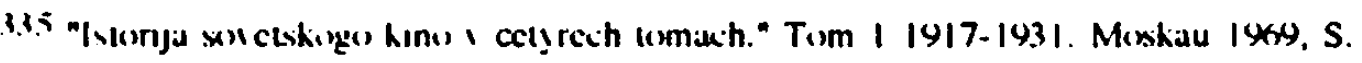

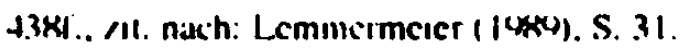

[31 GE. S. 87
} 
die Liebe zum "himmlischen Geschöpf" bzw, zum Mantel neben der zur Arbeit steht.

In diesem Film sollten der neue sowjetische Mensch und der Wirtschaftsaufbau dargestellt werden. "Die Wirtschaft wird hier jedoch nicht chronikalisch, sondern emotional - durch die Liebe zur Arbeit und zum Produktionsapparat dargestellt.".3.37 Vor allem diese Emotionalität. hervorgerufen durch die lyrische Darstellung des Lastwagens, gab Anlaß zu heftiger Kritik an dem Film. L.ebedev schreibt, sie hätten dem Film durch die Darstellung von Produktion und Technik ideologischen Gehalt geben wollen. jedoch nicht gewußt, wie sie diese organisch ins Sujet einfügen sollten. Er wirti den Fèksy formale Experimente sowie Unkenntnis des damaligen sowjetischen Lebens vor und sieht darin den Mißerfolg des Filmes begründet. ${ }^{3.38}$ Meiner Meinung nach ist diese Beurteilung entstanden aus der rigiden Einstellung zur Kunst. wie sie der Sozialistische Realismus auch in der Mitte der sechziger Jahre vertrat. Aus diesem Grund erscheint mir Nedobrovos Beurteilung dieses Films aus dem Jahr 1928 objektiver und gerechter. Er bemängelt nicht den fehlenden Realismus des Films, der schließlich gar nicht in der Intention der Fèksy lag. sondem untersucht die Methode. nach der die Fèksy das Problem der Beziehung zwischen Mensch Technik und Wirtschaft gelost haben. Die drei Einheiten Mensch. Wirtschaft und Technik sind verbunden im Verhältnis des Fahrers zu seinem Lastwagen. In dem Wunsch den alten I astwagen zu reparicren. zeigl sich einerseits seine Liebe zur Technik. andererseits aber auch seine Einstellung zur Wirtschaft. die er durch die Erhaltung von vorhandenem Material und damit durch die Vermeidung unnützer materieller Belastungen unterstutzt (wenn auch in weniger ausgeprägtem Maße. da bedingt durch eben diese Liebe zur Maschine). Zur Darstellung dieser Beziehung haben die Fèksy auch in "Bratyška" das Verfahren der Verbindung kontrastierender Begriffe angewendet. ${ }^{330}$ Der l.astwagen wird vermenschlicht. indem seine einzelnen Teile, wie Karosserie. Kühler. Räder. Muttern usw. in den verschiedensten Einstellungen gezeigt werden. Kozincev selbst schreibt. sie hätten ihm die Vergangenheit zugeordnet mit Szenen. in denen er während der Oktoberrevolution durch die Sıraßen fähn oder Rotarmisten mit Gewehren auf seinen

\footnotetext{
.3 .37 Nedobrisu ( 1923). S. 51 .

3.36 Lebcuti (1465). S. 3\%(1).

${ }^{330}$ Nedibriwo (1928), S. 52.
} 
Kotflügeln liegen. Und er selbst beschreibt die Sequenz, in der der Held nach langer Suche seinen Wagen auf dem Autofriedhof wiederfindet.

"Der Anblick des "entkulakisiernen" | zerstörten, d. Verf. | (wie die Fahrer heute sagen) Lastwagens erschütterte den Helden. Die Szene erschien uns nicht weniger lyrisch als das Duett von Romeo und Julia. Wir drehten bei Sonnenuntergang; der letzte Strahl schien die beschädigten Scheinwerfer des Lastwagens aufleuchten zu lassen. Und für einen Augenblick entflammten die Scheinwerfer auf dem ganzen Friedhof. Die verstümmelten Autos, schien es, blinzelten zärtlich.".34)

Einmal mehr zeigt sich hier der parodistische Umgang der Fèksy mit der neuen ideologisierten Terminologie. Diese Vermenschlichung der Maschine. die in ihrer starken Ausprägung fetischistische Züge bekommt, macht die Liebe des Fahrers zu seinem Wagen aber auch erst glaubhaft. Die Tatsache. daß der Held aber die Liebe zu dieser Maschine mit der Liebe zur Straßenbahnschaffnerin vermischt, kommentien Nedobrovo lakonisch mit der Aussage: "Im Leben würden solche Dinge unausweichlich zu innerfamiliären Schwierigkeiten führen. ..31 In der Person der Straßenbahnschaffnerin zeigt sich wiederum der Bezug zur Technik und die Umsetzung der Straßenbahn der Futuristen. Gleichzeitig wird mit ihr der neue Typ der berufstätigen Frau in den Film eingebracht.

Toeplitz sieht in dem Kontrast zwischen lyrischen Szenen und prosaischem Hintergrund etwas Neues und Erfrischendes und zitien Jutkevic. der diesen Film als Vorboten des italienischen Neorealismus der vierziger Jahre be-zeichnete. ${ }^{442}$ Toeplitz ist ebenso wie Nedobrovo der Meinung. daß der Mißerfolg von "Bratyska" unverdient war. ${ }^{3+.3}$ Denn der Film wurde zudem vom Verleih mit Schwierigkeiten sanktioniert, da man schon vor der Premiere davon ausging. daß er keine Erfolgschancen habe, und so lief er nur wenige Tage im Kino.

\footnotetext{
IN GE. S. W.

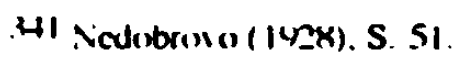

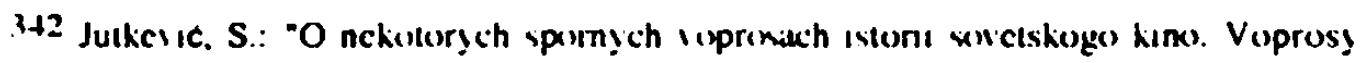

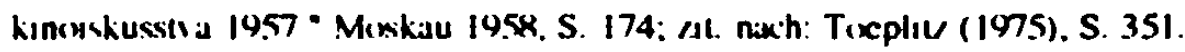

43 Treplity (1975). S. 354n.
} 


\title{
3.2.5. SWD (SVD)
}

Den wohl größten Erfolg bei Publikum und Kritik hatten die Fèksy 1927 mit dem Film "SVD" ("Sojus Velikogo Dela" = "Bund der Großen Tat"). Jurij Tynjanov hatte in Zusammenarbeit mit Jurij Oksman das Drehbuch zu diesem Film geschrieben. Interessant ist. daß Tynjanov zwei Drehbuchvariationen verfaßt hatte. wobei das erste keinen direkten Adressaten hatte. das zweite jedoch ausschließlich für die FEKS bestimmt war. ${ }^{34}$

"SVD" gilt als einer der besten historisch-revolutionären sowjetischen Filme der zwanziger Jahre und Sklovskij bezeichnete ihn 1928 als den "elegantesten Film der Sowjetunion. ".

Die Fèksy wollten hier einen neuen Typ des Historienfilms schaffen. in dem das Wichtigste nicht effektvolle Kostüme, exotische Altribute. oder eine Anhäufung historischer Persönlichkeiten waren. sondern der Mensch in der authentischen Atmosphäre seiner Epoche. ${ }^{3+1}$, Diese Aufgabe war an sich nichts Neues für Kozincev und Trauberg. da es ja schon bei der Verfilmung von "Sinel" ihr Anliegen gewesen war. den Geist der Nikolaitischen Epoche wiederzugeben. So galt ihr Hauptaugenmerk in "SVD" auch nicht den histurischen Tatsachen.

\begin{abstract}
"В 'Союзе великого дела' (С.В.Д.) нам предстояло показать один из эпизодов декабристского движения.. Героичность и одновременно обреченность мятежа. подготовленного людьми, далекими от народа; Пламя. на мгновение вспыхнувшее во мраке. Все это хотелось выразить романтическим строем. " "Im 'Bund der großen Tat' (S.V.D.) sollten wir eine der Episoden der Dekabristenbewegung zeigen. Die Heldenhaftigkeit und gleichzeitig Hoffnungslosigkeit einer Rebellion. die von Leuen vorbereitet worden war, die vom Volk weit entfernt waren: die Flamme, die für einen Augenblick in der Dunkelheit aufflammt. All das wollten wir in romantischer Form ausdrucken. ${ }^{n .347}$
\end{abstract}

\footnotetext{
ith Vgl. IbIJ., S. $1(44$.

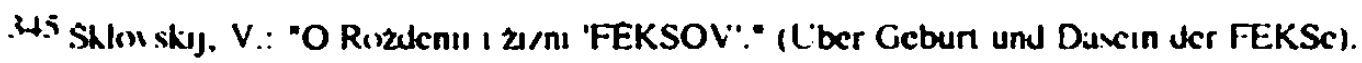

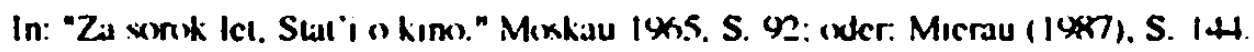

3th Vel. Vajsiclid (1941). S. 27.

$.4^{\top}$ GE. S. $\mathrm{KS}$.
} 
Als Episode wählten sie die Tragödie eines einzelnen Dekabristen und machten so auch in diesem Film ein Individuum und nicht das Kollektiv zum Helden. Diese Tatsache wurde ihnen spater bei der Beurteilung von "SVD" durch sozialistische Filmkritiker wieder einmal angekreidet. ${ }^{\text {.4k }}$, wobei diese Kritik einfach die Tatsache überging, daß es weder in der Absicht Tynjanovs noch der Fèksy lag. einen Revolutionsfilm im Stil von "Panzerkreuzer Potemkin", in den die Masse sinnvoll eingesetzt werden konnte, zu drehen. Die Konzentration auf ein Individuum in Zusammenhang mit dem Dekabristenaufstand durfte jedoch. zumindest teilweise, auch von Tynjanov ausgegangen sein. War doch schon 1925 Tynjanovs Romanbiographie "Kjuchlja" erschienen. über das Leben des romantischen Schriftstellers Wilhelm Kjuchel’beker. des Freundes Puśkins, der wegen Beteiligung am Dekabristenaufstand zu zehn Jahren Kerker und zwanzig Jahren Verbannung nach Sibirien verurteilt worden war. Nach der intensiven Beschäftigung mit einem Einzelnen. der an den historischen Ereignissen direkt teilgenommen hatte. lag es nahe. sich auch bei der filmischen Auseinandersetzung mit dem Thema auf einzelne Charaktere zu konzentrieren. Zudem wäre es historisch nicht zutreffend gewesen. den Dekabristenaufstand als Massenbewegung zu inszenieren. da an ihm nur ein kleiner Kreis adeliger Offiziere beteiligt war.

Doch zuruck zu "SVD". Der Inhalt des Films ist folgender: Leutnant Suchanov läßt eine unbekannte Frau eine eigentlich gesperrte Brücke passieren. Kurz darauf erhält er den Befehl. den Falschspieler und Hochstapler Medoks unter Arrest zu nehmen. Medoks erzählt ihm. er gehöre dem geheimen "Bund der großen Tat" ("Sojuz Velikogo Dela") an und zeigt ihm einen Ring mit den Initialen S.V.D.. den er in Wahrheit kurz zuvor im Spiel gewonnen hat. Suchanov glaubt Medoks und läßt ihn frei. Einige Zeit später belauscht Medoks eine Versammlung der Dekabristen und verrät danach den Namen des Anführers dieser Dekabristengruppe. General Viśnevskij, an die regierungstreuen Truppen. Viśnevskij wird verhaftet, wodurch der Aufstand ausgelöst wird, denn seine Anhänger, darunter Suchanov, beschließen. ihn zu befreien und rebellieren damit offen gegen die Regierung. Am Morgen nach der Befreiung treffen die Dekabristen auf offenem Feld auf die regierungstreuen Truppen und werden in einer kurzen. blutigen Schlacht von der (ibermacht vernichtend geschlagen. Die meisten Dekabristen werden getötet, einige gefangengenommen, und nur Suchanov

\footnotetext{
HX V'gl. Lcbovel (|x,5). S. 3*2.
} 
entkommt schwer verwundet. Er schleppt sich in die Spielhölle, in der Medoks sich aufhalt und bittet diesen um Hilfe. Medoks jedoch setzt Suchanov dem Gespött der anwesenden Spieler und Prostituierten aus und will ihn schließlich erschießen. Im letzten Moment taucht die Unbekannte von der Brïcke auf, die sich mittlerweile als Viśnevskijs Frau erwiesen hat, die von Medoks erpreßt wird. und rettet Suchanov das Leben. Suchanov flieht und wird von einem Wanderzirkus versteckt und gesundgepflegt. Medoks hat inzwischen einen Befehl an General Vejsmar gefunden. der besagt. daß Vejsmar sich zur Bestrafung der Rebellen unverzüglich an den Gouvernementvorsteher zu wenden habe. Als Adjutant verkleidet, uberbringt Medoks Vejsmar diese Nachricht wahrend einer Vorstellung in den Zirkus, in dem Suchanov sich versteckt. Suchanov belauscht das Gespräch zwischen Medoks und Vejsmar und erfährt dabei von einem unterirdischen Gang. der vom Gefangnis, in dem seine Freunde auf ihr Urteil warten, zu einer Kirche führt. Er beschließt, sie durch diesen Gang zu befreien und laßt sich selbst gefangennehmen. Im Gefängnis entschließt sich ein Teil der Dekabristen mit Suchanov zu fliehen. der andere Teil bleibt. um sich zusammen mit Viśnevskij dem Urteil zu stellen. Als das Exekutionskommando unter Leitung von Vejsmar kommt, wird die Flucht entdeckt, doch Vejsmar will nichts unternchmen. Medoks droht ihm. ihn an das Ministerium zu verraten. doch Vejsmar entlarvt ihn und läßt ihn gefangennehmen. Inzwischen sind Suchanov und seine Begleiter in die Kirche gelangt. wo sie jedoch eine Gruppe regierungstreuer Soldaten erwartet, bereit auf die Rebellen zu schießen. Der Befehlshaber dieser Gruppe erschießt einen der Dekabristen, worauthin er von einem anderen Dekabristen erschossen wird. Suchanov greift ein und überredet die Soldaten ihn und seine Freunde ziehen zu lassen. Beim Verlassen der Kirche wird Suchanov vom Befehlshaber der Soldaten, der nur verletzt ist, erschossen.

In Anlehnung an die Zeit. in der dieser Film spielt, hatte Tynjanov ein historisches Melodrama (so der Untertitel des Films) im Stil der romantischen Schule geschrieben. Nedobrovo erkennt im stilistischen Aufbau von "SVD" zahlreiche Ähnlichkeiten mit den Romanen Hugos. Dumas' und anderer französischer Autoren der Romantik. die von den zwanziger bis zu den vierziger Jahren des 19. Jahrhunderts in Rußland sehr populär waren: aber auch mit Lermontovs "Maskerade" oder Turgenevs "Drei Begegnungen". die 
unter dem Einfluß dieser französischen Literatur entstanden waren. ${ }^{349}$ Zudem stellt er fest. daß der Aufbau von "SVD" der Dramentheorie von Gustav Freytag entspricht ${ }^{3.50}$, die jedoch - wie Wilpert schreibt - nur auf das Zieldrama anzuwenden ist. das in seinem Aufbau auf die an das Ende verlegte Katastrophe hinzielt. ${ }^{351}$ Nach Freytag besteht ein Drama aus funf pyramidenförmig angeordneten Teilen. Der erste Teil ist die Exposition. wo der Zuschauer in das Geschehen eingefühn und die Verhälinisse und Zustände dargestellt werden, aus denen der Konflikt entsteht. Im zweiten Teil erfolgt die Steigerung der Handlung durch erregende Momente bis zum dritten Teil, dem Höhepunkt, an dem eine Wendung der Handlung eintritt. wonach diese im vierten Teil abfallt bis zum fünften Teil. der Katastrophe bzw. Lösung. Der vierte Teil kann bisweilen unterbrochen werden, durch das retardierende Moment der "letzten Spannung", das das vorausweisende Finale noch einmal ungewiß macht.

"Dies geschieht durch eine neue kleine Spannung, dadurch. daß ein leichtes Hindernis, eine entfernte Möglichkeit glücklicher Lösung. der bereits angedeuteten Richtung auf das Ende noch in den Weg geworfen wird. ${ }^{n 352}$

In "SVD" umfaßt die Retardation den Handlungsabschnitt der Befreiung der Dekabristen aus dem Gefangnis und bildet gleichzeitig den sechsten Teil des Dramas.

Die Exposition sind die ersten Sequenzen. die auf der Brücke und in der Schenke spielen. Hier werden die Hauptpersonen des Films. Suchanov. Višnevskaja und Medoks. vorgestellt, sowie die Verhältnisse, aus denen der Konflikt entsteht. Das sind die erste Begegnung zwischen Suchanov und Viśnevskijs Frau, die sich ineinander verlieben, sowie das Gespräch zwischen Suchanov und Medoks. Schon in der äußerlichen Darstellung der konflikıprovozierenden Situation liegt die Eleganz. die Sklovskij in "SVD" sah. Denn erst in dem Gespräch wird deutlich. daß Suchanov zu den Dekabristen gehört. weil Medoks ihn mit der Lüge. er gehöre ebenfalls zu einem Geheimbund dieser Bewegung. dazu bringt. die befohlene Verhaftung

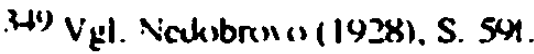

3.0 Ibid.. S. (x).

3.51 Vgl. Wilpert, Gero 1.: "Silchw(rrterbuch Jer Litcratur." Stuttgurt 1955. S. 112.

3.52 Freslag. Gustal: "Dic Technik des Dramis:" Stullgart 1983. S. 122. Al. nik:h: Gustul

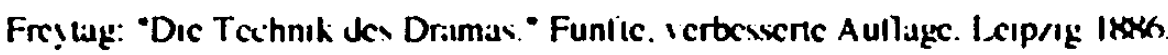


nicht vorzunehmen. Gleichzeitig entlarvt er sich für den Zuschauer als unwandelbarer Betrüger, da zuvor gezeigt wurde. wie er den Ring. dessen Initialen S.V.D. er für die Abkürzung dieses Geheimbundes ausgibt, von einem Fremden im Kartenspiel gewonnen hatte. In der schrittweisen, langsamen Ausarbeitung der Charaktere uandten die Feksy gekonnt das "Verfahren der erschwerten Form" an.

Der zweite Teil des Filmdramas, die Steigerung durch erregende Momente. umfaßt die Sequenzen des Treueeids der Soldaten, die sich nur unter Zwang zum Eid auf den Zaren bewegen lassen, der Versammlung der Dekabristen und der Verhaftung Visnevskijs auf der Eisbahn.

Den Höhepunkt und die Wendung der Handlung bilden die Sequenzen des Aufstandes und der Befreiung Višnevkijs. das Schlachtfeld in der Morgendämmerung und das Schlachtfeld in der Nacht nach dem Kampf.

Der vierte Teil der abfallenden Handlung besteht aus den Sequenzen im Casino. wo Medoks Suchanov erschießen will, und der Sequenz im Zirkus. Das retardierende Moment umfaßt die Sequenzen mit Suchanov im Gefangnis und in der Kirche, bis zu der Einstellung. in der auf Suchanov geschossen wird. In diesen Szenen wird das vermeintlich sichere Ende des Films noch einmal in Frage gestellt. Den sechsten Teil, die Katastrophe, umfassen die letzten Einstellungen vom Schuß auf Suchanov bis zu seinem Tod am Ufer des Teiches vor der Kirche.

Der gesamte Aufbau von "SVD" ist der eines Zieldramas, das im Handlungsablauf auf die Katastrophe am Ende hinzielt. Dieser Aufbau findet sich häufig im romantischen Schicksalsdrama. denn gerade in der Romantik war die Vorstellung von der Unabwendbarkeit des Schicksals aufgekommen.

Ein charakteristisches Verfahren des romantischen Dramas stellt auch die Verbindung einiger Handlungslinien durch einen Gegenstand. nämlich den Ring Medoks' dar. Dieser Ring verändert im Laufe des Films dreimal seine Bedeutung. Ursprünglich stehen die Buchstaben S V D (C В Д) für die Initialen der Braut des Fremden, der diesen Ring an Medoks verliert. Medoks selbst ändert dann die Bedeutung der Buchstaben je nach Situation. Zunächst untermauent er seine Lijge. zur Dekabristenbewegung zu gehören. mit der Behauptung. die Buchstaben ständen für den "Bund der Großen Tat" (Sojuz Velikogo Dela= Союз Великого Дела). Als Suchanov ihm geglaubt hat und gegangen ist, läßt Medoks die Karten entscheiden, auf welche Seite er sich tatsächlich stellen soll. Die Karten entscheiden für Zar Nikolaj. So änden Medoks die Bedeutung der Buchstaben für sich in: "Verfolgen!... 
Verraten!... Zerschlagen!" ("Sledit'!... Vydavat'!... Dobit'!" = "Следить!... Выдавать!... Добить!"). Nach der Zerschlagung des Aufstandes schließlich. als er sich wieder dem Spiel zuwendet, verändert er die Bedeutung des Rings noch einmal mit den Worten: "Их Союз Великого Дела разбит! Наш Союз Веселого Дела торжествует!." "Ihr Bund der Großen Tat ist zerschlagen! Unser Bund der Fröhlichen Sache feier!"

Die Bedeutungswandlungen des Ringes symbolisieren gleichzeitig die Lebenshaltung Medoks'. für den das ganze Leben ein Spiel ist, in dem er die gerade geitenden Regeln für seinen Gewinn auszunutzen sucht. ${ }^{35.3}$ In dieser Figur zeigt sich eine neue Variante des "Hazard". Hier handelt es sich nicht mehr um das fröhliche Experimentieren mit dem Zufall auf den Gebieten der niedrigen Kunst. Medoks ist ein Hazardeur im negativ besetzten Sinne des Wortes. der im Vertrauen auf sein Gluick und ohne Ruicksicht auf andere alles auf Spiel setzt. Er ist die Gestalt des Glucksspielers, die man in verschiedenen Variationen aus der Literatur kennt, wie z.B. die Gestalt des Silvio aus Puskins Erzählung "Der SchuB" ("Vystrel" ").

Wie schon im "Teufelsrad" bezogen die Fèksy auch in "SVD" wieder die Handlungsorte in das Spiel ein. indem sie ihnen eine bedeutungsschaffende Athmosphäre verliehen. Die zwielichtige Atmosphäre des Casinos wird vermittelt durch Tabakrauch und Rauchringe, wobei vor allem Medoks oft durch den Rauch oder die Ringe hindurch gefilmt wird. was den Eindruck der undurchsichtigen Gestalt verstärkt. Verstärkt wird die Atmosphäre des Casinos noch durch den gezieiten Einsatz von Schatten. Als Suchanov zur Versammlung der Dekabristen kommt und vom Wirt die Treppe hinuntergeführt wird. sind nur die Schatten der Spielenden an der Wand zu sehen. Während der Versammlung erscheint hinter dem Vorhang. der den Raum von den übrigen trennt. der Schatten von Medoks' Diener, der die Versammlung belauscht. Auch in den anderen Szenen, die im Casino spielen. (als Medoks nach der Schlacht kommt und kurz darauf der verletzte Suchanov) herrscht dort ein gleichwertiges Spiel von Menschen und menschlichen Schatten.

Die gespannte Atmosphäre auf der Eisbahn, wo sich Suchanov und die Višnevskaja begegnen. Medoks im unpassenden Moment auftaucht und Viśnevskij verhaftet wird. betont dagegen der Kontrast zwischen dem

${ }^{2.53}$ Vigl. Nakbrum (1928). S. 65. 
unbeschwerten Vergniigen auf der Eisbahn und dem Geschehen am Rande dieses Vergnügens.

Von besonders großer Bedeutung in diesem Film ist der Schneesturm. Er ist die Metapher für den Aufstand der Dekabristen. "SVD" beginnt mit den zwei Untertiteln: "Сто лет назад, когда в ожидании неизбежного мятежа... застыли большие лороги Россиской Империи..." "Vor hundert Jahren, als in Erwartung einer unausweichlichen Rebellion... die großen russischen Straßen im Frost erstarten...". Erst nach diesen beiden Untertiteln ist die erste Einstellung zu sehen. die einen wachenden Soldaten vor der Brücke zeigt. Der Soldat steht im Schneesturm. er schwankt leicht durch die Stärke des Windes, rührt sich aber nicht vom Fleck. Diese Einstellung wird bis zum Beginn des Aufstandes mehrmals wiederholt. In der Szene. in der die Visnevskaja an die Brücke kommt und Suchanov um Durchlaß bittet und etwas variert in den Szenen. in denen sich Offiziere und Soldaten zum Aufstand und zur Befreiung Visnevskijs sammeln. Die Wache steht jetzt nicht an der Brücke. sondern vor dem Haus, in dem der Kommandant. der Visnevskij zum Stab bringen soll. haltgemacht hat. Als Suchanov und seine Begleiter kommen. um Višnevskij zu befreien. drängen sie die Wache ins Schilderhaus zuriick. Diese Metapher bringt zum Ausdruck. daß3 die herrschende Ordnung vom Sturm der Rebellen zuruckgedrängt wird. Der Schneesturm herrscht die ganze Zeit bis zum Ende des Aufstandes. mit Ausnahme der Sequenz auf der Eisbahn. in deren Handlung erregendes und retardierendes Moment verbunden sind. Nedobrovo ordnet dem Schneesturm doppelte Bedeutung zu: auf der einen Seite überbringt er den Aufstand, auf der anderen vermittelt er das notwendige Tempo. ${ }^{3.5}$ Ich denke. hier sind nicht unbedingt zwei Seiten der Bedeutung zu sehen, sondern die Komplexität der Bedeutung. die sich in der Metapher des Sturmes für den Aufstand findet. Im Schneestrum liegen Tempo. mitreißende Kraft und (haos, die kennzeichnend für jede Rebellion sind. Diese Metapher ist jedoch nicht allein bei der FEKS zu finden. Umstürzende Ereignisse werden in Literatur und Film immer wieder in Begleitung von Stümen dargestellt (z.B. in Pudovkins "Sturm über Asien" 1928).

Für Kozincev war der Schneesturm auch wichtig für die Darstellung des Kontrastes zwischen zaristischer (Ordnung und dem Durcheinander des Aufstandes. Vor dem Aufstand filmten sie das Heer auf dem Übungsplatz in

3.5. Ibid.. S. 54. 
geometrischer Anordnung als Rechteck mit abgezirkelten Bewegungen der Figuren im Gleichschritt, die alle die gleiche Frisur, die gleichen Bärte und den gleichen Gesichtsausdruck hatten.

"По контрасту с геометрическими, как бы обездушенными кадрами - огонь и вихрь мятежа. Ритмическим мотивом всего монтажного эпизода стал ветер. На натурных съемках теперь часто появнлись аэросани: метель неслась по экрану. Москвин превращал снежный вихрњ в светяцуюся пелеку лучей. Трепетали огни факелов, росла толпа бунтовщиков ничего геометрическото уже не было в очертаниях, веселый мальчишка-барабанщик со счастливым лицом выбивал дробь; [...] "

"Im Kontrast mit den geometrischen. gleichsam unbelebten Bildern - stand das Feuer und der Wirbelwind des Schneesturms. Der Wind wurde zum thythmischen Motiv der gesamten Montageepisode. Bei den Außenaufnahmen erschienen jetzt oft Propellerschlitten: Schneesturm wurde uber die Leinwand getrieben. Moskvin verwandelte das Schneegestöber in einen leuchtenden Schleier aus Strahlen. Die Feuer der Fackeln zuckten, die Menge der Aufständischen wuchs in den Konturen war nichts Geometrisches mehr. - der fröhliche Trommler-Knabe schlug mit glücklichem Gesicht einen Trommelwirbel:|...|".3.5.5

Am Morgen nach dem Aufstand, bei dem Aufeinandertreffen der Dekabristengruppe mit der regierungstreuen Truppe. stehen letztere wieder in militärisch geometrischer Anordnung der ungeordneten Gruppe der Aufstandischen gegenüber. Der Aufstand ist voruber, der Schneesturm abgeflaut. es folgt die vemichtende Schlacht.

Die Atmosphäre nach der Schlacht wird durch Rauch und Nebel verstärkt. Wolkenfetzen ziehen iber den Nachthimmel und Rauch über das Schlachtfeld. Die Bewegung von Rauch und Wolken bildet hier den Kontrast zur Unbeweglichkeit des toten Raumes. ${ }^{3 . *}$. Gleichzeitig verstärken sie die Langsamkeit und Mühe. mit der sich einige Verletzte aufrichten, um sofort wieder zusammenzubrechen. Der kleine Trommler versucht. die Trommel zu schlagen. als wollte er die Toten und Verletzten aufrufen. sich zu erheben. doch auch er bricht über seiner Trommel zusammen. Diese Figur gewinnt im l aufe der Handlungsentwicklung immer mehr Bedeutung als Symbol für den Aufstand. In der Szene des Treueeids bildet sie noch das komische Element.

\footnotetext{
355 GE, S. XY

3.5. GE. S. $(x)$
} 
Während die Soldaten schweigend dastehen und sich weigem dem Zaren zuzujubeln. ist der Trommler der einzige, der laut "Hurra" ruft. Später jedoch ruft er mit seiner Trommel die Soldaten zum Aufstand zusammen. Hier erfolgen abwechselnd Einstellungen der oben erwähnten unbeweglich stehenden Wache und des begeister trommelnden Jungen im Schneesturm. sowie der zusammenlaufenden Soldaten. Als die Dekabristen am Morgen nach dem Aufstand erkennen mussen. da $B$ die Regierungstreuen sich ihnen nicht anschließen, sondern auf sie schießen werden, beginnt der Trommler noch einmal mit aller Kraft zu trommeln, wie um die plötzliche Verzagtheit der Dekabristen zu verreiben. Und schließlich steht seine Zusammenbruch nach der Schlacht für die endgültige Zerschlagung des Aufstandes.

In "Sinel" (s.u.) und "SVD" zeigt sich. welche Entwicklung die FEKS vom exzentrischen Theater bis zur Poetik des Films durchlaufen. Dabei haben die Künstler auch noch in "SVD" nicht ganz auf ihre alte Zuneigung zum Abenteuergenre verzichtet. ${ }^{357}$ Die Möglichkeit. diese mit dem romantisch historischen Drama zu kombinieren und eine andere Variante des "Hazard" auszuarbeiten, haben sie sinnvoll genutzt. Attribute des Abenteuerromans. wie den Ring mit den geheimnisvollen Initialen. die schöne Unbekannte. die gestuhlenen Briefe, oder den unterirdischen Gang konnten sie in "SVD" bedeutungsschaffend einsetzen. Dabei gelang es ihnen sogar, ihre große Liebe, den Zirkus, zumindest als Kulisse zu verwenden.

Die Fèksy haben mit "SVD" die gestellte Aufgabe gelöst. einen für ihre Zeit neuen Zugang zum historischen Material zu finden und damit eine neue Form des historischen Films zu schaffen. denn

"Путы возникновения стиля диалектичны. И экспрессионизм, хоторый, повидимому, избрали своим стилем ФЭКС'ы, только углубляет и освежает, но не возрождает былые традиции русского романтизма."

"Die Entstehungswege eines Stils sind dialektisch. Und der Expressionismus, den die FEKSy augenscheinlich zu ihrem Stil erwählt haben. vertieft nur und erneuert. aber wiederbelebt nicht die gewesenen Traditionen der russischen Romantik." ${ }^{3.3 *}$

Hierzu muß jedoch festgehalten werden. daß die Feksy sich keineswegs als Expressionisten verstanden und sich immer wieder gegen diese

\footnotetext{
$3.57 \mathrm{Vgl}$. Dubin (1963), S. 85.

3.58 Nedobrowo (1928). S. 70 ).
} 
Bezeichnung wehrten. In dem bereits erwähnten Interview mit Ulrich Gregor und Marcel Martin antwortete Kozincev auf die Frage, ob die FEKS nicht vom Expressionismus beeinflußt war.

"Nein. Der Expressionismus gefällt mir nicht. Unsere Generation wurde von Griffith beeinflußt, von Komödien. von Chaplin. Das war die Kunst, die wir liebten. aber nicht die absolut theatralischen expressionistischen Filme.".3.5)

Es war der Stil der Fèksy, die Ausarbeitung von Atmosphäre und Stimmung auf Kosten der Realität. die komprimierte Darstellung von Emotionen und Gefuhlen durch die ihnen eigene malerische Bildkomposition, durch Stilisierung und Verfremdung. kurz: ihre poetische Filmsprache, die immer wieder zum Vergleich mit dem Expressionismus führte.

Die fekssche "Poetik des Films", der Stil der Filmdichtung, ist jedoch ein eigener Stil und nicht mit dem Expressionismus gleichzusetzen, so wie auch ein poetischer Erzählstil in der Literatur nicht ohne weiteres mit dem literarischen Expressionismus gleichzusetzen ist.

\subsubsection{Das Neue Babylon (Novii Vavilon)}

Auf "SVD" folgte wiederum ein Film mit historisch-revolutionärem Thema. Die FEKS hatte von Goskino den Auftrag bekommen, einen Film über die Pariser Kommune zu drehen. Kozincev und Trauberg beschäftigten sich mit Marx ${ }^{36 x}$ und schrieben ein Drehbuch mit Episoden aus der zweiten Pariser Kommune, vom Frihjahr 1871. Der rote Faden, der die Episoden verbindet, ist die Liebesgeschichte einer Verkauferin aus dem Kaufhaus "Neues Babylon" und eines Versailler Soldaten, die auf verschiedenen Seiten der Barrikaden kämpfen. Die Handlung umfaßı den Zeitraum vom Beginn der Belagerung von Paris. bis zur Zerstörung der Kommune.

Der Film beginnt mit dem ausgelassenen. fast hysterisch fröhlichen Leben der Bourgeoisie in Paris während des Deutsch-Französischen Krieges. Die rauschhafte Atm ssphäre im Varieté wird vermittelt durch Tanzpaare, die sich unaufhörlich im Kreis drehen. und heftig applaudierende Zuschauer. Im

135) Gregur $(1(x(x))$. S. 144.

.3(x) GE. S. 1115. 
Kaufhaus "Neues Babylon" drehen sich Schirme und Fächer auf ihren Ständern. Kundinnen wühlen wie besessen in Stoffen, und die Verkäufer preisen ebenso fieberhaft ihre Waren an. Im Kontrast dazu werden Arbeiter und Arbeiterinnen mit deutlich langsameren Bewegungen gezeigt. Die Zuschauer und Tänzer im Varieté sind immer unscharf, wie durch einen Dunstschleier. aufgenommen. Diese Unschärfe wurde durch den Einsatz zweier Mittel erreicht. Wie Kozincev beschreibt, verwendete der Kameramann Andrej Moskvin für Einstellungen in der Totalen eine Optik, die an sich für Großaufnahmen vorbehalten ist, da sie die Bildränder aufweicht und keine Schärfentiefe bietet. ${ }^{361}$ Dadurch entsteht der gleiche Effekı wie bei Anwendung eines Weichzeichners. den die Filmtechnik zu dieser Zeit jedoch noch nicht kannte. Außerdem hatten die Fèksy sich von Pyrotechnikern verschiedenste Arten von Rauch anfertigen lassen, von leichtem Dunst bis zu dicken Schwaden. In den Varietészenen wendeten sie den Dunst an. So verschmelzen die Bewegungen der Feiernden und Tanzenden im Hintergrund durch die unscharfe Optik und den Dunst zu einer einzigen. Während der Weichzeichner oft eine romantische Stimmung betont. schafft die Unschärfe hier Distanz zum Geschehen.122, und verstärkt gleichzeitig das Unwirkliche und Unheildrohende der Situation. Auch werden die Bewegungen mit jeder Einstellung schneller, und als die Nachricht von der Niederlage der französischen Armee den Feiernden durch einen anwesenden Journalisten mitgeteilt wird. gipfeln sie schließlich in einer rasenden Folge von Einstellungen, die alle nicht länger als eine Sekunde sind. In den Bildern dieser schnellen Einstellungsfolge wird die Schrecksekunde wiedergegeben. in der die Menschen sich der Bedeutung der Nachricht bewußt werden, bevor sie in ihrem jeweiligen Handeln abrupt innehalten und dann fluchtartig auseinanderstrimen.

Es erfolgt ein zeitlicher Sprung in der Handlung. Die National garde der Arbeiter verteidigt die Stadt schon einige Monate und hat mit finanzieller Unterstützung der Arbeiter Kanonen gekauft.

In dem Haus. in dem die Verkäuferin mit ihrer Familie lebt. spielt sich die erste Begegnung zwischen ihr und dem Versailler Soldaten ab. Der Journalist

\footnotetext{
361 GE. S. 112 .

362 Vyl. Monalese, James: "Film versichen. Kunst. Technik. Spladihe, Gexhichic und Therne des Films." Ubers. naxch der 2 . icrbess. und eri cil. Aullage ion $19(9)$. Reinbek bei Hamburg 1987. S. 185.
} 
und einige andere Kommunarden haben sich don versammelt. Der Soldat betritt wie zufallig den Raum. Er bekommt Brot, und der Vater der Verkäuferin reparient ihm die Schuhe. Als der Journalist sagt. man dürfe nicht kapitulieren. da in dem Fall das Proletariat und nicht die Bourgeoisie fur diesen Krieg zahlen würde, kann der Soldat das nicht verstehen. In diesem Moment trifft die Nachricht von der Kapitulation ein. Bis auf die Verkäuferin und den Soldaten laufen alle hinaus, um die Kanonen der Arbeiter zu retten. Sie wirft ihm vor, daß er nicht mit den anderen geht. um zu kämpfen. Er antwortet. daß er nicht mehr kämpfen will und nur in sein Dorf zurückkehren möchte. In dieser Antwort wird die Tragik des Soldaten deutlich. der, die Zusammenhänge nicht begreifend. in den Strudel der Ereignisse hineingezogen wurde und nur kämpft. weil er Befehle auszuführen hat.

$\mathrm{Daß}$ er in seinem Unverständnis nicht allein ist, zeigt die nächste Sequenz. Die Versailler Soldaten sollen die Kanonen der Arbeiter wegschaffen. Während dieser Aktion kommen die Frauen der Arbeiter. geben den hungrigen Soldaten Milch und sind zunächst sehr freundlich zu ihnen. Dann schlägt die Stimmung plötzlich um, und die Frauen versuchen mit allen Mitteln das Fortschaffen der Kanonen zu verhindern. Schließlich kommen auch noch die Männer der Arbeitergarde hinzu. Nach kurzem Streit ziehen die Arbeiter zum Rathaus. während die Soldaten sich auf den Weg nach Versailles machen. weil ihr Befehlshaber ihnen versprochen hat. sie würden dort alle auf ihre Dörfer entlassen werden. Das Ende dieser Sequenz und die Tatsache, daß die Soldaten in Versailles nicht entlassen werden. sondern ausharren müssen. weil sich in Paris mittlerweile die Kommune gebildet hat. deren Zerstörung das Ziel der bürgerlichen Regierung ist. macht deutlich, daß der Soldat Jean nur als pars pro toto für das gesamte Heer der Versailler Soldaten steht. Es wird dargestellt als eine Menge unwissender Bauern. die von der Bourgeoisie gegen die Arbeiter aufgehetzt werden kann mit der Drohung. die Kommune würde ihnen ihr Land wegnehmen. Unwissenheit und Nichtierstehen werden aber nur Jean bewußt. als er im Kampf gegen die Kommunarden den Vater der Verkäuferin tötet. der ihm die Schuhe reparien hatte und schließlich das Grab für die Verkäuferin selbst graben und bei ihrer Erschießung anwesend sein muß.

Nach der romantischen Bearbeitung des historisch-revolutionären Themas in "SVD" (was Kozincev im nachhinein als Fehler bezeichnete). konzentrierten sich die Fëksy jetzt auf die politische und historische 
Ausarbeitung des Themas. ${ }^{32^{2}}$ Im "Neuen Babylon" hatten sie besonderen Wert auf die Darstellung der sozialen Generalisierung gelegt. wie sie es bei Marx beobachtet hatten.
"Схватка классов нередко олищетворялось у Маркса обобщениями, сгущенными до метафор."
"Der Klassenkampf wurde bei Marx nicht selten durch Ver- allgemeinerungen, verdichtet zu Metaphem, verkörpert.".3.

So waren alle dargestellten Charaktere typische Vertreter und damit Symbole ihrer jeweiligen Klasse. Aus der großen Zahl an Beispielen möchte ich hier nur einige herausgreifen. Die Schauspielerin und der Kaufhausbesitzer sind typische Verteter der Bourgeoisie, wobei das Herrschende und Gebieterische des letzteren durch einen Trommelwirbel betont wird. der bei jeder seiner Reden eingeblendet wird. Der Ton wird also sichtbar gemacht. Der Journalist. ein Wortführer der Kommune. steht für die Intelligenz. die die gesellschaftlichen Mißstände ändern möchte. Die Arbeiter werden immer in größerer Anzahl gezeigt. Wenn im Mittelteil des Films einzelne die Errungenschaften der Kommune verkünden. so ist klar. daß sie nur die Stimme aller Arbeiter sind.

Wie bereits beschrieben. werden auch die Soldaten immer nur als Menge dargestellt, wobei selbst die verschiedenen Gesichter einander oft ähneln. Nur der Soldat Jean und die Verkäuferin treten heraus aus dieser Verallgemeinerung der Charaktere. Dabei bildet Jean das Verbindungsglied zwischen den Soldaten und den Kommunarden. Durch seine tragische Beziehung zur Verkäuferin wird die Unmöglichkeit der Verständigung zwischen diesen beiden Gruppen verdeutlicht. Die Verkäuferin wiederum bildet die Verbindung zwischen den Arbeitem und der Bourgeoisie. da sie zu den einen gehört und für die anderen arbeitet. ${ }^{365}$ Durch ihre Arbeit ist sie täglich mit dem Kontrast zwischen Arm und Reich konfrontient und verkörpen somit auch das Erkennen der Mißstände durch die Arbeiter. Leyda zitient einen Artikel Elena Kuzminas. in dem sie über die Rolle der Verkäuferin schrieb:

This was a synthetic image of a communist girl at the time of the Paris Commune. and to create it we had to know all we could about the history and events of the Commune. to transport us there and communicate its sights and aroma. While

\footnotetext{
36.3 GE. S. 106.

36 Lx. cill.

.365 Vgl. Leyda (1983). S. 258.
} 
working on The New Bubylon it was Zola who gave us the most. All of us read all his works. ".3k6

Interessant ist, daB Kozincev die Arbeit mit der Literatur Zolas in Zusammenhang mit dem "Neuen Babylon" nicht erwähnt, während Lebedev.307. Vajsfel'd ${ }^{36 x}$, Dobin.36) und die Schauspieler der FEKS ${ }^{370}$ dieser Tatsache offenbar große Bedeutung beimessen. Tatsächlich scheint der stilistische Aufbau des gesamten Films eher auf Zola und damit auf den literarischen Stil des Naturalismus zu verweisen als auf Marx. So lassen sich im Vergleich auch überzeugende stilistische Gemeinsamkeiten zwischen dem Werk Zolas und dem Film "Das Neue Babylon" feststellen. Zola wandte die Milieutheorie auf die Ästhetik des Romans an und gab seinen Charakleren eine durch soziale und historische Umstände für die jeweilige Klasse allgemeingültige Prägung. Das gleiche taten die Fèksy in ihrem Film. Individuen werden hier fast ausschließlich im Zusammenspiel mit solchen der gleichen sozialen Gruppierung gezeigt. oder im Kontrast mil einer anderen, wodurch die Allgemeingültigkeit entsteht. Verstärkt wird sie außerdem durch die Namenlosigkeit der handelnden Personen. Im Film werden sie bei ihrem ersten Auftreten nur noch als "der Kaufhausbesitzer". "die Schauspielerin", "die Verkäuferin". "der Journalist" und "der Soldat" vorgestellt, während all diese Personen im Drehbuch noch mit Namen aufgeführt waren. Allein der Vorname des Soldaten, Jean, ist erhalten geblieben. taucht aber nur in den Untertiteln der Szenen auf, in denen die Verkäuferin den Soldaten direkt anspricht. Aber auch dieser Vorname ( der dem deutschen Namen Hans, oder dem russischen Ivan entsprich() kommt durch seine mangelnde Originalität der Namenlosigkeit gleich.

Fin anderes Mittel zur Erreichung der Generalisierung wandte Moskvin bei Großaufnahmen an. Er filmte die Personen in der Großaufnahme fast ausschließlich vor einem handelnden Hintergrund. Die Kamera zeigt nicht nur

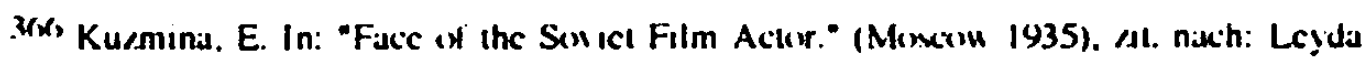
(14K3). S. 2.59.

36.7 Leboder ( $1 \times 2$ 2). S. 385 .

Ku lifvel d (1940). S. 31 .

3(1) Disin (1 $4 \times 3)$. S. 92.

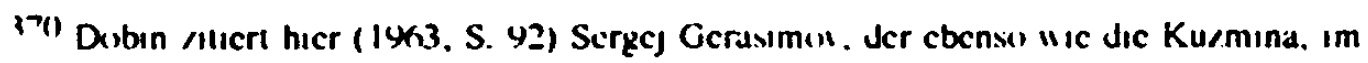

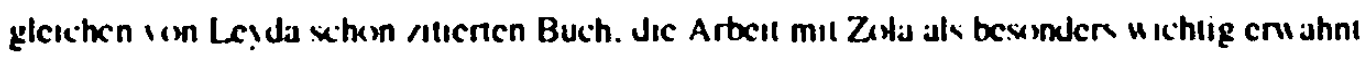
(1) Alnm 365)
} 
das Gesicht einer Person, sondern auch das Geschehen in der Umgebung dieser Person. Nur die Einstellungsfolge, die die Erinnerung des Soldaten an die Verkäuferin wiedergibt. zeigt diese ohne handelnden Hintergrund. Hier verliert die soziale Zugehörigkeit ihre Bedeutung. da in diesem Moment allein die individuelle Empfindung wichtig ist.

Bis zur Allegorie gesteigent ist die Generalisierung einer Gruppe im Bild des preußischen Dragoners. Hier wird - mal in größerer, mal in geringerer Entfernung zur Kamera - der Umriß eines Reiters, der eine preußische Pickelhaube trägt. vor dem Hintergrund der untergehenden Sonne gezeigt. Diese Figur ist die Allegorie der deutschen Armee, die Paris belagert.

Auch die bei Zola bisweilen auftretende Symbolisierung unbelebter Gegenstände, wie z.B. eines Bergwerkes oder einer L.okomotive ist im "Neuen Babylon" wiederzufinden. ${ }^{371}$ Der Film beginnt mit einer Einstellung. die eine mit Tricoloren geschmückte l okomotive zeigt. Die Menge jubelt den Soldaten zu, die mit diesem Zug an die Front fahren. Sehr viel später, als die Niederlage der französischen Armee bekannt wird. wird diese Lokomotive noch einmal in einer schrägen Einstellung gezeigt. Sie bewegt sich langsam zum rechten Bildrand hinunter und dient hier als Metapher für den Untergang der französischen Armee. "Das Neue Babylon" erscheint insgesamt wie ein Extrakt aus Zolas Romanzyklus "Die Rougon-Macquart". in dem die unterschiedlichsten sozialen Schichten geschildert werden. Die Darstellung des Pariser lebens und der verschiedenen Charaktere kommen einer direkten Umsetzung von Zolas Literatur in den Film gleich.

Der Kontrast zwischen den verschiedenen sozialen Gruppen wird stilistisch durch karikaturistische (Überzeichnung vor allem der bourgeoisen Charaktere und filmisch durch Parallelmontage hervorgehoben. Immer wieder werden der feiemden Bourgeoisie die leidenden Arbeiter gegenübergestellt. Am schärfsten ist dieser Kontrast in der Sequenz des Kampfes auf den Barrikaden hervorgehoben. Dieser Kampf zwischen Soldaten und Kommunarden wird unterbrochen von Finstellungen. die reiche Bürger beim Picknick auf den Versailler Hügeln zeigen. von wo sie den Kampf durch Ferngläser beobachten. Am Ende des Kampfes bleibt der Soldat Jean zuriick. der gerade den Vater der Verkäuferin getötet hat und blickt verständnislos zuriick. In den nächsten Einstellungen werden die applaudierenden Bürger gezeigt. wodurch

$371 V_{g l}$. Wilpert, Gero Iun (Hy.): Levikon Jer Welthteratur in 2 Banden. Dritte neubearb. Auflage. Stultgart 1\%. BJ. I. Auturen. S. 1671. 
der Eindruck entsteht. der Soldat würde zu ihnen hinübersehen. was in der Realität natürlich unmöglich ist.

Deutlich erkennbar ist auch der Einfluß des Impressionismus auf die bildnerische Gestaltung des "Neuen Babylon". Da, wie bereits erwahnt, alle Filme der FEKS durch eine malerische Bildkomposition gekennzeichnet waren, lag es bei diesem Film nahe, die Kunstrichtung der Malerei zum Vorbild zu nehmen. die um 1870 in Frankreich entstanden war. Wie weit die Beschätigung mit Zola, dem Freund und Befürworter der Impressionisten. dabei von Bedeutung war, läßt sich schwer sagen.

Kozincev beschreibt eine Szene, die durch den Ausdruck der Atmosphäre des Augenblicks lebt. Es handelt sich um die Sequenz. in der sich die reichen Bürger im Varieté vergnügen:

"Написанные густочерным и сверкающе-белым, как зловещие птищы, стояли люди во фраках, а позади несся кавардак пятен: месиво юбок, цилиндров, шляп. Прнзрачный, фантастический, лихорадочный мир был передо мной, он жил, стал реальностью.."

"Tiefschwarz und leuchtend weiß gezeichnet. wie Unglücksvögel, standen die Menschen im Frack und hinten ein Gewirr von Flecken: ein Gemisch aus Röcken, Zylindern. Hüten. Eine gespenstische. phantastische. Fieberhafte Welt lag vor mir, sie wurde Realität.".372

Auch dieser Eindruck wurde durch die Unschärfe der Bilder erreicht, was wiederum ein Merkmal der impressionistischen Malerei ist.

Vor allem die Einstellungen, die das Bürgenum zeigen, kommen einer Übertragung von Manets Stil in den Film gleich. ${ }^{377}$ Die Szenen der Feiernden im Varieté. oder der Bürger, die beim Picknick auf den Versailler Hügeln den Kampf zwischen Soldaten und Kommunarden beobachten. machen das besonders deutlich.

Weniger offensichtlich, da nicht direkt zitien, aber nicht zu leugnen, sind auch die Einfluisse von Degas und Renoir auf das "Neue Babylon".

"У Дега, в его изображениях балерин, продавщиц, прачек, жокеев Фексы нашли выразительность человеческото тела, характерный жест, нашли зффекты искусственното освецения и новые приниипы

\footnotetext{
372 GE. S. 112.

$37.3 \mathrm{Vgl}$. VajNICl'd (|y4h)). S. 31.
} 
композиция |...|. Ренуар производил впечатление свонми портретами, В которых с аналитической проницательностью и эмоциональной чуткостью схвачены мимолетные состояния людей."

"Bei Degas, in seinen Darstellungen von Ballerinen. Verkäuferinnen. Wascherinnen. Jockeys. fanden die Fèksy die Ausdrucksfahigkeit des menschlichen Körpers, die charakteristische Geste. fanden sie Effekte künstlerischen Lichts und neue Kompositionsprinzipien (...). Renoir beeindruckte mit seinen Porträts, in denen mit analytischer Bcobachtungsgabe und emotionalem Feingefühl die vergängliche Beschaffenheit der Menschen erfaßt ist. ${ }^{n .37 t}$

So stand die Anwendung der impressionistischen Malerei auf die Bildgestaltung des Films keineswegs im Widerspruch mit dem Bemühen um Realität in der Darstellung der Ereignisse, sondem wurde zum Verfahren.

"Das Neue Babylon" ist somit ein Schritt in der Entwicklung der Fèksy zum Realismus. In der Anwendung von Zolas Literatur und der impressionistischen Malerei auf den Film war es ihnen gelungen. sowohl die historische Atmosphäre von Paris in den Jahren 1870/71, als auch die Realität der politischen Ereignisse in Einklang zu bringen.

Die Generalisierung der Charaktere und gleichzeitige Emotionalisierung des Dargestellten mittels kontrastiver Montage und impressionistischer Bilder in "Das Neue Babylon" brachte sie zu der Zeit mehr in die Nähe von Fjzenstejns Theorie des "intellektuellen Films", den dieser als eine Synthese des emotionalen, dokumentarischen und absoluten Films definierte. ${ }^{375}$ Gleichzeitig war es wiederum die Übertragung eines literarischen Stils in die Sprache des Films und darin liegt der Unterschied zwischen dem Realismus des "Neuen Babylon" und dem der Maxim Trilogie, die ja schon unter der allgemeingültigen Doktrin des "Sozialistischen Realismus" entstand.So war auch der FEKS-typische Humor noch im ersten Film "Maxims Jugend" (1935) zu finden, doch zu den beiden Fortsetzungen schreibt Leyda:

"In The Return of Maxim the special film humour with its old louch of FEX grotesquerie of the wonderful first part was already dimming in the film's (and Maxim's) increased responsibilities. And there are few scenes in The Vyhorg Side that stay in the memory as long as the whole substance. three years earlier. of Muxim's Youth.".376

\footnotetext{
.374 Vijsiclid ( 1440$)$. S. 31.

375 V Vl. T(xplik. (1975), S. 352.

376 Lẹda (1963). S. 323.
} 
Auffallend ist die Tatsache, daß "Das Neue Babylon" im Ausland offensichtlich der bekannteste Film der FEKS ist. In den siebziger Jahren, aber auch in jüngster Zeit. wurde er immer wieder bei Stummfilmretrospektiven gezeigt. ${ }^{377}$ Ein Grund für diese besondere Beachtung mag die großartige Begleitmusik Sostakovics sein. Für "Das Neue Babylon" hatte der junge Komponist seine erste Filmmusik geschrieben. In diesem Werk war es ihm gelungen. statt der üblichen Untermalung. eine inhaltliche Ergänzung zum Filmgeschehen zu schaffen. ${ }^{378}$ Film und Musik riefen einen wochenlangen Streit in der sowjetischen Filmszene hervor. ${ }^{37}$ Einer der Hauptgründe dafür war wohl. daß Kritik und Publikum diese neue Art von Musik nicht verstanden. So wurde Sostakovics Musik drei Tage nach der Premiere bereits wieder abgesetzt und stattdessen kehrte man zudem üblichen Potpourri zurück. $^{3(*)}$ Trolz dieses Mißerfolgs war "Das Neue Babylon" der Ausgangspunkt für eine langjährige Zusammenarbeit zwischen Kozincev. Trauberg und Sostakovic. So schrieb der Komponist auch die Musik zu "Allein" ("Odna"). zur Maxim-Trilogie und zu fast allen Filmen. die Kozincev später allein drehte.

"Das Neue Babylon" wird allgemein als letzter Film der FEKS angesehen. da dieser der letzte Stummfilm war. den Kozincev. Trauberg und ihr Team drehten. und die FEKS in den intemationalen Filmgeschichten immer der Stummfilmzeit zugeordnet wird. Kozincev selbst sieht das Ende der FEKS friher und nicht als abruptes Fnde. sondem als allmähliche Auflösung.

1927 gründete das "Leningrader Institut für szenische Künste" (Leningradskij Institut sceniceskich iskusstv - ISI) eine Filmabteilung und bot Kozincev und Trauberg die Leitung dieser Abteilung an. So ging die Schauspielerwerkstalt der FEKS in diese Abteilung über und die Bezeichnung

377 Vgl. Burtses. Mikhaul: 'Premičre alter stvly jears.' In: "Cincpelis. Internalicinal Maga/ınc." Mkneriu. Nes. 1/91. S. 12ff.

378 Da ich nur cinmal dic Gelegenheit hattc. "Das Ncue Babjlun" in Verbindung mit Sxxtakowic Begleitmusik anzuschen und rudem nur uber laienhafic Kenntnisic auf Jem Gebiet Jer Musik I ertuge. "urde ich eine nithere Analỵse dieser Musik nicht w agen. und kinn nur Jen liefen Eindruck betenen. den das Zusimmenspicl ion Film und Musik auf mich gemiacht hat.

370) GE. S. I(1)II.

$3 \times 1)$ GE. $S .103$. 
"FEKS" verschwand. ${ }^{381}$ Kozincev. Trauberg, Moskvin und die meisten Schauspieler blieben jedoch zusammen. Die Zeit des Suchens und Experimentierens mit den Möglichkeiten des Films war Ende der zwanziger Jahre abgeschlossen, die Mitglieder der FEKS wollten sich auf einen endgültigen Filmstil festlegen. Nach einer Phase der Neuorientierung konzentrierten sie sich wie viele andere auf den Realismus und drehten erst 1931 ihren nächsten Film mit dem Titel "Odna" ("Allein").

Betrachtet man die Filmarbeit der FEKS in der Zusammenfassung, so entsteht zunächst der Eindruck, es sei eine Entwicklung vom futuristischen Exzentrismus uber die Romantik. den Naturalismus und Impressionismus hin zum Realismus gewesen. Nach der allmählichen Abkehr vom Exzentrismus ihrer Theaterarbeit haben die Feksy sich jedoch während ihrer Stummfilmarbeit nie mit einem bestimmten Kunststil identifiziert. Ihr Ziel wurde die Entwicklung einer küstlerischen Filmsprache. In Zusammenhang mit der Arbeit an "Sinel"" schreibt Kozincev: "Мы мечтали о зрительной поззии." "Wir träumten von einer visuellen Poesie.".383 So nahmen sie sich die literarische Workunst zum Vorbild, nach dem sie ihre visuelle Filmkunst gestalteten. Jeder ihrer abendfüllenden Filme war bestimmt von der Übersetzung eines literarischen Stils in die Filmsprache. Dieser Stil war entweder durch die Literaturvorlage vorgegeben, wie der Stil der Groteske in "Sinel'", oder der des romantischen Melodrams durch Tynjanovs Drehbuch zu "SVD".38t. oder er wurde bestimmt durch die Thematik. wie im "Teufelsrad" durch die Literatur der Odessaer Schule. oder auch gleichzeitig durch die Thematik und die historische Epoche. in der die Filmhandlung angelegt ist. wie in "Novij Vavilon". Zu jedem dieser Filme fanden Kozincev und Trauberg den entsprechenden Literaturstil, aus dem sie einen literarischen Filmstil erarbeiteten. Und in dieser Entwicklung einer "Poetik des Films", die den verschiedenen Stilen der Workunst die jeweiligen Stile der Filmkunst gegenüberstellt, liegı die Bedeutung der FEKS für die Filmgeschichte.

\footnotetext{
$3 \$ 1$ GE. S. 160).

32 Ene geniucere Anial se der Entwicklung der FEKS ertiolgl im S'hlubliapitel 5.

313 GE. S. 44. Der Begrili Поезия = Poxsic Jurfic hicrbel im eigenilichen Sinn als "Vortiunst" au verstehen scin und nicht als Pexsie im Gegensaly. au Prosia.

3at Vgl. diaru Kipilel 4.1.
} 


\section{Kapitel 4. "Sinel" "als Beispiel der Literaturverfilmung durch die FEKS}

\subsection{Voruberlegungen zur L jteralurverfilmung und zum Drehbuch als literarisches Genre}

Da die Beschäftignung mit Literaturverfilmungen eine spezifische Problematik in sich birgt. möchte ich an dieser Stelle zunächst einige grundlegende Fragen klären.

Weil die Untersuchung von Literaturverfilmungen keinem Wissenschaftszweig (wie etwa Filmwissenschaft oder Literaturwissenschaft) ausschließlich zuzusprechen ist, gerät jeder, der sich mit diesem Thema beschäftigt. zwangsläufig unter einen gewissen Legitimationsdruck und muß sich mitunter "den Vorwurf der 'Grenzüberschreitung' gefallen lassen.".385 Denn gerade auf diesem Gebiet gibt es zu viele Möglichkeiten für Ansatz und Betrachtungsweise, als daß man sich auf ein festgelegtes Schema beschränken könnte. So wird für den Filmwissenschaftler immer der Film als solcher im Vordergrund stehen und für den Literaturwissenschaftler die literarische Vorlage. In der Literaturwissenschaft kommt erschwerend hinzu. daß sich die traditionelle Auffassung von Literaturverfilmungen als Degradierung der literarischen Vorlage lange Zeit hielt $38 \%$ und man ebenso lange nur das Kriterium der Werktreue gelten ließ. Von diesem Standpunkt aus und in Anlehnung an Vertovs Filmtheorie der objektiven Kamera beurteilte Siegfried Kracauer in seiner 1960 erschienenen "Theorie des Films" Literatur als filmisch oder unfilmisch. Kracauer sprichı dem Film die Fähigkeit ab. das seelisch-geistige Kontinuum vieler Romane darstellen zu können. Verfilmbar und damit filmisch sei ein Roman nur. wenn seine inhalte im Bereich psychisch-physischer Korrespondenzen liegen. ${ }^{387}$ Er beschränkt damit die Ausdrucksmöglichkeiten des Films auf das objektiv Bildliche und negien die

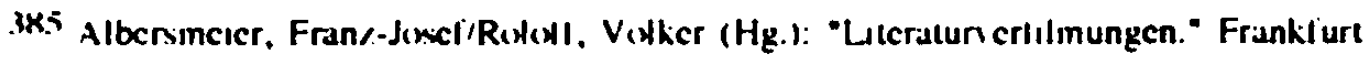
19xy. S. 15.

$3 \times \cdot v g l . ~ l i x:$ cit.

387 Kraciuer, Sicglined: "Therre des Films. Dic Errettung der außeren Wirklichkeit." Verm

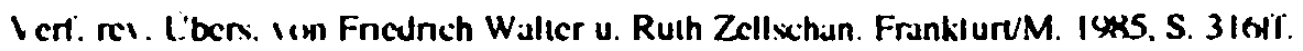


Bedeutung filmischer Mittel wie Montage. Beleuchtung. Ton etc. Wenn man so unmittelbar vergleicht und in der Verfilmung nur die Worte der Textvorlage wiederzuerkennen sucht. so wird man der Veränderung der Zeichensysteme bei der Übertragung von Literatur zu Film nicht gerecht und übersieht zudem den Prozeß, der zu dieser Veränderung geführt hat. $3 *$

Wenn man den Film dagegen als eigene Kunstform betrachtet, wie es Béla Balázs schon Mitte der zwanziger Jahre tat. ${ }^{380}$ dann bekommt er eine ganz andere Bedeutung. Er steht der Literatur gleichwertig gegenüber. In seinem Buch "Der Film" widerlegt Balázs außerdem schlüssig die Annahme, daß allein die Beschaffenheit eines Geschehens - sei es physischer oder psychischer Natur - dessen Zugehörigkeit zu einer bestimmten Kunstform festlegt.
"Es bedarf eines naiven Mystizismus, zu glauben, daß in den Tatsachen der Wirklichkeit ihre Zugehörigkeit zu bestimmten Kunstformen als Bestimmung vorhanden sei, derart, daß diese Tatsache nur für die dramatische, jene nur für die filmische Bearbeitung geeignet sei.
Die Wirklichkeit ist eine, von unserem Bewußtsein unab- hängige, objektive Realitäl. also auch unabhängig von der künstlerischen Betrachtungsweise des Menschen. |...| Kunst und Kunstformen sind die Betrachrung.sweise des die Wirk- lichkeit betrachtenden Menschen und in der betrachteten Wirk- lichkeit nicht a priori enthalten. ${ }^{n 3(x)}$

Es ist der Blickwinkel des Künstlers, aus dem er das Geschehen betrachtet. der ihm dieses für eine bestimmte Kunstform geeignet erscheinen läßt. Dieser Blickwinkel wiederum verwandelt den Stoff des Geschehens zum Inhalt. der die Form des Werkes bestimmt. Will er als Schriftsteller über eine besondere Begebenheit pointiert berichten. so wird diese zum Inhalt seines Werkes, den er dann wahrscheinlich in Form einer Novelle darstellt. Ist ihm die zentrale Verwicklung besonders wichtig. so wird er für diesen Inhalt vermutlich die Form des Dramas wählen. ${ }^{391}$ Unverändert bleibt jedoch die Betrachtung des Geschehens aus dem Blickwinkel der Literatur. Wenn ein Filmdrehbuchautor nun eine literarische Vorlage aus dem Blickwinkel des

\footnotetext{
38x Vgl. Schneider. Immela: "Der icrwandelte Tevt. Wege /u einer Theririe der Lileralurn crlilmung." Tubingen I9kI, S. 123.

3x9 Balids. Beli: "Schniten fum Film. Band I: Der sichtbare Mensch. Kritiken und Aufsiluc 1922-1926." Budapesi 1682. S. SRfr.

$30 x)$ Baliass, Bela: "Der Film. Werden und Wesen einer neuen Kunst." Eru. und uberarb.

Neuaullage. Wicn $|6|$ I. S. $27 \mid f$.

39) I Ibid., S. 274.
} 
Filmkünstlers betrachtet und sich dabei auf das reine Handlungsgeschehen konzentriert. das er als Darstellung der Wirklichkeit begreift, dann ist die Vorlage für ihn nur der Lieferant für die Fabel. In der Betrachtung des reinen Handlungsgeschehens unter dem Blickwinkel des Films bestimmt er dann selbst die Inhalte. die die Form seines Drehbuches festlegen. Diese Betrachtung einer Kunstform aus dem Blickwinkel einer anderen kommt jedoch immer auch einer Interpretation gleich. Denn der Künstler wählt aus der Vorlage die Inhalte, die ihm persönlich am auffälligsten und damit am wichtigsten erscheinen. Berucksichtigt er jedoch bei seiner Betrachtung auch Form und Stil der literarischen Vorlage. so werden diese auch zu Inhalten, die die Form seines Drehbuches bestimmen. Der daraus entstehende Film entspricht dann einer Übertragung von einer Kunstform in die andere. Wenn Drehbuchautor und Regisseur nicht identisch sind, dann kann es zu Schwierigkeiten kommen. falls dem Regisseur bei Erstellung seines Regisseursdrehbuchs andere Inhalte wichtig sind als dem Drehbuchautor. oder der Regisseur die vom Drehbuchautor dargestellten Inhalte anders begreift. Hier ist eine gut funktionierende Zusammenarbeit nötig. wenn der fertige Film nicht ein uneinheitliches Stückwerk aus literarischer Vorlage. literarischem Drehbuch und Regisseursdrehbuch bilden soll.

Cberhaupt stellt sich die Frage der Bedeutung des Drehbuchs als eigentliche literarische Vorlage bei Literaturverfilmungen. Im frühen sowjetischen Film maß man dem Drehbuch sehr bald große Bedeutung zu. Schon in den 20er Jahren "bildete sich eine spezielle Gattung des Drehbuchs heraus: das "literarische Drehbuch".312 In diesem literarischen Drehbuch waren alle filmspezifischen Angaben eingebunden in einen literarischen. in Prosaform geschriebenen Text. Die Entwicklung dieser Drehbuchform und deren Anerkennung als literarisches Werk ist nicht zuletzt Verdienst der Formalisten. die sich ja intensiv mit der Poetik des Films beschäftigten und selbst zahlreiche Drehbücher schrieben. In diesem Zusammenhang kann auch die Zusammenarbeit «wischen Kozincev. Tauberg und Tynjanov als beispielhaft gelten.

Daß ein Drehbuch in den westlichen Ländern allgemein nicht als literarisches Werk anerkannt wird. mag an der anderen Form liegen. in der es dort verfaßt wird. Es ist in sachlicher Form geschrieben, behandelt nur die

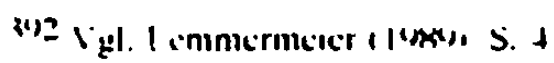


äußeren Handlungsabläufe und ist meist in zwei Parallelspalten (Handlungsgeschehen und Dialoge) unterteilt.

Wenn man jedoch von einem literarischen Drehbuch als eigenständigem Genre der Literatur ausgeht, dann müßte man streng genommen das Drehbuch mit dem fertigen Film vergleichen. In diesem Fall wäre auch "SVD" als Literaturverfilmung zu betrachten, da auch dieser Film nach einem literarischen Drehbuch Tynjanovs entstanden ist. Leider ist es mir nicht gelungen die Drehbuicher zu "Sinel"" oder "SVD" zu beschaffen. ${ }^{393}$ Ich gehe jedoch bei der Untersuchung von "Sinel" davon aus. daß es sich hier um eine zweifache Umsetzung, von der einen Literaturform in die andere und dann von der einen Kunstform in die andere handelt. So ist dieser Film gewissermaßen auch als doppelte Interpretation anzusehen. Die sowjetische filmwissenschaftliche Literatur geht ganz selbstverständlich von Tynjanovs Drehbuch als einem literarischen Werk aus und zieht es bei Beurteilung des Films genauso in Betracht wie die Arbeit der beiden Regisseure. Aus diesem Grund verstehe ich auch Tynjanov ebenso als Autor des Films wie Kozincev und Trauberg. Denn es waren in erster Linie die Inhalte. die Tynjanov in Gogol's Erzählung fand. und in seinem Drehbuch literarisch ausarbeitete. für die die Fèksy dann die Mittel zur filmischen Umsetzung fanden. Auch der fertige Film ist das Produkt der gleichwertigen Zusammenarbeit. da Tynjanov während der Dreharbeiten immer anwesend war und vor allem sämtliche Änderungen. die die Fèksy am Drehbuch vornahmen, akzeptierte. Wie Trauberg sich erinnert. soll Tynjanov nach Fertigstellung des Film gesagt haben: "Es ist nicht das. was ich geschrieben habe. aber das. wofür ich bereit bin, mich zu schlagen." ${ }^{.344}$

39.3 Nach meiner Informalion sind dic Drehbucher verloren gezangen. Aul grund Jieses Malenalmangels ist mir eine genaucre Untersuchung der Problemauk Ieider nicht moglich. Aus diesem Grund moxhte ich nur auf die oben sitierte Dissertation ion Duris Lemmermeier veni eisen. in der se cine umfiassende Anal! se gur Bedculung des literanxchen Drehbuches liefer.

344 Zl. nach: Trauberg. L.: 'Sam Junj Nikolaciıc.' In: "Kınovedoestic Zapiski." Hell 10. Monkiau 1991. S. 7. 


\subsection{Gogel 'in der Verfilmune durch Kozincev und Traubere}

N.V.Gogol's Erzählung "Der Mantel".395 (ersch. in St. Petersburg 1842) gehör zum Zyklus der "Petersburger Erzählungen" ("Peterburgskije rasskazy"), die in phantastisch groteskem Erzählstil das Großstadtmilieu behandeln.

Für ihre Verfilmung des "Mantel" begaben die Fèksy sich auf die Suche nach einer neuen Form der Literaturverfilmung. Nikita Lary bezeichnet es als "a way of challenging accepted conventions of cinematography". $3 \%$, Sie wollten brechen mit der kanonisierten Illustrierung literarischer Werke, die sich in der reinen Übertragung eines Sujets in bewegte Bilder erschöpfte, was oft zur Folge hatte. da $B$ in diesen Filmen Originalität und Eigenart der einzelnen Schriftsteller verlorengingen, und einer nicht mehr vom anderen zu unterscheiden war. $30 n$

In Zusammenarbeit mit Tynjanov fanden die Fèksy die Form für ihre Bearbeitung sowohl durch die Formalisten. als auch durch Gogol` selbst.

Bis in die Gegenwart ist einer der Hauptgrunde für negative Kritik an der FEKS-Adaption des "Mantel" deren Nähe zum Formalismus. Tynjanov hatte in seinem Drehbuch die Erkenntnisse Boris Ejchenbaums umgesetzl, die dieser bereits 1918 in seinem Artikel "Wie Gogol's Mantel gemacht ist".s"** gewonnen hatte. Aher gerade in der Betonung der formalen Elemente Gogol's liegt der Reiz dieser L.iteraturverfilmung. Dadurch tritt sie heraus aus der Masse der üblichen Literaturillustrationen, wird zum selbständigen Kunst-

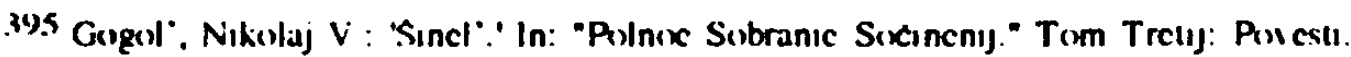

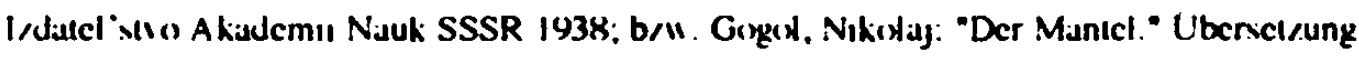
nach: Gogell'. N.V.: 'Polnex Subranic Sixincnij.' Tom Trelıj: Porcell. I/dalcl'slio Akiulemii Nauk SSSR. Stultgart 1973. Im Filgenden w'ird nach $\mathrm{dem}$ Zilat in Klammem Iunilchst dic Sciten/ahl der russischsprachıgen. Jann der deutschsprachıgen Ausgeabe ingegebeben.

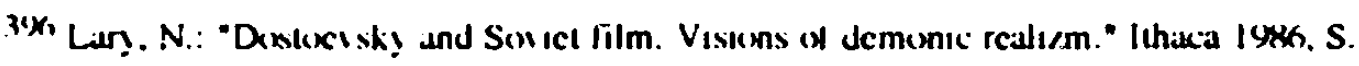
20.

397 vgl. GE. S. (x).

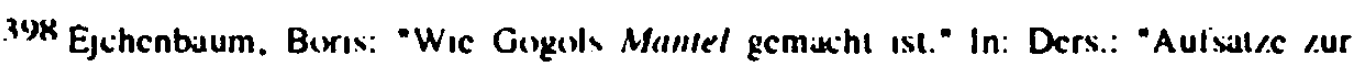
Therric und Geschichte der Litcralur." Ausgew. und aus Jem Russisethen ubers. Ion Alc iander Kucmple. FrankiturV M. 1965. S. 119.142. 
werk und kommt gleichzeitig dem Schriftsteller näher als andere Adaptionen. die nur das Sujet möglichst wortgetreu übernehmen.

Deshalb möchte ich an dieser Stelle ein längeres Zitat aus Ejchenbaums Aufsatz einfugen, das den Ausgangspunkt für einige wichtige formale Elemente des Films bildet:

"Der Stil der Groteske verlangt erstens, daß die beschriebene Situation bzw. das beschriebene Ereignis in die bis zum Phantastischen winzige Welt künstlicher Erlebnisse $|\ldots|$ eingeschlossen. daß es |das Ereignis| von der großen Realität. von der wirklichen Fülle und Vielfalt des seelischen Lebens abgehoben werde; und daß das, zweitens, nicht in didaktischer oder satirischer Absicht geschehe. sondem mit dem Ziel, Raum für das Spiel mit der Realität. für die Zersetzung und freie Verlagerung ihrer Elemente zu schaffen. so daß die gewohnten Bezuge und Bande (psychologische und logische) in dieser neuerrichteten Welt unwirksam werden. während jede Einzelheit gewaltige Ausmaße annehmen kann. Nur vor dem Hintergrund eines solchen Stils bekommt noch das geringste Anzeichen eines echten Gefuihls etwas Erschüttemdes. "3\%9

Die bis zum Phantastischen winzige Welt Akakij Akakievićs ist die Welt des Abschreibens, das reine Malen von Buchstaben. Nicht das Abfassen von Texten oder zumindest ganzen Sätzen erfüllt ihn. sondern nur die einzelnen Buchstaben, die Kalligraphie. Selbst in seiner Freizeit schreibt er und unterbricht diese Tätigkeit nur durch Essen. Schlafen. oder unvermeidliche Wege, wie den zum Schneider. Gogol' hat hier eine Welt geschaffen, die kleiner nicht zu denken ist.

In der Verfilmung wird diese Welt nicht in Buchstaben dargestellt, sondern in der winzigen Kammer, die der kleine Beamte bewohnt. Sie wird beherrscht von einem großen Schreibtisch, auf dem Gänsekiele und Papier liegen. Im ersten Teil des Films wird Akakij Akakievic in allen Szenen, die in seiner Behausung spielen, immer entweder am Schreibtisch sitzend oder in dessen unmittelbarer Nähe gezeigt. Der Schreibtisch wird hier zum Symbol seiner aufs engste begrenzten Welt.

Die beschriebene Situation ist hier Akakij Akakievics Verliebtheit, die im Film durch einen Fehler, den er beim Abschreiben macht. in die winzige Welt eingeschlossen wird. Wo er zunächst schrieb: "пониже означенний" ("unten angeführter"), schreibt er jetzt: "небесное создание" ("himmlisches

3(x) Ibid., S. 1.37i. 
Geschopf"). Das Mädchen vom Nevskij Prospekt ist also in seine sonst nur von Buchstaben beherrschte Gedankenwelt eingedrungen.

Abgehoben von der Realität werden sowohl das Mädchen, als auch der Mantel durch die Träume Akakij Akakievics. Dabei hat Gogol' diese Träume in seinen Novellen vorgegeben. Der erste Traum des Malers Piskarev aus "Nevskij Prospekı" wurde im Film auf Akakij Akakievic übertragen. Allerdings erkennt er am Ende nicht nur. daß die Schöne Unbekannte eine Prostituierte ist, sondern daß sie nicht in seine Welt gehört.

Ein anderes Mal träumt er vom Mantel als schöner Frau. In der Erzählung heißt es da:
"Seit dieser Zeit schien seine ganze Existenz irgendwie erfuillter zu sein. als ob er geheiratet habe. als ob ein anderer Mensch bei ihm sei. als ob er nicht allein sei, sondem als ob eine angenehme Lebensgefahrtin sich bereit erklärt habe. gemeinsam mit ihm den Lebensweg zu gehen. und diese Gefährtin war niemand anders als eben dieser Mantel mit dicker $W$ atte und mit festem. nicht verschlissenem Fut- ter." (154:43)

Kozincev und Trauberg haben ein gutes tilmisches Äquivalent zu dieser Passage gefunden. Akakij Akakievic sitzt an seinem Schreibtisch. der alte Überzieher hängt an seinem Haken an der Wand. In Baśmaćkins Vorstellung verwandelt sich dieser alte Uberzieher langsam in eine schonen, neuen Mantel und der Mantel wiederum verwandelt sich in eine schöne Frau. die ihm eine Tasse Tee reicht.

Alle Szenen, die Akakij Akakievićs Gedanken einschließen. sind durch das Spiel mit der Realität gekennzeichnet. Schon in der Anfangssequenz. werden die Grenzen verwischt, die gewohnten Bezüge und Bande unwirksam. Als Akakij Akakiević das Madchen erblickı, leert sich durch (ïherblendung der belebte Nevskij Prospekt und es sind nur noch der kleine Beamte und das Mädchen auf der Treppe zu sehen. Nach wenigen Augenblicken tauchen die flanierenden Menschen wieder auf. Dabei wird Akakij Akakievics Gedankenwelt im Film nicht in Absonderung von der ihm fremden IImwelt gezeigt. als vielmehr im Zusammenprall der beiden. Und mittels "Verseltsamung" von Gegenständen und Situationen wird die Verbindung zwischen Gedankenwelt und Umwelt hergestellt. sowie deren Grenzen verwischt. Die Anfangssequenz (die auf der mir zur Verfügung stehenden Videocassette leider nur bruchstuckhaft vorhanden ist) zeigt das sehr deutlich. Als Akakij Akakiević das Mädchen auf den Stufen des Cafés erblickt. erstarn er und mit ihm samtliche Bewegungen auf dem Prospekt. Aus ciner I aterne 
schieBt ein Feuerwerk hervor. Eine Brezel ubber dem Eingang zu einer Bäckerei nimmt langsam die Form eines Herzes an. $t(x)$

Ähnlich verhält es sich in den Szenen, in denen Akakij Akakievic von der Schönen Unbekannten träumt. Das Bindeglied zwischen Gedankenwelt und Umwelt ist hier die überdimensionale Teekanne im Hintergrund. Sie wird zunächst gezeigt. als gehöre sie nur zum spärlichen Inventar der Wohnung. wie die Blume am Fenster. Doch in den nächsten Einstellungen wird der oben erwähnte Schreibfehler Bašmačkins dargestellt. Zu Beginn der Traumszene. als der prachtvoll gekleidete Lakai erscheint. stößt die Teekanne soviel Dampf aus. daß das ganze Zimmer darin zu versinken scheint. wodurch die Überleitung von Realität zu Traum geschaffen wird. Im Traum vom Mantel als angenehmer Lebensgefährtin ist die Teekanne zu besonders geringer Größe geschrumpft. In der Hand dieser Frau wird sie zum Symbol der Zuwendung und Zuneigung der Frau für Akakij Akakievic. Die Verbindung von Umwelt und Gedankenwelt übernimmt hier der Mantel, der sich in die angenehme Lebensgefährtin verwandelt.(s.u.)

Das Spiel mit Realität und Phantastik erreicht seinen Höhepunkt im Traum von der Einladung. Der Raum. den Akakij Akakiević nach der Fahrt in der goldenen Kutsche betritt, ist gleichzeitig Kanzlei und vomehmer Salon. Nicht nur an Tischen. sondem auch auf Schränken und Regalen sitzen - teilweise in Generalsuniformen gekleidete - Beamte. Im Hintergrund, wo die Schöne Unbekannte wie auf einer Ottomane hingebreitet auf einem Schreibtisch liegt. befinden sich auch ein Orchester, bei dem die überdimensionale Leier ins Auge sticht, ein Jongleur. eine fünfköpfige Garde sowie ein Mann in Uniform und Haltung Napoleons. Einige Beamte reichen Akakij Akakievic dienstbeflissen Dokumente zum Unterschreiben. Die allgemeine Haltung ihm gegenüber ist ehrerbietig bis zu dem Zeitpunkt. an dem die Schöne ihr Tuch fallenläßt und der kleine Beamte - wie beim wirklichen Ereignis auf dem Nevskij Prospekt - stürzt. als er es aufheben will. Der angenehme Traum wird zum Alptraum, wobei dieser doch nur die wahre Stellung Akakij Akaievics in der Kanzlei und im l eben symbolisiert: die Verspottung durch die Kollegen und sein eigenes Unvermögen zur Soziabilität.

Nach Enttäuschung und Demütigung durch das "Himmlische Geschöpf" findet er in seine Welt zurück (der Ort ist jetzt die Kanzlei). indem er sich hinter Bergen von Papier - und damit Buchstaben - in seine persönliche

\#(x) Nedebrowo tuhri dic gesiamic Eunsicllungstolge an. Ibid., S. 36.38. 
"Normalität" zurickversetzt. Hier ist die Stelle aus der Erzählung eingefügt. als man ihm eine etwas andere, aber kaum anspruchsvollere Schreibarbeit anbietet. die Akakij Akakievic jedoch ablehnt. Im Film wird der Wunsch, in der gewohnten Welt nichts zu änderm. durch die vorangegangenen Ereignisse mit dem Mädchen vom Nevskij Prospekt an dieser Stelle auf eine andere Weise deutlich als in der Erzählung. Die Furcht vor neuen Einflüssen auf seine kleine Welt gründet hier auf der bitteren Erfahrung. die er soeben gemacht hat.

Gleichzeitig handelt es sich hier um die Sequenz, die zum zweiten Teil des Films. der eigentlichen Handlung von "Sinel" uberleitet. Verschiedene Beamte bringen große Aktenstöße und bauen sie um Akakij Akakiević herum zu einem Papierberg auf. hinter dem er vollig verschwindet. Nach Einblendung des Zwischentitels: "So wurde er zum ewigen Titularrat Baśmackin". wird dieser Papierberg wieder abgebaut und Akakij Akakievic kommt gealtert wieder zum Vorschein. Er hat jahrzehntelang in seiner engen Buchstabenwelt verharn und mit seinem Auftauchen hinter dem Papierberg wird ein neues. für seine Welt bedeutendes Ereignis eingeleitet. Kozincev und Trauberg haben hier eine sehr originelle. eigenwillige Filmmetapher für den Verlauf der Zeit gefunden, der sonst durch Uhren, erklärende Zwischentitel o.ä. verdeutlicht wird.

In der Verfilmung werden die Regeln der begrenzten Welt Akakij Akakievićs zweimal durch Ereignisse zerstönt. die von außen in diese Welt eindringen. Dabei fuhrt das erste noch nicht zur Katastrophe wie bei Piskarev, dem Helden aus der Erzählung "Nevskij Prospekt". Der erste Teil des Films ist vielmehr Einleitung und Erklärung für die unausweichliche Katastrophe, mit der der zweite Teil endet. In der Jugend ist die Gedankenwelt Akakij Akakievics noch nicht so fest begrenzt wie im Alter. Tynjanov und die Fèksy haben hier eine Bedeutungsverschiebung zu Gogol's Basmackin vorgenommen. Ihr Held ist nicht schon als ewiger Titularrat mit Glatze und in Uniform auf die Welt gekommen (143: 9). Er hat sich durch die Ereignisse mit dem Madchen vom Nevskij Prospekt dazu entw ickelt. Zwar lebt er auch in der Jugend schon in einer Welt der Buchstaben. aber die Grenzen dieser Welt sind noch nicht so verhärtet gegenuber der Umwelt. Nur dadurch kann er das von ihm selbst ausgehende Interesse fur die Unbekannte entwickeln. Der Titularrat von Geburt an hätte nie das Treiben auf dem Prospekt und die Menschen dort heobachtet. Denn bei Gogol' heißt es: 
"Außer diesem Abschreiben schien für ihn nichts zu existieren. |... | Nicht ein einziges Mal im Leben hatte er dem Beachtung geschenkt. was sich jeden Tag auf der Straße tut und ereignet. |...|." (145: 15)

Der junge Beamte im Film hat noch Interesse fur seine Umwelt, betrachtet sie allerdings schon vom Standpunkt seiner, zu dieser Umwelt nicht passenden Gedankenwelt. Der Zusammenprall dieser Welten führt zwangsläufig zum Ungluick, aufgrund dessen Akakij Akaievič die Grenzen seiner Gedankenwelt enger und fester zieht. Er wird zum ewigen Titularrat. ${ }^{\text {t01 }}$

Diese Art der Darstellung verletzt die von Ejchenbaum erklärten Stilgesetze der Groteske, da Baśmackins Welt in diesem Teil der Verfilmung noch nicht so beschränkt ist wie gefordert. Im Vergleich damit ist Piskarevs Welt auch genau begrenzt, denn in ihr gibt es nur das Gute und Schöne. Piskarev geht dann auch daran zugrunde, daß die Frau, deren Schönheit die Verkörpenung seiner Welt zu sein scheint. eine unbekehrbare Prostituierte ist. die durch ihre Haltung seine Welt zerstört.

Außerdem scheint mir in der filmischen Darstellung der Entwicklung Baśmackins eine didaktische Absicht vorzuliegen, die Ejchenbaum ebenfalls verurteilt. Denn die Darlegung des Grundes. aus dem Akakij Akakiević zum ewigen Titularrat wird, zielt offensichtlich auf die Erregung von Mitleid, was Gogol' nach Fjchenbaums Erklärung keineswegs beabsichtigte.

Aus diesem Grund scheint es mir umso erstaunlicher. daß die sowjetische Kritik den Fèksy vor allem das Fehlen der humanistischen Idee Gogol's vorwirft. Das Verständnis vom "Mantel" als Appell zum Mitleid für die Erniedrigten und Beleidigten hält sich hartnäckig in der gesamten Literaturwissenschaft. basiert aber nur auf einem mißverstandenen Satz Akakij Akakievics. In der Exposition der Erzählung wird die Begeisterung des kleinen Beamten für seine Arbeit beschrieben. in die er so versinkt. daß er sich nicht einmal von den Neckereien seiner Kollegen ablenken läßt. Nur wenn diese ihn so sehr belästigen. daß er sie nicht mehr ignorieren kann. sagt er: "Lassen Sie mich doch. warum kränken Sie mich?"(143: 11) Einer seiner jungen Mitarbeiter meint in diesen Worten die Bitte um Mitleid. sowie die Erklärung "ich bin dein Bruder" (144; 13) zu spuiren und reagiert besturrt. Hier wird jedoch nur die Reaktion dieses Mannes geschildert. und es ist

thl Vyl. Zwischentulel bei der Cberleitung iom ersien hum Aweiten Tell des Films: Tak превратикся он в вечного титулярното советннка Башмачкина. (Si I cri andelic cr sich in den ew igen Tilularra Basmackin). 
keineswegs die Meinung des Autors, die hier zum Ausdruck kommt. Ejchenbaum sieht in dieser Passage lediglich einen Kunstgriff.

"...wo der komische skast(02 durch eine sentimentalmelodramatische Abschweifung in der Manier des sentimentalen Stils unterbrochen wird. Dieser Kunstgriff hebt die Erzählung von der Ebene der Anekdote auf die der Groteske. " +1.3

Wenn man diese Stelle isoliert betrachtet, scheint es sich tatsächlich um einen reinen Kunstgriff zu handeln. Slonimskij jedoch betrachtet diese Stelle in Zusammenhang mit verschiedenen anderen der Erzählung. Nach seiner Interpretation ist sie "der Abschluß des ganzen komischen Entwicklungsgangs. ein organischer Teil der Erzählung" die Stelle uber den ewigen Titularrat, "ubber welchen sich bekanntlich hier schon verschiedene Schriftsteller lustig gemacht haben; diese können nun einmal nicht von der Gewohnheit lassen, gerade auf solche Leute loszugehen. die sich nicht zu wehren vermögen." $(141 / 142 ; 5 / 7)$ Eine andere Stelle. die ebenfalls die "humane Stelle" vorbereitet. sieht Slonimskij in dem Satz. mit dem der Erzähler die Kollegen Akakij Akakjevićs ebenfalls lächerlich macht.

t02 Der Bcgrill "Skar" (Im Zilul skas gexihrieben) bereichnel cinen subjekilicn, ofi umgangssprachlich ader dialcklal gelarbien Er/ahlstil. der meist in Jem Besireben angeirendel "ird. mil den kunonisicrten Er/ahlfirmen iu brechen. Vgl. Litcrarturnyj Enciklopediceskij Slowar'. Moxkial 14\%7. S. 382. Dic Firm des kiomischen Skiw. die mil

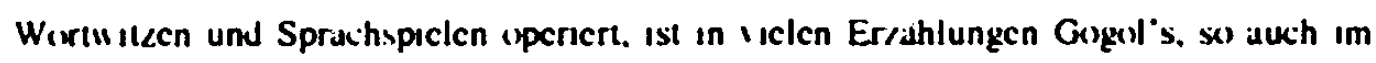
"Mantel" a linden. Ejchenbaum untersicheidet awei Arten Jes kirmixihen Skar: "1. Jen berichienden und 2. Jen reprexdu/ierenden skas. Der ersic operieri mil Wilien und s!noy mixtien Scherıen: der a weite bedient sich Jer Wortmımık und Wortzesuk - er ertindet komixche Artukulationen. Klangwil/c. ausgelallene Sal/kenstrutitionen usw. Der erste

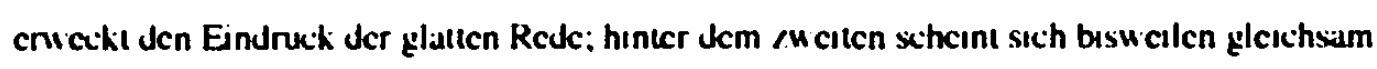
cin Komodiant i crstectit a halien. so dab Jer skas selbst den Charakier cines Spicls

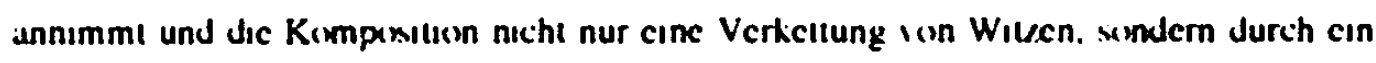
Sysiem irelfalliger mimisch-artikulatunscher Gesten gepragt ist." Diesc /weile Ant des komischen Stay ordnel er den Er/ahlungen Gogol's und besonders dem "Mantel" a. Ejchenbuum (1\%5). S. 120).

(1).3 ibid.. S. 135.

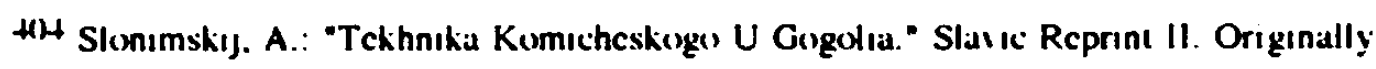
published in 1923 as part of the Vopross pretiki. Petrograd 1923. Intrexduction by Dunald Fianger. Brum n Linil crist! Press. Prow idence (Rhexde Istand) 1963. S. 18. 
als er sagt: "Die jungen Beamten spotteten und witzelten uber ihn, soweit ihr Kanzleiwitz überhaupt reichte." (143; 11$)$ In diesen Sätzen bereitet Gogol' eine ernsthafte Lösung des komischen Entwicklungsgangs vor, bei der er Akakij Akakievic in eine Situation bringt, in der er nicht mehr lächerlich ist. sondem bemitleidenswert. ${ }^{\text {ths }}$

In der Verfilmung findet sich die "humane Stelle" im Traum von der Einladung wieder, als die Beamten den gestürzten Baśmackin mit Papier und Gänsekielen bewerfen. Dabei geht es weniger um das Hervorrufen von Mitleid. als darum Akakij Akakievic auf eine menschliche Ebene zu bringen. "Erst auf dieser menschlichen Ebene kann Akakij für einen Moment als tragische Gestalt vor uns treten, was bei dem zum Automaten reduzierten Akakij undenkbar wäre. " Verbindung von Komik und Tragik, wobei die Tragik eben das Mitleid hervorruft. Dem entspricht die Aussage des Films an dieser Stelle. Gleichzeitig wird der Stil der phantastischen Groteske durch Umgebung und handelnde Personen beibehalten.

Am ersten Teil der Verfilmung kritisien die sowjetische Filmwissenschaft aber auch. daß Akakij Akakievic durch die Urkundenfälschung. die er dann für das Mädchen begeht. nicht mehr unschuldiges Opfer ist. ${ }^{+17}$ Gogol' selbst hat ihn jedoch keineswegs als unschuldiges Opfer dargestellt, sondem als "zutiefst lächerliche Existenz" ${ }^{n+}$, sodaB diese Interpretation wiederum das Ergebnis einer übertrieben mitleidsorientierten Auslegung ist. Wenn Akakij Akakievic im ersten Teil von "Sinel" Mitleid erregt und erregen soll, dann ist das in einem anderen Zusammenhang zu sehen. Tynjanov und den Fèksy ging es in erster Linie um die Vermittlung des Geistes der Nikolaitischen Epoche. ${ }^{+(x)}$ Diese Zeit gilt allgemein als besonders unerfreuliches Kapitel der russischen Geschichte. Die Errichtung eines bürokratischen Polizeiregimes

\footnotetext{
H(15 Slonimskij (1\%3). S. 18.

HK. Gunther. H.: 'Das Groteske BeI N.V. Gogell. Formen und Funktionen." Munchen 196x. S. 170.

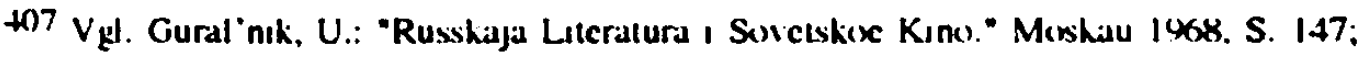
sou ic Tuncyn. V.: Tn Ekranıracil "Sıncli" N.V. Gogolja.' In: "Kino I I remja". Bjuleien" Grovill'mlionda." Vy.p. 4. Moxkau 1965. S. IIR8.

to18 Zclınsky. B.: 'Gogul - Der Mantel.' In: Ders. (Hz.): "Dic Russısche Nuvelle." Dusseldort 1962. S. 55

$\left.H()^{3}\right) V_{\text {gl. }}$ GE. S. $\times 3$.
} 
nach der Niederschlagung des Dekabristenaufstandes und die Bemühung jegliche Freiheitsbewegungen im In- und Ausland zu unterdrücken, hatten dem Zaren Nikolaj I. den Beinamen "Gendarm Europas" eingebracht. Es herrschte eine strenge Zensur. So war beispielsweise Lermontov für sein Gedicht "smert' poeta" ("Tod des Dichters") auf den Tod Puskins zuerst in den Kaukasus und dann nach Novgorod strafversetzt worden.

Bei der Übertragung der Atmosphäre dieser Epoche auf den Film ist es fast selbstverständlich, wenn der unter diesen Bedingungen lebende Mensch auch Mitleid erregt.

In der Atmosphäre. wie sie Gogol' in seinen Petersburger Novellen vermittelte. fanden die Fëksy die Groteske.

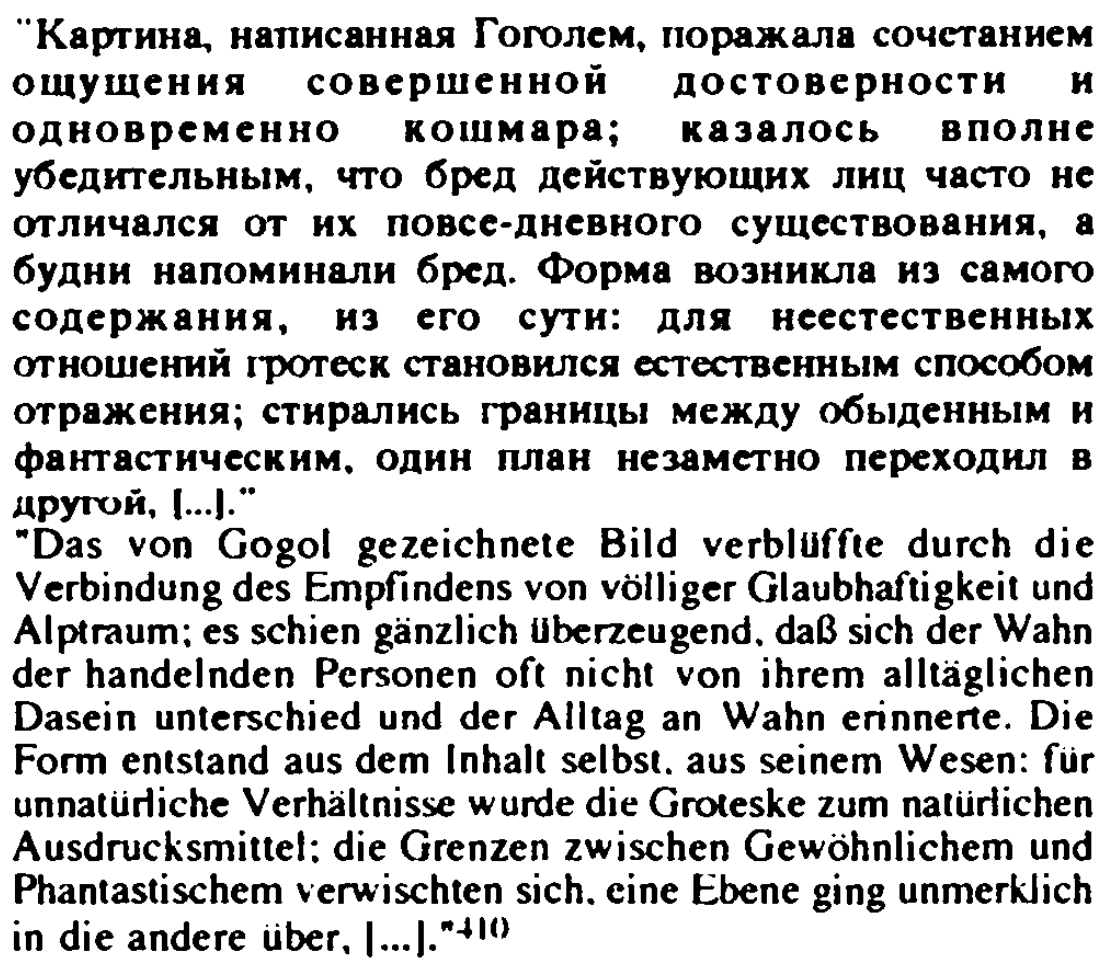

Die Darstellungsform der Groteske ergab sich ganz selbstverstänlich aus dem mimisch-deklamatorischen Skaz der Erzählung.

"Nicht ein skus-Erzahler, sondern ein Darsteller, fast ein Komödiant, verbirgt sich hinter dem Drucktext des Mantel." +11 Die Übertragung dieses Darstellers erfolgte einmal durch Zwischentitel. die - vermutlich durch Tynjanov - der Sprache Gogol's sehr gut angeglichen waren. Kommentaren

\footnotetext{
+10 GE. S. 83

+11 Fjchenbuum (1\%.5). S. 134.
} 
ähnlicher als erklärenden Zwischentiteln vermitteln sie Komik. Ironie und Wortspiele, wie man sie bei Gogol' findet.

Zum anderen war das Spiel der Schauspieler mit übertriebener Gestik und Mimik ein Mittel zur Übertragung dieses Skaz auf die Leinwand. Wobei die Übertreibung sicher nicht mehr als Besonderheit des Stummfilms zu verstehen ist. Aleksej Kapler als un/bedeutende Persönlichkeit verkörpent durch dümmlich arrogante Mimik und Gestik sehr gut den Typ des höheren Beamten, wie er in allen Petersburger Novellen anzutreffen ist. In der Darstellung des Schneiders Petrović und seiner Frau scheint noch einmal die Begeisterung der Fèksy für den Zirkus durch. Besonders die Art. in der der Schneider seinen FuB im gleichen Rhythmus bewegt wie die Hand, die die Nadel durch den Stoff führt. zeugt von akrobatischer Körperbeherrschung.

Allen voran hat jedoch Andrej Kostrickin hier eine schauspielerische Meisterleistung vollbracht. Seine Darstellung des unglickseligen jungen Beamten erregt Mitleid beim Zuschauer. während der gealterte Akakij Akakiević schon durch Gang. Mimik und Gestik zur grotesken Figur wird. Besonders Gang und Haltung tragen hier viel zum Ausdruck bei. Während der junge Baśmackin selten in Bewegung zu sehen ist. wird der komische Gang des alten Beamten häufig in langen Einstellungen gezeigt. Seine Konperhaltung gleicht mittlerweile der Fonn eines Frage zeichens. Der Ruchen ist krumm geworden, die Knie leicht gebeugt, er bewegt sich mit zaghaften. trippelnden Schritten und verändert so nie die Haltung, die er am Schreibpult cinnimmt. Durch die gekrummte und gebeugte Haltung wirkt er wesentlich kleiner als der junge Akakij Akakievic. Nur in den Szenen mit dem neuen Mantel hält er sich plötzlich wieder aufrechter und größer. er trippelt weniger und bewegt sich selbstbewußter. Nach dem Raub jedoch wird er noch krummer und gebeugter als in der Zeit vor Besitz des Mantels. In der Szene mit der bedeutenden Persönlichkeit schließlich erreicht diese Krümmung ein widernaturliches Ausmaß. Schon aus dieser Körperhaltung wird die Bedeutung des verlorenen Mantels für den kleinen Beamten sehr gut deutlich.

Seine Unsicherheit gegenüber der Umwelt wird immer wieder gezeigt durch Stürze. Zum ersten Mal fällt er, als er auf dem Nevskij Prospekı das Tuch des "himmlischen Geschöpfs" aufheben will. Der zweite Sturz ereignet sich im Traum von der Einladung zu dieser Schönen Unbekannten. Die anschließenden Einstellungen, in denen die im Raum anwesenden Beamten ihn mit Papier und Fedem bewerfen, verdeutlichen die hier stattfindende Vermischung von Realität und Traum. 
Ein anderes Mal stürzt Akakij Akakievic in der Kanzlei, nachdem er den neuen Mantel beim Portier abgegeben hat. In dem Moment, in dem er die neue, sein Selbstbewußtsein stärkende Hülle ablegt, ist sofort die alte Unsicherheit wieder da. Der schwerste Sturz erfolgt nach der Schimpftirade der bedeutenden Persönlichkeit gegen den beraubten Beamten. Akakij Akakievic sinkt immer mehr in sich zusammen. während die bedeutende Persönlichkeit immer größer zu werden scheint. und fallt schließlich - genau wie nach dem Raub des Mantels - auf den Ruicken (161: 63), wo er hilflos liegenbleibt. Bezeichnend ist. daß in den Fieberträumen vor seinem Tod noch einmal ein Sturz auf den anderen folgt. Die Darstellung des alten verknöcherten Männchens durch den fünfundzwanzigjährigen Schauspieler Kostrickin verdient großen Respekt.

Doch zuriick zur Groteske im Film. Auch eine ganze Reihe von teilweise ironischen Metaphern und Symbolen wurde zu deren Ausarbeitung verwendet. So zeigt die Einstellung vor der ersten Szene. die in der Kanzlei spielt, eine Ratte, die sich zwischen Papieren bewegt. Das ist die bildliche Umsetzung des Begriffs "Kanceljarskaja Krysa" (Kanzleiratte), was in etwa dem vergleichsweise freundlichen deutschen Ausdruck "Bürohengst" entspricht. An anderer Stelle verspricht Ivan Fedorov seinem Bekannten Petr Petrovic Ptizyn, die Erledigung seiner Sache wäre unter "Dach und Fach". Der russische Ausdruck dafü ist "delo v sljape" ( wörtl. "Die Sache ist im Hut"). Und die nächste Einstellung zeigt einen Zylinder mit einer Akte darin. Diese direkte Übertragung von erstarten Sprachmetaphern in innovative Filmmetaphem hatten die Feksy schon im "Teufelsrad" angewendet.

Symbolische Bedeutung bekam die Blume. die am Fenster von Akakij Akakievics Behausung steht. Im ersten Teil des Filmes bluht sie, wodurch das Zimmer und damit die enge Welt des jungen Beamten etwas freundlicher erscheinen. Im zweiten Teil steht sie vertrocknet und abgestorben auf dem Fensterbrett. Hier symbolisien sie diese trostlose Lebensperiode und die in ihr verbrachten. kümmerlichen Lebensjahre des ewigen Titularrats. Die Blume ist eine Metapher für Akakij Akakievićs Welt und seine mit dem Alter zunehmende Verkümmerung. also ein gutes Beispiel für den Chronotopos von Raum und Zeit im Film.

Der Papierberg schließlich. hinter dem die Verwandlung vom jungen zum alten Akakij Akakiević stattfindet. symbolisiert die jetzt aufs winzigste beschränkte Welt des Abschreibens. Der Film schließt mit dem Tod des 
ewigen Titularrat, der symbolisien wird durch die im Wind verlöschende Kerze und die Straßenlateme, die ein Nachtwächter ausbläst.

Ebenso wie im "Teufelsrad" werden auch im "Mantel" Orte. Plätze und Gegenstände in das Spiel cinbezogen und spielen selbst. Hier geschieht das jedoch in direkter Anlehnung an Gogol', der seinerseits den Nevskij Prospekt in der gleichnamigen Erzählung zur handelnden "Person" macht. Zu den spielenden Gegenständen zählen die oben erwähnte Teekanne, sowie die sich verwandelnde Brezel über der Bäckerei oder die zwinkernden Lampen. Die zuletzt genannten Gegenstände verhelfen gleichzeitig dem Nevskij Prospekt zu dem unglaubwürdigen Charakter, den der Schriftsteller ihm zuspricht. Tynjanov und die Fèksy haben sich bei seiner Darstellung auf die Tageszeit beschrankt, zu der dort. laut Gogol', Lug und Trug am deutlichsten werden.

"Er lujgt. er trügt zu jeder Stunde, dieser Newski Prospekt, am ärgsten aber dann. wenn sich die Nacht gleich einer undurchdringlichen Wolke auf ihn niedersenkt." +12 Deshalb drucken die oben erwähnten Gegenstände nicht nur die Gedankenwelt Akakij Akakievics aus, sondern auch den Lug und Trug des Nevskij Prospekt. von dem der kleine Beamte sich täuschen läßt. Ebenso wie in der Erzählung steht die Hauptstraße St. Petersburgs auch in der Verfilmung für die ganze Stadt.

"Der Nevskij Prospekt reprasentien Petersburg, mehr noch: Er i s t Petersburg. In ihm gelangt die Stadt zu sich selbst: an ihm ist ablesbar, welches innere Gesetz die Stadt zusammen und in Gang hält. Hier liegt der Lebensnerv der Hauptstadt bloß. Hier enthült sich ihr eigenes Leben. ihr eigenes Sein. ${ }^{n+13}$

Und das der Stadt eigene Leben und Sein sind Lug und Trug. Alles ist nur schöner Schein. Großartigkeit ohne Leben und menschliches Mitgefühl. So wird der Nevskij Prospekt auch im Film dargestellt. Gogol ${ }^{\circ}$ kommt in seiner Erzählung zu dem Schluß, daß der Teufel selbst dafür verantworlich ist. +14

Diese naheliegende Anwendung des Prinzips der Synekdoche ist gleichzeitig typisch für den russischen Film der zwanziger Jahre. Auch Ejzenstejn hat es im "Panzerkreuzer Potemkin" mehrmals angewendet, so in

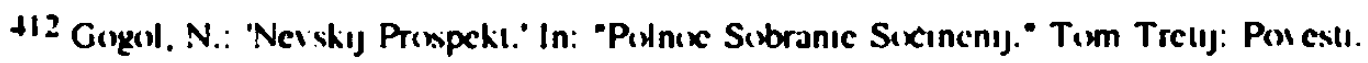
I/datel'sllo Ahademii Nauk SSSR 19.38. S. Wh: Lberwct/ung aus: "Gicummelte Werke in lunf Banden. BJ. 1: Ersihlungen " Stullgart 14k2. S. 747.

$\$ 13$ Zelinsk!. B.: "Russische Rimanilk." KilniWien 1975. S. 322.

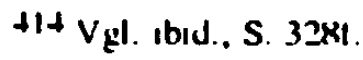


der Darstellung der Odessaer Treppe für die ganze Stadt, der Soldatenstiefel und Gewehre für das zaristische Heer etc.

Für Tynjanov und die Fèksy diente diese Darstellungsweise vor allem der Verkörperung des eisernen, mitleidlosen Regimes der Nikolaitischen Ära. Dabei stellten sie dem Nevskij Prospekt große Gebäude. Denkmäler und riesige leere Plätze zur Seite, wie den aus der Raubszene. In seiner Verzweiflung und Hilflosigkeit nach dem Raub des Mantels wendet sich Akakij Akakievic an eine überdimensionale steineme Sphinx, nachdem der angesprochene Wachmann ihn kaum beachtet hat. Die steinerne Sphinx - hier Symbol für das Regime - bleiby, wie zu erwarten. gleichgültig.

Die Anwendung filmischer Metaphern. Symbole und Allegorien war hier also in erster Linie ein Mittel zur Ubertragung des gogol'schen Skaz auf den Film. Nicht zuletzt damit erreichten Tynjanov und die Fèksy die filmische Wiedergabe seiner eigenwilligen Originalität.

Die Vermittlung der bedrückenden und zugleich grotesken Atmosphäre durch filmische Bilder ist vor allem das Verdienst des Kameramannes Andrej Moskvin. Er wandte Einstellungen und Perspektiven an, die man bis dahin. zumindest im sowjetischen Film, noch nicht kannte.

Die Einsamkeit und Hiltlosigkeit Akakij Akakievics, der gefangen ist in seiner engen Welt, erlangt besondere Eindringlichkeit durch den Kontrast zwischen dem kleinen Menschen und der großen Stadt. Dieser Kontrast wurde erreicht durch die Gregenüberstellung von großartigen Denkmälem und kleinem Beamten, von Menschenansammlungen in engen Räumen oder auf dem Nevskij Prospekt und großen leeren Plätzen und Straßen. Schon in der Anfangssequenz wird der Nevskij Prospekt immer wieder in weiten Einstellungen gezeigt, in denen der kleine Beamte nur zu erahnen ist. Sie wechseln ab mit Nahaufnahmen von Akakij Akakievic. wodurch der Kontrast betont wird. Auch die Wege Basmackins durch die Stadt sind meist in weiten Einstellungen gefilmt, wo sich die kleine Gestalt durch die große Stadt bewegt. Dabei entwickelt sich der Kontrast durch die Verwendung verschiedener Einstellungsgrößen und Kameraperspektiven langsam bis zum Grotesken in letzten Teil des Films. So z.B. bei den Bildem der Einstellung. in der Akakij Akakievic sich nach dem Raub des Mantels an die Sphinx wendet. Diese Bilder sind offenbar durch Zusammenschnitt oder Uberblendung entstanden. Die Sphinx überragt Akakij Akakievic um ein Vielfaches. Seine Gestalt wurde offensichtlich in weiter Einstellung gefilmt 
während die Sphinx vermutlich in Nahaufnahme aufgenommen wurde. Umgebung und Hintergrund verlieren sich in Dunkeln. In der nächsten Einstellung ist die reale Größe der Sphinx zu erkennen. Als Akakij Akakievic sich abwendet und weggeht, fallt sein Schatten auf den Sockel der Figur und reicht bis zu deren Füßen, während die Höhe seiner Gestalt in den ersten Bildem nicht einmal die Hälfte des Sockels erreicht. Es dürften hier also zwei Einstellungen von verschiedener Größe zusammengeschnitten, oder durch Übereinanderblenden zu einem Bild verbunden worden sein.

Akakij Akakievic wird besonders im zweiten Teil der Verfilmung meist aus einer leichten Obersicht gezeigt, um seine geringe physische wie soziale Größe zu unterstreichen. Die Zunahme an Selbstbewußtsein und sozialer Anerkennung wird in den Szenen, in denen Akakij Akakievic voller Stolz seinen Mantel trägt, durch eine Kameraperspektive in normaler Höhe vermittelt. Sobald er jedoch den Mantel auch nur an der Garderobe der Kanzlei abgibt, ist er wieder der alte. unbedeutende kleine Beamte, wie die Kameraperspektive deutlich macht, die ihn wieder aus der Höhe im großen leeren Raum zeigt. Zudem macht die Kamerafiihrung in den beschriebenen Szenen die Stilisierung des Mantels zum Fetisch klar. Aber auch die Einstellung. in der die Kamera den an der Garderobe der Kanzlei hängenden Mantel langsam von oben nach unten betrachtet. trägt dazu bei: ebenso wie die oben beschriebene Szene der Verwandlung vom Mantel zur Frau.

"Moskvin's treatment of the robbery in the snow is especially expressive." +15 Der Platz. auf dem sich der Raub abspielt. ist eine dunkle. mit unberïhrtem Schnee bedeckte Fläche. Akakij Akakievic zieht mit seinen Schritten eine Spur durch den Schnee von links nach rechts, bis er auf den ersten der Räuber trifft. Er wendet und geht in seiner Spur zurick. wo er auf halber Strecke plötzlich einem anderen Räuber gegenübersteht. Da wendet er sich nach rechts, wo wieder ein anderer steht und sich schließlich alle Räuber gemeinsam auf ihn stiirzen. ihm den Mantel vom Körper reißen und den Beraubten in den Schnee stoßen. Das ganze Geschehen ist wieder aus der mitleidlosen Obersicht gefilmt. Baśmaćkins Hin- und Hergehen bekommt durch das Verbleiben in der eigenen Spur etwas Auswegloses. (gleichzeitig bildet diese Spur ein Kreuz. das nur aus dieser Obersicht so klar erkannt werden kann). Zur Verstärkung der unwirklichen Szenerie trägt die Beleuchtung bei. Der Platz ist nur von einem breiten Lichtstrahl, der aus

H15 Leydu (1963). S. 202 . 
größerer Entfernung kommen muß. erleuchtet. Denn zunächst sieht man nur den langen Schatten Akakij Akakievićs, der sich über den Platz bewegt, bevor er selbst auftaucht. Die gesamte Handlung der Szene spielt sich innerhalb dieses Lichtstrahls ab.

Der ganze Film ist von Dunkelheit geprägt. Ein Großteil der Szenen spielt abends oder nachts, was eine gezieltere und wirkungsvollere Beleuchtung erlaubt als bei Tagaufnahmen. Das wird sowohl in der Raubszene als auch in den Einstellungen mit Akakij Akakiević und der Sphinx besonders deutlich. es gibt keinen Hintergrund und keine Umgebung in diesen Bildern. wodurch sie an Realität verlieren und eine alptraumhafte Phantastik eriangen.

Auch der abendliche Weg zur Teegesellschaft und zurick kommt vor allem durch die Beleuchtung der Beschreibung Gogol's sehr nahe. Der Hinweg ist eine Bewegung vom Dunkeln ins Helle. Es wird zunächst erklärt. daß der Finladende

"im vornehmsten Teil der Stadt wohnte. also nicht gerade sehr nahe bei Akakij Akakiewitsch. Zuerst muBte Akakij Akakiewitsch einige öde Straßen mit spärlicher Beleuchtung passieren. aber je mehr er sich der Wohnung des Beamten näherte. desto belebter, bevölkerter und besser beleuchtet wurden die Straßen." ( I58; 55)

Genauso wird der Weg auch im Film dargestellt. Während der Rückweg in der Novelle anders beschrieben wird als der Hinweg, zeigt der Film die gleichen Bilder wie auf dem Hinweg. wobei sich Akakij Akakiević hier in umgekehrter Richtung bewegt. Am Ende dieses Weges zitiert der Film den Satz: "Schon kamen die Häuser und Zäune aus Holz." +16 Im Film stößt an dieser Stelle ein Vorübergehender Baśmackin in den Schnee und ein Gesicht schaut iiber den Zaun. Dadurch kommt das Unheimliche der Situation zum Ausdruck und das drohende Ungluick wird angekündigt.

Wie oben beschrieben. ist die Dunkelheit im ersten Teil des Films. neben den handelnden Gegensiänden, die filmische Wiedergabe der letzten Sätze des Schriftstellers in "Nevskij Prospekt". Lug und Trug der Prachtstraße und damit der ganzen Stadt und schließlich der ganzen Gesellschaft. die am ärgsten zur Nachtzeit sind, sind im ersten Teil der Verfilmung durch die beherrrschende Dunkelheit immer gegenwärtig. Gleichzeitig stehen die dunklen Bilder im gesamten Film auch als Metapher für die "dunkle Zeit". in der das Geschehen stattfindet. Die Fèksy haben durch die Betonung der Dunkel-

+16. Gonget (1973). S. 61. 
heit ein düsteres Bild der Epoche gezeichnet. wie es gedanklich auch bei Goigol' zu finden ist.

Großartig gefilmt ist die Sequenz des Vorsprechens bei der bedeutenden Persönlichkeit. In den Szenen, in denen er auf Einlaß in den Amtsraum wartet, ist Baśmackin mehrmals in Obersicht aus einem sehr steilen Winkel aut genommen, wodurch Bedruickung und Furchtsamkeit betont werden. Als er sich schließlich in den Raum begibt, in dem die bedeutende Persönlichkeit sich aufhält, wird er weniger steil, dafür aus noch größerer Höhe gefilmt. als würden in diesem Haus alle und alles auf ihn herabsehen. Hier erfolgt die Verlebendigung einer versteinerten Sprachmetapher durch die Kameraperspektive. Die bedeutende Persönlichkeit dagegen ist aus der Untersicht in Großaufnahme gefilmt. als sie sich langsam von ihrem Schreibtisch erhebt. um zu sehen, wer sie da stört. Sie wirkt bedrohlich groß während sie auf den kleinen Beamten hinunterschaut. der in der nächsten halbtotalen Einstellung. steil und aus extremer Höhe aufgenommen, den Eindruck erweckt, er wolle im Boden versinken.

$\mathrm{Zu}$ Verallgemeinerung und grotesker Wirkung durch Verfremdung tragen u. a. Einstellungen bei, die die handelnden Personen wie im Scherenschnitt zeigen. Die erste dieser Einstellungen folgt auf die Anfangssequenz am Nevskij Prospekt. Als die unbedeutende Persönlichkeit dem Madchen zum Haus Ivan Fedorovs folgt. bleiben beide in einiger Entfernung vom Haus stehen. an dem sich die einzige. aber starke Lichtquelle des Bildes befindet. Der Zuschauer sieht nur die Silhouetten der Personen und erkennt sie aus den Umrissen. Das Mädchen bleibt stehen, während die unbedeutende Persönlichkeit eine großartige Gebärde mit ihrem Stock vollführt. Dann bewegen sich die beiden auf das Haus zu. Einige Einstellungen später folgt Ivan Fedorov und wird auf die gleiche Weise gefilmt. Diese drei verkörpern hier Typen. wie sie auf dem Nevskij Prospekt häufig anzutreffen sind: die Prostituierte, der Stutzer und der Gauner. Ein anderes Mal werden die Silhouetten Akakij Akakievićs und des Mädchens gezeigt. die nur dem Anschein nach an den Fenstern sich gegenüberliegender Häuser stehen und vom anderen eben nur den Umriß sehen. Diese Einstellungen haben jedoch verschiedene Bedeutung, abhängig von der jeweils betrachtenden Person. Während Akakij Akakievic beim Anblick der Silhouette des Mädchens von ihm als vormehmer schöner Unbekannter zu träumen beginnt. sieht das Mädchen in seinem Umriß nur den typischen kleinen Beamten, den es auszunutzen sucht. 
Und noch einmal verwendete Moskvin die Scherenschnitteinstellung in der ersten Einstellung des Wachpostens, an den sich Akakij Akakievic nach dem Raub des Mantels wendet. Hier steht diese Stilisierung der Person des Wachpostens wieder für die allgemeine Teilnahmslosigkeit gegenuber dem Schicksal des Einzelnen.

Insgesant leistet die subjektive Kamerafuhnung einen wesentlichen Beitrag zur filmischen Ausarbeitung von Gogol's subjektivem Erählstil.

Durch die ausdrucksvolle Bildgestaltung Moskvins wird besonders "Sinel" immer wieder mit dem deutschen expressionistischen Film und vor allem mit Robert Wienes "Kabinett des Dr. Caligari" (1921) oder Friedrich Murnaus "Der letzte Mann" (1924) verglichen. 117

Kozincev bestreitet diesen Einfluß, da sie zu diesem Zeitpunkt die deutschen expressionistischen Filme noch nicht kannten und er. wie bereits erwähnt. den expressionistischen Film nicht sehr schätzte. Die Bildgestaltung des Films war dem realen Zustand Petrograds im eisigen Winter 1920/21 entnommen.

\begin{abstract}
"Кадры 'IIинели' - снежная площадь, пересеченная тенями грабителей, Акакий Акакиевич, зовущий о помощи среци безлюцья черных ирегісктов, грозныс памятники в метели, кривыс тени печных труб на стене каморки - были навеяны не немецкими фильмами, а самой реальностью."

"Die Bilder des 'Mantels' - der schneebedeckte Platz, zerschnitten von den Schatten der Räuber. Akakij Akakievic. der in der Menschenleere der schwarzen Prospekte um Hilfe ruft. die drohenden Denkmäler im Schneesturm, die krummen Schatten der Ofenrohre an der Kammerwand - waren nicht durch die deutschen Filme wachgerufen worden, sondem durch die Realität selbst."
\end{abstract}

Trotzdem lassen sich die auffallenden Ahnlichkeiten zwischen "Sinel" , dem "Kabinett des Dr. Calgari" und dem "letzten Mann" natürlich nicht leugnen.

Dabei wurde ich in der (jestalt Akakij Akakievics weniger Ähnlichkeit zum Schlafwandler aus "Dr. Caligari" sehen. ${ }^{+1 \%}$ als vielmehr zum Portier aus dem "letzten Mann". Beide sind Kleinbuirger, die in einer eng begrenzten Welt

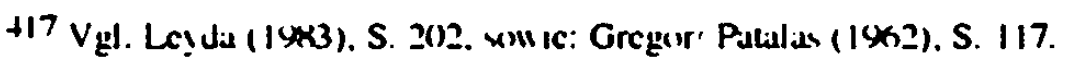

H18 GE. S. 821.

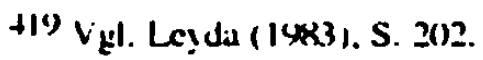


leben, und deren soziale Anerkennung von einem Kleidungsstuick abhängt: dem Mantel und der Uniform des Hotels. In "Der letzte Mann" wird die Uniform des Portiers fast ebenso stark stilisient wie der Mantel in "Sinel" . Und genau wie bei Akakij Akakievič zeigt sich die Bedeutung der Uniform für den Portier sehr deutlich in seiner Körperhaltung und seinem Gang. Solange er die Uniform trägt hält er sich aufrecht und stolz. Als man sie ihm wegnimmt, sackt er zusammen, knickt in den Knien ein wie Akakij Akakievič und bekommt eine gebiickte Haltung.

Auf beide Filme trifft Toeplitz' Aussage zu: "Für den Expressionismus ist die Isolierung, die Vereinsamung des Menschen charakleristisch. ${ }^{n 20}$ Isolierung und Vereinsamung sind in beiden Filmen nur in umgekehrter Reihenfolge dargestellt. Akakij Akakievič tritt durch den Besitz des Mantels kurzfristig aus seiner Isolierung heraus. und genießt plötzlich eine gewisse soziale Anerkennung. fält jedoch nach dem Raub umso tiefer in die alte Vereinsamung zurück. Der Portier dagegen verliert die Anerkennung zusammen mit der (Iniform. gewinnt sie jedoch am Ende des Films durch die Erbschaft in verstärktem Maße zurück. Die Idee beider Filme ist aber die Isolierung des Menschen in seiner Zeit und Umwelt. So sind auch beide Filme in realen Städten aufgenommen, die allein durch ihre Größe den Kontrast zwischen Mensch und Umwelt verdeutlichen. der durch stilisierende Kamerafuhrung noch betont wird.

Im "Kabinett des Dr. Caligari" ist die Dekoration das bestimmende Element des Films. Sie ist von ebenso großer Wichtigkeit wie die Handlung und vermittelt mehr als diese die Ungiiltigkeit der gewohnten Ordnung. sowie die Almosphäre von Furcht und Bedrückung. Denn auch die Idee des "Kabinett des Dr. Caligari" ist eine andere als in "Sinel" oder "Der letzte Mann". Es ist die Auflehnung "gegen das Geordnete. gegen das allen als heilig und feststehend Empfundene, in dem die Gewalt wirkt." +21 Diese Ordnung schuitzt sich dadurch, daß sie diejenigen, die sich gegen sie auflehnen. für verrückt erklärt. Die Rahmenhandlung. durch die diese Aussagen erst entsteht. wurde gegen den Willen der Drehbuchautoren Hans Janowitz und Carl Mayer hinzugefügt. Doch der letzte Ausruf Francis'. der jetzt Patient in der Irrenanstalt ist, stellt diese Ordnung noch einmal in Frage.

\footnotetext{
${ }^{420}$ T(xplice (1975). S. 230 ).

+21 Ibid.. S. 217.
} 
wenn es im Zwischentitel heißt: "Ihr glaubt alle - ich sei wahnsinnig! Es ist nicht wahr - - der Direktor ist wahnsinnig!! Er ist Caligari!"

Alle drei Filme kritisieren also in ausdrucksbetonender Art und Weise die Gesellschaftsordnung der Zeit, in der sie spielen. Dabei weisen jedoch "Sinel'" und "Der letzte Mann" durch ähnliche Bearbeitung der Realität sehr viel mehr Gemeinsamkeiten in der Darstellungsform auf als "Sinel'" und "Das Kabinelt des Dr. Caligari". Dieser Film erinnert in seiner äußeren Form stark an die expressionistische Malerei und Graphik, "Sinel'" und "Der letzte Mann" dagegen eher an den literarischen Expressionismus. Im Falle von "Sinel'" scheint diese Ähnlichkeit jedoch eher auf Zufall und einer ähnlichen Sicht der darzustellenden Inhalte zu beruhen. wenn man sich an Kozincevs Aussage dazu erinnnert.

Viele sowjetische Filmkritiker meinen in "Sinel" "aber auch einen starken Einfluß der Phantastik E.T.A. Hoffmanns zu erkennen. Von verschiedenen Seiten wird den Fèksy vorgeworfen. sie hätten nur die Phantastik der Novelle "Nevskij Prospekt" in ihren Film einfließen lassen, den Realismus Gogol's völlig außer acht gelassen und den Schriftsteller so zu einem Epigonen Hoffmanns gemacht. ${ }^{22}$ Doch das Phantastische in "Sinel" ist nur ein Kunstgriff der Groteske. Das Spiel der Vermischung von Realität und Irrealität, von Komik und Tragik wurde in dieser Verfilmung adáquat umgesetzt, was schließlich das Ziel Tynjanovs und der Fèksy war.

\subsection{Vergleich der Verfilmungen des "Mantel" durch Kozincev und Trauberg (1926) und durch Batalov (1959)}

Die zweite sowjetische Verfilmung des "Mantel" effolgte erst 1959 durch Aleksej Batalov. Für Batalov, den erfolgreichen Schauspieler, war es die erste Regiearbeit. Als Absolvent des MCHAT und Schiiler von losif Chejfiz war er ein Vertreter des Realismus. wie er in der klassischen russischen L.iteratur zu finden ist. Daher war fuir ihn auch bei Gogol' vor allem dieser Aspekt wichtig. Die Sichtweisen aus den Blickwinkeln verschiedener Kulturströmungen bei Batalov und den Fèksy bilden dann auch den größten Unterschied der beiden Adaptionen. So haben Tynjanov und die Fèksy eine

+22 Tunc!n (14x5). S. 1(17. winle: Lebeder (1465). S. 377. 
phantastische Groteske im Film geschaffen, während unter Batalovs Regie eine Tragikomödie in realistischer Darstellung entstand.

Batalovs Akakij Akakiević ist tatsächlich eine "zutiefst lächerliche Existenz $^{n+23}$ bis zu dem Zeitpunkt. wo ihm der Mantel gestohlen wird. Die einzige Ausnahme bildet die "humane Stelle", die Batalov wörtlich übernommen hat. Hier bekommt das Gesicht des Schauspielers Rolan Bykov plötzlich einen leidenden und mitleiderregenden Ausdruck von ungeahnter Expressivität. In allen anderen Szenen wirkı Baśmackkin in erster Linie lächerlich. Diese Lächerlichkeit ist jedoch hauptsächlich auf die Darstellungsweise dieser Figur durch Drehbuchautor und Regisseur zurickzufuhren. Schon in der ersten Szene mit dem erwachsenen Akakij Akakievic muß dieser sich vor seiner Wirtin halb hinter der Tür verbergen. weil der Schneider Petrović ihm seine Hosen noch nicht gebracht hat. Der kleine Beamte wird dadurch gleich zu Beginn als Witzfigur charakterisien und die Lächerlichkeit wird im weiteren Verlauf des Films bis zum Raub des Mantels immer wieder hervorgehoben. Das geschieht vor allem in Szenen, die in der literarischen Vorlage fehlen. also dem urspriinglichen Sujet hinzugefügt wurden. So in der Szene, in der Akakij Akakiević neidvoll die Münzen im Hut eines Bettlers betrachtet. der ihn wiederum mißtrauisch ansieht. Wenn er seine Wäsche selber wäscht, um zu sparen, als der Zar auf dem Nevskij Prospekı vorbeifährt und Akakij Akakievič zunächst glaubt, die Leute würden ihm in seinem neuen Mantel zujubeln, um dann jedoch selbst jubelnd dem Schlitten des Zaren nachzulaufen, oder auch in seiner Begegnung mit der Prostituierten auf dem Heimweg von der Teegesellschaft. Alle diese Stellen fehlen in der literarischen Vorlage.

Zelinsky schreibt die Lächerlichkeit Baśmaćkins dem Fehlen jeglicher Originalität dieses Charakters zu, wobei schon der Name "Akakij Akakievic" besonders lächerlich ist. ${ }^{+2+}$ Die Lächerlichkeit liegt hier also in seiner Persönlichkeit, während sie bei Batalov durch Situationen und die Reaktionen des Beamten entsteht. So ist sie bei Gogol ' ein Verfahren der Groteske, bei Batalov dagegen ein Verfahren der Komödie. Hinzu kommt. daß der Akakij Akakiević aus Batalovs Film in vielen Szenen eher peinlich lächerlich wirkt als mitleiderregend. Er benimmt sich lächerlich, während er bei Gogol ". aher auch bei Kozincev und Trauberg der Lächerlichkeit ausgesetzt wird.

$\$ 23$ Siche Anm. 41)7.

$+2+v_{g}$. Zclinsh! (19k2). S. 55 . 
Gural'nik schreibt dazu, der Zuschauer könne diesen Akakij Akakievič nicht mögen, weil die Verfilmer ihn nicht mögen, sondern ihren Helden mit kaltem Interesse präparieren. Dadurch sei das Mitleiden am Schicksal des Beamten unmöglich gemacht. Er lastet diesen Umstand jedoch nicht nur den Filmautoren an, sondern schreibt ihn auch dem Schauspieler Rolan Bykov zu. der auf seiner reichen Palette an Darstellungsmöglichkeiten kalte und harte Farben bevorzugt habe. ${ }^{+2.5}$ Meiner Meinung nach ist es aber vor allem Bykovs Spiel, das in wenigen Szenen doch Mitleid erregt.

Eine dieser Szenen ist die oben erwähnte humane Stelle. eine andere ist die Szene der Verzweiflung nach dem Raub des Mantels. Mit der Finstellung. die den sich langsam erhebenden Akakij Akakievic zeigt, schlägt Batalovs Komödie um in eine Tragödie. Die Handlung der gesamten Raubsequenz wurde vom großen weiten Platz in einen scheinbar endlosen Säulengang verlegt, aus dem es keinen Ausweg für den verfolgten Basmackin gibt. Aber noch der Raub und Akakij Akakievics Verfolgung der Räuber (die ebenfalls dem Sujet hinzugefügt wurde) wirken in erster Linie komisch.

Der eigentliche Raub endet mit einer Einstellung, die die Räuber und Baśmaćkin. den sie in den Schnee stoßen, in großer Entfernung am Ende des Säulenganges zeigt. In den folgenden Einstellungen kommt die völlige Verzweiflung uber den Verlust des Mantels sowohl in Bykovs Spiel als auch in der Mise en Scène gut zum Ausdruck. Bykovs Gesicht vermittelt sehr deutlich das langsame Begreifen des Vorgefallenen. Sein Verzweiflungsschrei als Reaktion darauf hallt ungehört in den endlosen, menschenleeren Gängen wieder. die von der Kamera in ihrer ganzen Länge gezeigt werden. In der nächsten Einstellung taucht Akakij Akakievic zwischen hohen Häusem auf und stolpert voran bis zu einem Zaun, an dessen Eisenstäben er sich festhält. Er ruft um Hilfe. doch auch hier ist kein Mensch zu sehen und niemand hört ihn. Er dreht sich um und läuft zurück.

Der Schneesturm, die hohen Häuser, die das Bild an beiden Seiten begrenzen, und die Eisenstäbe des Zauns, die an Gefängnisgitter erinnern. tragen wesentlich zur Vernittlung von Verzweiflung und Hilfosigkeit bei. In diesen Einstellungen haben Batalov und sein Team - ähnlich wie Kozincev und Trauberg - dem hilflosen kleinen Menschen die steinerne. gefühllose Stadt gegenubergestellt.

125 Gural'nik ( I sxy). S. Indi. 
Ein anderes Beispiel, wo auch in diesem Film die Kulisse aus ihrer bloßen Bedeutung als IImgebung heraustritt, sind die Einstellungen des Weges zur bedeutenden Persönlichkeit. Auf dem Weg zu ihr geht Akakij Akakiević zögernd eine riesige Treppe hinauf, nach dem unglücklichen Vorsprechen stürzt er förmlich diese Treppe hinunter. Die Wichtigkeit der bedeutenden Persönlichkeit. sowie die Schwierigkeit zu ihr zu gelangen und ihr vernichtendes Verhalten Akakij Akakievic gegenüber. werden hier durch die Treppe verdeutlicht. Im ubbrigen Film dienen die Kulissen aber rein als Handlungsort.

Gut ausgearbeitet ist die Bedeutung des Mantels als "ewige Idee" und "angenehme Lebensgefahrtin". Die Zeit des Hinarbeitens auf den Mantel ist schr ausführlich dargestellt, auch wenn die Bemühungen. das nötige Geld z.u beschaffen, teilweise wieder lächerlich wirken. Doch die eigentliche Herstellungsphase des Mantels macht dessen Bedeutung für Akakij Akakievic gut deutlich. In der ersten Aufnahme. die den Mantel zeigt. ist dieser aus der Untersicht gefilmt und überragt Baśmackin um ein großes Stück. Der wiederum ist im Gegensatz dazu in der gesamten Sequenz der Anprobe aus der Obersicht gefilmt, ähnlich wie bei Kozincev und Trauberg. In der nächsten Sequenz. in der Petrovic den fertigen Mantel bringt. erfolgt nach dessen Weggang eine lange Ënstellung. die Akakij Akakievic mit dem Mantel im Arm aus leichter Untersicht zeigt. Der Wechsel zwischen Ober- und Untersicht wird in Batalovs Film jedoch nicht so konsequent angewendet wie bei der FEKS-Verfilmung. da er sich auf die beschriebenen Szenen beschränkt.

Nach dem Tod Baśmackins wandelt sich der Film noch einmal von der Tragödie zur Komödie. Das wird besonders deutlich in der kurzen Sequenz. in der die Polizei zur Wohnung des toten Beamten kommt, ihn auf dem Bett liegen sieht. neben dem der Sarg steht. und fragt, ob der Tote in der vergangenen Nacht weggegangen sei. Diese Sequenz ist die Übertragung des Polizeierlasses. den Toten tot oder lebendig zu fangen (170; 87). Hier wird jedoch der noch greifbare Tote verfolgt. während es sich bei Gogol ${ }^{\bullet}$ um einen ungreifbaren Geist handelt. Batalov ist auch im Schlußteil ausschließlich auf der realistischen Fbene geblieben. wogegen Gogol' in der Begegnung des Geistes mit lebenden Personen noch einmal besonders ausgeprägt die Vermischung von Realität und Irrealität als Verfahren der Groteske anwendet. Bei Batalov wird die bedeutende Persönlichkeil vom gleichen lehenden Rauber ihres Mantels beraubt wie Akakij Akaievic. und sie sieht den Geist 
des Beamten nur in ihrer von einem schlechten Gewissen belasteten Phantasie. Durch dieses strenge Verbleiben auf der realistischen Ebene verlien der Film jedoch an Nähe zu Gogol'. Ihm fehlt jegliche Phantastik der Groteske, die über die alltägliche Welt hinausführ.

Es mag allerdings auch nicht in Batalovs Absicht gelegen haben, diese Merkmale von Gogol's Petersburger Novellen auf die Leinwand zu bringen. Ihm war offenbar nur der Realismus des Schriftstellers wichtig. Das Fehlen von Merkmalen der Groteske ist allerdings insoweit auffallend. als Ejchenbaum bei dieser Verfilmung Konsultant war, von einem Einfluß seiner Sicht des "Mantels" in Batalovs "Sinel" aber nichts zu spüren ist.

Gural'nik schreibt die Fehler des Films dem schlechten Drehbuch zu, das eine einfache Nacherzählung der Novelle sei und dessen Fehler Batalov und seine Mitarbeiter nicht gänzlich ausgleichen konnten. ${ }^{+2 x_{3}}$

Der Vergleich der beiden Filme veranschaulicht das am Anfang des Kapitels beschriebene Problem von Inhalt und Form eines Kunstwerkes. Der Inhalt. der die Form der FEKS-Adaption bestimmte, war die Atmosphäre des Geschehens. Ihnen ging es, wie erwähnt, um die Wiedergabe des Geistes der Nikolaitischen Epoche. wobei sie die von Gogol' vorgegebene Form der Groteske in die Sprache des Films übertugen.

Der formbestimmende Inhalt in Batalovs film war das Schicksal des Individuums in einer mitleidlosen Gesellschaft. Dafür wählte er die realistische Darstellungsform.

Die Fèksy sind in ihrer Adaption dem Stil Gogol's sicher näher gekommen als Batalov. Finen großen Beitrag dazu leistete allerdings zweifellos die Hilfe Tynjanovs, in dem die relativ unerfahrenen Regisseure einen erfahrenen Literaturwissenschaftler zur Seite hatten. Beiden Verfilmungen fehlt jedoch die für Gogol's Erzählung typische Abwechslung von Komik und Emsthaftigkeit. Während im FEKS-Film die Komik fast völlig fehlt, ist sie in Batalovs Film streng begrenzt auf die Handlungsabschnitte vor dem Raub des Mantels und nach dem Tod Akakij Akakievics.

In der Erzählung wird der Wechsel von Komik zu Emsthaftigkeit und umgekehrt von Ernst zu Komik zum bestimmenden Schema des Sujets. ${ }^{+27}$ Die Komik des einleitenden Handlungsablaufes. die an der humanen Stelle unerwartet in Tragik umschlägt, wird gleich darauf wieder von einem

\footnotetext{
420 Ibid.. S. $\mid(x)$.

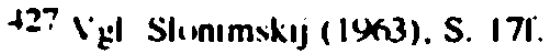


weiteren komischen Handlungsteil abgelöst. in dem die Liebe des ewigen Titularrats zu seiner Arbeit beschrieben wird. An diesen Teil wiederum schließt sich die mit geradezu übertriebenem Pathos formulierte Beschreibung verschiedener Feierabendbeschäftigungen der Petersburger Beamten an. die dann unerwartet mit den Worten endet:" ...sogar dann. wenn alles sich zu zerstreuen suchte. gab sich Akakij Akakiewitsch keiner Zerstreuung hin." (146. 19). Dabei entsteht die Komik dieser Stelle durch eine "groteske Verkehrung der 'normalen' Proportionen" +28 , wo das Unwesentliche im Vordergrund steht und das Wesentliche nur am Rande erwähnt wird. So ist die Komik der Erzählung allgemein sehr viel subtiler und hintergrundiger als in Batalovs Film. Dort entsteht Komik nicht durch die Art der Darstellung. sondern durch das Dargestellte, also die Situation: in hosenlosen Akakij Akakievič, im Hund, der ihn im neuen Mantel nicht crkennt und ihn anbellt. im zu hoch geschraubten Schemel bei der Teegesellschaft. seinem Zurickbleiben dort am leeren Tisch, oder seinem Niederknien, um durch die Beine der vor ihm Stehenden die Tanzenden betrachten zu können. wobei er wiederum nur deren Beine zu sehen bekommt. Dabei liegt in diesen Szenen. ebenso wie in den oben beschriebenen. weniger echte Komik als Lächerlichkeit.

Wenn Batalovs Verfilmung also tatsächlich als Aufruf zur Menschlichkeit und der Liebe zum Menschen verstanden werden soll, wie Pinsker schreibt+2'), dann wird diese Absicht durch die Lächerlichkeit der Figur Akakij Akakievićs nicht deutlich. weil diese Iächerlichkeit die Sympathie zerstört. die der Zuschauer in dem Fall für den kleinen Beamten empfinden müBte. Finzig das Spiel Rolan Bykovs ruft an den beschriebenen Stellen das Mitgefühl hervor, das nötig wäre, um den Film als Aufruf zur Menschlichkeit verstehen zu können. Die realistische Darstellungsform. wie Batalov sie gewählt hat. läßt kein Pathos zu. sie ist erbarmungslos gegenüber dem Helden.

Wenn man die beiden Verfilmungen vergleicht. muß man jede aber auch im Kontext ihrer Zeit und der Fntwicklungsphase ihrer Autoren sehen. Fiir die Fèksy war "Sinel'" der zweite abendfüllende Film. Der sowjetische Film war selbst noch sehr jung und die Regisseure dieser Zeit suchten bei ihrer

\footnotetext{
$\$ 28$ Gunther (1968). S. 171.

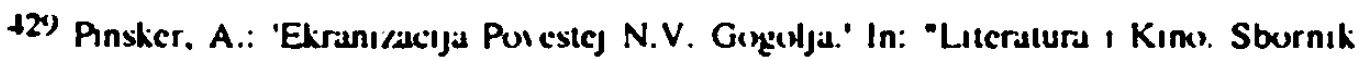
Slitej ${ }^{*}$ Mhrikial Leningrad 1965, S. 53.
} 
Arbeit nach Ausdrucksmöglichkeiten in der neuen Kunstform. Zweifellos haben die FEKS und Tynjanov mit ihrer Adaption Wichtiges für die Entwicklung des sowjetischen Films geleistet. Auch wenn die Kritik negativ auf diese Verfilmung reagiente, so darf man doch nicht außer acht lassen. daß die Regisseure in den zwanziger Jahre einen bis Ende der achtziger Jahre nie wieder gekannten Freiraum für Themenwahl. Ausarbeitung und Experimente hatten.

Im Vergleich damit dürfte Batalov, auch wenn seine Verfilmung in die relativ offene Zeil des "Tauwetters" fällt, durch wesentlich mehr Beschränkungen behindert worden sein. Denn die Doktrin des Sozialistischen Realismus hatte auch in dieser Zeit ungebrochene Gültigkeit.

Insgesamt bin ich der Meinung. daß die Verfilmung der FEKS und Tynjanovs mehr Aussagekraft und Originalität besitzt als die Batalovs. Der FEKS-Adaption ist die intensive Auseinandersetzung mit dem Stil des Schriftstellers deutlich anzumerken und die Übertragung der An Gogol's auf den Film ist gelungen. Batalor hat sich dagegen rein auf die Übernahme des äußeren Handlungsgeschehens beschränkt und den Stil des Autors nicht berücksichtigt. Er hat die literarische Vorlage "nur als Rohstoff betrachtet. also das künstlerische Produkt als lebendige Wirklichkeit aufgefaßt und jenseits der Form nur die Mitteilung des reinen Geschehens darin erblickt." +30

Den Unterschied der beiden Filme in ihrem Verhältnis zu Gogol'. sowie in ihrer Stellung als Kunstwerke von eigenem Wert. verdeutlichen die Bewertungskategorien für Bearbeitungen, die Lessing in seinem "Laokoon" aufgestellt hat. Ausgehend von der grundsätzlichen Berechtigung der Bearbeitung eines Kunstwerkes in einer anderen Kunstform, sieht er den Wert einer Bearbeitung in der Unterscheidung des Bearbeiters als "Original" oder "Kopist". Er erklärt diesen Unterschied am Vergleich der Erzählung Vergils und der spätantiken Laokoon-Gruppe.

"Wenn man sagt. der Künstler ahme dem Dichter nach. oder der Dichter ahme dem Künstler nach, so kann dieses zweierlei bedeuten. Entweder der eine macht das Werk des andern zu dem wirklichen Gegenstande seiner Nachahmung. oder sie haben heide einerlei Gegenstände der Nachahmung. und der

t.31) Balias (1961). S. 2741. 
eine entlehnet von dem andern die Art und Weise es nachzuahmen.

Wenn Virgil das Schild des Aeneas beschreibet, so ahmet er dem Künstler, welcher dieses Schild gemacht hat. in der ersten Bedeutung nach. Das Kunstwerk, nicht das was auf dem Kunstwerke vorgestellet worden. ist der Gegenstand seiner Nachahmung; und wenn er auch schon das mitbeschreibt, was man darauf vorgestellet sieht, so beschreibt er es doch nur als ein Teil des Schildes, und nicht als die Sache selbst. Wenn Virgil hingegen die Gruppe Laokoon nachgeahmet hătte. so würde dieses eine Nachahmung von der zweiten Gattung sein. Denn er würde nicht diese Gruppe. sondem das. was diese Gruppe vorstellet. nachgeahmet. und nur die Züge seiner Nachahmung von ihr entlehnt haben.

Bei der der ersten Nachahmung ist der Dichter Original. bei der andem ist er Kopist. Jene ist ein Teil der allgemeinen Nachahmung, welche das Wesen seiner Kunst ausmacht, und er arbeitet als Genie. sein Vorwurf mag ein Werk anderer Kunste, oder der Natur sein. Diese hingegen setzt ihn gănzlich von seiner Würde herab; anstatt der Dinge selbst ahmet er ihre Nachahmungen nach. $|\ldots|^{m+3 \mid}$

Lessing fordert also die Nachahmung der charakteristischen Form eines Kunstwerkes durch eine andere Kunstart, wobei der Künstler eben diese Form nachzuahmen habe und nicht einfach die dargestellten Gegenstände oder Ereignisse reproduzieren solle. So kritisiert er "die Vertreter der Werktreue mit dem Hinweis auf die kunstarten-spezifischen Unterschiede zwischen Malerei und Dichtung. und er verteidigt die $\bowtie$ Nachahmung von Kunstwerken $\propto$. indem er den künstlerischen ProzeB derartiger Nachahmungen markiert. ${ }^{n+32}$

Diese Aussagen lassen sich ohne weiteres auf die Nachahmung der Literatur durch den Film und somit auch auf die vorliegenden Literaturverfilmungen übertragen.

Tynjanov und die Fèksy haben in ihrer Verfilmung verschiedene Werke Gogol's (vor allem aber "Nevskij Prospekt" und "Der Mantel") zum Gegenstand ihrer Nachahmung gemacht und dabei das Sujet nur als deren Teil, aber "nicht als die Sache selbst" gesehen. Die Übertragung der literarischen Form der Groteske in die des Films war ihr Ziel. Durch Suchen. Experimentieren und Finden filmischer Möglichkeiten ist es ihnen gelungen

\$31 Lessing. G.E.: "Liwsicx)n Oder Uber Dic Gren/en Der Malereı Und Presic." Der Tell folgt: Lessing, Werke. Vollstandige Ausqabe in funfund/u an/sg Teılen. Hrsg. I In Julıus Petersen und Waldemar von Olshausen. Vierter Teil. Hrsg. Ion Walther Riczler. Berlın/Leıp/sg/ Wien/ Stuttgart: Bing. [1925]. Stutigan 1987. S. 61f.

$\$ 32$ Schneider (1981), S. 68. 
eine Groteske mit filmischen Mitteln zu erarbeiten. So entstand trotz aller Mängel ein Kunstwerk, das die Vorlagen nachahmt, jedoch nicht kopiert. Dadurch wird der Film auch seinem Untertitel gerecht, der ihn als "Filmstuck in der Art Gogol's" ("Кино-пьеса в манере Гоголя") deklariert.

Batalovs Film dagegen ahmt in erster Linie das nach, was die Erzählung vorstellt: die Geschichte eines kleinen Beamten, dem sein mühsam erworbener neuer Mantel gestohlen wird.

"Фильм, поставленный А. Баталовым в конце 50-х
годов, лишен ряда кннематографических достоинств,
которыми обладала старая немая лента - лаконизма и
выразительности ее киноязыка."
"Der Film, der von Batalov Ende der 50er Jahre inszenient
wurde. entbeht einer Reihe von kinematographischen Quali-
taten. die der alte Stummfilm besaß - Lakonismus und Aus-
drucksstärke seiner Filmsprache." +.3.

Gural'nik bezeichnet diesen Film außerdem als traditionelle Filmerzählung. die sich Schritt für Schritt an die literarische Vorlage hält. jedoch keine neuen filmischen Möglichkeiten entdeckt und die alten. von den Fèksy entdeckten. vergißt.+3t Dabei scheint mir das Eine durch das Andere bedingt zu sein. Durch die Konzentration auf die Wiedergabe des Sujets haben Batalov und sein Team offenbar der Kunstform Film und deren speziellen Darstellungsmöglichkeiten weniger Beachtung geschenkt als ihre Vorgänger. Deshalb fehlt es dieser Verfilmung an Originalität und Ausdrucksstärke. um sie aus der Reihe der üblichen Literaturadaptionen hervorzuheben.

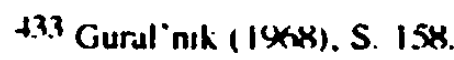

t.14 Ibid.. S. 159.
} 


\section{Schlußbemerkungen}

Ziel dieser Arbeit war es. Wesen, Werke und damit die Bedeutung der "Fabrik des exzentrischen Schauspielers" fiir den frühen sowjetischen Film zu untersuchen.

Ausgangspunkt war eine Kontextanalyse der vielgestaltigen historischen Situation des russisch/sowjetischen Theaters in den ersten zwanzig Jahren dieses Jahrhunderts. da der Einfluß des Theaters und vor allem der Theaterschaffenden auf den frühen sowjetischen Film von besonderer Wichtigkeit ist. Im vorrevolutionären Theater war vor allem Mejerchol'ds Theaterarbeit von entscheidender Bedeutung für die spätere Entwicklung der FEKS. Die Zersplitterung von Theaterstuicken in Episoden als Vorstufe zum Film. die Wiederbelebung vergessener Volkstheatertraditionen und die Parodierung des ernsthaften Theaters hatte er als erster Regisseur im russischen Theater des zwanzigsten Jahrhunderts angewendet.

Im nachrevolutionären Theater hatte die Form der Parodierung des traditionellen Theaters. wie Radlov und Foregger sie praktizierten. den stärksten Einfluß auf Kozincev und Trauberg.

Wie gezeigt. waren die Feksy nicht die einzigen. die in konsequenter Entwicklung vom Theater zum Film übergingen. Auch beruhmte Regisseure wie Ejzenstejn. Jutkevič oder Pudovkin hatten ihren Weg zum Film im Theater begonnen.

Als Kinder ihrer Zeit begeisterten sich die Gründer der FEKS für die Revolutionienung des Theaters und der Kunst allgemein. Aus Merkmalen und Programmen verschicdener Avantgardebewegungen und -kunstler vor allem aher der Futuristen. sowie einem ihnen eigenen Amerikanismus formten sie ihren fröhlichen "Exzentrismus" und propagierten Lachen und Parodie als Mittel zur Überwindung der alten Kunst und Kultur. Dabei besitzt die exzentrische Fröhlichkeit einen ähnlichen Charakter wie das mittelalterliche Lachen. das, wie Bachtin erklärt. von der Furcht vor "dem autoritären Verbot, dem Vergangenen, vor der Macht" +35 befreit und gleichzeitig mit

\$3.5 Bischtın. M.: "Litcratur und Karnes al. Zur Romantheunc und Likhhultur." L'bers. I. Alcrander Kaxmpre. Munchen 1985. S. 39. 
Geburt. Erneuerung und Zukunft zusammenhängt, "daß es ihnen den Weg bahnt." + .3.

Eben das sollte, nach Meinung der Feksy, auch die neue Kunst leisten, und so machten sie mit Clowns. Charlie Chaplin und den Figuren ihrer Theaterstucke und ersten Filme Gestalten zu Wahrheitsverkündem, die im weitesten Sinne alle aus dem mittelalterlichen Narren hervorgegangen sind. Diese Gestalten der Volkskunst gewährleisteten zudem den Zugang zum Volk, das ja seit Jahrhunderten in den verschiedenen Formen mit ihnen vertraut war.

Während der Arbeit an ihren Theaterinszenierungen erkannten Kozincev und Trauberg bald, daß der Film sehr viel mehr Möglichkeiten für die Erarbeitung des Exzentrismus bot als das Theater und kamen auf diese Weise ähnlich wie Ejzenstejn zu dieser neuen Kunstform.

Mit dem Film "Das Teufelsrad" taten sie den ersten Schritt zur Abwendung vom Exzentrismus als Parodierung der Vergangenheit, um sich mit der Gegenwart und damit auch mit der Realität zu beschäftigen. Zwar weist dieser Film noch Züge von Detektivromanen in der An der Nat Pinkerton Geschichten auf, er ist jedoch vor allem der erste Versuch der Fẻksy, die Wirklichkeit darzustellen.

Ihr erstes Meisterwerk schufen sie mit "Sinel'". Dabei ging es ihnen weniger um die Wiedergabe des Gogol'schen Realismus. als vielmehr um die Übertragung des Stils der Groteske in den Film, was ihnen auf überzeugende Art und Weise gelungen ist.

Die letzten Filme der FEKS. "SVD" und "Das Neue Babylon" haben beide eine historisch-revolutionäre Thematik. sind aber ebenso wie "Sinel'" durch eine enge Verbindung zur Literatur gekennzeichnet. Das literarische Drehbuch zu "SVD" war von Tynjanov geschrieben worden, während "Das Neue Babylon" große Ahnlichkeit mit der Literatur Zolas aufweist.

Die drei großen Filmen der FEKS. "Sinel ", "SVD" und "Novij Vavilon", zeichnen sich dadurch aus. daß sie in Erzählform und Bildkomposition die Literatur und Malerei der Zeit, in der sie jeweils spielen, widerspiegeln. Die Feksy fanden adäquate Mittel zur Umsetzung dieser Kunstformen in die des Films und zeigten damit Wege zur schöpferisch filmischen Bearbeitung von literarischen Kunstwerken. Darin liegt vor allem ihre Bedeutung für den sowjetischen Film.

4 (K) Ibid. S. 4 I 
Die Entwicklung der Fëksy von der exzentrischen Komödie zur Tragödie im Film mag paradox erscheinen. Es liegt hier jedoch eine logische kulturgeschichtliche Entwicklung vor.

Naum Klejman erklärt das Wort "Exzentrismus" als eine Bewegung aus dem Zentrum heraus. die das herrschende Gleichgewicht zerstör und eine neue Richtung einschlägt. So eine Fortbewegung aus dem alten Zentrum hat jedoch im Laufe der Kunstgeschichte öfter stattgefunden. wenn ein Stil den anderen ablöste, oder neue Elemente der Ausdrucksfähigkeit gefunden wurden. +37

Die Feksy haben mit ihrem Exzentrismus so eine Bewegung hervorgerufen. mit dem Herausführen ihres künstlerischen Systems aus dem alten Zentrum. dieses dabei aber gleichzeitig aktualisien und gefestigt. Zu Beginn wandten sie sich von der "hohen Kunst" ab und den "niedrigen Genres" zu. ${ }^{+38}$ Mit den neuen Elementen der Ausdrucksmöglichkeiten. die sie dann im Exzentrismus ihrer Theaterstucke und frühen Filme fanden. schufen sie spater etwas Neues in der Kunstform Film. das heute wiederum als "hohe Kunst" angesehen wird. Auch in dieser Tatsache scheint ein Paradox zu liegen, das jedoch ebenso nur Ergebnis einer logischen Entwicklung ist. da neue Erscheinungen in der Kultur zu ihrer Entstehungszeit zunächst immer als exzentrisch und unstimmig angesehen werden. weil sie dem Rezipienten nicht vertraut sind und die gewohnten Regeln der Kunst vertetzen.

Der Übergang von der Komödie zur Tragödie in der Arbeit der FEKS zeigt dabei die Entwicklung vom spielerischen Ausprobieren und Entdecken neuer Möglichkeiten zur ernsthaften Anwendung des Entdeckten auf das Genre der Tragödie.

Mit dieser Entwicklung ist den Fèksy etwas gelungen. das über die Arbeit von Regisseuren wie Radlov oder Foregger hinausgeht. Die Parodierung der Kunst war für Kozincev und Trauberg eine Lehrzeit. in der sie Möglichkeiten zur Entwicklung einer neuen Kunstform (der des Films) fanden, während die Arbeit Radlovs und Foreggers sich in der Parodierung des Theaters erschöpfte. Auf diese Weise bildete der fröhliche Exzentrismus den Ausgangspunkt für die "Poetik des Films", wobei er sich zum Exzentrismus wandelte, wie Sklovskij ihn verstand: als neuartige, nicht automatisierte

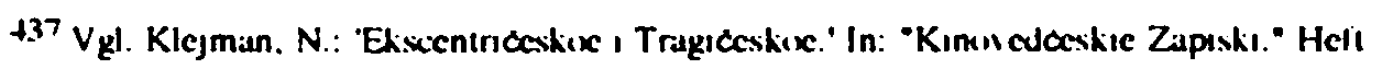

7. Moxkau 1990). S. 133.

t.38 Vill. lox: cil. 
Verbindung ausgewählter Eindrucksmomente. als Kampf gegen Gewöhnung und traditionelle Sicht des Lebens. ${ }^{+39}$

+34) Siche Anm. 25\%. 


\section{Literaturverzeichnis}

Albersmeier, Franz-Josef/ Roloff, Volker ( $\mathrm{Hg}$.): Literaturverfilmungen. Frankfurt/M. 1989.

Apollonio, Umbro: Der Futurismus. Manifeste und Dokumente einer kủnstlerischen Revolution 1909 -1918. Köln 1972.

Aucouturier. Michel: Theatricality as a Category of Farly Twentieth-Century

Russian Culture. In: Kleberg. L./Nilsson. N. (Ed.): Theater and Literature in Russia 1900-19.30. A Collection of Essays. Stockholm 1984.

Bachtin. Michail: Literatur und Karneval. Zur Romantheorie und I achkultur. München 198.5.

Baikova-Poggi. Tamara: Teatral'nost' u Evreinov i u russkich futuristov. Revue des études slaves 1981 . Nr.1.

Balázs. Béla: Der Film. Werden und Wesen einer neuen Kunst. Erweiterte und überarbeitete Neuauflage. Wien 1961.

Balázs. Béla: Schriften zum Film. Bd. I Der sichtbare Mensch. Kritiken und Aufsätze 1922 - 1926. Bd.II Der Geist des Films. Artikel und Aufsätze 1926 - 1931. Gemeinschaftsausgabe des Akadémiai Kiadó. Budapest. des Carl Hanser Verlages. München und des Henschelverlages Kunst und Gesellschaft. DDR-Berlin. Budapest 1982.

Batalov. A.: Krasneckaja M.: Dialog v Antrakte. Moskau 1975.

Baumgarth. Christa: Geschichte des Futurismus:. Reinbeck bei Hamburg 1966.

Beilenhoff, Wolfgang: Der sowjetische Revolutionsfilm als kultureller Text. Diss. Bochum 1978.

Beilenhoff. Wolfgang: Poetik des Films. Deutsche Erstausgabe der filmtheoretischen Texte der russischen Formalisten mit einem Nachwort und Anmerkungen. München 1974.

Benjamin. Walter: Das Kunstwerk im Zeitalter seiner technischen Reproduzierbarkeit. Drei Studien zur Kunstsoziologie. Frankfur/M. 1963.

Bergius. H./ Miller. N./ Riha K. (Hg.): Johannes Baader Oberdada. Schriften. Manifeste. Flugblätter. Billets. Werke und Taten. LahnGießen 1977. 
Billington. Sandra: A Social History of the Fool. Brighton/ New York 1984. Braun. Fdward: The Theatre of Meyerhold. Revolution on the Modem Stage. London 1979.

Brauneck. Manfred: Die rote Fahne. Kritik. Theorie, Feuilleton 1918 - 1933. Müchen 1973.

Brauneck. Manfred: Theater im 20. Jahrhundert. Programmschriften. Stilperioden. Reformmodelle. Reinbek bei Hamburg 1986.

Brauneck. Manfred: Klassiker der Schauspielregie, Positionen und Kommentare zum Theater im 20. Jahrhundert. Reinbek bei Hamburg 1988.

Bulgakova, O.L.: Bul'vardizacija avangarda - fenomen FEKS. In: Kinovedceskie Zapiski. Heft 7. Moskau 1990.

Chaplin. Charles: Die Geschichte meines Lebens. FrankfurtM. 1977. Chersonkij. Chrisanf: Stranicy junosti kino. zapiski, kritika. Moskau 1965.

Christie, lan: Fèksy za granicej. Kul 'tumo-političeskie aspekty vosprijatija sovetskogo kino za rubeżom. In: Kinovedceskie Zapiski. Heft 7. Moskau 1990.

Civ jan, Ju.G.: Rannie fèksy i kul'turnaja tematika 20-ch godov. In: Kinovedceskie Zapiski. Heft 7. Moskau 1990.

Daemmrich. Horst und Ingrid: Wiederholte Spiegelungen. Themen und Motive in der Literatur. Bern 1978.

Ditschek. Eduard: Politisches Engagement und Medienexperiment. Theater und Film der russischen und deutschen Avantgarde der zwanziger Jahre. Mannheimer Beiträge zur Sprach- und Literaturwissenschaft Bd.17. Tübingen 1989.

Dobin. E.: Kozincev i Trauberg. I eningrad/ Moskau 1963.

Dolinskij. M.: Svjaz vremën. Moskau 1976.

Eichenbaum, Boris: Aufsätze zur Theorie und Geschichte der Literatur. ausgew. und aus dem Russischen übers. von Alexander Kaempfe. Deutsche Erstausgabe. Frankfurt/M. 1965.

Eimermacher. Kart ( $\mathrm{Hg}$.): Texte des sowjetischen literaturwissenschaftlichen Strukturalismus. Muinchen 1971.

Eisenstein. Sergej M.: Die Montage der Attraktionen. Zur Inszenierung von A.N. Ostrovskijs "Eine Dummheit macht auch der Gescheiteste" im Moskauer Proletkult. In: Ästhetik und Kommunikation. Beiträge zur politischen Erziehung. Heft 13. Dez. 1973. Jg.4. 
Eisenstein. Sergej M.: YO Ich selbst. Memoiren. hrsg. von Naum Klejman und Walentina Korschunowa. Einleitung von Sergej Jutkewitsch. Bd.I. aus dem Russischen von Regine Kühn und Rita Braun. Frankfurt/M. 1988.

Eisenstein, Sergej: Über mich und meine Filme. Bertin (Ost) 1975.

Erlich. Viktor: Russischer Formalismus. mit einem Geleitwort von René Wellek. aus dem Englischen von Marlene Lohner. München 1964/ Frankfur/M. 1987.

Everson. William K.: American Silent Film. New York 1978.

Fischer. Rolf: Filmische Literaturdokumentation und -interpretation. Möglichkeiten und Grenzen. Phil. Diss. Tübingen 1967.

Flaker. Aleksandar: Der russische Formalismus - Theorie und Wirkung. In: Zmegac. V./ Śkreb. Z. (Hg.): Zur Kritik literaturwissenschaftlicher Methodologie. Frankfurt/M. 1973.

Frenzel. Elisabeth: Motive der Weltliteratur: ein Lexikon dichtungsgeschichtlicher Längsschnitte. 3. überarb. u. eru. Aufl.. Stuttgart 1988.

Freytag. Gustav: Die Technik des Dramas. Philipp Reclam jun. Stuttgart 1983. nach: Gustav Freytag: Die Technik des Dramas. Fünfte. verbesserte Auflage. Leipzig 1886.

Gogol'. N.V.: Polnoe Sobranie Socinenij. Tom Tretij. Povesti. Izdatel'stvo Akademii Nauk SSSR 1938.

Gogol'. Nikolaj: Gesammelte Werke in fünf Bänden. Bd.I Erzählungen. Stuttgan 1982.

Gogol. Nikolaj: Der Mantel. Verlag Philipp Reclam jun., Stuttgart 1973. ubers. nach: Gogol'. N.V.: Polnoe Sobranie Socinenij. Tom Tretij. Povesti. Izdatel'stvo Akademii Nauk SSSR 1938.

Gorsen. Peter/ Knödler-Bunte. Eberhard: Proletkult I. System einer proletarischen Kulturdokumentation. Stuttgan - Bad Cannstatt 1974.

Gorsen. Peter/ Knödler-Bunte. Eberhard: Proletkult 2. Zur Praxis und Theorie einer proletarischen Kulturrevolution in Sowjetrußland 1917 1925. Stuttgart - Bad Cannstatt 1974.

Green. Michael (Ed. and Transt.): The Russian Symbolist Theatre. An Anthology of Plays and Critical Texts. Ardis Publishers 1986.

Gregor, Ulrich $(\mathrm{Hg}$.): Wie sie filmen. Fünfzehn Gespräche mit Regisseuren der Gegenwart. Gütersloh 1966.

Gregor, Ulrich/ Patalas. Enno: Geschichte des Films. Gütersloh 1962. 
Günther. Hans: Das Groteske bei N.V. Gogol'. Formen und Funktionen. Müchen 1968.

Gunther, Hans/ Hielscher, Karla (Hg.): Marxismus und Formalismus. Dokumente einer literaturtheoretischen Kontroverse. München 1973.

Gural'nik. U.A.: Russkaja Literatura i Sovetskoe kino. Moskau 1968.

Hansen-Löve. Aage A.: Der Russische Formalismus. Methodologische Rekonstruktion seiner Entwicklung aus dem Prinzip der Verfremdung. Wien 1978.

Helmers. Hermann: Verfremdung in der Literatur. Darmstadt 1984.

Heresch. Elisabeth: Schnitzler und Rußland. Aufnahme. Wirkung. Kritik. Wien 1982.

Herms. Dieter: Grundkurs Englisch. Eine Einführung in die Amerikanistik. (Argument - Studienheft) Berlin 1982.

Hielscher, Karla: S.M. Eisensteins Theaterarbeit beim Moskauer Proletkult (1921-1924). In: Ästhetik und Kommunikation. Beiträge zur politischen Erziehung. Heft 13. Dez. 1973. Jg.4.

Hielscher, Karla: "Mysterium buffo" und die Anfänge des linken Avantgardetheaters. In: Majakovskij: 20 Jahre Arbeit. Neue Gesellschaft für bildende Kunst. Berlin 1978.

Holthusen. Johannes: Russische Literatur im 20. Jahrhundert. Munchen 1978.

Huelsenbeck, Richard (Hg.): Dada. Eine literarische Dokumentation. Hamburg 1984.

"Ja casto dumaju o Vas...". Iz perepiski Tarkovskogo s Kozincevym. In: Sandler, A.M. (Hg.): Mir I Fil'my Andreja Tarkovskogo. Moskau 1991.

Jutkewitsch. Sergej: Kontrapunkt der Regie. Übers. von I.illi Kaufmann. Berlin (Ost) 196.5.

Jutkević, Sergej: Poetika režissury, teatr i kino. Moskau 1986.

Keil, Wolf-Dietrich: Gogol. In Selbstzeugnissen und Bilddokumenten. Reinbek bei Hamburg 1985.

Kleberg. Lars/ Nilsson. Nils Áke (Ed.): Theater and Literature in Russia 1900-1930. A Collection of Essays. Stockholm 1984.

Klejman. Naum I.: Ekscentriceskoe i tragičeskoe. In: Kinovedceskie Zapiski. Hefi 7. Moskau 1990.

Kozincev. Grigorij M.: Glubokij Ekran. Moskau 1971.

Kozincev. Grigorij M.: Vremja i Sovest'. Moskau 1981. 
Kozincev. Grigorij M.: Sobranie soćinenija v njati tomach. 3. tom. Leningrad 1983.

Kozinceva, V./Butovskij, Ja.: K istorii Ekscentriceskogo teatra. In: Kinovedžeskie Zapiski. Heft 7. Moskau 1990.

Kracauer. Siegfried: Theorie des Films. Die Errettung der äußeren Wirklichkeit. vom Verf. rev. Übers. von Friedrich Walter u. Ruth Zellschan. Frankfur/M. 1985.

Lary. Nikita M.: Dostoevky and Soviet film. Visions of demonic realizm. Ithaca 1986.

Lary, Nikita M.: Sklovskij i FEKS. In: Kinovedćeskie Zapiski. Heft 7. Moskau 1990.

Lebedev. N.A.: Ocerk istorii kino SSSR. Nemoe kino. 2-e pererabotannoe dopolnennoe izdanie. Moskau 1965.

Lechner, Ulrike: Literatur und Film. Affinitäten und Korrelationen. Phil. Diss.Salzburg 1976.

Lemmermeier. Doris: Literaturverfilmung im sowjetischen Stummfilm. Analyse ausgewählter Drehbuicher. Wiesbaden 1989.

Lessing. G.E.: Laokoon Oder (Jher Die Grenzen Der Malerei Und Poesie: Der Text folgt: Lessings Werke. Vollständige Ausgabe in funfundzwanzig Teilen. Hrsg. von Julius Petersen und Waldemar von Olshausen. Vierter Teil. Hrsg. von Walther Riezler. Berlin/Leipzig/Stuttgart: Bong [1925]. Verlag Philipp Reclam jun. Stuttgan 1987.

Leyda. Jay: Kino. A History of the Russian and Soviet Film. Princeton. New Jersey 1983.

Lövgren, Håkan: Sergej Radlov's Electric Baton: The "Futurization" of Russian Theater. In: Kleberg. $U$ Nilsson. N.(Ed.): Theater and Literature in Russia 1900 - 1930. A Collection of Essays. Stockholm 1984.

Mailand-Hansen. Christian: Mejerchol'ds Theaterästhetik in den 1920er Jahren - ihr theaterpolitischer und kulturideologischer Kontext. Kopenhagen 1980.

Mailand-Hansen, Christian: Kinoteorija i kinopraktika russkich formalistov. In: Kinovedźeskie Zapiski. Heft 7. Moskau 1990.

Majakowski. Wladimir. Wolke in Hosen. Mit einem Vorwort von Stephan Hermlin. Deutsch von A.E. Thoß. Berlin Verlag Volk und Welt 1949. 
Majakowski. Wladimir: Ausgewählte Werke in 5 Bänden. Hrsg. von Leonhard Kossuth. Übers. von Hugo Huppert. Bd. 5: Publizistik. Berlin 1975.

Markov, Vladimir: Russian Futurism. A History. Los Angeles 1968.

Mejerchol'd, Vsevolod E.: "Balagan." (1912) Zit. n.: Brauneck. Manfred:

"Klassiker der Schauspielregie. Positionen und Kommentare zum

Theater im 20. Jahrhundert." Reinbek bei Hamburg 1988.

Mejerchol'd. V.E./ Tairov. A.J./ Vachtangov, J.B.: 'Theateroktober.' In: Brauneck (1986).

Mejerchol'd, Vsevolod E.: 'Das stilisierte Theater.' (1907) Zit. nach: Brauneck (1988).

Mierau. Fritz (Hg.): Die Erweckung des Wortes. Essays der russischen formalen Schule. Leipzig 1987.

Monaco. James: Film verstehen. Kunst. Technik, Sprache. Geschichte und Theorie des Films. übers. nach der 2. verbess. und erweit. Auflage von 1980. Reinbek bei Hamburg 1987.

Nedobrovo. Vladimir: FEKS. Grigorij Kozincev Leonid Trauberg. Moskau/Leningrad 1928.

Nosova, Valerija V.: Komissarzevskaja. Moskau 1964.

Paech. Joachim: Das Theater der russischen Revolution. Theorie und Praxis des proletarisch-kulturrevolutionären Theaters in Rußland 1917-1924. Kronberg/ Ts. 1974.

Paech. Joachim: Literatur und Film. Sammlung Metzler. Stuttgan 1988.

Pinsker. A.: Ekranizacija povestej N.V.Gogolja. In: Literatura i Kino. Sbomik statej. Moskau/ Leningrad 1965.

Poljakowa. Elena Iwanowna: Stanislawski. Leben und Werk des großen

Regisseurs. Übers. aus d. Russischen. Bonn 1981.

Rach. Rudolf: Die filmische Adaption literarischer Werke. Köln 1964.

Riha. Karl: TATÜ DADA. Dada und nochmals Dada his heute. Aufsätze und Dokumente. Hotheim 1987.

Ripellino. Angelo Maria: Majakowskij und das russische Theater der Avantgarde. aus d. Italienischen von Marlies Ingenmey. Köln 1964.

Rudnitsky, Konstantin: Russian and Soviet Theatre. Tradition and the AvantGarde. Translation from Russian by Roxane Permar. London 1988.

Rudnizki. Konstantin: Explosion der Kräfte und extreme Ansichten. Zum Verhältnis Blok-Meyerhold. In: Sieg über die Sonne. Aspekte russischer Kunst zu Beginn des 20. Jahhunderts. Katalog zur Ausstellung der 
Akademie der Künste. Berlin. und der Berliner Festwochen vom I.

September bis 9. Oktober 1983. Berlin 1983

Rühle, Jürgen: Das gefesselte Theater. Köln/ Berlin 1957.

Sadoul. Georges: Das ist Chaplin! Sein Leben. Seine Filme. Seine Zeit. Wien 1954.

Sadoul, Georges: Geschichte der Filmkunst. Erw. deutschsprachige Ausgabe unter Red. von Hans Winge. Wien 1957.

Schneider. Irmela: Der verwandelte Text. Wege zu einer Theorie der Literaturverfilmung. Tübingen 1981.

Schnitzer. Luda and Jean. Martin Marcel: Cinema in Revolution. The Heroic Era of the Soviet Film. New York 1987.

Sépman. I.V.: Ekscentrizm kak sposob razvertyvanija istoriceskogo sjuzeta. Scenamye raboty Ju. N. Tynjanova. In: Kinovedceskie Zapiski. Heft 7. Moskau 1990.

Shdan. W: (Vorwort u. Gesamtredaktion): Der sowjetische Film. Bd. I: Von den Anfägen bis 1945. Berlin (Ost) 1974.

Silbermann, A./ Schaaf, M./ Adam. G.: Filmanalyse. Grundlagen Methoden - Didaktik. Muinchen 1980.

Sireks. Pavel: Režissëry - sobesedniki. Sojus Kinematografistov. Vsesojusnoe tvorcesko-proizvodstvennoe ob edinenie "Kinocentr". Moskau 1989.

SkJovskij, Viktor: Za sorok let. Stat i o kino. Moskau 1965.

Sklovskij. Viktor: Gamburgskij scët. Stat $i$ - Vospominanija - Esse (1914 1933). Moskau 1990.

Slonimskij. Aleksandr L.: Tekhnika Komicheskogo u Gogolia. Slavic Reprint II. originally published in 1923 as part of the voprosy portiki. Brown University Press Providence (Rhode Island) 1963.

Stempel, W.-D. (Hg.): "Texte der russischen Formalisten." Bd. II. München 1972.

Tairov Alexander: Das entfesselte Theater. Neuausgabe als wortgetreue Wiedergabe der Ausgabe von 1923. Köln 1964.

Thun. Nyota: Das erste Jahrzehnt. Literatur- und Kulturrevolution in der Sowjetunion. Berlin 1973.

Tichy. Wolfram: Chaplin in Selbsizeugnissen und Bilddokumenten. Reinbek bei Hamburg 1974.

Tietze, Rosemarie (Hg.): "Wsewolod Meyerhold: Theaterarbeit 1917 1930." Muinchen 1974. 
Toeplitz. Jerzy: Geschichte des Films 1895 - 1928. Autorisierte Übertragung aus dem Polnischen und Redaklion: Lilli Kaufmann. München 1975.

Trauberg, Leonid Z.: Dvadcatye gody. In: $1 z$ istorii "Lenfil'ma". Stat $i$, vospominanija. dokumenty. Leningrad 1970.

Trauberg. Leonid Z.: Kogda zvëzdy byli molody. Moskau 1976.

Trauberg. Leonid Z.: Izbrannye proizvedenija v 2-ch tomach. Moskau 1988.

Tretjakov, Sergej: Das Theater der Altraktionen. Die Auffuhrungen "Eine

Dummheil macht auch der Gescheiteste" und "Hörst Du, Moskau" im

Ersten Arbeitentheater des Proletkult. In: Ästhetik und Kommunikation.

Beiträge zur politischen Erziehung. Heft 13, Dez. 1973, Jg.4.

Turicyn. V.: Tri Ekranizacii "Sineli" N.V. Gogolja. In: "Kino i vremja"

Bjuleten' Gosfil'mfonda. Vyp. 4.. Moskau 1965. S. $103-128$.

Tynjanov. Jurij: Die literarischen Kunstmittel und die Evolution in der

Literatur. Ausgewählt und aus dem Russischen übersetzt von Alexander Kaempfe. Frankfurt/M. 1967.

Vajsfel'd. I.: G.Kozincev i L.Trauberg. Trorceskij put'. Moskau 1940.

Vajsfel'd. I.: Tak nacinalos' iskusstvo kino. Moskau 1988.

Veresaev, V.: Gogol' v źizni. Sistematiceskij svod podlinnych cridetel'stv sovremennikov. Moskau 1990.

Verkauf. Willi (Hg.): Dada. Monographie einer Bewegung. Teufen (AR). Schweiz 1961.

Weise. Eckhard: Sergej M. Eisenstein in Selbstzeugnissen und Bilddokumenten. Reinbek bei Hamburg 1975.

Wilpent. Gero von: Sachwörterbuch der Literatur. Stuttgart 1955.

Wilpert. Gero von (Hrsg.:) Lexikon der Weltliteratur. Bd.1: Autoren, Bd.2:

Werke. 3. neubearb. Auflage. Stuttgan 1988.

Zelinsky. Bodo $\left(\mathrm{Hg}_{\mathrm{g}}\right.$ ): Das russische Drama. Düsseldorf 1986.

Zelinsky. Bodo (Hg.): Die russische Novelle. Duisseldorf 1982.

Zelinsky. Bodo: Russische Romantik. Köln/Wien 1975.

Zmegac. Viktor/ Skreb. Zdenko (Hg.): Zur Kritik literaturwissenschaftlicher

Methodologie. Frankfurt/M. 1973. darin: Flaker, Aleksandar: Der russische Formalismus - Theorie und Wirkung.

Zuk. O. A.: "Certovo Koleso" i gorodskaja kul'tura. In: Kinovedceskie Zapiski. Heft 7. Moskau 1990. 


\section{Zeitschriften}

Ästhetik und Kommunikation. Beiträge zur politischen Erziehung. Heft 13. Dez.1973. Jg. 4.

Cinepolis. International Magazine. Nr.1. Moskau 1991.

Iskusstvo Kino. Nr.12. Moskau 1991

Kinovedceskie Zapiski. Heft 7. Moskau 1990. Heft 10. Moskau 1991.

sowie:

Manifest "Ekscentrizm". Petrograd 1922.

Textliste zum Film "Sinel'" von 1926. Regisseure: G.Kozincev. L. Trauberg.

Sovetskoe Iskusstvo 20-30-ch godov. Katalog vremennoj Vystavki. Leningrad 1988. 


\section{Anhang}




\section{Chronologie und Filmographie der FEKS}

5.12 .1921

Friihjahr 1922

25.9 .1922

29.12. 1922

4.6.1923

Juni 1923
Gründung der FEKS mit dem "Disput über das exzentrische Theater" im Petrograder Theater "Freie Komödie". Vorträge von G. Kozincev, G. Kryżickij und L. Trauberg.

Erscheinen des Manifestes "Ekscentrizm". Autoren: G. Kozincev.

G. Kryżickij. L. Tauherg und S. Jutkevič.

Erste Theaterauffiihrung der FEKS im Saal des Petmgrader Proletkul' 't. "Streich in drei Akten: 'Die Heirat'". Maschinisten der Inszenierung: G. Kozincev. L. Trauberg.

Am "Exzentrischen Freitag" Auffihrung der "Amerikanischen Vorstellung der FFKS" im "Freien Theater".

Auffuihrung der "Amerikanischen Operette in einem Akt: 'Drei Trillionen Yen'm.

Auffuihrung von "Außenhandel auf dem Eiffelturn" im Theater "Musikalische Komodie". Maschinisten der Inszenierung: G. Kozincev. L. Trauberg.

Filme

9.12.1924 Premiere der exzentrischen Filmkomödie "Die Abenteucr der Okijahrina".

1924

Eröffnung der Schauspieler-Werkstalt der FEKS zur Ausbildung von Filmschauspielem.

"Miska gegen Judenič"

Mär 1926 Premiere ion "Das Teufelsrad" 
10.5.1926 Premiere der Filmgroteske "Der Mantel" (in der Art Gogol's).

1927

"Briderchen"

23.8.1927

Premiere des Filmmelodrams "Der Bund der großen Tat".

16.3.1929

Premiere von "Das Neue Babylon". 


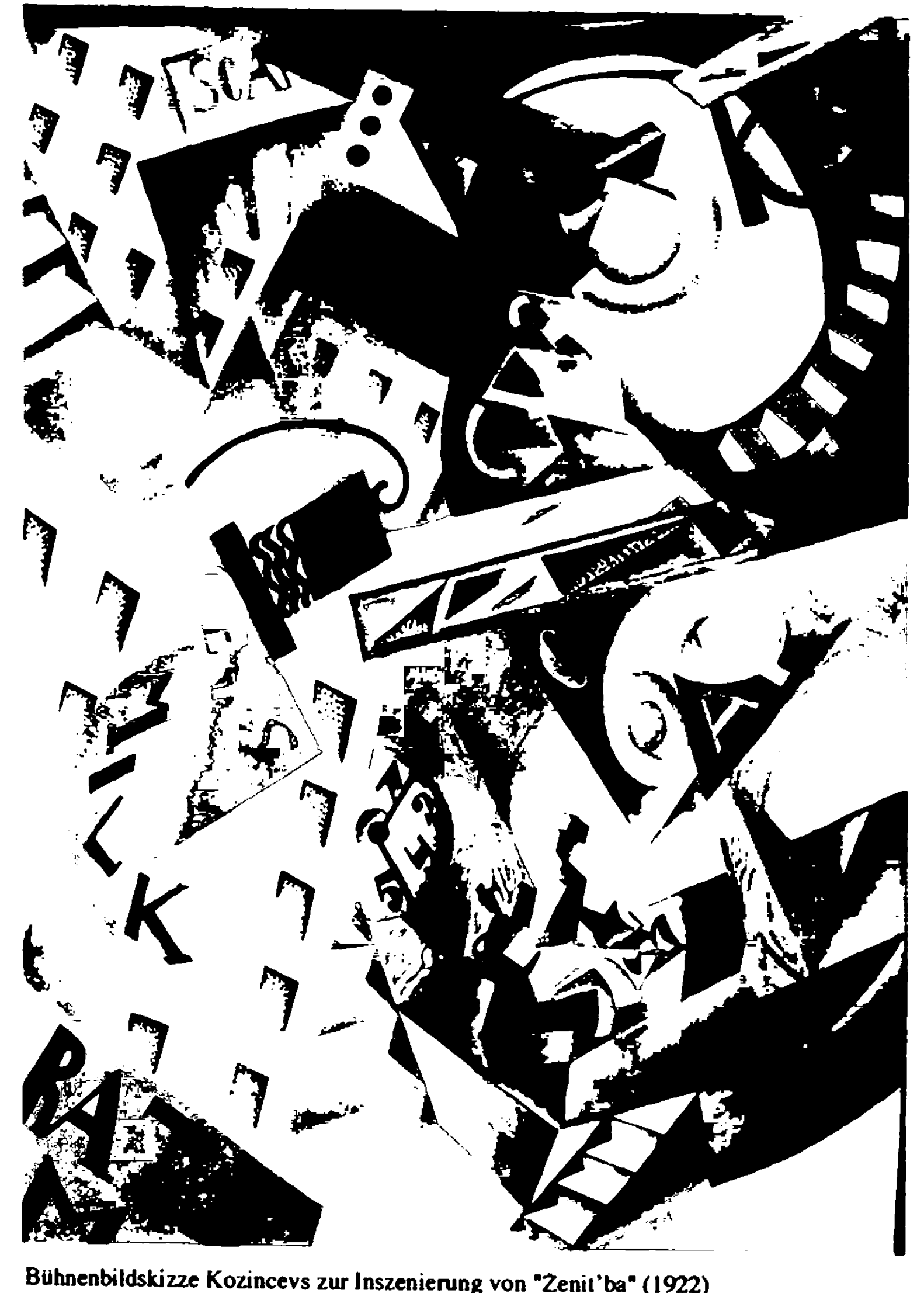

